Politics and Governance 2013 | Volume 1 | Issue 1

Politics and Governance is an international, open access, academic, interdisciplinary journal, published by Librello.

\section{Cover image}

Tower of Babel, c. 1563, Kunsthistorisches Mu-

seum, Vienna, Austria

Artist: Pieter Bruegel the Elder 


\section{About Politics and Governance}

Politics and Governance is an innovative new offering to the world of online publishing in the Political Sciences. An internationally peer-reviewed journal, Politics and Governance publishes significant, cutting-edge and multidisciplinary research drawn from all areas of Political Science. Its central aim is thereby to enhance the broad scholarly understanding of the range of contemporary political and governing processes, and impact upon of states, political entities, international organizations, communities, societies and individuals, at international, regional, national and local levels. Submissions that focus upon the political or governance-based dynamics of any of these levels or units of analysis in way that interestingly and effectively brings together conceptual analysis and empirical findings are welcome.

Politics and Governance is committed to publishing rigorous and high-quality research on a quarterly basis. To that end, it undertakes a meticulous editorial process, providing both the academic and policy-making community with the most advanced research on contemporary politics and governance.

The journal is an entirely open-access online resource, and its in-house publication process enables it to swiftly disseminate its research findings worldwide, and on a regular basis. In its first year of operation, Politics and Governance welcomes scholarly articles of 8,000-12,000 words. Future submissions will likely include reflective 'state of the art' pieces, and book reviews.

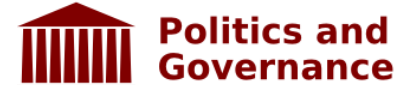




\section{Editorial Team}

\section{Editors-in-Chief}

Amelia Hadfield - Vrije Universiteit Brussels \& Institute for European Studies, Belgium Andrej Zwitter - University of Groningen, The Netherlands

\section{Managing Editor}

António Vieira - Librello, Switzerland

\section{Editorial Board}

Vinod Aggarwal - University of California at Berkeley, USA

Richard Bellamy - University College London, UK Ingrid van Biezen - Leiden University, The Netherlands Jens Blom-Hansen - Aarhus University, Denmark Thomas Bräuninger - University of Mannheim, Germany Mark Brawley - McGill University, Canada Marla Brettschneider - University of New Hampshire, USA Chris Brown - London School of Economics, UK Wouter van der Brug - University of Amsterdam, The Netherlands Gerald Chan - University of Auckland, New Zealand David Coen - University College London, UK A. Claire Cutler - University of Victoria, Canada Keith Dowding - Australian National University, Australia John Entelis - Fordham University, USA Lee Epstein - University of Southern California, USA Maurizio Ferrera - University of Milan, Italy Mervyn Frost - King's College, UK Jack Goldstone - George Mason University, USA Donald Green - Columbia University, USA Kristian Harpviken - Peace Research Institute Oslo, Norway Paul Heywood - University of Nottingham, UK Jon Hovi - University of Oslo, Norway Stein Kuhnle - University of Bergen, Norway \& Hertie School of Governance, Germany Annica Kronsell - Lund University, Sweden Adrian Little - University of Melbourne, Australia Allan McConnell - University of Sydney, Australia Catherine Moury - New University of Lisbon, Portugal Malik Mufti - Tufts University, USA Costas Panagopoulos - Fordham University, USA Inderjeet Parmar - City University London, UK Dianne Pinderhughes - University of Notre Dame, USA Isabella Proeller - University of Potsdam, Germany Sonja Puntscher-Riekmann - University of Salzburg, Austria John Ravenhill - Australian National University, Australia Sieglinde Rosenberger - University of Vienna, Austria Richard Sakwa - University of Kent at Canterbury, UK Marian Sawer - Australian National University, Australia Vivien Schmidt - Boston University, USA Karen Smith - London School of Economics, UK Maritta Soininen - University of Stockholm, Sweden Simon Tormey - University of Sydney, Australia Reeta Tremblay - University of Victoria, Canada 


\section{Table of Contents}

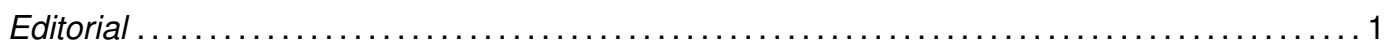
Inaugural Editorial

Amelia Hadfield ${ }^{1, *}$ and Andrej J. Zwitter ${ }^{2, *}$

${ }^{1}$ Institute for European Studies, Vrije Universiteit Brussels, Belgium

${ }^{2}$ Faculty of Law, University of Groningen, The Netherlands

* Corresponding authors

Research Article. 6 Breaking Empirical Deadlocks in the Study of Partisanship: An Overview of Experimental Research Strategies

Donald P. Green

Department of Political Science, Columbia University, USA

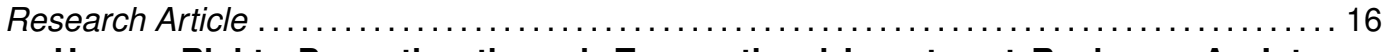
Human Rights Promotion through Transnational Investment Regimes: An International Political Economy Approach

A. Claire Cutler ${ }^{1,2}$

${ }^{1}$ Department of Political Science, University of Victoria, Canada

${ }^{2}$ Hague Institute for the Internationalisation of Law, The Hague, The Netherlands

Research Article

Forecasting Stability or Retreat in Emerging Democratic Regimes

Snigdha Dewal ${ }^{1}$, Jack A. Goldstone ${ }^{1,2, *}$ and Michael Volpe ${ }^{1}$

${ }^{1}$ School of Public Policy, George Mason University, USA

${ }^{2}$ Russian Presidential Academy of National Economy and Public Administration, Russia

* Corresponding author

Research Article 48

Towards a Genuine Economic and Monetary Union-Comments on a Roadmap

Ansgar H. Belke

Department for Macroeconomics, University Duisburg-Essen, Germany

Research Article 66

Campaign Duration and Election Outcomes

Costas Panagopoulos

Department of Political Science, Fordham University, USA

Research Article

From Needs to Rights-A Socio-Legal Account of Bridging Moral and Legal Universalism via Ethical Pluralism

Andrej J. Zwitter

Department of Legal Theory, University of Groningen, The Netherlands

Research Article ....

The Political Economy of Extraterritoriality

Paul Stephan

School of Law, University of Virginia, USA 


\title{
Inaugural Editorial: Politics and Governance
}

\author{
Amelia Hadfield ${ }^{1, *}$ and Andrej J. Zwitter ${ }^{2, *}$ \\ ${ }^{1}$ Institute for European Studies, Vrije Universiteit Brussels, Pleinlaan 5, 1050 Brussels, Belgium; \\ E-Mail: amelia.hadfield@vub.ac.be \\ ${ }^{2}$ Faculty of Law, University of Groningen, Oude Kijk in 't Jatstraat 26, 9712 EK Groningen, The Netherlands; \\ E-Maill: a.zwitter@rug.nl \\ * Corresponding authors
}

Submitted: 19 February 2013 | Accepted: 20 February 2013 | Published: 5 March 2013

\section{Introduction}

We are proud to welcome our readers, contributors and reviewers to this inaugural issue of Politics and Governance, published by Librello Publishing Housea peer reviewed, open-source journal dedicated to the study of politics in the national, regional and global realm, and the modes and methods of governance in all its manifestations. We are thrilled to be so ably supported by an editorial board that is not only strongly international, but inherently multi-disciplinary in its academic orientations, and welcome them, and the new readership and future authors, to this new open-source journal. As outlined below, while the envisaged scope of Politics and Governance is reassuringly broad, and our vision for its development ambitious, the dedication of the Editorial Board and Editors-in-Chief to rigor and to quality will be steadfast.

Politics and political thought is now a mature field of study. The dynamics and indeed study of governance, however, is more recent, and betokens a shift in the power, policy, and polity of government that emerged in the late twentieth century, and is increasingly the international pattern of the twentyfirst century. The difference between the two is as fascinating as the measure by which one constitutes the other, the degrees of conflation, reinforcement, tension between traditional modes of politics, as well as the challenge to those modes by emerging structures of governance. Whether investigated as dual forces, or examined separately, the journal interprets both the concept and practice of politics and governance broadly, and as such, will seek contributions on that basis.

\section{Open-Source Publishing}

The idea of publishing an open-source journal comes at a time when international policy makers increasingly value the principle that high-quality research can and must be as freely available as possible, and thus accessible to the widest academic audience. Indeed, under the aegis of transparency, a key feature of international governance has been the increasingly open-source, publicly available outputs of local, national and international actors. An open-source mandate therefore has an innately social component by fostering methods that attempt to lessen varieties of knowledge inequality and inaccessibility perpetuated in some sense through costly subscriptions to journals (particularly in hard form) that can limit the accessibility of research to students, academics and critically informed members of civil society from developed and developing regions of the world. Politics and Governance therefore takes a somewhat idealist perspective in its goal of bringing high-quality, cutting-edge research on key aspects of politics and governance more effectively to scholars of all stripes as well as to professionals and policy makers, in a way that reduces the innate tendency for 'ivory towerism' and replaces it with a dynamic journal that cultivates 
intelligent research on fast-moving topics, presented in a suitably contemporary platform.

In order to achieve these admittedly ambitious goals, Politics and Governance has a variety of editorial touchstones by which it assesses contributions.

\section{Editorial Touchstones}

- Open School: the journal is not a vehicle for any one school of thought, but operates rather an 'online agora' for a range of disciplinary approaches, methodological structures and interpretations ([1], p. 1).

- Conceptual/practical interface: articles that present empirical findings that effectively test theoretic propositions of politics and/or governance in a methodologically sound manner appropriate to the material are particularly welcome.

- Inter-disciplinary: articles that draw intelligently and appropriately from one or more academic disciplines in order to complement the investigation at hand, and in doing so, redefine problems or enrich our understandings. Such articles reflect not only the key ethos of the journal, but also uncover the multilayer genealogy by which the forces of politics and governance are constructed.

- Comparative: contributions that tackle the uneasy nexus within and between politics and governance, both as topics of academic investigation and as contemporary practices of power, are especially welcome.

\section{Journal Structure and Content}

Envisaged as a four-issue/year journal, Politics and Governance will draw heavily upon a wide range of reviewers (beginning with the members of its Editorial Board), and will contain in its standard issues the following sections:

- 8,000-12,000 word (single-blind) peer-reviewed scholarly articles, with a maximum of eight articles per issue.

- From 2014: a Politics and Governance Working Forum: two to three peer-assessed features, 20003000 words in length, and written as a 'reflective pieces' by current policy-makers on developing themes, the practical implementation, and changing nature of politics and/or governance.

- From 2014: a Book Review Section reviewing 2-3 texts, monographs and even scholarly articles that have been published in the last 18 months.

From mid-2014, we envisage an annual Special Issue highlighting a prominent theme drawn from within the wide canon of politics and/or governance, on the basis of a consensus reached amongst the members of the Editorial Board.

\section{Inaugural Issue}

The contributions to this inaugural issue represent in practice the Editorial Touchstones outlined above.
With a focus on 'Politics' as opposed to Governance, the range of contributions range from ethical investigations concerning human rights, to research on national politics and decision-making, to a review of methodological strategies with a view to solving empirical research deadlocks.

The editorial team behind Politics and Governance places a premium on pieces that fuse together as many of the Editorial Touchstones as possible. Pieces that constitute an inherently international, interdisciplinary, methodically rigorous approach that critically, intelligently and clearly investigate the conceptual development and/or practical unfurling of key aspects of politics and governance are therefore, to misquote Shakespeare, forms of scholastic consummation for which the editorial board devoutly wishes.

The following section constitutes a brief exercise in which the two co-editors, Andrej and Amelia, reflect respectively upon aspects of contemporary politics and governance.

\section{Politics and Governance as Fields of Investi- gation}

As mentioned above, we see politics and governance as dual forces both conceptually and in practice. Both fields share a lot of common ground and degrees of conflation, they might reinforce each other, or cause tensions between traditional modes of politics and modern modes and structures of governance.

Politics has long expanded upon its heritage of focusing on electoral studies and high-level decisionmaking and has become a field of study that nowadays also incorporates psychological, sociological and philosophical investigations. It has further developed to integrate the fields of economics and law as integral part of political life. Our conception of politics as a field of study encompasses grass-roots politics just as much as international relations and global commerce and communication. States have to some extent lost their ontological primacy as research subjects and need to be viewed in a field of stresses and strains imposed by non-governmental actors and internationally operating organizations. Politics, therefore, sometimes due to the sheer complexity of intervening variables, faces difficulties viewing the world from a purely behaviouralist perspective, and it cannot close its eyes anymore from clashes of normative preconceptions.

The journal's pillar of 'politics' aims to explore political science in its wider sense. Political and moral philosophy ask questions that put current systems under scrutiny and demand for improvements to normative presuppositions often taken for granted. Social, cognitive, and political psychology have made advances that require us to rethink the functioning of individual and collective decision-making. Legal and economic research highlight the fields of tension that states find themselves in when facing normative 
regimes on different levels. All this and more indicates the need for multi-disciplinary and where possible inter-disciplinary approaches concerning both the content of study, such as the interaction between economy, law and politics, as well as the methods used to investigate emerging phenomena.

Among other issues, the normative/empirical divide will be of particular interest to the politics pillar. The normative/empirical divide is not merely the distinction between is and ought, it can encompass the distinction between ideal theory and non-ideal theory [2] just as much as it can relate to the normative content of politics in empirical reality [3]. The former describes the theorist's paradigmatic shift between ideal-world normative prescriptions and non-ideal world modifications requiring a prudent assessment of the empirical and its normative power. The latter asks for the investigation of the normative content of the empirical as well as of the normative power of it.

Another issue could be the increasing interdisciplinary focus of politics, which allows theoretical perspectives such as the social mechanisms approach of sociology or the works of Kahneman and Tversky on cognition and decision-making questioning whether traditional rational economic models should remain a standard of investigation in the political realm [4]. Politics thereby stops being its own separate field in the social sciences, but becomes the subject of study of interdisciplinary scholars embracing the open school, where under the condition of scientific rigor and the laws of science theoretical and methodological cross-fertilization is not only accepted, but in fact encouraged.

The pertinent questions that emerge in the realm of politics are challenging, salient and deserving of further study: what do these findings mean for the practice of political conduct; how can policy makers learn from research that reveals a complexity that reshapes the political realm as we speak? As stated before, Politics and Governance is interested in the theoretical and philosophical developments that shape political science in its current state, but it also strongly encourages contributors to think beyond their sphere of comfort about the practical implications of their work.

While widely interpreted, politics-as a topic of scholarly investigation-will generally denote the process by which formal state institutions ensure public order internally, and undertake collective representation and action externally. Scholars are familiar with the accompanying dynamics of government, and indeed, hunger for new and surprising postWestphalian dimensions, from cross-border integration to collective security, from state intervention to full-fledged development policy. Some of these transitions, however, indicate not merely new forms of state behaviour, but a wholly new category of political power. Wholly new in institutional form, altered in policy content, and while operating with recognizable attributes of state-based politics, strikingly changed in the 'location' of its own self, its own polity.

Is governance merely Politics 2.0 ? Is it the latest in a rather predictable series of shifting patterns arising from world states torn between vying globalist and localist forces? Possibly. But more likely, the signifier itself has changed. To be sure, traditional styles of governing remain, and in some cases, have become reactively entrenched. Sovereignty is in no danger of serious attenuation, nor is the nation-state in danger of obsolescence. And yet, in virtually every major policy area, across the majority of developed regions, the state as a unit, and sovereignty as its key attribute, are irrevocably changed. Each has been subjected to the requirements of having to incorporate a range of 'externalities', whether through top-down forces of membership with major institutional organizations, or via bottom-up requirements of enhanced cross-border connectivity. Having altered themselves in this process, states, and their dominant attributes, have thus reordered the 'condition of ordered rule' ([5], p. 652).

Governance is therefore a wholly new political condition, arising from altered structures, which in turn has produced an emphatic, and possibly permanent change upon both the forces of national power and the societies upon which that power is brought to bear.

The outcome is deeply paradoxical. On the one hand, the practices of governance appear unnervingly innovative, with relentless integration apparently transforming the entire composition of states, their national economies, and even the means and ends of standard public policy-making. From this perspective, governance represents a series of new mechanisms that are categorically different from traditional national government structures, and which operate with little or no "recourse to the authority and sanctions of government" ([6], p. 18). Instead, how governance operates is stimulated through a critical multiplicity of interactions with others, near and far, across every imaginable policy area, and which perforce requires viable, but uncommon structures resting on efficient, but new (and frequently untried) processes. In this respect, governance forces a very real change in the conditions for ordered internal rule and external action. Consequently, the outputs of governance are intrinsically different from the traditional political arena associated with 'government'.

Equally however, governance-drawing as it does from an undeniably resistant sovereign wellspringproduces outcomes that while categorically different, do still "parallel those of the traditional institutions of government" and in this sense, are disconcertingly similar to the outputs of government, in which any apparent change is, as argued by Stoker, "rather a matter of a difference in process" ([6], p. 17).

There are a number of major variants that have emerged, and upon which the journal ought to focus:

- Political Governance: forensic analyses of 
major exemplars of governance, ranging from NATO, the UN and the EU, should be considered. Given recent upheavals, the EU for example, could spark contributions that question why modes of 'Eurogovernance' have not yet produced a confederal European state, but rather "encouraged Europeans to embrace, or to entangle, the rest of the world in their amorphous constructions" ([7], p. 130). However, other policy-driven and regional examples of governance should also be explored. Equally, 'in-state' trends of devolution, local government, the blurring of public and private sectors, all constitute interesting examples of the changed conditions of ordered rule. Ultimately, as examined by James Rosenau, such investigations force us to ask strikingly essentialist questions, the most salient of which is whether we can "presume the presence of governance without government" and still reasonably explain how new systems can and must cope with the enduring systemic realities in which any governing unit "has to cope with external challenges, to prevent conflicts among its members...to procure resources....and to frame goals and politics designed to achieve them" ([8], p. 3).

- Economic Governance: the post-2008 world has highlighted a series of do's and don'ts for world leaders, suggesting either that markets should be untouched and untrammeled, or moderately managed, or heavily regulated. Interestingly, the spectrum of economic government has conflated terms that formerly were held in opposition: integration, regulation, globalization. An interesting point of departure for future contributions may be examinations of the erstwhile oppositions between Chicago School and Harvard School methodologies of global vs. semiglobal outputs, and the political and policy-making implications thereof [9].

- Legal Governance: underwriting some, though not all, major institutional examples of governance, is a formidable legal framework that has been steadily constructed alongside, or frequently, in opposition to national law, and at times in uneasy relation to international law (EU Law being the strongest example here). In what ways has international, regional, and national law making been the recipient of, and vehicle for, changed conditions of ordered rule? Is law a measure of governance, or a mode by which to keep it at bay? Normative issues that drive the modes of regime-construction are equally pertinent here: the rules, regulations, norms and values that codify the original vade mecum of an organization and endow it with not merely a recognizable form, but legitimate content, and justifiable outputs.

- Socio-cultural Governance: societal compositions and inter-minglings produce both the strongest and most surprising areas of trans-national overlap; and also highlight the immeasurably immovable areas of national, and local allegiance. If governance represents less, or at the least, transformed government, what impact if any, does it have upon national communities, forms of cultural identity, and societal vehicles like education, communication, or commercialism? Explorations into the socio-cultural dimension of governance suggest both pragmatic practices in which culture is afforded merely a new framework by which to constitute itself, and far more transformative outcomes in which the discourse of governance itself (and its chosen modes), reflects new value-based points of reference.

- Epistemic Governance: this term could in the first instance reflect the growth of knowledge communities that are moving to outflank political structures and transcend traditional modes of policymaking. Equally however, epistemic governance could represent 'state of the art investigation' journal submissions, reviewing and clarifying salient aspects of the conceptually eclectic roots of governance.

\section{Comfortable Words}

As outlined above, Politics and Governance aims to provide freely accessible, cutting edge and original research to a wide variety of interested scholars, students, researchers, policy makers and interested individuals. Our goals should therefore line up well with our recommendations to potential contributors. In order to facilitate accessibility, clear writing on intelligently discerned topics are most welcome.

Originality is the hallmark of every decent piece of writing, but it can be exemplified in numerous ways. First, salience: demonstrating why and how key issues matter, and to which audiences, as well as providing partial responses to those pesky perennial totems about the management of power ([10], p. 1). Second, meta-narratives allowing readers to gain a clearer sense of the connectivity between a multiplicity of governing factors, or indeed an emerging trend in the study of such factors. Last, utility, in terms of enhancing the ability of scholars and policymakers alike to reach greater clarity in terms of the processes and consequences of key aspects of politics and governance.

These categories are indicative, rather than exhaustive. However, particular articles are subsequently placed into the overall structure of Politics and Governance, they will all, like the journal itself, provide an exciting lineup of cutting-edge commentary on an emerging dualism of contemporary political life: the enduring forces by which politics are determined and displayed, and the transforming, even transcending of these same forces by structures and dynamics of governance. 


\section{References}

1. Zuckert M. Greetings from the Editor. American Political Thought. 2012;1(1):1-2.

2. Rawls J. A Theory of Justice. Oxford, UK: Oxford University Press; 1999.

3. Morgenthau $\mathrm{HJ}$. The Twilight of International Morality. Ethics. 1948;58(2):79-99.

4. Levy JS. Daniel Kahneman: Judgment, Decision, and Rationality. Political Science and Politics. 2002;35 (2):271-273.

5. Rhodes R. The New Governance: Governing without Government. Political Studies. 1996;44(4):652667.

6. Stoker G. Governance as Theory: Five Proposi- tions. International Social Science Journal. 1998;50 (155):17-28.

7. Rabkin JA. Law without Nations? Why Constitutional Government Requires Sovereign States. Princeton, USA: Princeton University Press; 2005.

8. Rosenau J. Governance, Order and Change in World Politics. In: Rosenau J, Czempiel E-O, editors. Governance without Government: Order and Change in World Politics. Cambridge, UK: Cambridge University Press; 1992, pp. 1-30.

9. Ghemawat P. World 3.0: Global Prosperity and How to Achieve It. Boston, USA: Harvard Business Review Press; 2011.

10. Hochschild JL. Introduction and Observations. Perspectives on Politics. 2003;1(1):1-4. 


\title{
Breaking Empirical Deadlocks in the Study of Partisanship: An Overview of Experimental Research Strategies
}

\author{
Donald P. Green \\ Department of Political Science, Columbia University, 420 W. 118th Street, 7th Floor IAB, New York, NY 10027, \\ USA; E-Mail: dpg2110@columbia.edu
}

Submitted: 19 December 2012 | In revised form: 9 February 2013 | Accepted: 20 February 2013 |

Published: 5 March 2013

\begin{abstract}
The vast literature on party identification has gradually become bogged down by disputes about how to interpret observational data. This paper proposes the use of experimental designs to shed light on the responsiveness of party identification to short term forces such as retrospective performance evaluations. Examples of recent field experiments are used to illustrate two types of experimental designs and the assumptions on which they rest.
\end{abstract}

Keywords: causal inference; field experiments; party identification; research design

\section{Introduction}

The vast behavioral literature on party identification has been propelled by a series of methodological innovations. The initial conceptualization of party identification as an enduring attachment that shapes the way in which voters view political figures and issues [1] was prompted by the growth and development of survey research in the early 1950s, and theoretical refinements followed as surveys became more widespread and sophisticated [2-4]. During the mid-1970s, nonrecursive statistical models became part of the political science toolkit, and a torrent of studies called into question the assumption that causation flows in one direction from party attachments to issue positions $[5,6]$, performance evaluations $[7,8]$, and candidate evaluations [9]. This line of attack drew on a wide array of surveys, including several conducted outside the United States [10]. By the mid-1980s, political scientists had grown deeply skeptical of the view that party identification is an unmoved mover, developed early in life and unresponsive to short-term changes in the political environment. The simultaneous equations models of the 1970 s and early 1980s, however, came under criticism in the wake of another methodological development, the analysis of covariance structures as a means of addressing biases due to measurement error. Response error was said to produce a variety of statistical artifacts, leading scholars to exaggerate the rate of partisan change $[11,12]$ and the responsiveness of partisanship to short-term shifts in the way that voters evaluate incumbent performance and candidates' issue stances [13] in a variety of cross-national settings ([14], but see [15-17]). The most recent methodological innovation was the analysis of aggregate survey data, made possible by the accumulation of several decades of quarterly polling data by commercial and news organizations [18]. This evidence was initially interpreted as demonstrating the malleability of partisan-

(C) 2013 by the authors; licensee Librello, Switzerland. This open access article was published under a Creative Commons Attribution License (http://creativecommons.org/licenses/by/3.0/). 
ship in the wake of economic fluctuations and scandals, although subsequent work that took sampling variability $[19,20]$ and question wording effects [21] into account tempered this conclusion.

Each wave of methodological innovation has introduced new evidence into debates about the nature and origins of party attachments, but uncertainty remains about how to interpret the results given the welter of competing methodological claims. The study of partisanship currently finds itself in a state of deadlock between theoretical perspectives that emphasize the stability of partisan identities (and social identities more generally) in polities where the parties and their social constituencies are stable [22] and theoretical perspectives that regard partisanship as a running tally of past performance evaluations [7,23], a summary of expectations about future performance [24], or a manifestation of voters' ideological proximity to the parties $[6,15]$.

How might researchers break this deadlock? Many of the central debates ultimately come down to questions of causal inference. The reason methodological debates about two-way causal flows, measurement error, and other specification issues have played such a prominent role in the literature on party identification is that the evidence base is almost entirely drawn from nonexperimental research. Cross-sectional surveys, panel surveys, and aggregate time-series furnish the data analyst with variation in partisanship and variation in the putative causes of partisanship. What to make of the correlation between these two sets of variables hinges on the substantive modeling assumptions that researchers bring to bear when analyzing the data. Do voters' policy views cause them to adjust their partisan attachments in light of party platforms, or do voters instead follow party leaders' pronouncements on prominent issues of the day [25]? Or do correlations between policy views and party attachments reflect unmeasured variables with which they are both correlated? Sorting out cause and effect statistically requires the researcher to trace this correlation to some putatively exogenous initial conditions. For example, in cross-sectional analysis (e.g., [5]), the identifying assumption is that certain demographic variables predict issue stances but are unrelated to omitted causes of party identifications. In panel analysis, the core assumption is slightly weaker: subjects' background attributes and prior attitudes are related to current partisanship only insofar as they influence contemporary issue stances and performance evaluations (e.g., [8]). In time-series analysis, the identifying assumptions are somewhat more complex because they involve a range of propositions about how partisanship and short-term forces are measured over time and how the dynamics of each series are modeled $[19,23,26]$. Each of the competing modeling approaches involves strong and untestable modeling assumptions. New statistical techniques (e.g., matching) that introduce untestable assumptions of their own are unlikely to advance this literature. Even if voters who harbor different policy views were precisely matched in terms of their measured attributes, a researcher might still wonder whether their different partisan attachments reflect unmeasured attributes, such as pre-adult socialization experiences, that are correlated with policy stances [27].

During the past decade, largely in response to the kinds of identification problems just mentioned, another methodological innovation has taken root in the social sciences. Increasingly, researchers in political science and economics have turned to randomized experiments in order to facilitate causal inference. Experimental designs by no means eliminate problems of inference, but they nonetheless represent an important advance that, at a minimum, calls attention to subtle issues of identification and interpretation. This essay discusses a pair of recent studies that illustrate two broad classes of experimental designs. The first addresses the question of what kinds of stimuli cause people to alter their partisan attachments; the second addresses the question of what downstream consequences follow from an exogenously-induced change in partisanship. We begin by introducing the logic of inference that underlies randomized experiments, discuss the identification strategies that underlie each study, and suggest how an experimental agenda might advance the literature on party identification.

\section{Inference from Direct and Downstream Experi- ments}

Randomized experiments-and research designs that attempt to approximate random assignment-are often explicated in terms of a potential outcome framework $[28,29]$. The advantages of this framework for statistical practice are twofold: it makes clear what is meant by causal influence and encourages researchers to attempt to estimate causal parameters without invoking the assumption that all individuals are subject to the same treatment effect. These advantages have special value for the literature on party identification, which tends to gloss over important issues of identification, especially as they pertain to variation in treatment effects from one person to the next. What follows is a brief introduction to the potential outcomes framework, drawing on the more extensive presentation in [30].

Before delving into the specifics of how partisanship is influenced by other factors, such as voters' economic assessments or policy stances, let's consider the problem of causal inference in abstract terms. We begin by supposing that each person $i$ harbors two 
potential outcomes. Let $Y_{i}(0)$ be $i$ 's partisanship if $i$ is not exposed to the treatment, and $Y_{i}(1)$ be $i$ 's partisanship if $i$ is exposed to the treatment. The treatment effect is defined as:

$$
\tau_{i} \equiv Y_{i}(1)-Y_{i}(0)
$$

In other words, the treatment effect is defined as the difference between two potential states of the world, one in which the individual receives the treatment, and another in which the individual does not. Extending this logic from a single individual to a set of individuals, we may define the average treatment effect (ATE) as follows:

$$
A T E \equiv E\left[\tau_{i}\right]=E\left[Y_{i}(1)\right]-E\left[Y_{i}(0)\right]
$$

where $E[\cdot]$ indicates an expectation over all subjects. Although empirical research may serve many purposes, one principal aim is to estimate the ATE, the average effect of introducing some sort of information, policy, or incentive.

In an actual experiment or observational study, we observe subjects in either their treated or untreated states. Let $D_{i}$ denote the treatment status of each subject, where $D_{i}=1$ if treated and 0 if not. The difference in expected outcomes among those who are treated and those who are not treated may be expressed as:

$$
E\left[Y_{i}(1) \mid D_{i}=1\right]-E\left[Y_{i}(0) \mid D_{i}=0\right]
$$

where the notation $E\left[A_{i} \mid D_{i}=B\right]$ means the average value of $A_{i}$ among those subjects for which the condition $D_{i}=B$ holds. For example, one could compare average outcomes (party identification scores) among those who evaluate the economy positively $\left(D_{i}=1\right)$ to average outcomes among those who evaluate the economy negatively $\left(D_{i}=0\right)$.

In a typical observational study, the observed difference in partisanship between those who evaluate the economy positively or negatively may not, in expec-tation, reveal the average causal effect of economic perceptions. We observe average outcomes for the treated subjects in their treated state and average outcomes of the untreated subjects in their untreated state. To see how this quantity is different, in expectation, from the ATE, we rewrite Equation (3) as:

$$
\begin{aligned}
& E\left[\left(Y_{i}(1)-Y_{i}(0)\right) \mid D_{i}=1\right] \\
& +\left\{E\left[Y_{i}(0) \mid D_{i}=1\right]-E\left[Y_{i}(0) \mid D_{i}=0\right]\right\}
\end{aligned}
$$

In other words, the expected difference in outcomes of the treated and untreated can be decomposed into the sum of two quantities: the average treatment effect for a subset of the subjects (the treated), and a selection bias term. The selection bias term (in braces) is the difference between what the outcome $Y_{i}(0)$ would have been for those who are treated had they not been treated and the value of $Y_{i}(0)$ observed among those who were not treated. The threat of selection bias arises whenever systematic processes determine which people receive treatment. In this example, if people choose the sorts of economic news they read and remember, expected $Y_{i}(0)$ potential outcomes may be quite different among those who evaluate the economy positively or negatively.

Random assignment solves the selection problem. When random assignment determines which treatment each subject receives, $D_{i}$ is independent of potential outcomes. Those randomly selected into the treatment group have the same expected outcomes in the treated state as those randomly assigned to remain untreated (control group):

$$
E\left[Y_{i}(1) \mid D_{i}=1\right]=E\left[Y_{i}(1) \mid D_{i}=0\right]=E\left[Y_{i}(1)\right]
$$

By the same token, those randomly assigned to the control group have the same expected $Y_{i}(0)$ outcomes as those assigned to the treatment group:

$$
E\left[Y_{i}(0) \mid D_{i}=0\right]=E\left[Y_{i}(0) \mid D_{i}=1\right]=E\left[Y_{i}(0)\right]
$$

Equations (5) and (6) reveal why, when subjects are randomly treated, the selection bias term vanishes and the difference between treatment and control group averages provides an unbiased estimate of the ATE. This identification result can be shown by substituting Equations (5) and (6) into Equation (3):

$$
E\left[Y_{i}(1) \mid D_{i}=1\right]-E\left[Y_{i}(0) \mid D_{i}=0\right]=E\left[Y_{i}(1)\right]-E\left[Y_{i}(0)\right]
$$

This proof demonstrates an attractive property of randomized experiments. At the same time, it glosses over two implicit assumptions. One assumption, which plays a minor role in the analysis that follows, is the stable unit treatment value assumption [29], which stipulates that potential outcomes do not depend on which subjects are assigned to treatment. This assumption is jeopardized, for example, when the treatment administered to one subject affects the outcomes of other subjects. More pertinent to our discussion below is the exclusion restriction assumption [31], which requires that outcomes respond solely to the treatment itself and not to the assigned treatment or other backdoor causal pathways that are set in motion by the assignment to treatment or control. For example, we must assume that when we randomly assign economic evaluations, we are not inadvertently deploying other treatments, such as information about the party platforms on environmental issues. 
Readers may be wondering whether an experiment could feasibly assign how people evaluate the economy. The answer is probably not, and we must therefore introduce another layer of notation to describe the imperfect translation of intended treatments into actual treatments. Let $Z_{i}=1$ if a subject is assigned to the treatment group, and $Z_{i}=0$ if the subject is assigned to the control group. In experiments with full compliance, all those assigned to the treatment group $\left(Z_{i}=1\right)$ also receive the treatment $\left(D_{i}=1\right)$, and all those assigned to the control group $\left(Z_{i}=0\right)$ are untreated $\left(D_{i}=0\right)$. In experiments with some degree of noncompliance, $D_{i}(z) \neq Z_{i}$. Encouragement designs, for example, attempt to induce some subjects to take the treatment $D_{i}$ but recognize that there may be some subjects who will fail to do so or who will take the treatment even when not encouraged.

In the context of experiments that encounter noncompliance, the exclusion restriction holds that $Y_{i}(d, z)=Y_{i}(d)$ for all values of $d$ and $z$. In other words, potential outcomes respond solely to actual treatment, not assigned treatment. Consider a recent survey experiment by Middleton [32] that randomly encourages some subjects to read upbeat news stories about the economy $\left(Z_{i}\right)$ in an effort to change their assessment of national economic conditions $\left(D_{i}\right)$, which in turn may affect their partisanship $\left(Y_{i}\right)$. The causal effect of interest is the influence of $D_{i}$ on $Y_{i}$, but $D_{i}$ itself is not randomly assigned. The exclusion restriction holds that assignment $Z_{i}$ has no influence on $Y_{i}$ except insofar as it affects $D_{i}$, which in turn affects $Y_{i}$. In other words, the encouragement to read a news story is assumed to affect partisanship only insofar as the encouragement changes assessments of national economic conditions.

In order to recover the causal effect of $D_{i}$ on $Y_{i}$ using an encouragement design, we need one further assumption known as monotonicity [31]. Describing this assumption requires a bit more terminology. Depending on the way their received treatments potentially respond to treatment assignment, subjects may be classified into four types, Compliers, Nevertakers, Always-takers, and Defiers. Compliers are subjects who take the treatment if and only if assigned to the treatment. For this group $D_{i}(1)-D_{i}(0)=1$. Never-takers are those who are always untreated no matter their assignment: $D_{i}(1)=D_{i}(0)=0$. Conversely, Always-takers are those who are always treated no matter their assignment: $D_{i}(1)=D_{i}(0)=1$. Defiers are those who take the treatment if and only if they are assigned to the control group: $D_{i}(1)-D_{i}(0)=-1$. The monotonicity assumption stipulates that there are no Defiers. In context of our running example, when assigned to receive upbeat economic news, everyone's economic assessments either remain unchanged or become more buoyant. Notice that the monotonicity assumption has nothing to do with potential outcomes concerning partisanship, $Y_{i}$. Monotonicity refers only to the relationship between assigned treatment and actual treatment.

Under the stable unit treatment value, exclusion restriction, and monotonicity assumptions, one can identify the ATE among Compliers [31]. This quantity, the Complier Average Causal Effect (CACE), is estimated by dividing two quantities. The numerator in Equation (8) is the average outcome in the assigned treatment group minus the average outcome in the assigned control group; the denominator is the observed rate of treatment in the assigned treatment minus the observed rate of treatment in the control group:

$$
\widehat{C A C E}=\frac{\left(\hat{E}\left[Y_{i} \mid Z_{i}=1\right]-\hat{E}\left[Y_{i} \mid Z_{i}=0\right]\right)}{\left(\hat{E}\left[D_{i} \mid Z_{i}=1\right]-\hat{E}\left[D_{i} \mid Z_{i}=0\right]\right)}
$$

This ratio is equivalent to the estimate generated by an instrumental variables regression of $Y_{i}$ on $D_{i}$ using $Z_{i}$ as an instrumental variable. Because the denominator is a difference between two quantities that are subject to sampling variability, this ratio is consistent but not unbiased and becomes undefined when the treatment rate in the two experimental groups is the same. Precise estimation requires a substantial difference in treatment rates, a point that has special importance for the analysis of what Green and Gerber [33] refer to as downstream experiments.

A downstream experiment is one in which an initial randomization causes a change in an outcome, and this outcome is then considered a treatment affecting a subsequent outcome. For example, in Middleton's study of news coverage on economic assessments [32], subjects in an internet survey were assigned to read newspaper coverage of the 2008 economic crisis. Random assignment produced a change in economic evaluations. A downstream analysis might examine the consequences of changing economic evaluations on party identification. This analysis parallels an encouragement design in terms of its underlying assumptions (stable unit treatment value, exclusion restriction, monotonicity), mode of analysis (instrumental variables regression), and causal estimand (the CACE). Of special importance is the exclusion restriction, which holds that exposure to news stories had no effect on party identification through paths other than economic evaluations. When these assumptions are met, the experimenter obtains consistent estimates of the ATE among Compliers, who are in this case those whose economic evaluations are favorable if and only if they are exposed to the news stories. In order to estimate the CACE with reasonable power, there must be ample numbers of Compliers, which is to say that the news stories must have a sizable impact on economic evaluations. Small numbers of Compliers also mean that a slight violation of the exclusion restriction may lead to severe bias. 
Thus, the most informative experiments are those that set in motion substantial changes in causal variables, such as economic assessments.

In sum, random assignment allows researchers to sidestep the selection problem, but important assumptions remain. Both full-compliance and encouragement designs force the researcher to impose exclusion restrictions. Encouragement designs require the additional assumption of monotonicity and confine the causal estimand to the average treatment effect among Compliers. Whether one can safely generalize from the ATE among Compliers to the ATE for other subgroups is an open question that may be addressed empirically through replication using different sorts of encouragements ([30], chapter 6).

From the standpoint of estimation, this framework departs markedly from the way in which researchers typically analyze observational data. Using the estimator described in Equation (8), a researcher compares subjects according to their experimental assignments, not according to the treatments they actually receive. Precise estimation requires that the assigned treatments bear a reasonably strong relationship to the treatments that subjects actually receive. In other words, the use of instrumental variables regression to estimate the CACE requires an experimental design that generates ample numbers of Compliers.

In order to see these assumptions and design considerations in action, we next consider a pair of recent experiments. The first assesses the influence of information about incumbent performance on party identification. The second considers the downstream effects of randomly-induced party registration on party identification. Because the technical issues surrounding the downstream study are more complex, we discuss the experiment in more detail.

\section{Chong et al. (2011) [34]}

Chong, De La O, Karlan, and Wantchekon [34] report the results of a field experiment conducted in Mexico shortly before its 2009 municipal elections. Their intervention followed in the wake of a federal audit of municipal governments. These audits graded municipal governments according to whether they had accounting irregularities indicative of corruption; the auditors also noted whether local administrators had failed to spend federal grant money, suggesting a low level of administrative competence. The researchers conducted a precinct-level leafleting campaign designed to publicize some aspect of the auditors' reports. Some 1,910 precincts were randomly selected to a control group that received no leaflets. Three random subsets of 150 precincts apiece each received one type of treatment flyer. The first treatment publicized the degree to which the municipality failed to spend federal grant funds. The second publicized the failure to spend grant funds that were supposed to aid the poor. A third graded the municipality according to the amount of evidence of corruption.

Much of the authors' report focuses on how precinct-level vote outcomes changed in the wake of the leafleting campaign; for our purposes, the relevant part of the study examines the effects of the intervention on individual-level attitudes of 750 respondents who were sampled from 75 of the precincts and surveyed two weeks after the election. Since Mexican elected officials are forbidden to seek reelection, voter displeasure cannot be directed at incumbent candidates; the relevant target is the incumbent party. Chong et al. find that negative report cards addressing corruption (but not failure to spend grant money) significantly diminish respondents' approval of the incumbent mayor and identification with the incumbent's political party. Unfortunately, no follow-up surveys were conducted to assess the extent to which the effects persisted beyond two weeks. Nevertheless, the study remains one of the first experiments to show that party attachments change when performance evaluations are altered exogenously.

Given the sheer number of studies on the topic of party identification, readers may be surprised to learn that the Chong et al. study is among the very few that have attempted to influence party identification via an experimental manipulation. One exception is Cowden and McDermott [35], which reports the results of a series of laboratory studies that sought to influence party attachments though, among other things, roleplaying exercises in which undergraduate subjects were asked to take a pro- or ant-Clinton position. None of their interventions succeeded in changing party attachments. Similarly, although split ballot designs have often been used to assess the effects of question wording on responses to party identification measures (e.g., [36]), survey experiments have seldom assessed whether party identification moves in the wake of information about party platforms or performance. A notable recent exception is Lupu [37], which uses a split ballot design to assess the effects of information on party identification in Argentina. Lupu's work builds on Russian, Polish, and Hungarian experiments reported by Brader and Tucker [38]. Unfortunately, these experiments do not measure whether information effects persist over time, a limitation that makes it difficult to interpret the small and contingent treatment effects that these authors report. One of the attractive features of the Chong et al. study is that its intervention and outcome assessment occur at different points in time.

Let's now consider the Chong et al. study from the standpoint of the core assumptions discussed in the previous section. The exclusion restriction in this instance stipulates that random distribution of 
corruption-related leaflets influences outcomes because it provides evaluative information about incumbent performance. The authors present convincing evidence that the leaflets did tarnish the image of incumbents who were accused of corruption and that precinct-level votes for incumbents accused of corruption were lowered significantly. As for the assumption of excludability, which holds that random assignment does not affect outcomes, it seems there are few backdoor paths that could explain the effect on partisanship: the leaflets were distributed toward the end of the campaign period, preventing incumbents from responding to the messages; the leaflets themselves did not mention political parties; and the post-election surveys did not prime the respondents to think about the leaflets they might have received. The lack of immediate connection between the intervention and the survey represents an advantage of the Chong et al. design in comparison to the split ballot experiments of Lupu [37] and Brader and Tucker [38].

In sum, the Chong et al. design represents an instructive example of an experimental study that measures the extent to which party identification responds to a theoretically informative, real-world intervention. Although more research of this kind needs to be done before one can draw robust conclusions about party attachments in Mexico or elsewhere, this study seems to suggest that performance-related information regarding corruption has a short-term effect on partisanship, while somewhat more issue-related information concerning spending had negligible effects.

\section{Gerber, Huber, and Washington (2010) [39]}

In the context of the hotly contested presidential primaries of 2008, Gerber, Huber, and Washington [39] conducted an experiment in which they sought to create partisan attachments among self-identified independents. In January of 2008, as the presidential primaries of both parties were intensifying, the authors conducted a survey of registered voters in Connecticut who, when registering, declared themselves unaffiliated with any political party. This declaration rendered them ineligible to vote in the upcoming presidential primaries. Among those who declared themselves in the survey to be independents (including those who "lean" toward the Democrats or Republicans when asked a standard follow-up question about which party they feel closer to), half were randomly selected to receive a letter a week or two later informing them that they must register with a party in order to vote in that party's presidential primary election on 5 February. The letter also included a registration form enabling them to register with a party. In June, respondents were reinterviewed and asked about their party identification, as well as their issue stances and other evaluations.

This experiment parallels the encouragement design described earlier. The pool of experimental subjects comprised self-described independents who were interviewed in January. Random assignment $\left(Z_{i}\right)$ determined which of the subjects was sent a letter. The letter was literally an encouragement to register with a political party. Although the letter might ordinarily be considered the treatment in a standard design, the treatment in the downstream experiment $\left(D_{i}\right)$ was whether the subject actually registers as a Democrat or Republican. (The authors discuss other potential outcomes variables, such as whether subjects vote in the presidential primaries; what follows is a simplified version of their analysis that conveys the basic logic of the design.) Some members of the control group registered without encouragement; some members of the treatment group failed to register despite encouragement.

The mismatch between assigned and actual treatment prevents us from estimating the ATE for the sample as a whole; instead, we must set our sights on estimating the ATE for Compliers, those who register with a major party if and only if encouraged. In order to identify the CACE, we must assume monotonicity, or the absence of Defiers. In this case, Defiers are those who would register with one of the two major parties if and only if they are assigned to the control group. Intuition suggests that few voters are so hostile to form letters from public officials that they would cancel their plans to register with a major party if (and only if) encouraged to do so. Monotonicity appears to be a plausible assumption here.

Under monotonicity, those who register with a major party in the control group are Always-Takers, and those who register in the treatment group are a combination of Always-Takers and Compliers. Since the treatment and control groups were selected randomly, in expectation they should have the same shares of Always-Takers and Compliers. Thus, the share of Compliers can be estimated by subtracting the party registration rate $(7.23 \%)$ in the control group $(\mathrm{N}=346)$ from the party registration rate $(13.61 \%)$ in the treatment group $(\mathrm{N}=360)$. This estimate $(0.1361-0.0723=0.0639)$ forms the denominator of the estimator in Equation (8). The t-ratio for this estimated effect is 2.78. Using the full sample of subjects (rather than just those reinterviewed in June) leaves no doubt about the robustness of the relationship. For these 2,348 subjects, the tratio is 5.48. The experiment did not generate an enormous share of Compliers, but clearly there are enough to support a downstream analysis.

The numerator of Equation (8) is the observed difference in outcomes, in this case, identification with a major party when re-interviewed several 
months later. Identification could be measured in various ways; for purposes of illustration, we will use the convention of measuring partisan strength by folding the 7-point party identification scale at the center (pure independent) and counting independent leaners as 1 , weak partisans as 2, and strong partisans as 3. Using this scoring method, partisan strength averaged 1.0361 in the treatment group, as compared to 0.9624 in the control group. In other words, assignment to receive a letter boosted the apparent probability of identifying with a party by $1.0361-0.9624=0.0737$ scale points. Putting the numerator and denominator together gives us the instrumental variables regression estimate of the CACE:

$$
\begin{array}{r}
\widehat{C A C E}=\frac{\left(\hat{E}\left[Y_{i} \mid Z_{i}=1\right]-\hat{E}\left[Y_{i} \mid Z_{i}=0\right]\right)}{\left(\hat{E}\left[D_{i} \mid Z_{i}=1\right]-\hat{E}\left[D_{i} \mid Z_{i}=0\right]\right)} \\
=\frac{(1.0361-0.9624)}{(0.1361-0.0723)}=\frac{0.0737}{0.0639}=1.153
\end{array}
$$

This estimate suggests that among Compliers, those who register with a party if and only if encouraged to do so, the act of registering with a party increases partisan strength by 1.153 scale points. The magnitude of this effect is not trivial: in their pre-election round of interviews with registered voters who were not registered with a party (including respondents who were not part of the letter experiment because they were weak or strong partisans), the average level of partisan strength was 1.01 with a standard deviation of 0.85 .

Before drawing substantive inferences based on this estimate, let's first evaluate the plausibility of the exclusion restriction in this application, an issue that Gerber, Huber, and Washington discuss in detail ([39], pp. 737-741). Clearly, the encouragement letters $\left(Z_{i}\right)$ influenced party registration $\left(D_{i}\right)$ and partisan strength $\left(Y_{i}\right)$. The question is whether the exclusion restriction $Y_{i}(d)=Y_{i}(d, z)$ is plausible; could it be that potential outcomes for partisan strength respond not only to whether people register with a party but also to whether they receive a letter? The letters themselves were designed to be empty of partisan content; they simply remind voters of the administrative fact that a change of registration will be necessary if they want to participate in an upcoming election. In terms of measurement procedures, the authors took care to assess outcomes in the June survey in ways that preserved the symmetry between treatment and control groups, avoiding any questions that would prompt members of the treatment group to recall the letter or the circumstances surrounding their change in registration. In terms of substantive confounders, it is possible that the letters piqued voters' interest in the campaign, so that even if they did not change their registration, their partisan attachments were altered. This backdoor pathway from $Z_{i}$ to $Y_{i}$ seems unlikely, and the authors found no evidence that subjects in the treatment group were any more interested or hungry for political information when interviewed in June (p. 739).

If we accept the exclusion restriction, two issues of interpretation remain. The first is whether one can generalize from the estimated ATE for Compliers to causal effects for other subjects, contexts, and interventions. Would the results be the same if one's treatment caused every person who was registered but unaffiliated with a party to change party registration? This question is best settled by follow-up experiments that assess whether the results depend on number and frequency of encouragements (which will affect the proportion of Compliers) or the particular arguments that are used in the encouragement. The same goes for experimenting with different contexts: instead of offering voters a chance to vote in both parties' contested primaries, what about circumstances in which only Republican candidates are vying for the nomination?

Another question of interpretation is what to make of the effect of changing registration. A variety of hypotheses could be adduced: a public declaration of a partisan identity changes the way one regards oneself, sets in motion a search for information to justify one's partisan choice, or causes political campaigns to make increased efforts to mobilize and persuade (p. 737). Each of these subsidiary hypotheses has testable implications, and the authors investigate whether subjects in the treatment and control group evaluate partisan figures differently or have different types of interactions with political campaigns. They find that partisan evaluations do change concomitantly with changes in party identification (p. 735), but there is no apparent relationship between the treatment and contact with campaigns or other manifestations of greater interest in issues or information. Over the course of a few months, change in partisanship seems to have coincided with changes in partisan attitudes but not changes in behaviors such as searching for information or discussing politics with others.

We say "coincided" because one cannot distinguish the causative effects of each of the changes that were set in motion by the letter. The authors note that "receipt of the letter informing the recipients about the need to be affiliated with a party in order to vote in that party's primary increased partisan identity, partisan registration, voter turnout, and partisan evaluations of political figures" (p. 737). With just a single randomly assigned treatment (the letter), one cannot separately identify the effects of each intervening variable. For example, one cannot separately identify the effects of registration and the effects of actually voting; voting is just one of the many possible by-products of registration. If one 
wanted to isolate the effect of registration per se, a different design would be needed-perhaps encourage unaffiliated voters to re-register with a party shortly after the primary has passed in order to estimate the effect of (solely) registering with a party? Conversely, one could determine whether voting per se increases partisanship by urging people to vote using nonpartisan messages (see [40]). The single-factor encouragement used in this study paves the way for more elaborate encouragement designs that aim to identify distinct sources of partisan change.

\section{Discussion}

The two studies summarized above provide a template for future research. The Chong et al. [34] study offers an example of how one might fruitfully study causes of partisan change by deploying an array of different kinds of interventions. In that study, information about corruption in municipal government led voters to change their party attachments. The Gerber et al. [39] study deploys a treatment that in itself had no partisan content and functioned solely to facilitate behaviors that are believed to reinforce partisanship. By setting in motion randomly generated direct and downstream effects, these experiments provide a method for studying partisanship that is both informative and methodologically defensible.

This style of intervention-oriented research could be expanded to include information about the parties' policy stances, their financial backers, their level of support among different segments of the electorate, and so forth. A combination of treatments could be designed to test competing theories about how party identities are formed. One kind of treatment might be designed to affect retrospective performance evaluations, while another might be crafted to alter perceptions of the parties' platforms or support among voters with different social identities. What makes this approach distinctive is that scholars intervene to mint partisans through randomly assigned treatments rather than to observe passively the partisan changes that occur on their own.

Both experiments illustrate how this approach might be deployed in a field setting (perhaps as a byproduct of a broader field experiment), but the basic design applies also to laboratory research [35] and survey research $[32,37,38]$. One could imagine a lab or on-line study in which subjects are pre-screened for weak partisan attachments, randomly exposed to theoretically-inspired appeals that are designed to move them closer to a political party. For example, one could imagine a "social identity" video that explains what sorts of people favor the Democratic and Republican parties and a competing "spatial proximity" video that explains the ideological stances of the party with respect to several leading issues. Indeed, one can even imagine a vacuous "feel-good" video that deploys slogans and attractive imagery while endorsing one of the parties-in this case, the same video could be adapted to support each party. The main practical constraints are the need to expose the control group to something that is vaguely similar (but not party-focused) so that subjects in both groups have similar suspicions about what the study is about when reinterviewed at some later point in time.

More challenging is the task of designing experiments to test the effects of partisan attachments on other attitudes and behavior. For example, partisanship is said to alter issue stances, economic evaluations, and interest in political news. In an ideal design, a randomly assigned intervention would affect party attachments without directly affecting these outcomes. This exclusion restriction obviously rules out the use of economic news as an inducement to identify with the allegedly more competent party. It may also rule out naturally occurring random assignments, such as the Vietnam draft lottery [41], which may affect both partisanship and issue stances directly. Developing effective interventions that seem to satisfy the exclusion restriction may require a fair amount of trial-and-error. Social scientists are relatively unaccustomed to developing interventions that successfully change partisanship; the experiments discussed above are important first steps in that direction.

\section{Acknowledgements}

An earlier version of this paper was presented at the CISE-ITANES Conference "Revisiting Party Identification: American and European Perspectives". LUISSGuido Carli, Roma, 7-8 October 2011. The author is grateful to the Institution for Social and Policy Studies at Yale University, which furnished the replication data analyzed in this paper. 


\section{References}

1. Campbell A, Converse PE, Miller WE, Stokes DE. The American Voter. New York, USA: Wiley; 1960.

2. Campbell A, Converse PE, Miller WE, Stokes DE. Elections and the Political Order. New York, USA: Wiley; 1966.

3. Butler D, Stokes DE. Political Change in Britain. London, USA: Macmillan; 1969.

4. Jennings KM, Niemi RG. Generations and Politics: A Panel Study of Young Adults and Their Parents. Princeton, NJ, USA: Princeton University Press; 1981.

5. Jackson JE. Issues, Party Choices, and Presidential Votes. American Journal of Political Science. 1975;19(2):161-185.

6. Franklin $\mathrm{CH}$, Jackson JE. The Dynamics of Party Identification. American Political Science Review. 1983;77(4):957-973.

7. Fiorina MP. Retrospective Voting in American National Elections. New Haven, CT, USA: Yale University Press; 1981.

8. Brody RA, Rothenberg, LS. The Instability of Partisanship: An Analysis of the 1980 Presidential Election. British Journal of Political Science. 1988; 18(4): 445-465.

9. Page BI, Jones CC. Reciprocal Effects of Policy Preferences, Party Loyalties, and the Vote. American Political Science Review. 1979;73(4):1071-1089.

10. Budge I, Crewe I, Farlie D, editors. Party Identification and Beyond: Representations of Voting and Party Competition. New York, USA: John Wiley and Sons; 1976.

11. Achen $\mathrm{CH}$. Mass Political Attitudes and the Survey Response. American Political Science Review. 1975;69(4):1218-1231.

12. Green DP, Palmquist B. How Stable Is Party Identification? Political Behavior. 1994;16(4):437-466.

13. Green DP, Palmquist B. Of Artifacts and Partisan Instability. American Journal of Political Science. 1990;34(3):872-902.

14. Schickler E, Green DP. The Stability of Party Identification in Western Democracies: Results from Eight Panel Surveys. Comparative Political Studies. 1997;30(4):450-483.

15. Bartle J, Bellucci $P$, editors. Political Parties and Partisanship: Social Identity and Individual Attitudes. New York, USA: Routledge; 2009.

16. Clarke HD, McCutcheon AL. The Dynamics of Party Identification Reconsidered. Public Opinion Quarterly. 2009;73(4):704-728.

17. Neundorf A, Stegmueller D, Scotto TJ. The Individual-Level Dynamics of Bounded Partisanship. Public Opinion Quarterly. 2011;75(3):458-482.

18. Mackuen MB, Erikson RS, Stimson JA. Macropartisanship. American Political Science Review. 1989;83(4):1125-1142.

19. Green DP, Palmquist B, Schickler E. Macroparti- sanship: A Replication and Critique. American Political Science Review. 1998;92(4):883-899.

20. Green DP, Schickler E. A Spirited Defense of Party Identification Against Its Critics. In: Bartle J, Bellucci P, editors. Beyond Party Identification and Beyond. New York, USA: Routledge; 2009, pp. 180-199.

21. Abramson PR, Ostrom CW Jr. Macropartisanship: An Empirical Reassessment. American Political Science Review. 1991;85(1):181-192.

22. Green DP, Palmquist B, Schickler E. Partisan Hearts and Minds: Political Parties and the Social Identities of Voters. New Haven, USA: Yale University Press; 2002.

23. Erikson RS, Mackuen MB, Stimson JA. What Moves Macropartisanship? A Response to Green, Palmquist, and Schickler. American Political Science Review. 1998;92(4):901-912.

24. Achen $\mathrm{CH}$. Parental Socialization and Rational Party Identification. Political Behavior. 2002;24(2):141170.

25. Lenz GS. Follow the Leader: How Voters Respond to Politicians' Policies and Performance. Chicago, USA: University of Chicago Press; 2012.

26. Box-Steffensmeier JM, Smith RM. The Dynamics of Aggregate Partisanship. American Political Science Review. 1996;90(3):567-580.

27. Sekhon JS. Opiates for the Matches: Matching Methods for Causal Inference. Annual Review of Political Science. 2009;12(1):487-508.

28. Neyman J. On the Application of Probability Theory to Agricultural Experiments. Essay on Principles. Section 9. Statistical Science. 1990;5(4):465-480.

29. Rubin D. Formal Mode of Statistical Inference for Causal Effects. Journal of Statistical Planning and Inference. 1990;25(3):279-292.

30. Gerber AS, Green DP. Field Experiments: Design, Analysis, and Interpretation. New York, USA: W.W. Norton; 2012.

31. Angrist JD, Imbens GW, Rubin DD. Identification of Causal Effects Using Instrumental Variables. Journal of the American Statistical Association. 1996; 91(434):444-455.

32. Middleton J. On the Foundations of Economic Voting: An Experimental Study [PhD Dissertation]. New Haven, CT, USA: Department of Political Science, Yale University; 2011.

33. Green DP, Gerber AS. The Downstream Benefits of Experimentation. Political Analysis. 2002; 10(4):394-402.

34. Chong A, de la O AL, Karlan D, Wantchekon L. Looking Beyond the Incumbent: The Effects of Exposing Corruption on Electoral Outcomes. NBER Working Paper No. 17679, December 2011.

35. Cowden JA, McDermott RM. Short-Term Forces and Partisanship. Political Behavior. 2000;22(3):197-222.

36. Johnston R. Party Identification Measures in the Anglo-American Democracies: A National Survey 
Experiment. American Journal of Political Science. 1992;36(2):542-559.

37. Lupu N. Party Brands and Partisanship: Theory with Evidence from a Survey Experiment in Argentina. American Journal of Political Science. 2013;57(1):49-64.

38. Brader TA, Tucker JA. Reflective and Unreflective Partisans? Experimental Evidence on the Links between Information, Opinion, and Party Identification. Proceedings of the Stanford Workshop on Comparative Politics, Stanford University, Stanford, CA, USA, 19 May 2008.

39. Gerber AS, Huber GA, Washington E. Party
Affiliation, Partisanship, and Political Beliefs: A Field Experiment. American Political Science Review. 2010;104(4):720-744.

40. Gerber AS, Green DP. The Effects of Canvassing, Direct Mail, and Telephone Contact on Voter Turnout: A Field Experiment. American Political Science Review. 2000;94(3):653-663.

41. Erikson RS, Stoker L. Caught in the Draft: The Effects of Vietnam Lottery Status on Political Attitudes. American Political Science Review. 2011;105(2):221237. 


\title{
Human Rights Promotion through Transnational Investment Regimes: An International Political Economy Approach
}

\author{
Claire Cutler ${ }^{1,2}$ \\ ${ }^{1}$ Department of Political Science, University of Victoria, SSM A316, 3800 Finnerty Rd., Victoria, BC V8P 5C2, \\ Canada; E-Mail: ccutler@uvic.ca \\ ${ }^{2}$ Hague Institute for the Internationalisation of Law, Bezuidenhoutseweg 16A, 2594 AV, The Hague, \\ The Netherlands
}

Submitted: 21 January 2013 | In revised form: 21 March 2013 | Accepted: 3 April 2013 |

Published: 9 May 2013

\begin{abstract}
International investment agreements are foundational instruments in a transnational investment regime that governs how states regulate the foreign-owned assets and the foreign investment activities of private actors. Over 3,000 investment agreements between states govern key governmental powers and form the basis for an emerging transnational investment regime. This transnational regime significantly decentralizes, denationalizes, and privatizes decision-making and policy choices over foreign investment. Investment agreements set limits to state action in a number of areas of vital public concern, including the protection of human and labour rights, the environment, and sustainable development. They determine the distribution of power between foreign investors and host states and their societies. However, the societies in which they operate seldom have any input into the terms or operation of these agreements, raising crucial questions of their democratic legitimacy as mechanisms of governance. This paper draws on political science and law to explore the political economy of international investment agreements and asks whether these agreements are potential vehicles for promoting international human rights. The analysis provides an historical account of the investment regime, while a review of the political economy of international investment agreements identifies what appears to be a paradox at the core of their operation. It then examines contract theory for insight into this apparent paradox and considers whether investment agreements are suitable mechanisms for advancing international human rights.
\end{abstract}

Keywords: human rights; incomplete contract theory; international arbitration; investor-state arbitration 


\section{Introduction}

Bilateral and international investment agreements (BITs/IIAs) are foundational instruments in an increasingly privatized transnational investment regime that governs how states can regulate the foreign-owned assets and the foreign investment activities of private actors. There are over 3,000 agreements that regulate investor-state relations and that govern key governmental powers ([1], p. 81). These agreements form the backbone of an emerging transnational investment regime that significantly privatizes, denationalizes, and decentralizes investment decision-making [2]. In addition, investment protection is increasingly included in bilateral and multilateral economic agreements containing investment chapters and in free trade agreements, such as the North American Free Trade Agreement (NAFTA). This growing maze of agreements is often described as a network, although there are no explicit links between and amongst these arrangements. Rather, it is their shared language, principles, and decision-making and interpretive structures that underlie the network metaphor and lead to the conclusion that there has been a significant "treatification of international investment law" ([3], p. 151).

Investment agreements are typically entered into between developed capital-exporting states and developing capital-importing states, but increasingly they are being negotiated between developing states. They set limits to state action in a number of areas of vital public concern, including the protection of human and labour rights, the environment, and sustainable development. They determine the distribution of power between foreign investors and host states and their societies. However, the societies in which they operate seldom have any input into the terms or operation of these agreements, raising crucial questions of their democratic legitimacy as mechanisms of governance. This paper draws upon insights from political science and law to develop a political economy analysis of the investment regime and examines whether investment agreements are potential vehicles for promoting international human rights and advancing the democratic legitimacy of the investor-state regime. The advancement of human rights through investment agreements faces major obstacles stemming from the nature of state responsibility under international law and the difficulty of attaching legal duties to private corporations. However, this analysis suggests that there is a growing recognition of international corporate social responsibilities that may well give rise to increased corporate human rights accountability.

The analysis opens with an account of the empirical incidence of international investment agreements, briefly traces their history in the Post World War II period, and reviews their politico-legal and economic functions. A review of the political economy of investment agreements identifies what appears to be a paradox at the core of their operation. It then examines contract theory for insight into this apparent paradox. In a review of a few high-profile cases involving contestation over the right to water and other human rights the analysis considers whether investment agreements are analytically and theoretically suitable governance mechanisms for advancing international human rights. The paper concludes with discussion of the prospects and challenges of private transnational governance through the investor-state regime.

\section{Investment Arbitration as a Foundation for International Contracting}

International commercial arbitration is one of the oldest instances of private transnational governance, dating in historic forms from the medieval ages, and even earlier [4-7]. Today its roots are associated with the medieval law merchant or lex mercatoria, the private settlement of disputes amongst merchants in merchant courts and under merchant laws that were not enforced in local courts of law. However, this association belies a major distinction between the medieval and modern systems of dispute resolution. The medieval system of commercial arbitration operated between and amongst private actors and through private institutions and private law, while the contemporary system of international commercial arbitration involves a mix of public and private actors, institutions, and processes [8]. The modern regime is comprised by a system of private commercial arbitral institutions based upon the lex mercatoria and by a public international investor-state system of investor protection that regulates the way states treat foreign investment assets and activities. But, importantly, the latter investor-state regime is modelled on the lex mercatoria and thus imports many private laws and standards into inter-state dispute settlement:

Thus, unlike international commercial arbitration based on rules of lex mercatoria, the system of investor protection does not resolve private disputes or regulate the conduct of private parties. Rather, the purpose of the system is to limit how governments regulate multinational enterprises. For this reason, an investor-state dispute pursuant to a treaty is an inherently public dispute; one that involves the exercise of the sovereign power to regulate individuals within a state's territory. Even though the system relies on the model of international commercial arbitration and expands private authority as a method of governance, the system exists within the realm of public international lawnot international commerce-and it remains tied to the authority of states. It is states that established 
the system through a series of treaties that first recognized commercial arbitration as an international institution and then extended the jurisdiction of private arbitration to encompass investment disputes within the private realm ([9], pp. 604-605).

The importation of private law norms into investorstate arbitrations brings some symmetry to the two systems and thus there is a tendency to conflate them [10]. Further symmetry derives from the common rooting of both systems in bilateral or international investment treaties (BITs/IIAs). BITs form the core or central mechanism for the enforcement of contracts in the global political economy, without which individuals and corporations would be powerless against states. They provide credible enforcement mechanisms, which were unavailable under international law prior to their adoption. Moreover, BITs and IIAs have significant capacity to oust the jurisdiction of national courts of law and to internationalize contractual disputes. In many ways, BITs may be said to constitutionalize investment protection by providing for the rule of law and the normative core and foundation for international contracting and the transnational investment regime [11-13]. It is useful to consider the distinction between governance through contract and governance by means of contract in order to clarify the various roles played by investment agreements. The former focuses on the regulatory role of the contract in ordering the rights and relationships of the parties, while the latter focuses on the use of contract to achieve extracontractual regulatory or governance goals. An investment agreement may be analyzed as a form of governance through contract as "an institutional framework and mechanism of 'self-guidance' for private and public parties" ([14], p. 260). As such the agreement functions like a contract to regulate the terms of the investment arrangement. In this respect a BIT creates a framework for the investor-state relationship and, as we shall discuss later, provides for a number of investment protections that structure the relationship, allocate power and interests between the state and the investor in particular ways, and provide for means of dispute resolution. In contrast, governance by means of a BIT directs attention to its extra-contractual function "as an instrument for steering behavior and for achieving regulatory goals" ([14], p. 260). In this way, investment agreements may be conceptualized as performing extracontractual roles in achieving public goals that are extraneous to the parties and international investment laws. They "fulfil[s] an ordering function for the international investment relationship and the implementation of this law may be described as a global public good" ([15], p. 2). Thus, in theory, investment agreements may be utilized to advance broader social and political goals, such as liberalization and privatization. Indeed, Stephan Shill observes that investment treaties "have a constitutional function in providing a legal framework within which international investment activities can take shape and expand. As such, investment treaties are embedded in a larger framework of international law that overarches the individual bilateral treaty relations and establishes uniform rules for the conduct of host States that consist in adopting a liberal attitude vis-à-vis market mechanisms and that accept the limited role of the State vis-à-vis the economy" ([16], p. 17).

Others also emphasize that investor-state arbitration, while modelled on the private law of commercial transactions, is "not merely another form of private law commercial arbitration, with one party now being a state, but...is more fittingly understood as a form of dispute settlement that...also operates in a public law context" ([17], p. 285).

However, the tendency to conflate the private and public dimensions of dispute resolution raises some very interesting questions. Are international investment agreements to be regarded as treaties governed by principles of international law or as contracts governed by contract law? Noemi Gal-Or explores this ambiguity in the context of international agreements that provide for investor-state arbitration, arguing that on one hand they are treaties, but on the other hand they contain "elements of a state-private party contract" ([18], p. 215). If considered a contract, whose contract law applies - that of the investor, the host, or delocalized, transnational contract law? To what extent are BITs subject to the same third party limitations imposed by theories of privity of contract? What are the appropriate interpretive techniques? What mechanisms govern intervention by non-parties in arbitration proceedings or access to documents, the publication of arbitral awards, or appeal proceedings? The importation of private law norms into a public law arena thus poses serious governance challenges. However, before considering these more fully, it is necessary to consider how and why investment arbitration forms a fundamental constitutional foundation for the transnational investment regime. This involves an examination of the history of the investor-state regime and the nature and operation of international investment agreements as essential mechanisms of a private transnational regulatory regime.

\section{History and Function of the Investor Protec- tion Regime}

Historically, disputes over foreign investment were settled by force and "gunboat diplomacy" ([19], p. 780). However, by the nineteenth century colonial powers entered into treaties of Friendship, Commerce, and Navigation (FCN treaties). While FCN treaties were not directed specifically at foreign investment, but were drafted to encourage international trade, they did offer some protection for the assets of foreigners [20]. Over-time greater protections were 
included in these treaties, although they did not provide for direct dispute resolution by investors against host states. Foreign investors essentially had two options if their investment was somehow impaired by the host state. The doctrine governing international legal personality identifies states as the primary subjects of international law and generally does not allow an individual or corporation to take a legal action against a state [21]. As a consequence, foreign investors had to rely on diplomacy and political influence in order to persuade their home state to advance a legal claim on their behalf. The alternative was to initiate a claim in the national court of the host state under national law. Neither option proved to be satisfactory for the foreign investors; the first did not guarantee compensation, while the second rarely resulted in their success ([19], p. 781). Nor did the rules of customary international law provide for the right of a foreign investor to make monetary transfers from the host state or to bring in personnel to operate their investments, while the standards governing compensation were ill-defined [22].

After World War II the United States began incorporating investment protections into its FCN treaties. The United States supported what was known as the "Hull Rule", articulated by American Secretary of State, Cordell Hull, in a note to the Mexican Minister of Foreign Affairs, concerning compensation due upon the Mexican expropriation of foreign-owned agrarian and oil properties. The Hull Rule describes the standard of compensation due under customary international law as "prompt, adequate, and effective" compensation. However, while supported by the developed world, this rule was challenged in the post World War II period by developing countries who were emerging as independent states during decolonization. The wave of nationalizations and expropriations (direct takings) without compensation that took place during this time led to the erosion of the rule as a principle of customary international law. Mexico rejected the rule, as too did the Soviet Union and other Latin American countries. These states engaged in massive expropriations without compensation. Jeswald Salacuse observes that the average number of nationalizations of foreign investor property rose steadily from about fifteen per year in 1960 to over fifty a year in 1975 ([2], p. 435, note 42).

During this time the United Nations General Assembly (UNGA) was the focus of developing countries claims for a New International Economic Order. The 1962 UNGA Resolution on Permanent Sovereignty Over Natural Resources articulated the standard of compensation as appropriate compensation in accord with the laws of the host state and by the mid 1970s the rule had ceased to have the status of customary international law ([23], p. 641). This left the law governing foreign investment uncertain, with capital exporting states advancing the Hull Rule, and capital importing states rejecting it in a standoff.

International investment agreements emerged as the solution to this uncertainty in the late 1960s, although the first BIT was entered into before this in 1959 between West Germany and Pakistan and later Japan in 1977, and the United States in 1982 ([23], p. 653). They are "based on the presumption that the guarantees provided to foreign investors by the domestic legal system of the host country may be-or may turn out to be-insufficient for the special purpose intended by those treaties, which is primarily the creation of an investment climate designed to attract the foreign investment desired by the host state" ([24], p. 954).

The International Centre for the Settlement of Investment Disputes (ICSID) was created in 1966 under the auspices of the World Bank to provide investors with the institutional framework for taking direct legal action under a BIT against host states. At first the developing countries were unwilling to use it and ICSID only heard its first case in 1972 ([2], p. 439). However, the pace of BIT signing picked up and saw vast expansion by the 1990s, leading to today's situation where investor-state arbitrations occur regularly under the auspices of ICSID and NAFTA Chapter 11.

The development of this investor-state regime and the steady global expansion of international investment agreements are thus due to a number of geopolitical, economic, institutional, and ideological developments [25]. But how do these agreements function and why do they form an essential part of the emerging private transnational regulatory order?

As noted earlier, BITs provide direct legal access for foreign investors against host states without having to go to national courts, bypassing the exhaustion of local remedies. In providing for investor-state arbitration BITs give "private persons and companies the right to compel a sovereign state to appear before a tribunal and defend its sovereign actions ostensibly taken to protect the public interest" ([2], p. 460). This has been described as a "revolutionary innovation" that has caused a "paradigm shift" in and "profound transformation" of international law, which was unprecedented ([26], p. 46, note 175). Even in the World Trade Organization (WTO), which possesses one of the most developed dispute settlement systems, private actors do not have legal standingonly states may bring actions. Salacuse notes of these important developments:

Thus the global investment regime has granted a private right of action to investors. It has thereby privatized the decision-making process to a large extent. Not only are private parties involved as litigants, but also as arbitrators-the decision makers in the process-who are private persons compensated by the disputants, not officials of governments or international organizations $([2]$, p. 460). 
But, in addition to the privatization of dispute resolution under investor-state proceedings, the process has been transnationalized by significantly delocalizing and denationalizing its institutional context, procedures, and substantive law. The now classic definition of transnational relations articulated by Robert Keohane and Joseph Nye is "regular interactions across national boundaries when at least one actor is a non-state actor" ([27], pp. xii-xvi). While influential, this definition of transnationalism obscures the important insight that the transnational is not a territorially defined physical space existing at some level above the state, but is constituted within states where legislation, such as that implementing the New York Convention on the Enforcement of Foreign Arbitral Awards, legislation limiting national judicial review of foreign arbitral awards, or legislation and policies permitting the waiver of the exhaustion of local remedies rule, enable private actors to operate in a deterritorialized and denationalized legal space. I have elsewhere argued that the transnational is, ontologically and epistemologically, not a level of analysis, distinct from the national or domestic levels, but rather "extends across and thereby links as well as transcends, different (territorial) levels" [28]. Moreover, it links local and global orders through privatized processes of dispute resolution. Alec Sweet Stone goes to great lengths to emphasize the fundamental difference between the transnational investment regime as fundamentally distinct as a "private transnational space" from that of the European Union, which he characterizes as a "public supranational space" constructed by states ([29], p. 628).

Importantly, most BITs provide general consent to delocalized, binding arbitration, unlike specific consent in a contract to arbitrate where the parties will be governed by the domestic rules of contract under the applicable system of private international law/conflicts of law. Gus Van Harten [9] identifies three ways in which a state may consent to the compulsory arbitration of future investment disputes: by contract with an investor containing a binding arbitration clause; by legislation that provides for compulsory arbitration of investment disputes within a state's territory; and by treaty providing for compulsory investor-state arbitration. The latter two provide general consent, while the first provides specific consent to disputes arising out of the contract.

The notion of general consent signaled a profound shift in the nature and consequences of investorstate arbitration. A general consent by the host state allows investors to initiate compulsory arbitration of an investment dispute in the absence of a contractual relationship between the investor and the state. Thus disputes about the regulatory authority of the state are brought within the jurisdiction of international arbitration tribunals. Policy questions regarding the exercise of govern- mental powers are resolved, at the instance of the investors, by private arbitrators whose decisions are insulated from review by public courts (whether domestic or international). In this way, the general consent to investor-state arbitration is the conception of the system of investor protection as an instrument of transnational governance ([9], p. 607).

The general consent given by a host state "is general because it authorizes the arbitration of any future dispute with any foreign investor [of the state party] in the states territory" ([9], p. 607). In this way a general consent in an investment agreement operates like "blank cheque which may be cashed for an unknown amount at a future and as yet unknown date" ([9], p. 607). In so doing it "transforms investor-state arbitration from a modified form of commercial arbitration into a system to control the states exercise of regulatory authority with respect to investors as a group" ([9], p. 608).

The requirement to exhaust local remedies is a traditional rule of international law and requires that a natural or legal person must first have recourse to all means of redress available in the domestic law of the host state before bringing a claim against that state in an international forum. However, for ICSID proceedings states agree in advance on the basis of provisions of the ICSID Convention to refrain from requesting that local remedies be pursued for investment arbitrations arising out of leases, concessions or other contracts governed by the investment treaty. In return the home start agrees not to grant diplomatic protection of its nationals. This in effect suspends the operation of local laws and "lifts individuals onto the international plane vis-à-vis the host state" ([24], p. 957). The UNCITRAL Arbitration Rules are silent on the matter.

BITs differ in their treatment of the exhaustion of local remedies rule: only a few BITs concluded since 1985 provide for the application of the rule prior to arbitration under the BIT ([30], p. 50). Jan Paulsson notes that some BITs contain the requirement to exhaust local remedies for a period of time, while others do not, indirectly waiving the requirement ([31], p. 240). Romanian BITs typically articulate the rule, as too does the Germany-Israel BIT, whereas the Australia-Czechoslovakia BIT states that local remedies need not be exhausted. Some BITs provide for arbitration if the dispute has not been settled through local means after a certain amount of time, as in the Argentina-German BIT. Also, some BITs articulate a fork in the road provision whereby once a particular dispute settlement route has been chose it forecloses electing another route, reflecting the Latin maxim via electa non datur recursus as alteram: "Once a road is chosen, there is no recourse to the other" ([30], p. 51). A study of 148 German BITs reveals that the majority explicitly waive the local remedies rule, many do not even raise it, and only three require the exhaustion of 
local remedies ([30], p. 52). From 2000 onward Germany, who has the highest number of BITs in force, has explicitly waived the rule in German BITs [30].

The general consent feature of an investment treaty thus "exposes a state to a broad range of claims by a foreign investor related to the states exercise of public authority. These investment treaties, which initially were aimed at reducing an investor's risk of investing abroad, have now been transformed into tools with which to assail an extensive range of host states governmental activity" ([19], p. 782).

An investment agreement will generally contain three elements: definitions, substantive obligations for host states, and provisions for binding investor-state dispute resolution. Breaches of BITs constitute breaches of international law and the protections for investors are much stronger and broader than those under the Hull Rule. Whereas the Hull Rule mainly addressed direct expropriations, today it is takings, short of expropriation that most often engage arbitrators ([23], p. 644). "Investment" is defined in most treaties, such as the Model US BIT, to include a broad range of agreements as investment and thus governed by the BIT. A broadly defined BIT can bring under its jurisdiction many types of contracts and subject them to delocalized arbitration even when the terms are silent on the matter ([32], p. 76). Also "umbrella clauses" may be used which create the possibility of bringing all contractual arrangements the state may enter into with the foreign investor under the investment treaty, thereby transforming the breach of any contract entered into between the state and investor into a breach of their BIT. There is considerable doctrinal and jurisprudential debate over the operation of these clauses, which has been described as one of the most contentious issues of international investment law ([33], p. 5). They are regarded as reflecting the desire to delocalize the law applying to international contracts:

The emergence of the clause in modern investment protection treaties must be seen in the broader context of efforts to internationalize the legal framework applicable to international concession contracts. Whereas many capital importing countries used to emphasize the exclusive applicability of their domestic legislation to concession contracts concluded with foreign investors, various efforts have been made to withdraw these contracts from the unilateral regulatory power of the host state ([24], p. 965).

However, Rudolf Dolzer also notes that the internationalization and delocalization of a contract by a BIT is complicated and depends on the nature of the breach as a contract breach or a treaty breach, as well as whether the contract provides for exclusive national court jurisdiction for breach of contract. The first case to consider this was Lanco International Inc. $v$. The Argentine Republic [34]. There an ICSID arbitration tribunal held that consent to arbitration under the BIT prevailed over a provision in the concession contract for the submission of disputes to local courts. Andrew Guzman argues that "by making any breach of an agreement a violation of an international treaty...BITs allow such agreements to be treated as contracts between private parties..." ([23], p. 655), internationalizing the contract. However, Francisco Vicuña rejects that the internationalization of a contract turns it into a treaty-it just brings treaties and contracts into a closer nexus and subjects the latter to international law: "treaties and contracts, albeit different, pursue the same objective of ensuring the rule of law and the observance of legal commitments in the international community and are thus called to increasing interaction. To this end, treaties are becoming privatized by allowing a greater role for individuals in their operation, just as contracts are becoming public to the extent that states and international law extend their guarantees to their observance. All of it points towards the need for global protection in a global society, where perhaps the distinction between public and private law will become less meaningful" ([35], p. 357).

In addition to providing definitions of investment, the typical BIT will establish general standards of behavior of the host state. The common standards include "fair and equitable treatment", "full protection and security", "national treatment", "most-favorednation treatment", and "treatment in accordance with international law". The BIT will also include specific standards concerning the investment, such as dealing with monetary transfers, expropriation, investor rights during war, revolution or civil unrest. The BIT rarely states specific consequences of a breach, but arbitration tribunals have held uniformly that compensation is due upon breaches resulting in injury on the basis of customary international law ([2], p. 446).

Finally, the BIT will provide for a binding enforcement mechanism for investors and will often designate the arbitration institutions and rules to be adopted. Andrew Guzman observes that "BITs offer foreign investors greater protection than the Hull Rule ever did...by providing a mechanism through which a potential investor and a potential host can establish a contract that is binding under international law" ([23], p. 658), which was not possible under customary international law. Absent a BIT, a state is not able to credibly bind itself to an investor: domestic law is not a credible option as the laws may be changed and there is no guarantee of a fair hearing, while there are virtually no mechanisms for securing contractual promises between a state and private firm under international law, as noted earlier. Binding dispute resolution through international arbitration thus allows foreign investors to sue host states directly if they believe that the investment agreement governing their investment has been violated. BITs thus revolutionize contractual enforcement. In fact, investor-state 
arbitration is described by Jan Paulsson as "not a subgenre of an existing discipline. It is dramatically different from anything previously known in the international sphere" ([31], p. 256). Another notes that this delocalization produces a democratic deficit:

State parties to investment agreements can no longer legislate at will in the public interest without concern that an arbitral tribunal will determine that the legislation constitutes interference with an investment. Thus investment arbitration may result in an overall loss of state independence and sovereignty, which has implications for democratic governance (...) The question arises whether state exercises of public authority should be adjudicated by foreigners, largely on the basis of commercial principles, when the adjudicators are unconcerned with the wider effects of their decisions ([19], p. 799).

Investor-state arbitral proceedings differ so fundamentally from adjudication in courts of law that many question the formers adequacy in settling disputes that raise public interest issues. Questions concerning the independence and impartiality of private arbitrators, limited public access to the arbitral documents, proceedings, and awards, the absence of appeal mechanisms, and the application of private commercial law standards and conceptions to public law issues are some of the more serious defects in process that invite criticisms of the democratic deficit and undemocratic supremacy of governance through arbitration $[18,19]$.

Specialists note an epistemological divide between international commercial lawyers and public international lawyers that creates conflicting approaches to investor-state arbitration. "Even though public and private law perspectives mostly merge in investment treaty arbitrations, there remains a divide in the conceptual frameworks of the private and public law perspectives and in the epistemic communities of commercial arbitration and public international lawyers" ([36], p. 10). Moreover, regulatory competition amongst states for foreign investment in the 1980 s and 1990s resulted in the legislation of limits on judicial interference with foreign arbitral awards by many states. Belgium in 1985 removed any oversight of foreign awards by Belgian courts and has been criticized for bowing to competitive pressures to become more attractive investment site ([9], p. 617). Competitive pressures have also generated forum shopping by investors for the states that offer the most attractive investment regimes. This is said to contribute to governance gaps, as noted by John Ruggie, former Special Representative of the UN Secretary General on the issue of human rights and transnational corporations:

Investor protections have expanded with little regard to States duties to protect, skewing the balance between the two. Consequently, host states can find it difficult to strengthen domestic social and environmental standards, including those related to human rights, without fear of foreigninvestor challenge, which can take place under binding international arbitration ([37], p. 29).

Indeed, while this section has reviewed the history of the investor protection regime and the emergence of investment treaties as central institutions in providing for the stability of investment relations, it notes that these agreements also raise concerns about their impact on state autonomy and the broader democratic legitimacy of the investor-state legal regime. Indeed, Stephan Schill argues that clauses that limit state legislative and policy autonomy, like umbrella and stabilization clauses, function to privately order investor-state relations precisely by preventing states from pursuing opportunistic behaviour that might present itself over the course of a long-term contract [33]. These clauses highlight the tensions between the investors' interest in securing investment against future political risks and the host states interest in ensuring adequate policy autonomy in the face of changing circumstances or unanticipated developments not addressed in the agreements. Such concerns have led some to question why states would agree to bind their legislative and policy independence into the future. The following section will examine this question and will consider the insights afforded by theories of incomplete contracts into the political economy of investment agreements. It argues that although governance through BITs raises significant governance gaps, BITs also create distinctive political economies that have implications for the advancement of development and human rights.

\section{The Political Economy of Investment Agree- ments and Contract Theory}

The President of Bolivia once stated that in investorstate arbitrations Latin American developing countries "never win the cases. The transnationals always win" ([38], p. 436). In a review of allegations of the systemic bias of the arbitral system against developing countries, Susan Franck notes that Nicaragua promotes withdrawal from ICSID, while Ecuador is eliminating investment arbitration ([38], pp. 436437). Venezuela has renounced the ICSID Convention [39]. These developments are not surprising, given the well-known fact that the system is a product of an alliance between a multinational investment lobby and central capital exporting states and is clearly weighted in favour of investor protection. ICSID is a creation of the World Bank whose weighted voting system favours powerful developed states. The investor-state regime allocates power between foreign investors and the host state, creating political economies that result in significant distributional outcomes. A number of people have identified a paradox for developing countries at the heart of the system. Salacuse asks: 
"why do developing countries, who usually have few national investors in need of protection abroad, sign investment treaties whose effect is to restrain their own governments in their dealings with foreign investors?" ([2], p. 440). Note that BITs do not impose duties on foreign investors and nor do they give the host state the capacity to sue the foreign investor ([40], p. 499). While the ICSID Convention has given rise to a few claims made by states, they are regarded as anomalous ([41], p. 101). Indeed, the lopsided nature of the investor protection regime has prompted some to conclude that it distorts the balance between public and private authority:

\section{(...) the one-sided nature of the dispute settlement system, in which only private investors may initiate a claim and only states must pay damages, privileges private property and contract rights over the public interest. It creates a system of third- party beneficiaries, making the regime more rigid. It promotes private rights and relegates states to defensive status. BITs thus collapse the public/ private binary and shift the boundary between the public good and private interests by privatizing part of the public. This re-conceptualization limits the influence of public concepts traditionally considered part of the state such as human rights, the environment, and democracy ([40], p. 519).}

The proliferation of BITs entered into by developing states that provide much greater protection for foreign investors than the Hull Rule ever did appear to be incongruous, if not contradictory with their earlier rejection of the Hull Rule. Some suggest that developing countries may in fact be better off under customary international law than under BITs ([42], p. 615). M. Sornarajah ([43], p. 259; [44], p. 90) refers to this contradiction as "duplicitous", while Guzman poses the question even more provocatively, in a paper entitled "Why LDCs Sign Treaties That Hurt Them" [23].

Various international relations and political economy theories may be advanced to explain the position adopted by developing countries and to account for the nature and operation of the investorstate regime. Hegemonic stability theory draws on neorealist theories and posits that international regimes will arise when they are promoted and enforced by a powerful state. However, this theory clearly provides a blunt analytical instrument for no single hegemonic state has advanced the investorstate regime and it does not explain why developing countries would join, despite their rejection of Hull Rule ([2], p. 433). Theories of international cooperation and international contracting based upon liberal foundations in rational choice theory, transactioncoast analysis, and theories of collective goods provide some insight [45]. They suggest that the regime advances the interests of all parties by reducing the relative costs of investing-capitalexporting states reduce their enforcement costs and the risk of default (expropriation, etc.). Capitalimporting states wish to attract foreign investment and so enter into agreements to reduce the perceived risk of default and to enhance their competitive edge against other capital-importing states.

In fact, BITs have been described as "quintessentially liberal documents. The typical BIT cites two goals in its preamble: the creation of favorable conditions for investment by nationals and companies of one party in the territory of the other, and increased prosperity in both states" ([46], p. 627). While challenged by economic nationalists and Marxists, who regard foreign investment agreements to be overwhelmingly of disproportionate and declining benefit over-time to the foreign investor, liberal analysts argue that the parties gain mutually (but not necessarily equally) under investment agreements when they are based upon the comparative advantages of the parties ([46], p. 624). According to liberal theory, BITs thus operate to protect the investment from state interference, to "insulate the market from politics", and to encourage foreign investment in the host state, who limits its role to "protecting private rights of property and contract", thereby producing efficient exchange ([46], pp. 623-624; see $[47,48]$ ).

As Elkins, Guzman and Simmons find, "the proliferation of BITs-and the liberal property rights regime they embody-is propelled in good part by the competition among potential host countries for credible property rights protections that direct investors require" ([49], p. 812). But we know that BITs are tilted in favour of the capital-exporter and do not benefit all parties equally, so this still does not address the paradox of why the capital-importer would agree to a one-sided bargain.

The theory of limited contracting provides useful insight into the political economy of BITs. "Contract theory is primarily an analytical approach to explain why parties enter into contracts in the first place and why they write the contracts that they do, in light of what courts do. It also helps to answer questions of optimal contracting" ([50], p. 515). Liberal economic theory of contract assumes that parties to a contract act rationally and desire to enter into agreements that optimize their benefits both at the time of contracting and in the future. However, the future poses problems of uncertainty that can affect the distribution of benefits under the contract ([51], p. 280). Inspired by the work of Oliver Wiliamson [52], limited contract theory analyzes the power structure of contractual relationships. Incomplete contracts are forms of relational contracting where the contract operates over a period of time and incompletely specifies the performance obligations. They are contrasted with discrete contracts, the latter being fully specified ([48], pp. 140-141). The theory of limited contract suggests that over time in situations of asset specificity there will be an incentive for one of the parties to delay or in some way hold up performance 
under the contract. As Robert Scott puts it, "the investing party (...) risks being held up by a promisor (...) who can renege on his promise and force a renegotiation of the contract. This threat will be credible if the (...) investment cannot be used for other purposes outside the relationship (...) [T] sunk costs will increase the risk that the Buyer will threaten to walk away from the deal unless the Seller [investor] agrees to renegotiate the initial contract terms" ([51], p. 284).

When applied to international relations, incomplete contracting theory identifies a paradox that bears some likeness to the paradox identified in this paper concerning the entry of developing countries into investment agreements that impose far greater limits on their sovereignty than those imposed by the Hull Rule. States highly desire to protect their sovereignty, but regularly enter into agreements that limit it, such as the Treaty of Rome that created the EEC [53]. This seems at odds with the general anarchic character of international relations and uncertainty about the longterm implications and distributional consequences of agreements limiting their sovereignty. The absence of some sort of centralized enforcement mechanism to ensure that the parties honour their commitments also suggests that states will avoid such arrangements. However, BITs have proliferated in both the developed and developing worlds.

(...) incomplete contracting theory can clarify how and why states choose to bundle and unbundle their sovereignty, what the dynamics will likely be of future renegotiation, why some of these incomplete contracts might unravel (...) Theories of incomplete contracting are particularly instructive for explaining the organizational boundaries of the international system (...) The lack of a central governing authority ensures that states must be wary of the long-term distributional consequences of their actions and be hesitant to commit to longterm agreements (...) In such an environment incomplete contracts offer two important advantages for states. First, incomplete contracts delineate general principles and broad goals to which states can aspire (...) Second, contractual renegotiation acts as an important institutional check on the future behavior of actors (...) Incomplete contracts also offer added flexibility to correct for distributional asymmetries that may arise as the result of the initial agreement. In short, incomplete contracts between states are framework agreements that do not fully apportion sovereignty. Instead such agreements make the distribution and allocation of sovereign rights a matter of on-going negotiation between the contracting parties or between those parties and a third party, such as a supranational organization ([53], pp. 5-6).

Incomplete contracts are used by states in condi- tions involving variety of uncertainties and transactions costs that prevent states from entering into fully specified agreements. There are procedural reasons arising from uncertainty costs (inability of states to anticipate all future contingencies), negotiating costs (information limitations that prevent the negotiation of optimal agreements), and enforcement costs (inability to negotiate an enforcement mechanism). There are also strategic reasons for negotiating incomplete contracts. In cases where the contract governs specific assets and the transactions are frequent the owner of the assets will have strategic reasons in order to extract more benefits under the agreement later in time. As Cooley and Spruyt note "[i]n certain cases of incomplete contracting, such as contracting over natural resource use, the host country tends to gain more leverage as the foreign country (investor) sinks more transaction-specific assets into such exploitation" ([53], p. 11).

Drawing an analogy between an investment agreement as an incomplete contract, we may analyze BITs as incomplete contracts between states [54]. Indeed, Anne van Aaken argues that BITs "may be interpreted as mechanisms to overcome commitment problems between investor and host state in order to generate mutual benefits. A state thereby promises not to infringe on the property rights of foreign direct investors so as to attract more investment" ([50], p. 509). She suggests that in terms of law, BITs may be conceptualized as contracts in favour of third parties ([50], p. 520). Host states thus trade off some sovereignty for credibility by restricting their regulatory capacities and agreeing to submit to compulsory binding arbitration. In the case of the BIT, sovereignty is apportioned between the host state, the foreign investor, and the designated binding arbitration tribunal. The challenge, however, is for the parties to strike the right balance between commitment and flexibility-too much commitment can reduce flexibility and the ability to adjust to changing circumstances that alter the distribution of the benefits and costs of the agreement.

As mentioned already, incomplete contracting theory indicates that the incentive structure and distribution of benefits changes over the course of a contractual relationship. Incomplete contracts "alter the relative bargaining positions and change the distribution of benefits to contracting parties over time" and importantly, "the holder of residual rights of control will be able to determine the future allocation of sovereign rights that were not covered in the initial agreement" ([53], p. 11). Guzman argues that while BITs may reduce the overall welfare of developing states, the competitive pressures to attract foreign investment create an incentive structure that encourages the negotiation of significant concessions to foreign investors at the onset of the relationship [23]. The absence of a credible contracting mechanism dictates that host states agree to binding dispute settlement and the various standards that are common- 
place in the usual BIT. At this point the foreign investor is in the driver's seat. However, once the investment is made, the host state no longer has to offer incentives to attract new investment, but now is concerned about keeping the existing investment. At this point the host gains power in the relationship and is in a position to extract benefits from the foreign investor through tax increases or other policy measures.

Raymond Vernon describes the plight of the foreign investor as an "obsolescing bargain" because of the decline in the bargaining power of the foreign investor during the course of the investment ([55], p. 46). Once the investment has been made the investor cannot easily move its assets without incurring major costs. For these reasons parties often include renegotiation and stabilization clauses, but these clearly open the relationship up to conflicts of interest between the host state and the foreign investor. Incomplete contracting theory also suggests that an important variable in determining who holds power in a contractual relationship is the party who retains ownership rights in the residual assets. Drawing on the work of Oliver Hart [56], David Lake addresses the power significance of the "locus of rights of residual control":

(...) contracts vary in both their specificity and the rights of residual control possessed by each member; indeed, the latter is the defining attribute of relational hierarchy (...) In constructing contracts, states are defining the terms of their transactions; the potential for cheating, defection, and other forms of opportunism; and the means for controlling one anothers behavior. In this approach, contracts are instruments through which to control the behavior of others ([57], p. 10).

Host states, by retaining residual property rights in the investment are, in theory, able to exert pressure on the foreign investor to extract further benefits under the BIT. However, BITs also provide for compulsory binding arbitration, suggesting that residual rights have been transferred, at least in some measure, to a third party [58]. Thus the ability of the host state to hold up the agreement might be limited in important ways by the outcome of arbitral proceedings. Tribunals differ in the strictness in which they interpret the provisions of BITs, with ICSID being known for strict interpretations ([50], p. 528). However, other tribunals can be more generous in their interpretation of substantive BIT provisions. Thus third party involvement inserts further uncertainty into the agreement and might well open up a governance gap that functions as a window of opportunity for the advancement of extra-contractual objectives in the investment relationship, such as the promotion of human rights. To what extent can BITs create opportunities for the advancement of human rights?

\section{BITs and the Advancement of Human Rights}

Human rights may enter into the investor-state relationship in a variety of ways. They may be raised by the foreign investor in a claim or as a defence to a claim under a BIT. They may also be put in issue by the host state or utilized by arbitrators as construction aids in interpreting the provisions of a BIT. Finally, human rights may be expressly incorporated into a BIT. Each will be considered in turn.

Corporations and individual investors are entitled to human rights protections under a number of regional and international human rights treaties. Specifically, the protections afforded by the European Convention on Human Rights in cases taken before the European Court of Human Rights has been a significant venue for investor claims, in addition to claims being made before arbitrations under the relevant BITs ([59], p. 23, note 44). Arbitrators have looked to the jurisprudence of the European Court of Human Rights Human Rights in Mondev v. United States [60], a NAFTA Chapter 11 claim by a Canadian investor against the United States Government to the effect that the US courts had violated his rights under international law. The Tribunal held that decisions from the European Court "provide guidance by analogy" concerning the scope of NAFTA's guarantee of "treatment in accordance with international law, including fair and equitable treatment and full protection and security" ([60], para. 144). In Tecmed v. Mexico [61], a case involving a Mexican refusal to renew a permit to operate a landfill site near an urban centre, precipitated by local opposition for environmental and health reasons, arbitrators also consulted European Court of Human Rights jurisprudence in interpreting the host states duties under the BIT with respect to expropriations and nationalization. This approach was later followed by an ICSID tribunal in Azurix v. Argentina dealing with the interpretation of an expropriation clause in the US-Argentina BIT ([62], paras. 311-312). The Tribunal agreed that the European Court of Human Rights provided "useful guidance" in interpreting the BIT.

In Glamis Gold Ltd. v. United States of America [63] Glamis Gold Ltd., a publicly-held Canadian corporation engaged in the mining of precious metals, submitted a NAFTA claim to arbitration under the UNCITRAL Arbitration Rules on behalf of its enterprises Glamis Gold, Inc. and Glamis Imperial Corporation for alleged injuries relating to a proposed gold mine in Imperial County, California. Glamis claimed that certain federal government actions and California measures with respect to open-pit mining operations resulted in the expropriation of its investments and denied its investments the minimum standard of treatment under international law. The California measures included regulations requiring backfilling and grading for mining operations in the 
vicinity of Native American sacred sites. Glamis claimed damages of not less than $\$ 50$ million. The Tribunal released the Award, dismissing Glamiss claim in its entirety and ordering Glamis to pay two-thirds of the arbitration costs in the case.

In this case, the Quechan Indian Nation submitted an amicus curiae brief arguing that the NAFTA provisions should be interpreted in a manner consistent with US obligations in treaty and customary law to protect indigenous peoples' land and resources. In general, the award contains many references to the Quechan Nation, particularly during the course of the factual overview, which details their involvement in various environmental and cultural impact assessments. The backfilling and grading requirements were imposed by the state as an attempt to strike a balance between the need to protect adjacent Quechan sacred sites without imposing an outright ban on mining, or even more excessive costs on Glamis. The tribunal held that the economic impact of the state's measures were not sufficient to effect expropriation of Glamiss investment. The respondent did not choose to incorporate into its defence the arguments made in the amicus curiae brief of the Quechan Indian Nation. As a result, there is no reference to human rights claims or their incorporation into the concept of fair and equitable treatment, either in the respondents arguments or in the tribunals analysis.

In Grand River Enterprises Six Nations, Ltd., et al. v. United States of America [64] the company comprised by Canadian First Nations individuals engaged in the manufacture and export of tobacco products to the United States made a claim under the investor-state provision of NAFTA, Chapter 11 against the United States Government. The claimants argued that the government had violated the national treatment and most favoured nation treatment provisions, as well as customary international legal standards of fair and equitable treatment, and full protection and security, which resulted in an expropriation of their investment. The claimants invoked the UN Declaration on the Rights of Indigenous Peoples, customary international law, and the jurisprudence of the Inter-American Court of Human Rights in advancing their claim that indigenous rights should be taken into special consideration in a NAFTA Arbitration. In a restrained decision the Tribunal found that while there may be a principle of customary international law concerning fair and equitable treatment that requires special consultation with indigenous peoples when their rights are affected, it was not applicable to an individual investor ([63], para. 213).

In terms of the host state raising human rights claims, there are a number of BIT arbitrations involving claims by host states of breaches of the human right to water [65]. Many of these cases were brought against Argentina, while a few involved Bolivia and Tunisia. In each case, the state was engaged in water sector privatization schemes and the granting of concessions to foreign water corporations. In Suez, Sociedad General de Aguas de Barcelona S.A. and Vivendi Universal S.A v. Argentine Republic [66] investors were claiming in an ICSID arbitration a breach of a number of BITs that Argentina had entered into with their home countries. The case involved a thirty year contract to manage a water and sewage concession. Over the course of the relationship a number of disputes arose and with the intensification of the Argentine financial crisis the parties were at odds over the tariff-rates charged to consumers and the investors wanted to modify the rates under the economic equilibrium clause in the concession agreement. However, Argentina resisted. The human right to water was invoked by Argentina as one argument in its defence of necessity to its termination of the water concession, supported by an amicus curiae submission filed by five NGOs (this case is the first under ICSID in which such submissions were accepted in spite of the objections of one of the parties). In general, the tribunal emphasized the "defenses exceptional nature" and the strict conditions surrounding its application ([66], para. 258) and rejected Argentina's defence because Argentina's measures in violation of the BITs were not the only means to satisfy its essential interests and "because Argentina itself contributed to the emergency situation that it was facing in 2001-2003" ([66], para. 265).

The tribunal's evaluation of the human right to water argument is relatively brief (quoted in toto below) and occurs within its consideration of the third condition for the defence of necessity, that the treaty obligation does not exclude the necessity defence, a condition Argentina was held to have met. Nevertheless, it emphasized that Argentina's obligations to uphold human rights were in addition to their obligation to uphold their investment treaty commitments and did not relieve them from those obligations:

Argentina and the amicus curiae submissions received by the Tribunal suggest that Argentina's human rights obligations to assure its population the right to water somehow trumps its obligations under the BITs and that the existence of the human right to water also implicitly gives Argentina the authority to take actions in disregard of its BIT obligations. The Tribunal does not find a basis for such a conclusion either in the BITs or international law. Argentina is subject to both international obligations, i.e. human rights and treaty obligation, and must respect both of them equally. Under the circumstances of these cases, Argentina's human rights obligations and its investment treaty obligations are not inconsistent, contradictory, or mutually exclusive. Thus, as discussed above, Argentina could have respected both types of obligations ([66], para. 262).

Impregilo S.p.A. v. Argentine Republic [67] involved a factual background similar to the Suez case and was 
a dispute over Argentina's refusal to permit price increases in the context of currency devaluation brought about by the Argentine financial crisis and the state's eventual transfer of the water and sewage service back to a state-sponsored company. As in the Suez case, Argentina invoked the defence of necessity based in part on its obligation to fulfil the human right to water.

The human right to water, even though raised by Argentina, was only indirectly addressed in the majority's decision. The tribunal held that the state's obligations to provide water were encompassed by the definition of an essential interest which a defendant must prove has been imperilled in claiming the defence of necessity:

[T] he term 'essential interest' can encompass not only the existence and independence of a State itself, but also other subsidiary but nonetheless essential interests, such as the preservation of the States broader social, economic and environmental stability, and its ability to provide for the fundamental needs of its population. It follows that, in addition to Argentina's overall stability, the need to provide the population with water and sewage facilities represented an 'essential interest' which, in regard to thousands of people, was to be served by AGBAs concession and which would allegedly be imperiled for them but for the acts of the Argentine authorities ([67], para. 346).

Although the tribunal found that there was a grave and imminent peril to the essential interest of Argentina's economic stability, it ultimately held that Argentina contributed to the crisis and thus was not successful in invoking the necessity plea, with no further reference to the human right to water.

These cases do not exactly indicate the robust influence of human rights laws on arbitration proceedings. Rather, the tribunals seem to be very cautious in elevating human rights laws to the same status of investment protections. Arguably the number of cases reviewed is too small to draw meaningful conclusions about a tribunal's potential influence over the power residing with residual ownership. In some cases the investor won and in some the host state won.

However, these cases do raise the important issue of the propriety of addressing human rights in the context of investment arbitration [68]. It is highly likely that arbitrators trained in international commercial law and most often acting for private parties are neither willing nor competent to engage in the construction and interpretation of human rights. To what extent would the situation change if human rights protections were to be incorporated expressly into the BIT? Can governance gaps be filled in by human rights? This is the position taken by John Ruggie, former Special Representative of the UN on Business and Human Rights, in the Guiding principles:
States should maintain adequate domestic policy space to meet their human rights obligations when pursuing business-related policy objectives with other States or business enterprises, for instance through investment treaties or contracts (...) Economic agreements concluded by States, either with other States or with business enterprisessuch as bilateral investment treaties, free-trade agreements or contracts for investment projectscreate economic opportunities for States. But they can also affect the domestic policy space of governments. For example, the terms of international investment agreements may constrain States from fully implementing new human rights legislation or put them at risk of binding arbitration if they do so. Therefore, States should ensure that they retain adequate policy and regulatory ability to protect human rights under the terms of such agreements, while providing the necessary investor protection ([37], p. 12).

The Guiding Principles on Business and Human Rights advanced by John Ruggie carefully differentiate between the legal duties held by states to protect human rights and the social responsibilities of business corporations to respect human rights. The distinction between legal duties and social responsibilities, of course, reflects the operation of the doctrine governing international legal personality and the limited persona of private business corporations under international law, discussed earlier.

While, International Chamber of Commerce opposes the inclusion of labour or environmental standards into BITs, and few BITs mention human rights save perhaps in general terms in the preamble, as does the Dutch Model BIT, some model BITs are moving in this direction ([9], p. 614). Canada developed a new model Foreign Investment Protection Agreement (FIPA), the Canadian equivalent of a BIT. The model FIPA embodies changes resulting from controversial experiences arbitrating under NAFTA Chapter 11 investor-state provision. Controversy over Chapter 11 arbitrations stemmed from the criticisms advanced by environmental and civil society groups that investment commitments under NAFTA negatively impact on public policy in a number of areas and inhibit sustainable development. Concerns about the secrecy of the arbitral proceedings and lack of public access to information about investment disputes motivated a review of NAFTA arbitrations by the NAFTA Free Trade Commission which issued guidelines on the participation of non-disputing parties. As a result Canada and the United States agreed to open NAFTA arbitrations to the public and have recently made the draft negotiating texts of NAFTA publicly available. The new model treaty addresses many of the concerns expressed. The Canadian Model refers to sustainable development in the preamble and contains a GATT-like general exception that applies to all the 
obligations in the model treaty [69]. This exception covers measures adopted for the protection of human animal or plant life or health and conservation purposes. The Model also provides for public access to all documents and arbitral hearings are open to the public. In addition, it provides a procedure for nondisputing parties to file written submissions. The US Model BIT goes further and addresses relation between investment and labour rights.

Whether increasing the specificity of investment agreements, providing for public policy exceptions, and efforts to render arbitration processes more transparent and participatory will enhance or undermine the investor-state system is an open question, but one that has major implications for the future of governance through international investment agreements.

\section{The Legitimacy of Private Transnational Gov- ernance through BITs}

This paper has examined the centrality of the investor-state regime to the regulation of the global political economy, characterizing the regime as an instance of private transnational governance. The regime provides for a highly privatized system for binding dispute resolution that significantly delocalizes and denationalizes the laws and procedures governing dispute settlement. It provides foreign investors with an efficacious system that goes a long way to enhance certainty in international commercial contracting.

The analysis also explores the political economy of investment agreements and suggests that contract theory is analytically and theoretically able to tell us a considerable amount about governance through BITs. We have seen that international investment agreements function to create an institutional framework for investor-state relationships by providing for substantive standards of behaviour and compulsory dispute resolution that address credibility problems that plagued investment relations prior to the emergence of the investor-state regime. In addition, contract theory is useful in explaining the apparent paradox at the core of the regime concerning the asymmetric distribution of benefits under investment agreements. Incomplete contract theory indicates that the incentive structure and distribution of benefits changes over the course of the investment relationship, according more power over time to the host state as the owner of residual rights of control. At this point the host is in a position to extract benefits from the foreign investor through tax increases or other public policy measures that might open the door to advancing human rights concerns.

However, the analysis also suggests that contract theory and practice are uncertain in accounting for governance by means of BITs, particularly when the protection or advancement of human rights are at issue. Most BITs are silent on the broader regulatory and constitutional functions of investment agree- ments. Notwithstanding this silence, such concerns have entered into debate through the submissions of state parties to investment agreements and by the business corporations affected by the agreements. Human rights concerns have also been raised in the amicus curiae applications of non-parties and through the agency of arbitrators. However, arbitrators vary greatly in the strictness with which they interpret the provisions of BITs and the extent to which they are willing to consider the impact of investment agreements on human rights [50]. In addition to differences in interpretive strategies and cultures, as Van Aaken ([50], p. 528) notes, contract theory assumes disinterested third-party adjudication, but conflicts of interest and arbitrator bias are well-known problems in investment arbitration. This raises the important issue of the proper role of the arbitrator. Arguably, most arbitrators regard themselves as acting for the parties to resolve specific disputes and would consequently be reluctant to engage in significant public policy debates. Clearly, their competence and legitimacy in doing so are also at issue [70].

Critics of the investment arbitration regime identify a shrinking of domestic policy space, inflexibility of treaty obligations, lack of democratic accountability and pro-investment bias, secrecy and confidentiality of arbitral proceedings, conflicts of interest and arbitrator bias, forum shopping, and competitive pressures that produce a race-to-the bottom in standards [71]. Countries are beginning to defect from the regime. Bolivia was the first to reject the ICSID Convention in 2007, while Ecuador withdrew its consent to ICSID arbitrations for dispute dealing with oil and mining contracts and terminate a number of BITs [40]. Venezuela has denounced the ICSID Convention.

Pressure from civil society groups, including human rights and environmental organizations has resulted in significant changes in investor-state arbitration under NAFTA, while Norway has integrated corporate social responsibility and the protection of health, safety, the environment, labour, democracy and human rights into its Model BIT. Asha Kaushal submits that these are clarion calls to roll back the foreign investment regime. Countries and civil societies are calling for restraint of foreign property and contract rights in favour of national sovereignty ([40], p. 495). To add further fuel to the fire, there are studies suggesting that BITs do not necessarily encourage foreign investment or development $[40,72]$. Many believe that developing countries are bargaining away their sovereignty for uncertain gains ([40], p. 519).

In conclusion, governance through BITs has an uncertain capacity to advance human rights. Reordering the priority accorded to private and public interests in the investment relationship turns on the ability of states to reclaim the public space that has been traded off for the security of foreign investors. This requires states to take seriously their legal duties to protect human rights in investment relationships. 
Important, as well, is the balance that arbitrators are willing to strike between private or public politico-legal traditions in their decision-making. For the moment it might be that the most that can be hoped for from business corporations is the advancement of human rights through the gradual development of notions of corporate social responsibility in investor-state relations.

\section{References and Notes}

1. UNCTAD. World Investment Report 2010. Geneva, Switzerland: United Nations; 2010, p. 81. Available from: http://www.unctad.org/en/docs/wir20 10_en.pdf (accessed on 15 March 2012). The Netherlands has one of the largest networks in the world with some 98 agreements. See UNCTAD. Bilateral Investment Treaties Database. Available from: http://www.unctadxi.org/templates/DocSearch__ 77 9.aspx (accessed on 15 March 2012).

2. Salacuse J. The emerging global regime for investment. Harvard International Law Journal. 2010; 51(2):427-473.

3. Salacuse J. The treatification of International Investment Law. Law and Business Review of the Americas. 2007;13(1):155-166.

4. Cutler AC. Private power and global authority: Transnational merchant law in the global political economy. Cambridge, UK: Cambridge University Press; 2003.

5. Shapiro M. The globalization of freedom of contract. In: Shapiro M, Sweet AS, editors. On law, politics and judicialization. Oxford, UK: Oxford University Press; 2000.

6. Sweet AS. Islands of transnational governance. In: Shapiro M, Sweet AS, editors. On law, politics and judicialization. Oxford, UK: Oxford University Press; 2000.

7. Mattli W. Private justice in a global economy: From litigation to arbitration. International Organization. 2001;55(4):919-947.

8. Cutler AC. Transnational law and privatized governance. In: Pauly L, Coleman W, editors. Global ordering: Institutions and autonomy in a changing world. Vancouver and Toronto, Canada: UBC Press; 2008, pp. 144-163.

9. Van Harten G. Private authority and transnational governance: The contours of the international system of investor protection. Review of International Political Economy. 2005;12(4):600-623. Although Van Harten argues that investment treaty arbitration does not regulate the conduct of private parties, this paper argues that regulating the behavior of states toward foreign investment necessarily affects the rights and duties of private parties. However, there is disagreement over whether investment treaties grant investors procedural rights, substantive rights or mere benefits. One view, informed by traditional principles of public international law regards the investor as holding

\section{Acknowledgements}

The author would like to thank the Hague Institute for the Internationalisation of Law (HiiL) for its generous support in completing the research informing this paper during her tenure as the Morris Tabaksblat Visiting Chair on Private Actors and Globalisation.

derivative rights, delegated to them by their state. See The Loewen Group Inc. v. United States, ICSID, Case No. ARB(AF)/98/3, para 3, 2003, which held that claimants are permitted for convenience to enforce what are in origin the rights of party states. The alternate view is rooted in contract law terms and regards investors as third party beneficiaries under the BIT. See Occidental Exploration and Production Co. v. Republic of Ecuador, [2005] EWCA (Civ) 1116, para. 20; [2005] 2 Q.B. 432, 450 (C.A.), where the English Court of Appeal held that the fundamental assumption underlying the investment treaty regime is clearly that the investor is bringing a cause of action based upon the vindication of its own rights rather than those of its national State. See also Douglas Z. The hybrid foundations of investment treaty arbitration. British Yearbook of International Law. 2003; 74(1):151-289.

10. See Browne M, Coon J. The impact of market ideology on transnational contract law. Loyola of Los Angeles International and Comparative Law Review. 2008;30(2):91-110 for an informative analysis of the foundation of transnational contract law in classical eighteenth and nineteenth century liberal conceptions of individual responsibility, laissez-faireism, and universality.

11. See May $C$. The rule of law as the grundnorm of the new constitutionalism. In: Gill S, Cutler AC, editors. New consitutionalism and world order. Cambridge, UK: Cambridge University Press; forthcoming.

12. Schneiderman D. Constitutionalizing economic globalization: Investment rules and democracy's promise. Cambridge, UK: Cambridge University Press; 2008.

13. Franck S. Foreign direct investment, investment treaty arbitration, and the rule of law. Pacific McGeorge Global Business and Development Law Journal. 2007; 19(2):337-373.

14. Möslein F, Riesenhuber K. Contract governance-A draft research agenda. European Review of Contract Law. 2009;5(3):248-289.

15. Azeem Z. Issues of arbitration in the international law of investment. Business Recorder. 3 March 2011:2.

16. Schill SW. The multilateralization of international investment law. Cambridge, UK: Cambridge University Press; 2009.

17. Burke-White W, Von Staden A. Private litigation in a public law sphere: The standard of review in investor-state arbitrations. Yale Journal of Interna- 
tional Law. 2010;35(2):283-346.

18. Gal-Or N. Dispute resolution in international trade and investment law: Privatization of the public? In: Graz J-C, Nölke A, editors. Private transnational governance and its limits. New York, USA, and London, UK: Routledge; 2008, pp. 209-221.

19. Choudhury B. Recapturing public power: Is investment arbitrations engagement of the public interest contributing to the democratic deficit? Vanderbilt Journal of Transnational Law. 2008;41 (3):775-832.

20. Salacuse J. BIT by BIT: The growth of bilateral investment treaties and their impact on foreign investment in developing countries. International Lawyer. 1990;24(3):655-675.

21. See Cutler AC. Critical reflections on Westphalian assumptions of international law and organization: A crisis of legitimacy. Review of International Studies. 2001;27(2):133-150 for discussion of the doctrine of international legal personality and the legal status of individuals and corporations.

22. Salcuse J, Sullivan N. Do BITs really work? An evaluation of bilateral investment treaties and their grand bargain. Harvard International Law Journal. 2005;46(1):67-75.

23. Guzman A. Why LDCs sign treaties that hurt them: Explaining the popularity of bilateral investment treaties. Virginia Journal of International Law. 1998; 38(January):639-688.

24. Dolzer R. The impact of international investment treaties on domestic administrative law. New York Journal of International Law and Politics. 2005; 37(4):953-972.

25. See generally, Dezalay $Y$, Garth B. Dealing in virtue: International commercial arbitration and the construction of a transnational legal order. Chicago, USA, and London, UK: University of Chicago Press; 1996.

26. Braun $T$. Investors as subjects of public international law. In: Tietje C, Kraft G, Lehmann M, editors. General public international law and international investment law: A research sketch on selected issues. Halle (Saale), Germany: International Law Association German Branch Working Group; No: 105, 2011, pp. 43-48.

27. Keohane RO, Nye Jr. JS. Transnational relations and world politics. Cambridge, UK: Cambridge University Press; 1971.

28. Van Apeldoorn B. Cited in: Cutler AC. Legal pluralism as the common sense of transnational legality. In: Cohen E, Cutler AC, editors. Law, contestation, and power in the global political economy; forthcoming.

29. Sweet AS. The new lex mercatoria and transnational governance. Journal of European Public Policy. 2006;13(5):627-646.

30. Lorz $R$. The local remedies rule as part of international law. In: Tietje C, Kraft G, Lehmann M, editors. General public international law and international investment law: A research sketch on selected issues. Halle (Saale), Germany: International Law
Association German Branch Working Group; No: 105; 2011, pp.48-59.

31. Paulsson J. Arbitration without privity. Foreign Investment Review Journal. 1995;10(2):232-257.

32. Cotula L. Investment contracts and sustainable development: How to make contracts for fairer and more sustainable natural resource investments. London, UK: International Institute for Environment and Development; Natural Resource Issues No. 20, 2010.

33. Schill S. Enabling Private Ordering: Function, Scope and Effect of Umbrella Clauses in International Investment Treaties. Minnesota Journal of International Law. 2009;18:1-97.

34. Preliminary Decision on Jurisdiction of 8 December 1988, ILM 40 (2001), 457.

35. Vicuña F. Of Contracts and Treaties in the Global Market. Max Planck Yearbook of United Nations Law. 2004;8:341-357.

36. Introduction. In: Tietje C, Kraft G, Lehmann $M$, editors. General public international law and international investment law: A research sketch on selected issues. Halle (Saale), Germany: International Law Association German Branch Working Group; No: 105; 2011, pp. 9-28.

37. Report of the Special Representative of the Secretary General on the issue of human rights and transnational corporations and other business enterprises, John Ruggie-Guiding principles on business and human rights: Implementing the United Nations "Protect, Respect and Remedy" Framework. Geneva, Switzerland: United Nations; A/HRC/17/31, 2011. Available from: http://www.ohchr.org/documents/issues/bus iness/A.HRC.17.31.pdf (accessed on 30 April 2013).

38. Quoted in Franck S. Development and outcomes in investment treaty arbitration. Harvard International Law Journal. 2009;50(2):435-489.

39. Venezuela Withdraws from the World Bank's International Centre for the Settlement of Investment Disputes. Milibank Litigation. 30 January 2012:1. Available from: http://www.milbank.com/images/con tent/7/2/7277/Venezuela-Withdraws-From-ICSID-1-30 -2012.pdf (accessed on 30 April 2013).

40. Kaushal K. Revisiting history: How the past matters for the present backlash against the foreign investment regime. Harvard International Law Journal. 2009;50(2):491-534.

41. Laborde G. The case for host state claims in investment arbitration. Journal of International Dispute Settlement. 2010;1(1):97-122.

42. Guzman AM. Review Essay of Sornarajah, The International Law of Foreign Investment. European Journal of International Law. 1995;6(3):612-633.

43. Sonarajah $M$. The international law of foreign investment. Cambridge, UK: Cambridge University Press; 1994.

44. Sonarajah M. State responsibility and bilateral investment treaties. Journal of World Trade. 1986:20 (1):79-98. 
45. For a classic statement of liberal analysis drawing upon rational choice and collective goods theories that invoke transaction-cost analysis to explain the emergence and operations of international legal regimes see Keohane RO. After hegemony: Cooperation and discord in the world political economy. Princeton, USA: Princeton University Press; 1994. For the economic analysis of law, see Posner E. Economic Analysis of Law. Toronto, Canada: Little Brown; 1986; and Thompson A. Applying rational choice theory to international law: The promise and pitfalls. The Journal of Legal Studies. 2002;31(S1):S285-S360. For a critical political economy approach to international economic law and international relations see [4].

46. Vandevelde K. The political economy of a bilateral investment treaty. American Journal of International Law. 1998;92(4):621-641.

47.For the contribution of property and contract laws to economic efficiency, see Frankel T. The legal infrastructure of markets: The role of contract and property law. Boston University Law Review. 1993;43 (4):389-404.

48. See Collins H. Regulating contracts. Oxford, UK: Oxford University Press; 1999 for analysis of the social foundations of contract law.

49. Elkins Z, Guzman AT, Simmons BA. Competing for capital: The diffusion of bilateral investment treaties, 1960-2000. International Organization. 2006; 60(4):811-846.

50. Van Aaken A. International investment law Between commitment and flexibility: A contract theory analysis. Journal of International Economic Law. 2009; 12(2):507-538.

51. Scott R. The law and economics of incomplete contracts. Annual Review of Law and Social Science. 2006;2:279-297.

52. Williamson $\mathrm{OE}$. The economic institutions of capitalism. New York, NY, USA: The Free Press; 1985.

53. Cooley A, Spruyt H. Contracting states: Sovereign transfers in international relations. Princeton, NJ, USA: Princeton University Press; 2009.

54. Other treaties have been analyzed as incomplete contracts, including the Treaty of Rome (see Majone D. Dilemmas of European integration. Oxford, UK: Oxford University Press; 2005) and NAFTA [53]).

55. Vernon R. Sovereignty at bay: The multinational spread of US enterprises. New York, NY, USA: Basic Books; 1971.

56. Hart O. Incomplete contracts and the theory of the firm. Journal of Law, Economics and Organization. 1988;4(1);49-139 and Hart O. Firms, contracts and financial structure. Oxford, UK: Clarendon Press; 1995.

57. Lake D. Anarchy, hierarchy, and the variety of international relations. International Organization. 1996;50(1):1-33.

58. There is some uncertainty as to the actual legal status of the right held by the foreign investor.
See discussion at [9].

59. See Peterson L. Human rights and bilateral investment treaties: Mapping the role of human rights law within investor-state arbitration. Montreal, Canada: International Centre for Human Rights and Democratic Development; 2009 concerning the Russian oil company, Yukos and claims against the Ukrainian government made by Limited Liability Company AMTO.

60. ICSID. Case no. ARB/(AF)/99/2, Award of 11 October 2002, para. 144.

61. ICSID. Case no. ARB/(AF)/00/2, Award of 29 May 2003, paras. 116-122.

62. ICSID. Case no. ARB/01/12, Award of 14 July 2006, paras. 311-312.

63. ICSID. Award of 8 June 2009, [2009] 48 ILM 1039.

64. Claimants Memorial, 10 July 2008; ICSID. Case no. ARB/10/5. 11C 481, Award of 12 January 2011.

65. See Peterson ([59] p. 26, note 59) for a listing of a dozen BIT arbitrations in the water sector.

66. ICSID Case no. ARB/08/19 Award of 30 July 2010.

67.ICSID Case no. ARB/07/17, Award of 21 June 2011.

68. Sweet AS, Grisel F. Transnational investment arbitration: From delegation to constitutionalization? In: Dupuy P-M, Petersman E-U, Francioni, F, editors. Human rights in international investment law and arbitration. Oxford, UK: Oxford University Press; 2009.

69. The General Exceptions in the Canadian FIPA are provided for in Article 10: 1 . Subject to the requirement that such measures are not applied in a manner that would constitute arbitrary or unjustifiable discrimination between investments or between investors, or a disguised restriction on international trade or investment, nothing in this Agreement shall be construed to prevent a Party from adopting or enforcing measures necessary: (a) to protect human, animal or plant life or health; (b) to ensure compliance with laws and regulations that are not inconsistent with the provisions of this Agreement; or (c) for the conservation of living or non-living exhaustible natural resources.

70. The issue of the arbitrators' role as private or public in nature is a very important, but is beyond the scope of this paper and forms the basis of another study currently being conducted by the writer.

71. Waibel M, Kaushal A, Chung K-H, Balchin C, editors. The backlash against investment arbitration. Leiden, The Netherlands: Kluwer Law International; 2010.

72. Hallward-Dreimeier M. Do bilateral investment treaties attract foreign direct investment? Only a bit... and they could bite. Washington, DC, USA: World Bank; Working Paper No. 3121, 2003. 


\title{
Forecasting Stability or Retreat in Emerging Democratic Regimes
}

\author{
Snigdha Dewal ${ }^{1}$, Jack A. Goldstone ${ }^{1,2, *}$ and Michael Volpe ${ }^{1}$ \\ ${ }^{1}$ School of Public Policy, George Mason University, 3351 Fairfax Drive, 5th Floor, MS 3B1, Arlington, VA 22201, \\ USA; E-Mails: sdewal@gmu.edu (S.D.); jgoldsto@gmu.edu (J.A.G.); mvolpe2@gmu.edu (M.V.) \\ ${ }^{2}$ Russian Presidential Academy of National Economy and Public Administration, Vernadskogo prospect 82, \\ 119571 Moscow, Russia
}

* Corresponding author

Submitted: 8 January 2013 | In revised form: 8 March 2013 | Accepted: 10 March 2013 |

Published: 6 May 2013

\begin{abstract}
Drawing on the literatures on elite transitions, factionalism and the new institutionalism, this paper hypothesizes that the stability of partially democratic and emerging democratic regimes is dependent on the willingness of elites to make credible commitments to cooperate and comply with democratic rules. That willingness (or lack thereof) can be signaled by the presence of cooperative or conflict-precipitating events and actions in the periods around elections. We identify and analyze a variety of intra-elite interactions and demonstrate that conflict-precipitating events significantly increase the odds of a democratic retreat in the months before or just after an election, while cooperative events can balance them and prevent retreat. Using event data collected from 40 low- and middle-income countries for two-year periods around national elections between 1991 and 2007 we show that the imbalance of conflict-precipitating over cooperative events is far greater in cases of retreat from democracy. Furthermore, international intervention and pressure had a negative relationship with democratic stability. A logistic regression model accurately identified democratic retreat in 79 percent of the cases examined. Factor analysis revealed several common patterns of intra-elite conflict that can lead to democratic retreat, or conversely, patterns of cooperative events that bolster democratic consolidation. Finally, the data strongly argues for a model of democratic development that depends on open-ended elite maneuvering and the emergence of elite agreements, rather than a model where strong prior institutional constraints determine elite actions.
\end{abstract}

Keywords: conflict; cooperation; democracy; elites; institutions; opposition; stability; violence 


\section{Introduction}

Progress toward democracy is usually considered desirable-except for the problem that partial and emerging democracies have long been flagged as particularly vulnerable to violence or collapse $[1,2]$. Elections are a particularly risky and uncertain time for emerging democracies, as they can lead to greater consolidation, or to the outbreak of violence against the government or to government repression of the opposition. This leaves political analysts with a puzzle - how to identify when partial and emerging democracies are making progress toward stable consolidation, and when are there signs that such regimes are heading toward turmoil?

This study explores whether any specific pattern of events surrounding elections in partial and emerging democracies forms a reliable indicator of the eventual fate of these regimes. In particular, we examine the role of intra-elite interactions as signals of underlying patterns of relationships that may prevent or precipitate violence or further retreat from democracy. The elite groups examined include the ruling party, the dominant opposition and the military. This paper classifies various types of elite actions and events that indicate the presence or absence of formal and informal intra-elite cooperation and conflict, and then examines whether such events have a statistically significant relation to the continued stability, or the retreat from, democratic rule.

Democratic transitions have often been identified as arising from the development of cooperative arrangements or pacts among elites [3-5]. Numerous studies have explored the roots and dynamics of political instability in partially democratic regimes [111]. These studies have identified divisions among the elites as both a catalyst for democracy as well as a major cause of democratic retreats. However, this literature is lacking in three ways. First, it has not clearly specified the types of elite actions that lead to either regime collapse or stability. Instead, much of the focus is on the forging of agreements or pacts [35] or on elite adoption of specific institutions [12-14]. Except in hindsight, there is no way to tell if such agreements will hold or if compliance with the formally adopted institutions will last. Second, much of the study of elite factionalism and political conflict is undertaken in single-country case studies, providing a rich understanding of a country's conflict trajectory, but leaving unanswered the question of whether the same elite actions that contribute to democratic retreat or sustainability in one country would apply to other national contexts [15-17]. Finally, the literature on political conflict tells us much less about how to observe acts of elite cooperation than elite conflict, despite a growing recognition of the former's importance in maintaining regime stability $[3,18]$.

This research adds to our understanding of regime stability by improving our ability to identify and differentiate between cooperative and conflictprecipitating patterns of elite actions. A second aim is to enhance the effectiveness of intervention strategies in emerging democracies by accurately predicting instances when elections are likely to lead to further consolidation of, or retreat from, democratic governance.

\section{Theoretical Background}

To identify candidate events and actions that could indicate progress toward consolidation or democratic retreat, this study draws on insights from the literatures on elite theory, structural theories, factionalism and the new institutionalism. Elite theory as laid out by classical theorists like Pareto, Mosca and Michels focuses on the pre-eminence of a small and organized minority in key governance and nongovernance positions, determining the fates of the larger unorganized minority. The elites in this paper for the most part are those whom Mosca calls the "political classes". These elites are an inherent feature of almost all societies and systems, whether they are effective regimes, dysfunctional democracies, or primitive autocracies. Elite theory sees the interactions among elites-whether cooperative or conflictual-as the essential determinant of whether institutional arrangements will prove stable or not [3].

The structuralist school of thought regarding democratic transitions stresses that elites are bound by context; that is, democratic transitions come about as a result of changing economic structures that create divisions within the old dominant elites that lead to regime collapse $[19,20]$. Transitions to democracies occur when new elite alignments arise in which elites cooperate in maintaining the rules of democratic competition. Structuralists also emphasize that powerful nations wield significant influence over elite dynamics and democratic transitions in less powerful states $[19,21]$.

The literature on factionalism argues that countries with high levels of factionalism have high risks of regime instability and violent conflict. Factionalism reflects the presence of parochialism (a focus on group interests rather than national issues and interests), polarization (intense conflict in a winnertake-all, hostile environment), and violent factional mobilization $[22,23]$. Scholars of factionalism believe that international intervention is often the only way to change or influence elites' political actions. As Keefer and Knack [24] note, "in situations where political systems are highly polarized...a political stalemate between the two groups develops and, unless a force emerges that encourages cooperation [the stalemate] will prevent the development of coherent policy until one group emerges victorious or until the divisions shake the polity apart".

From the new institutionalism perspective (e.g., [25]), the concept of credible commitments forms the lever that either reduces or strengthens factionalism. 
Credible commitments are formal and informal interactions among political competitors that ensure that factional interests are protected, that parochialism is overcome by compromise, and that polarization is avoided. Positive interactions entail the perception of fair treatment and a mutual commitment to resolving issues through established channels, irrespective of which group holds official power. Compensation to elite ruling coalitions for withholding coercion and allowing stability to exist within the state comes in the form of political and economic rents, which are shared among the members of the coalition. The status quo is threatened when new groups demand a share in the rents and a role in the ruling coalition. North, Wallis and Weingast argue that the government's failure to make or keep its credible commitments to maintain stability and sharing economic and political rents increases the odds of a regime collapse. Other institutionalist approaches similarly argue that long-established patterns of cooperative behavior rooted in colonial or legal traditions reflect agreements and pay-offs that promote intraelite cooperation and thus maintain democratic institutions $[12,13,26,27]$. Goldstone and Ulfelder [18] argued that "the key to maintaining stability appears to lie in the development of institutions that promote fair and open competition, avoid political polarization and factionalism, and impose substantial constraints on executive authority".

All of these theoretical perspectives argue for the importance of elite actions-whether shifts in alignments, agreements, commitments, or polarization and conflict-in shaping the progress toward democracy. Yet all also tend to take a long-term view of change, showing how differences emerge across decades or even centuries. This is of little help in identifying, as an emerging democratic state approaches its early national elections, whether any newly forged elite agreements or newly adopted institutions will hold. Certainly some countries that were not blessed with a long history of favorable institutions have made successful transitions to stable democracy, including Greece, Spain and Portugal in Europe, Brazil and Colombia in Latin America, South Korea and Indonesia in Asia, to name just a few. Yet other countries appeared to have adopted sound democratic institutions, but failed to sustain them and went into democratic retreat, such as Chile in the 1970 s, or Nigeria several times reverting to military rule, as just two examples. Our goal in this paper is primarily empirical; we ask: among low-income emerging democracies, does the evidence regarding elite interactions around national elections reveal any particular patterns, or are there any specific cooperative or conflictual events or actions, that are significant predictors of later stability or retreat?

Yet our analysis also lets us address theoretical issues. If the new institutionalists are correct, and democratic progress rests on strong institutions 'tying the hands' of elites to prevent conflictual actions, then in the period around elections in countries moving to stable democracy we should see very few conflictual actions and almost entirely cooperative events and actions, as the institutions shape behavior. Countries lacking strong institutions to bind elites would conversely show mainly conflictual behavior, as elites maneuver to grab power and elections are just another occasion for power struggles. By contrast, if the theorists of democracy as emerging from hardwon elite bargains and evolving agreements are correct, so that elites retain great autonomy and have to decide whether or not to cooperate in upholding democratic institutions, we expect that the period around elections in emerging democracy would show a combination of conflictual and cooperative events, with the balance shifting somewhat toward cooperation where stable democracy develops, but shifting toward conflict where democracy breaks down. We can thus shed light on the institutional constraints vs. elite bargaining paradigms by asking: are different outcomes associated with clear patterns of predominantly conflictual or cooperative behavior?

We also can address the structuralists' claims about the importance of international intervention-when we add international efforts to reinforce democratic behavior to the mix of elite interactions and events, how significantly do such efforts shift the odds for stable democracy in the near future?

Thus this paper asks three empirical questions: Do any specific elite actions or events observed around national elections in low-and middle-income states show a significant tendency to portend future democratic stability or retreat? Does the mix of cooperative and conflictual events observed around such elections indicate strong effects of institutions creating predominantly cooperative or predominantly conflictual settings, or does the mix reflect more fluid and closely balanced settings in which elites appear to be moving back and forth toward settlements? Does international intervention around national elections make a significant difference in promoting stable outcomes?

\section{Data and Methods}

These questions were addressed by developing typologies of conflict-precipitating and cooperative events, and counting the various types of events that occurred in 40 partial democracies in the eighteen months before and six months following national elections for either national legislatures or national executives between 1991 and 2007. The partial democracies were selected, as described in more detail below, to include counties that both sustained democracy for years after their elections, and countries that failed to do so. The countries and periods studied in this research are shown in Appendix 1. 


\subsection{Independent Variables}

From a review of the literature on democratic transitions, factionalism and the new institutionalism, we identified 23 discrete types of events and actions involving elites. We began with 11 "conflict-precipitating" and 12 "cooperative" events/actions. A "conflictprecipitating" event or action is described as one that initiates or heightens hostility, conflict and tensions between opposing parties and reduces the scope for mutual trust and cooperation. A "cooperative" event or action brings parties previously hostile, in conflict or not cooperating to a greater level of mutual trust and cooperation.

We do not distinguish between "actions" and "events", as the events we are observing are usually just the outcomes of prior elite actions. Some observers might treat a boycott of elections as an event; others as an action. The arrest of an opposition leader is an event, but it is also an action by the ruling elites. Our goal was to identify events or actions that could be given a specific date and place and identified from news accounts regarding a country in the months leading up to and following a national election. Thus, every time a riot is reported, a conflict event is recorded; we divide these events into two categories-those that draw little or no response from the government, and those that draw a strong military response from the government. A full description of all identified cooperative and conflict-precipitating events and actions is given in Appendix 2 [28].

Information on the occurrence of cooperative and precipitating events and actions was obtained from an examination of local and international print media over a two-year period for each country revolving around a potentially contentious upcoming national election. The time period stretches from 18 months prior to the election to six months following the election. Elections present a critical opportunity for change in the political system. It is around election time that the opposition is most vocal and looking to strengthen its support base, while the ruling party is reactive and attempting to maintain its supremacy. Interactions in the months leading up to an election, or in the months immediately following, when results may be contested, offer ample opportunity for both government and opposition leaders to signal whether they intend to cooperate with opponents or not.

We found that, as the time before or after the election date increased, fewer elite actions or events occurred. Once the data had been coded, we discovered that within the 18-month period prior to an election, an average of 7.003 months passed before the first event was coded. Furthermore, in the sixmonth period following the election, we found that an average of 4.55 months passed between the last coded event following the election month, and the end of the six month period. What this shows clearly is that the vast majority of identified elite actions and events took place within the period from one year before to two months after the election. The further one stretches the time frame, the steeper the drop off in the observed cooperative and conflictual events.

Two coders populated the dataset, checking for the presence of any of the identified events in a monthby-month examination of media accounts of state politics. A sample of results was replicated by each coder to ensure inter-rater reliability of the coders.

Those events that did not occur at all in the groups of countries analyzed, or were observed in only a handful of instances, were omitted from the list of variables. For cooperative events, the resulting refined list included seven (out of the original twelve) cooperative events. Five were internal events: Bringing the opposition into the government (BringOpp), concession or agreement by government leaders to accept or act on opposition demands (ActOnOpp), a big win by either the regime or the opposition in a free and fair election (BigWin), explicit negotiations between government and opposition leaders to resolve disputes (ExplNeg), and agreement of a regime leader to step down prior to the scheduled election, usually to clear the way for another candidate (StepDown). Two types of international interventions were observed: international intervention to promote free and fair elections (Interv) and international pressure for reconciliation and fair play (IntPres). All of these events could be seen as changing the calculus of political actors in the direction of democratic stability. BringOpp, ActOnOpp, ExplNeg, and StepDown all indicate that ruling groups are willing to make a constructive, compromising response to demands of the opposition. BigWin, Interv, and IntPress all indicate to both ruling and opposition groups that either the electorate or the international community is strongly committed to backing fair and cooperative conduct.

A similar refinement was undertaken with conflictprecipitating events, as we set aside those that were not or only rarely observed in the cases investigated. The resulting six (out of the original eleven) events were: No action by the government in response to opposition protests (NoAction), extremely harsh military actions against a guerrilla rebellion, opposition group or protestors (MilExt), political acts by the opposition to undermine the elections or the ruling regime, such as boycotts, assassinations or refusal to accept election results (OppActs), constitutional struggles in which groups contest key rules of the game, challenging or seeking to change the constitution (ConstStr), coercive acts by the regime to undermine or hinder the opposition from fairly contesting an election, such as arresting or assassinating opposition politicians or banning an opposition party (ContrlOpp), and guerrilla or terrorist acts by the opposition (VioActs).

\subsection{Dependent Variables}

We started with a group of 14 cases identified in the 
Political Instability Task Force Problem Set [29] that experienced a major democratic retreat or instability within a year of scheduled elections (before or after) between 1991 and 2007. These constituted our cases of democratic retreat centered on elections. In each of these cases, there occurred a retreat from democracy, defined as any of the following conditions being met: There is a successful coup, the regime indefinitely postpones or cancels an election, or the regime outlaws the opposition or disqualifies it from participating in an upcoming election.

We began with 1991, because the period following the end of the Cold War created a new world, reflecting rapid changes in global power as well as regimes. Focusing on the post-Cold War era gave us a more consistent time frame in which to test relationships. We ended with elections no later than 2007, because we wanted to be able to check our work for longer event horizons - up to two years beyond the elections, and when we began this research in late 2010, complete data was only available through 2009. However, as we noted above, stretching out the time frame provided few or no important additional events -all the 'action' appears to take place in the months immediately before and after the scheduled elections. The chosen period of 1991-2007 also offered reasonably complete and accessible information on political events from on-line references such as Keesing's World News Archive and LexisNexis, and a manageable number of cases for coding.

We then selected a random sample of 26 countries (roughly twice as many as the problem cases, since the former are relatively rare) from those low and middle-income countries (GNI/capita under $\$ 10,000$ in constant 2000 U.S. Dollars) that held national elections between 1991 and 2007, and did not experience a democratic retreat within the two years following their election. We restricted ourselves to low and middle-income countries because of Przeworski et al.'s [6] finding that high income democracies do not retreat from democracy; we wanted comparison cases in which such a retreat was possible, but did not occur. In three of these countries, two national elections were held during this period; we thus ended up with 29 cases of elections that did not lead to a democratic retreat.

In this paper we refer to the 14 country cases in which a retreat from democracy occurred around a scheduled election (either in the twelve months before or after) as the "retreat" cases. The "no retreat" cases consist of 29 elections in 26 countries, in which no such retreat occurred in a similar twenty-four month period bracketing the election.

The countries we examined had Polity IV regime scores that varied widely, ranging from -7 to +10 on the Polity IV scale during the period of analysis. Figure 1 shows the trajectories of the average Polity scores for the retreat and no retreat cases over a four year period: two years before, the year of, and the first year after the observed elections.

As can be seen from the graph, for both sets of countries-the retreat and no retreat cases-the average Polity score over the observed period was 2.6. In other words, most of the countries were indeed emerging democracies, with Polity scores barely above the zero point separating democracies from dictatorships. However, while the no retreat countries started, on average, with a negative polity score, they ended with a positive score. By contrast, the retreat countries started with an average polity score of +4 , but declined by nearly seven steps over the four years we observed them to an average score of -2.71 .

In some of the democratic retreat cases, such as Armenia and Thailand, there were very dramatic declines in the Polity scores from high positive values (7 and 9) to large negative values ( -5 and -6 ). Moreover, violence often flared or intensified-in six of the fourteen cases of democratic retreat, civil wars were started, resumed, or intensified in response to the calling or miscarriage of elections.

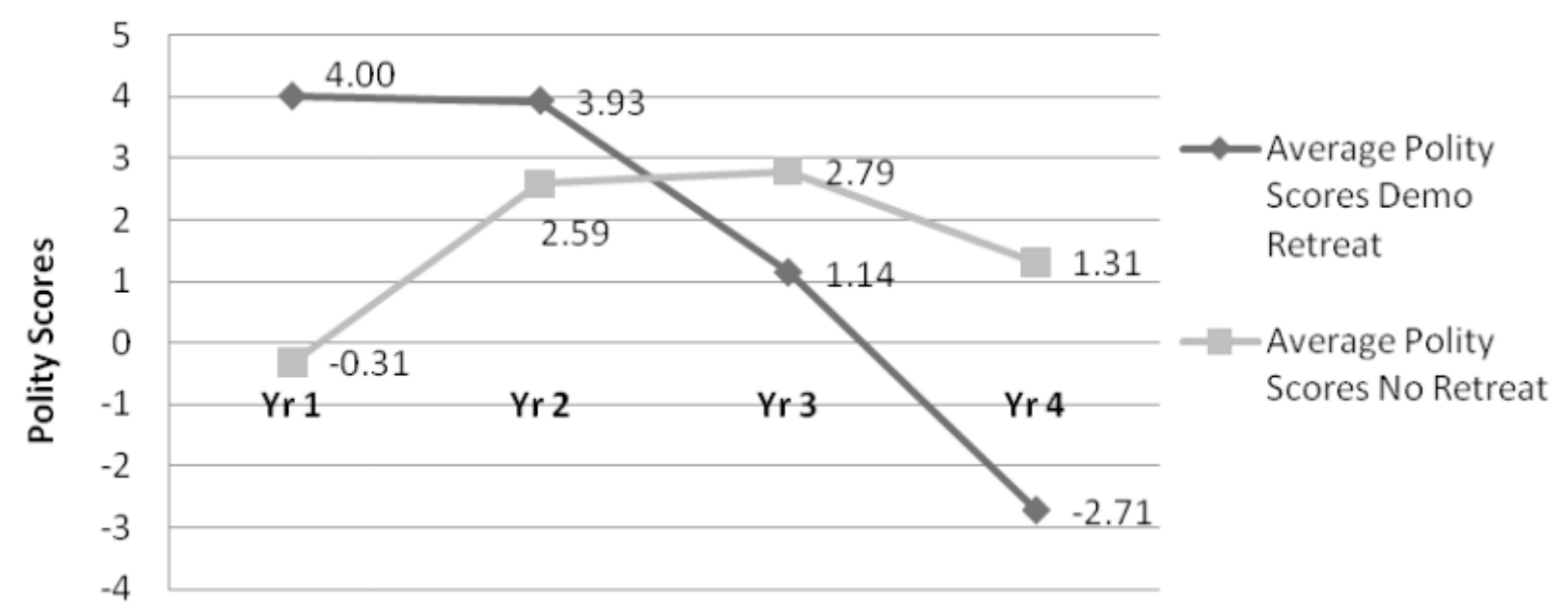

Figure 1: Polity movement across all cases. 
For most no retreat cases, the difference between the Polity scores for countries at the beginning and end of their analysis period was either zero or a small positive gain, indicating that there was a continuation of the status quo rather than significant progress. In many cases, the prevailing situation was far from ideal. Some no retreat countries-Mauritania, Djibouti, Guinea, Chad and Tunisia-had scores that were consistently negative, ranging from -7 to -2 . These regimes may have been only partially democratic, but even in unpromising circumstances they were able to hold elections with some opposition participation and experienced no marked retreat from democratic processes or collapse of government institutions.

\section{Analysis and Results}

For our initial analysis, we explored the relationship of the individual cooperative and precipitating events to the retreat and no retreat outcomes using Chisquared tests. We found five of the six common conflict-precipitating events to have a statistically significant positive association with democratic retreat at the $10 \%$ level: NoAction, ConstStr, ContrlOpp, OppActs, and VioActs. (ContrlOpp, OppActs and VioActs were also significant at the $5 \%$ level.) These events therefore act as indicators of a coming democratic failure, presumably by showing that the ruling coalition and/or the opposition will not work with each other in ways that respect legal processes and promote stability.

We found that only two cooperative events, AcceptDef and IntPres, had a statistically significant relationship with democratic retreat at the $10 \%$ level. Interestingly, the effect of IntPres was negative, as it was observed more frequently in cases of democratic retreat. Indeed, we found to our surprise that several of the cooperative variables occurred more frequently in the retreat cases than in the no retreat cases.

As we demonstrate below, this was because the cases of democratic retreat had both a higher level of cooperative events and a much higher level of conflictual events. It appears that cases with high levels of conflict also elicited a large number of cooperative actions as efforts to respond to the conflict. This higher volume of cooperative events in cases of democratic retreat meant that several of the cooperative events and actions showed an unexpected, positive relationship to democratic retreat when examined individually.

It is therefore necessary to examine the joint effects of the two kinds of events and actions and their relationship to democratic outcomes. Figure 2 presents these findings, showing the average number of conflict precipitating events, the average number of cooperative events, and the difference between them for both the democratic retreat and the no retreat cases.

It is quite striking to see how much the difference between the number of precipitating and cooperative events differs in the two groups of countries. In countries where a retreat from democracy occurred, we observed on average 2.6 more precipitating events than cooperative events; where no retreat occurred the difference went in the other direction, with on average 0.3 fewer precipitating than cooperative events. The magnitude of the difference between conflict and cooperation appears to be crucial in whether democratic retreat occurs.

This difference is driven mainly by the incidence of conflict-precipitating events and actions. There was a significantly higher average number of conflictprecipitating events in countries with democratic retreat (7.7 vs. 3.1). There were more modest differences in the average number of cooperative events (5.1 vs. 3.4). Still, there was a higher prevalence of cooperative events in countries where there was a democratic retreat. At first glance, this may seem counterintuitive. However, it demonstrates that in countries sliding toward political crisis, there are usually attempts to reverse the slide through cooperative acts. The fact that cooperative events were fairly similar in incidence in both retreat and no retreat cases accounts for the finding that most cooperative events were not statistically significantly associated with no retreat outcomes, and that several in fact were more commonly found in the no retreat cases.

Thus the answer to our first question is that there are observable differences in the frequencies of conflictual and cooperative events that can distinguish between the cases where democracy suffered a retreat and those where it did not. In particular, it is difference between the level of conflictual and cooperative events and actions that appears crucial.

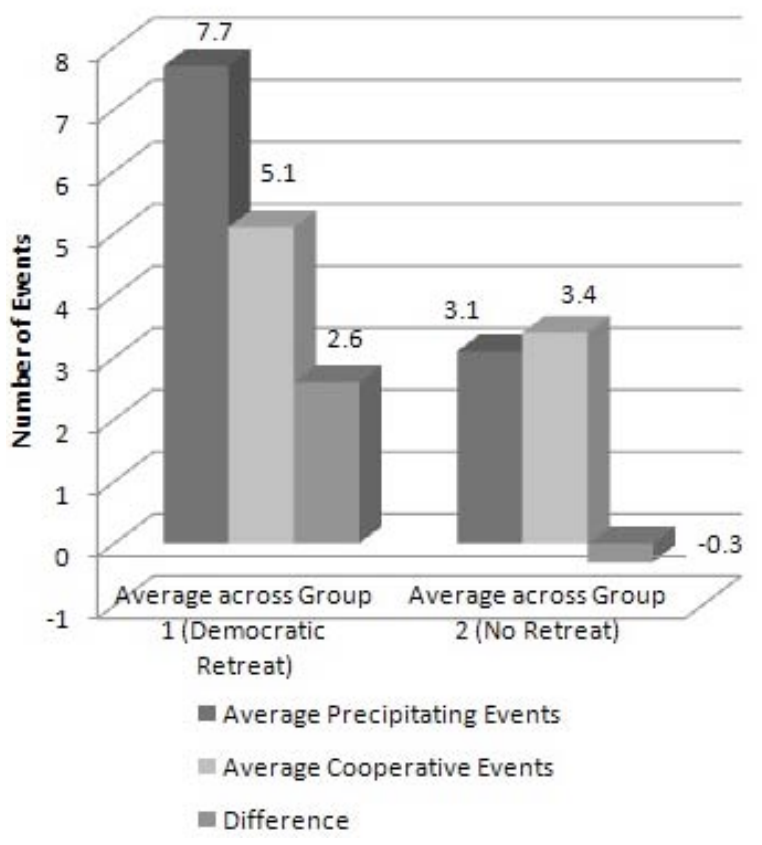

Figure 2: Frequency distribution of conflictprecipitating and cooperative events. 
It is where conflict-precipitating events occur considerably more often than cooperative events and actions that democracy will likely fail. On the other hand, where cooperative events balance closely or even slightly outweigh conflict-precipitating events, democracy is unlikely to retreat. Perhaps our most interesting finding is that it is not necessary for cooperative events to dominate, nor for conflict to be wholly absent, for democracy to prevail and continue. All that is necessary is for cooperative actions and events to fully balance conflictual events, and to avoid a strong imbalance in elite interactions and events in favor of conflict.

We go further to identify the most important such events and actions, and develop a regression model of their effects, in the following section.

In regard to our second question, the evidence clearly favors the theory of democracy as emerging from elites freely bargaining and maneuvering toward agreements, rather than being bound or strongly guided by prior institutional arrangements. In the no retreat cases, the numbers of cooperative and precipitating events were very nearly even, with cooperative events only slightly dominating. We therefore find no evidence that during these periods around national elections, prior existing institutions strongly restrained elites from conflictual actions. Rather, it appears that in a rough balance between cooperative and non-cooperative actions and events, the cooperative actions and events only slightly won out. Similarly, the retreat cases do not show a wholly unrestrained conflictual pattern of elite interactions. Rather, these cases show quite significant efforts by elites to work toward cooperation, with even more cooperative actions or events than in the no retreat cases (average 5.1 vs. 3.4 per case), that were in the end overwhelmed by even greater numbers of conflictual actions and events. It thus appears than an institutional theory of democratic success vs. failure does not fit our data, at least for the very short-term framework being investigated here (outcomes up to one year beyond the election). Rather, it seems that elites were constantly choosing and shifting between conflictual and cooperative approaches, and that stable resolutions reflected a very narrow triumph of cooperative choices.

The cases of Thailand, Bulgaria, and Estonia illustrate how the frequency of, and gap between, conflict-precipitating and cooperative events can affect regime stability. Thailand is an extreme case of cooperation and conflict. There were 16 total events of cooperation and conflict during the two-year period under study (October 2004-2006, bracketing the April 2006 election). Of these, four were cooperative events and 12 were conflict-precipitating events. In early 2005, then Prime Minister Thaksin Shinawatra's Thai Rak Thai (TRT) Party won a major victory at the polls. The Democrat Party conceded defeat, sacking their party leader. Yet instead of working within the political system, with this new mandate Thaksin began to consolidate power in the executive, and attempted to silence the media through the courts and through purchases of media outlets. Thaksin's cabinet approved a special decree-"The Emergency Powers Act"- that gave Thaksin sweeping powers to deal with Muslim separatists in Southern Thailand. His administration also put on trial individuals who criticized the government.

The opposition Democrats and their allies reacted strongly to these actions, pressuring the government through means outside of the system of political cooperation, such as bomb plots and street protests, to give up its attempts to consolidate power and control the media. There were few attempts at elite cooperation. One came during the height of antigovernment protest marches when Thaksin signaled that he would step down and not run again if protest leaders agreed to end street protests. This act of cooperation was isolated and was not followed up by other signals of cooperation and compromise. A distrusting Democrat Party boycotted the 2 April 2006 election, resulting in the TRT being able to grab most of the seats in the parliament. With an absolute majority in the parliament, Thaksin took on the power of the military, seeking to undermine senior officers. But the military struck back-in October 2006 he was ousted in a coup, thus producing a democratic retreat.

Bulgaria shows a different pattern. As a loss for the ruling BSP party seemed imminent in the presidential and parliamentary elections scheduled for 1997, marked instances of conflict arose. However in light of widespread public protests, the ruling party bowed to pressure and refrained from forming a new cabinet and instead allowed a caretaker government to take over until the parliamentary elections were over. The government eventually stepped down and allowed the opposition party UDF to take over the reins of government. Thus, the country was able to avoid retreat due to a prevalence of cooperative events which allowed for a smooth transition of power.

Estonia provides a case where retreat could have happened, given that the legislature passed a noconfidence motion in 1994 against the reigning Prime Minister Mart Laar, who was forced to step down and allow Andres Tarand to take over. However, the country surprisingly saw no conflict-precipitating events on the part of the ruling regime or the opposition. Instead the 1995 elections were allowed to take place and the opposition party KMU won, eventually forming a coalition government with the Centre Party.

While the frequency of cooperative and precipitating events and the gaps between them are important factors in democratic retreat, there may also be a pattern in how elite interactions unfold within a particular election period that may be important for understanding regime outcomes. That is, do cooperative and conflictual events tend to cluster together, and does one type tend to have a higher event density than the other? To explore this, an event density 
score was calculated for each country to understand what effect, if any, event clustering had on regime stability [30]. Figure 3 illustrates the results of the examination of event clustering.

The average cluster value of events for the democratic retreat cases was 0.81 , whereas the average cluster size for cases in which there was no democratic retreat was 0.73 . So in both cases, all events tended to occur in clusters, rather than as isolated incidents.

In distinguishing between retreat and no retreat cases, the cluster analysis follows the same pattern as the event counts-it is the difference between precipitating and cooperative events that matters. The cluster value for cooperative events is about the same for both retreat and no retreat cases (0.69 vs. 0.67$)$. However, in the cases of democratic retreat the clustering value for conflict-precipitating events is higher than for cooperative events (0.75 vs. 0.69), while for the no retreat cases the clustering value for precipitating events is lower than for cooperative events (0.54 vs. 0.67). Thus we find a strong preponderance of density of cooperative events over precipitating events characterizes the no retreat cases; while a modest preponderance in the density of precipitating events over cooperative events characterizes the cases of democratic retreat. This means that in either outcome, it is usually a series of events, rather than one specific event or action, that tilts the outcome and determines democratic retreat or stability.

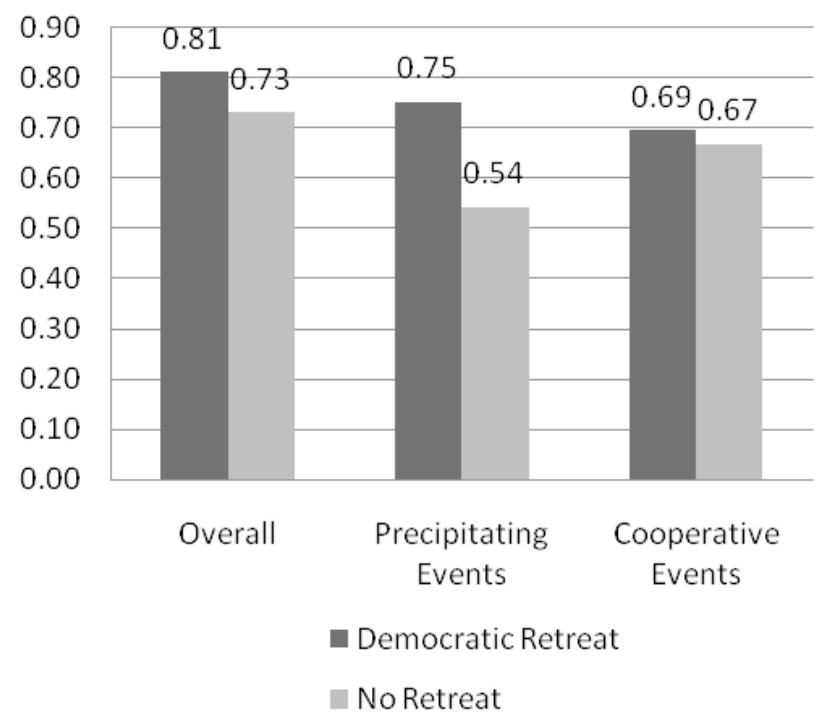

Figure 3: Cluster value results.

\subsection{Specific Variables and a Democratic Retreat Model}

The next stage in the analysis was to determine the relative impact of specific events and actions on democratic retreat or persistence. We did this by conducting a multivariate logistic regression, pooling all the cases and events [31]. The results showed four events were statistically significant. These were
BigWin, ConstStr, ContrlOpp, and VioActs. The regression model is depicted in Table 1 . The model had a $0.5 R^{2}$ value.

Table 1: Four variable logistic model.

\begin{tabular}{ccc}
\hline Indep. Var. & Odds Ratio & Std. Err. \\
\hline BigWin & 0.063 & $(0.076)^{* *}$ \\
ConstStr & 3.306 & $(2.229)^{*}$ \\
ContrlOpp & 1.709 & $(0.455)^{* *}$ \\
VioActs & 7.099 & $(4.868)^{* * *}$ \\
\hline
\end{tabular}

Note: Entries are based on unstandardized parameter estimates in logistic regression equations for the cases in our sample. Standard errors are depicted in parentheses. $* \mathrm{p}<0.1$; $* * \mathrm{p}<0.05 ; * * * \mathrm{p}<0.01$

The odds ratios indicate that in our sample an incidence of event BigWin sharply decreases the relative odds of a democratic retreat by approximately $94 \%$. Evidently, a decisive victory in an election that is considered free and fair gives the winning party sufficient standing to deal with opponents from a position of security. It may also deprive opposition elites of the strength to keep contesting the regime's right to hold power. Conversely, the incidence of event ContrlOpp increases the relative odds of a democratic retreat by $70 \%$. Thus, regimes that are willing to place significant new restrictions on opponents in the run-up to elections are well on their way to a full retreat from democratic government. Another way that governments restrict opponents is through changes to the constitution. An incident of ConstStr raises the relative odds of democratic reversal by $230 \%$, more than twice as much as an incident of ContrlOpp. The strongest effect is from an incident of VioActs; this increases the relative odds of a democratic retreat by roughly $610 \%$, more than twice as much as constitutional struggles. Violence by the opposition (not the government, which is MilExt) either in the run-up, or immediately following, national elections seems to give the ruling regime an opportunity to suppress the opposition and retreat from democracy in the name of security. It may also be a signal that the opposition believes the regime is not giving it a fair opportunity in the elections, and therefore has to pursue its aims by direct attacks on the government.

The probability of a democratic retreat was predicted for each of the countries in the analysis using the logistic regression. The model correctly predicted no retreat in $89.66 \%$ of the cases that remained democratic and correctly predicted retreat in $78.57 \%$ of the cases that experienced a significant retreat.

\subsection{Patterns of Regime-Opposition Interactions}

We further explored, through factor analysis, the possibility that our events and actions fell into 
patterns of cooperative and precipitating events. Such composite factors might characterize common trajectories that lead to democratic retreat or stability. For our paper we use principal component factor analysis. From a factor rotation with up to 5 factors, a possible three-factor solution emerged. This threefactor solution is outlined in Table 2 along with the factor score coefficients for each of those variables. The factor coefficients indicate that each factor is composed of roughly equal weighting on its component variables.

New composite variables were created by combining the variables in each factor. These were: Factor 1Violence, Intervention and Negotiation; Factor 2Elections and Policy; and Factor 3-Ruling Party Actions. The factor score method was used (factor scales are preferred for binary data). Individually the variance for Factor 1 is 2.42, variance for Factor 2 is 2.22, and variance for Factor 3 is 2.16. A logistic regression was conducted using the factor scores. Table 3 illustrates the results of the regression. The model had a $0.25 R^{2}$ value.

An increase in Factor 1: Violence, Intervention and Negotiation (VioActs, IntPres and ExpNeg) increased the relative odds of democratic retreat. Factor 1 can be thought of as indicating a process in which violent acts-usually a guerrilla war or acts of terrorism-on the part of the opposition result in international pressure, which then brings parties to the negotiation table. However, this pattern of international pressure and explicit negotiation in conjunction with violent opposition actions had a negative impact on democratic stability.

This pattern is exemplified by the politics of CongoBrazzaville between 1996 and 1998. In July 1996, armed militias loyal to former President and opposition leader Denis Sassou-Nguesso occupied the northeastern town of Mossaka to prevent the installation of the new mayor Jean-Michel BokambaYangoma, a member of the presidential group, who had defeated an opposition candidate close to SassouNguesso in recent mayoral elections. Over the next year, the conflict descended into Civil War, as the regime, led by democratically elected president Pascal Lissouba, and the opposition engaged in large scale tit-for-tat violence. In June of 1997, President Jacques Chirac of France appealed personally to Lissouba and Sassou-Nguesso to end hostilities. Both factions engaged in explicit negotiations, including ceasefires and UN and African Union sponsored peace talks. These efforts ultimately failed when a coup took place in October 1997, orchestrated by former president Sassou-Nguesso.

Yet this process of violence, international pressure and negotiation is just one possible route of the political process.

Table 2: Three-factor solution.

\begin{tabular}{|c|c|c|c|}
\hline \multicolumn{2}{|c|}{ Factor/Label } & Variable & Coefficient \\
\hline \multirow{3}{*}{ Factor 1} & ExplNeg & $\begin{array}{l}\text { Explicit negotiations between government and opposition } \\
\text { leaders to resolve disputes. }\end{array}$ & 0.301 \\
\hline & IntPres & $\begin{array}{l}\text { International pressure on competing political leaders or } \\
\text { parties for reconciliation and fair play. }\end{array}$ & 0.260 \\
\hline & VioActs & Guerrilla or terrorist acts by the opposition. & 0.352 \\
\hline \multirow{4}{*}{ Factor 2} & BigWin & $\begin{array}{l}\text { A free and fair election that produces a large majority in favor } \\
\text { of one party. }\end{array}$ & 0.297 \\
\hline & StepDown & $\begin{array}{l}\text { Willingness of a government leader to step down (whether } \\
\text { because of term limits, retirement or electoral defeat). }\end{array}$ & 0.255 \\
\hline & OppCont & $\begin{array}{l}\text { Evidence that the opposition will successfully contest for } \\
\text { power. }\end{array}$ & 0.253 \\
\hline & NewPol & $\begin{array}{l}\text { New policy departures by a civilian regime where the military } \\
\text { is strong and concerned. }\end{array}$ & 0.269 \\
\hline \multirow{4}{*}{ Factor 3} & ActOnOpp & $\begin{array}{l}\text { Concession or agreement by government leaders to accept or } \\
\text { act on opposition demands. }\end{array}$ & 0.330 \\
\hline & NoAction & $\begin{array}{l}\text { Popular pressure by riots or demonstrations combined with an } \\
\text { indecisive or inactive regime. }\end{array}$ & 0.324 \\
\hline & ConstStr & $\begin{array}{l}\text { Constitutional struggles in which groups contest key rules of } \\
\text { the game, challenging or seeking to change the constitution. }\end{array}$ & 0.322 \\
\hline & ContriOpp & $\begin{array}{l}\text { Coercive acts by the regime to undermine or hinder the } \\
\text { opposition from fairly contesting an election. }\end{array}$ & 0.292 \\
\hline
\end{tabular}


Table 3: Three factor logistic regression.

\begin{tabular}{ccc}
\hline $\begin{array}{c}\text { Independent } \\
\text { Variable }\end{array}$ & Odds Ratio & Std. Err. \\
\hline Factor 1 & 2.267 & $(0.92)^{*}$ \\
Factor 2 & 0.519 & $(0.23)$ \\
Factor 3 & 2.701 & $(1.12)^{*}$ \\
\hline Note: Entries are based on unstandardized \\
parameter estimates in logistic regression \\
equations for the cases in our sample. Standard \\
errors are depicted in parentheses. $* \mathrm{p}<0.05$
\end{tabular}

Instead of using violence, the opposition could pressure the regime through non-violent action [32]. The international community could decide that pressure alone is insufficient to thwart a political crisis and intervene directly in the election, and the opposition could choose constitutional and peaceful means, instead of violence, to protest regime repression. A number of potential pathways of political conflict are illustrated in Appendix 3.

Factor 2: Elections and Policy (OppCont, BigWin, StepDown, NewPol) demonstrates a pattern of events and actions that had substantial positive effects on democratic survival. This result is in accord with expectations since it reflects an environment of political competition in which both sides respect the process and are willing to accept the results of elections. That is, the opponents are able to effectively contend for power, one side scores a clear and decisive victory in elections, and the losing party steps down from power while civilian leaders create new policies to diminish the military's role.

This process occurred in Bulgaria during the 1996 presidential election. In the run up to the election, polls indicated that the UDF opposition coalition candidate Peter Stoyanov had a good chance of winning the presidential election. The election resulted in Stoyanov winning $59.9 \%$ of votes. Prime Minister (PM) and ruling party leader Zhan Videnov agreed to step down as both PM and party leader. In April, 1997, the UDF won a decisive parliamentary election. During this period there were no regime actions to control the opposition or prevent them from fairly contesting the election.

The case of Bulgaria shows that while partial democratic regimes sometimes tip the scales in their favor, they may choose not to overtly suppress the opposition. Instead, democratic consolidation is advanced if the regime displays a willingness to compete for political power within the political system. There are other options open to both the opposition and ruling regime along the way that would set the country on a different course. For example, once the ruling regime saw that the opposition was running a strong campaign, they could decide to suppress them. And if the opposition wins, the ruling party could refuse to step down, resulting in the failure of democracy (see Appendix 3). Factor 2 shows the positive power of this cluster of cooperative events and actions to preserve democratic institutions.

Factor 3: Ruling Party Action (ActOnOpp, NoAction, ConstStr, ContrlOpp) represents the opposite pattern-a cluster of conflict-precipitating events and actions-and had the largest impact on the odds of democratic retreat. Factor 3 reflects an option-choice framework. In this scenario the opposition is active, and the regime considers them a threat. The regime chooses from several options-give in to opposition demands, ignore them, or suppress the opposition using a change in the constitutional rules or forcesometimes using all of these options in the lead-up to an election. The presence of the latter three variables in the factor indicates a choice to deal with the opposition by constraining them rather than engaging with the opposition. ContrlOpp and ConstStr reflect the suppression of new groups and changing of the rules of the game to benefit the ruling coalition. Thus the third factor runs the spectrum of responses from conciliation, to ignoring, to actively suppressing the opposition.

Albania seems to exemplify this pattern. In Albania there were multiple instances in which the regime tampered with the constitutional and legal system. These included dismissing the head of the Supreme Court, barring officials that had served under the erstwhile Communist regime, and the passage of new laws requiring screening of public officials' activities under the communist regime. Among many political arrests and prosecutions, the ruling party convicted the leader of the Albanian Socialist Party on dubious grounds and the police on numerous occasions broke up meetings of the opposition party PSS. Under intense international pressure, an attempt was made by the major parties to come to the negotiating table and the ruling party did eventually agree to several of the opposition demands. Nonetheless, Albania's democracy still experienced a sharp retreat.

The factor analysis does not provide a superior model for forecasting democratic outcomes across the entire data set. This is because these particular clusters only occur in some of the cases; better results are obtained with the four variable logistic regression shown in Table 1, as these particular events are found more commonly across the cases. However, the factor analysis does show that certain of our events and actions do tend to align together in characteristic patterns.

The pathways to these patterns are indicated in Appendix 3. This figure shows how many 'decision points' we found where elites could choose cooperative or conflictual interactions. We do not rule out the fact that once a democracy becomes consolidated these choices become institutionalized or rule-bound, so that in established democracies, certain choices (e.g. banning an opposition party or using extreme military force against political opponents) become unthinkable, and cooperative events completely dominate. Our analysis of the events around elections 
in emerging democracies, however, shows how often both conflictual and cooperative events arose. Clearly, a theory of elite interactions that involves a high degree of elite choice, and outcomes that, in the near term, depend on whether the preponderance of those choices leans toward cooperation or conflict, best fits the conditions in emerging, partial democracies.

\section{Conclusions}

This paper provides significant evidence for the importance of elite interactions in the development of democratic stability and retreat. An analysis of the total numbers of events across two groups of countries with different outcomes revealed that the observed incidence of elite interactions and events in a precipitating or cooperative direction in the months around national elections is crucial in determining those outcomes.

The logistic regression analysis bears out our hypothesis that specific actions and events can predict, at least for the short term, whether an election will lead to the continuation or ending of progress toward democracy. The four variable model identified democratic retreat and democratic continuance for the cases in this data set approximately $79 \%$ and $90 \%$ of the time, respectively. A key finding is that we generally do not see a simple pattern of all cooperative events and actions in successes vs. all conflictprecipitating events and actions in failures. Rather, in all our observed emerging democratic countries we see a combination of cooperative and conflictual events/actions around elections; what differs is the balance and specific combinations of events and actions. A significantly higher incidence of precipitating events, such as violent acts by the opposition, control of the opposition through overt repression, and control of the opposition through manipulation of the constitutional rules is indicative of a failure on the part of the ruling coalition to keep up its commitments toward withholding violence, maintaining stability and sharing political and economic power with new claimants. Conversely, a preponderance of cooperative actions indicates a willingness to keep to commitments to "play by the rules" and indicates a high probability that democratic institutions will endure.

In cases of democratic retreat it is not just that the total number of conflict-precipitating events and actions is higher than in cases of democratic survival; rather, it is the difference between that number and the number of cooperative events that is most significant. On average, there were $66 \%$ more precipitating than cooperative events in cases of democratic retreat, whereas there were $11 \%$ fewer precipitating events than cooperative events in cases in which there was no retreat from democracy. The clustering analysis revealed that there is a greater concentration of precipitating events in cases of democratic retreat than in cases in which a retreat did not take place.
However, the clustering of cooperative events was similar across both groups of cases. This means that in retreat cases there was, within a short time, a flurry of concentrated conflict events that was not balanced by a similar concentration of cooperative events to counteract the damage to democracy.

It should be pointed out that it is the total balance of events over a sustained period around an election that matters. Observing several cooperative events in the run-up to an election is hopeful, but not sufficient, as a flurry of conflictual events may arise soon after the election, derailing that progress. This appears to have been the case in the recent elections in Egypt, where cooperative events marked the months before the Presidential election, but shortly afterward constitutional struggles, boycotts, and actions to control the opposition arose.

An analysis of which events happened most frequently provides the first clues in understanding democratic retreat. The very high incidence of the conflictual events control the opposition through overt repression (ContrlOpp) and political acts by the opposition to undermine an election or the ruling regime (OppActs) in the retreat cases indicates that the opposition was fairly strong and that the government was repressive. This conclusion is consistent with the social movement literature on repression and mobilization, which points to regime repression being most severe in circumstances where the opposition is well organized and possesses significant resources [33].

Conversely, the prevalence of the cooperative events bringing the opposition into the government (BringOpp) and a free and fair election that produces a big win at the polls (BigWin) in the no retreat cases indicates that it often takes explicit initiatives on the part of regimes to follow democratic processes and to allow the opposition a role in the political process to ensure democratic outcomes. It should be noted that not all countries in the no retreat group allowed free and fair elections to take place. In cases like Cameroon and Tunisia, the opposition chose to boycott the elections and there were serious doubts about the validity of the results. But elections did take place and most importantly, the ruling party was able to maintain power without resorting to violent suppression of the opposition and the opposition itself was not very vocal or used less overt protest tactics. Such cases may not be ideal in terms of democratic practice, but they avoided the coups, cancelled elections, and suppression of opposition that mark major retreats or endings of democratic processes.

We also wish to highlight our findings regarding international intervention. These clearly show that international pressures cannot substitute for the willingness of domestic elites to engage in cooperative actions or create cooperative events. We found that both international engagement variables were observed more often in cases of democratic retreat. In fact, either international pressure to promote recon- 
ciliation and fair play (IntPres) or intervention to promote free and fair elections (Interv) occurred in 9 of the 14 cases of democratic retreat. Of the 10 cases where IntPress was observed, 6 of the 10 ended in democratic retreat. IntPres was also significant in the factor analysis, where it occurred as part the factor leading to democratic retreat (Factor 1 ).

While this may be a case of the international community getting involved in only those cases where there is extreme violence and thus the highest risk of democratic retreat, it might also be that international involvement has unintended consequences. One possibility is that international involvement alters the factional power balance by pressuring the regime to negotiate, and this emboldens the opposition by creating a political opportunity that may lead to more overt and confrontational protest tactics and increased mobilization. The message sent by international involvement may be that the regime cannot maintain peace alone or that the international community disapproves of its actions toward the opposition. The opposition exploits this message, thereby "upping the ante". International pressure then can do more harm than good.

Where the regime is unable or unwilling to signal

\section{References and Notes}

1. Goldstone JA, Bates R, Epstein D, Lustik $M$, Marshall M, Ulfelder J, Woodward M. A Global Model for Forecasting Political Instability. American Journal of Political Science. 2010;54(1):190-208.

2. Mansfield ED, Snyder JL. The Sequencing Fallacy. Journal of Democracy. 2007;18(3):5-9.

3. Higley J, Burton M. Elite Foundations of Liberal Democracy. Lanham, MD, USA: Rowman \& Littlefield; 2006.

4. Linz J, Stepan A. Problems of Democratic Transition and Consolidation. Baltimore, MD, USA: Johns Hopkins University Press; 1996.

5. Linz J, Stepan A. Toward Consolidated Democracies. In: Diamond L, Plattner MF, editors. The Global Divergence of Democracies. Baltimore, MD, USA: Johns Hopkins University Press; 2001.

6. Przeworski A, Alvarez ME, Cheibub JA, Limongi F. Democracy and Development: Political Institutions and Well-Being in the World, 1950-1990. New York, NY, USA: Cambridge University Press; 2000.

7. Tilly C. Regimes and Repertoires. Chicago, IL, USA: The University of Chicago Press; 2006.

8. Diamond L. Thinking about Hybrid Regimes. Journal of Democracy. 2002;13(2):21-35.

9. O'Donnell G, Schmitter P. Transitions from Authoritarian Rule: Tentative Conclusions about Uncertain Regimes, Vol. 4. Baltimore, MD, USA: Johns Hopkins University Press; 1986.

10. Fearon J, Laitin D. Ethnicity, Insurgency, and Civil War. American Political Science Review. its willingness to cooperate or compromise, international involvement cannot make up for this absence. International pressures thus only seem likely to contribute to democratic progress where the international actors have sufficient leverage to get the regime and opponents to engage in cooperative actions themselves, such as direct negotiations, stepping down, and abiding by election results.

A final conclusion from this analysis is that it is a worthwhile endeavor to further develop event-count analysis to understand conflict trends (cf. [34]). The fact that many events had strong and significant relationships with democratic retreat and that there were several common patterns of conflict and cooperation is an encouraging sign in the study of event patterns as antecedents to political conflict and democratic collapse.

\section{Acknowledgements}

We gratefully acknowledge that this paper was made possible with funding from the United States Institute of Peace. We also extend thanks to the anonymous reviewers, whose suggestions greatly strengthened the paper.

2003;97(1):75-90.

11. Mansfield ED, Snyder, JL. Democratic Transitions, Institutional Strength, and War. International Organization. 2002;56(2):297-337.

12. Acemoglu $D$, Robinson JA. A Theory of Political Transitions. The American Economic Review. 2001;91(4):938-963.

13. Acemoglu D, Robinson JA. Economic Origins of Dictatorship and Democracy. New York, NY, USA: Cambridge University Press; 2006.

14. North D, Wallis J, Weingast B. Violence and Social Orders: A Conceptual Framework for Interpreting Recorded Human History. Cambridge, UK: Cambridge University Press; 2009.

15. Lee SJ. Democratization and polarization in Korean society. Asian Perspective. 2005;29(3):99-125.

16. LeBas A. Polarization as Craft: Party Formation and State Violence in Zimbabwe. Comparative Politics. 2006;38(4):419-438.

17. Layman GC, Carsey TM, Horowitz JM. Party polarization in American politics: Characteristics, causes, and consequences. Annual Review of Political Science. 2006;9(June):83-110.

18. Goldstone JA, Ulfelder J. How to Construct Stable Democracies. The Washington Quarterly. 2004;28(1):9-20.

19. Rueschemeyer D, Stephens EH, Stephens JD. Capitalist Development and Democracy. Chicago, IL, USA: University of Chicago Press; 1993.

20. Moore Jr B. Social Origins of Dictatorship and Democracy: Lord and Peasant in the Making of the Modern World. Boston, MA, USA: Beacon Press; 1966. 
21. Skocpol T. States and Social Revolutions. Cambridge, UK: Cambridge University Press; 1979.

22. Sartori G. Parties and Party Systems. Cambridge, UK: Cambridge University Press; 1976.

23. Marshall MG. Political Conflict, Measurement of. In: Kempf-Leonard K, editor. Encyclopedia of Social Measurement. San Diego, CA, USA: Academic Press; 2004.

24. Keefer $P$, Knack S. Polarization, Politics, and Property rights. Washington, DC, USA: The World Bank; 2000.

25. North DC, Wallis JJ, Weingast BR. Violence and Social Orders: A Conceptual Framework for Interpreting Recorded Human History. Cambridge: Cambridge University Press; 2009.

26. Acemoglu D, Johnson S, Robinson JA. The Rise of Europe: Atlantic Trade, Institutional Change and Economic Growth. 2005;95(3):546-579.

27. Glaeser EL, LaPorta R, Lopez-de-Silanes F, Shleifer A. Do Institutions Cause Growth? Journal of Economic Growth. 2004;9(3):271-303.

28. A timeline of observed events for each case is available from the authors online from: http://jackgold stone.gmu.edu/replication-data-forecasting-stability-or -retreat-in-emeging-democratic-regimes/

29. Center for Global Policy. Political Instability Task Force Consolidated Problem Set. 2011. Available from: http://www.systemicpeace.org/inscr/PITF\%20C onsolidated\%20Case\%20List2011.pdf (accessed on 24 April 2013).

30. Event density measures the clustering of precipitating and cooperative events. We looked at the full two-year period (18 months preceding an election to 6 months following the election). The equation used was a numerator of the total number of observed events minus the number of isolated events and the denominator was the total number of observed events. Isolated events were defined as those that did not have another event occurring during the month or in the month prior or following. A cluster density of close to 1 indicates events were very densely clustered while a density of close to 0 indicates that events were very spread out.

31. According to Peng, Less and Ingersoll (2002) "logistic regression is well suited for describing and testing hypotheses about relationships between a categorical outcome variable and one or more categorical or continuous predictor variables". In this case, the variables under study are in the form of count data that list the number of occurrences of cooperative and precipitating events and the dichotomous dependent variables of democratic outcome ( $1=$ retreat, $0=$ no retreat). See Peng CY], Lee $\mathrm{KL}$, Ingersoll $\mathrm{GM}$. An Introduction to Logistic Regression. Journal of Educational Research. 2002;96(1):3-14.

32. Chenoweth $E$, Stephan M. Why Civil Resistance Works: The Strategic Logic of Nonviolent Conflict. New York, NY, USA: Columbia University Press; 2011.

33. Davenport C, Johnston $\mathrm{H}$, Mueller C. Repression and Mobilization. Minneapolis, MN, USA: University of Minnesota Press; 2005.

34. Schrodt PA. Event Data in Foreign Policy Analysis. In: Neack L, Hey JAK, Haney PJ, editors. Foreign Policy Analysis: Continuity and Change. New York, NY, USA: Prentice-Hall; 1994. 
Appendix 1: Countries and time periods studied.

\begin{tabular}{|c|c|c|}
\hline \multirow{15}{*}{ Group 1 (Retreat) } & Country & Time Period \\
\hline & Albania & December 1994-December 1996 \\
\hline & Angola & March 1991-March 1993* \\
\hline & Armenia & January 1994-January 1996 \\
\hline & Bangladesh & July 2005-August 2007 \\
\hline & Belarus & October 1993-October 1995 \\
\hline & Burundi & November 1991-December 1993* \\
\hline & Congo-Brazzaville & January 1996-January 1998* \\
\hline & Guinea-Bissau & January 2002-January 2004 \\
\hline & Haiti & January 1999-January 2001 \\
\hline & Iran & August 2002-August 2004 \\
\hline & Ivory Coast & January 2001-January 2003* \\
\hline & Nepal & March 2001-April 2003* \\
\hline & Thailand & October 2004-October 2006* \\
\hline & Zambia & May 1995-May 1997 \\
\hline \multirow{30}{*}{ Group 2 (No Retreat) } & Country & Time Period \\
\hline & Benin & September 2001-September 2003 \\
\hline & Bulgaria & April 1995-April 1997 \\
\hline & Cameroon 1 & September 1990-September 1992 \\
\hline & Cameroon 2 & November 1995-April 1998 \\
\hline & Chad & October 2000-October 2002 \\
\hline & Comoros & October 2000-October 2002 \\
\hline & Djibouti & June 1996-June 1998 \\
\hline & East Timor & December 2005-December 2007 \\
\hline & El Salvador & October 1997-October 1999 \\
\hline & Equatorial Guinea & August 1994-August 1996 \\
\hline & Estonia & September 1993-September 1995 \\
\hline & Guatemala & May $1998-$ May 2000 \\
\hline & Guinea & June 1992-June 1994 \\
\hline & Greece & March 1995-March 1997 \\
\hline & Jordan & January 2002 - January 2004 \\
\hline & Laos & August 2000-August 2002 \\
\hline & Madagascar & May 1995-May 1997 \\
\hline & Mauritania 1 & May 2002-May 2004 \\
\hline & Mauritania 2 & July 1990-July 1992 \\
\hline & Moldova & June 1995-June 1997 \\
\hline & Mongolia & November 2003-November 2005 \\
\hline & Niger & August 1991-August 1993 \\
\hline & Papua New Guinea 1 & February 2001-February 2003 \\
\hline & Papua New Guinea 2 & December 2005-December 2007 \\
\hline & Poland & May 1994-May 1996 \\
\hline & Romania & May 1995-May 1997 \\
\hline & Solomon Islands & October 2004-October 2006 \\
\hline & Tanzania & April 1994-April 1996 \\
\hline & Tunisia & April 2003-April 2005 \\
\hline
\end{tabular}

*Civil war started, resumed, or intensified during this period 
Appendix 2: Full typology of elite interaction events.

Precipitating Events

Abbreviation

Evidence that the opposition will successfully contest for power.

OppContes

New policy departures by a civilian regime where the military is strong

and concerned.

NewPol

Popular pressure by riots or demonstrations combined with an

indecisive or inactive regime.

NoAction

Constitutional struggles in which groups clearly differ in their

interpretation, or their efforts to change, basic rules that define access

ConstStr

to power and how it is exercised.

Military actions against a guerrilla rebellion, peaceful protest, opposition

party or activists, where the actions are extreme and clearly violate

democratic and human rights norms.

\begin{tabular}{ll}
\hline Military threats or actions against the government. & MilThreat \\
\hline $\begin{array}{l}\text { A victory by a political party whose policy platform is viewed as } \\
\text { threatening to ruling elite interests. }\end{array}$ & RefVic \\
\hline $\begin{array}{l}\text { Coercive acts by the regime to undermine or hinder the opposition from } \\
\text { fairly contesting an election. }\end{array}$ & ContrlOpp \\
\hline $\begin{array}{l}\text { Political acts by the opposition to undermine elections or the ruling } \\
\text { regime. }\end{array}$ & OppActs \\
\hline $\begin{array}{l}\text { Acts by other nations that affect the regime or opposition in terms of } \\
\text { their resources or capabilities for political actions. }\end{array}$ & IntActs \\
\hline Guerrilla or terrorist acts by the opposition. & VioActs \\
\hline
\end{tabular}

\section{Cooperative Events}

Abbreviation

Bringing opposition political leaders into the cabinet or executive

position or leading roles in the legislature.

BringOpp

Agreement by the government or opposition to accept defeat in a free and fair election.

AccptDef

A free and fair election that produces a large majority in favor of one party.

BigWin

Popular support or acceptance for measures by the government to deal

with an unruly opposition.

PopSupp

Concession or agreement by government leaders to accept or act on

opposition demands.

ActOnOpp

Explicit negotiations between government and opposition leaders to resolve disputes.

ExplNeg

International intervention to promote free and fair elections. Interv

Willingness of a government leader to step down (whether because of term limits, retirement, or electoral defeat).

StepDown

The natural or accidental death of government or opposition leaders

who were especially fractious or polarizing.

LedDeath

International pressure on competing political leaders or parties for

reconciliation and fair play.

IntPres

Government lifts ban on some type of political activity.

LiftBan

Government, dominant party or leader publicly accepts a court ruling

that weakens their political position.

AccRulg 
Appendix 3: Flowchart of intra-elite maneuvering.

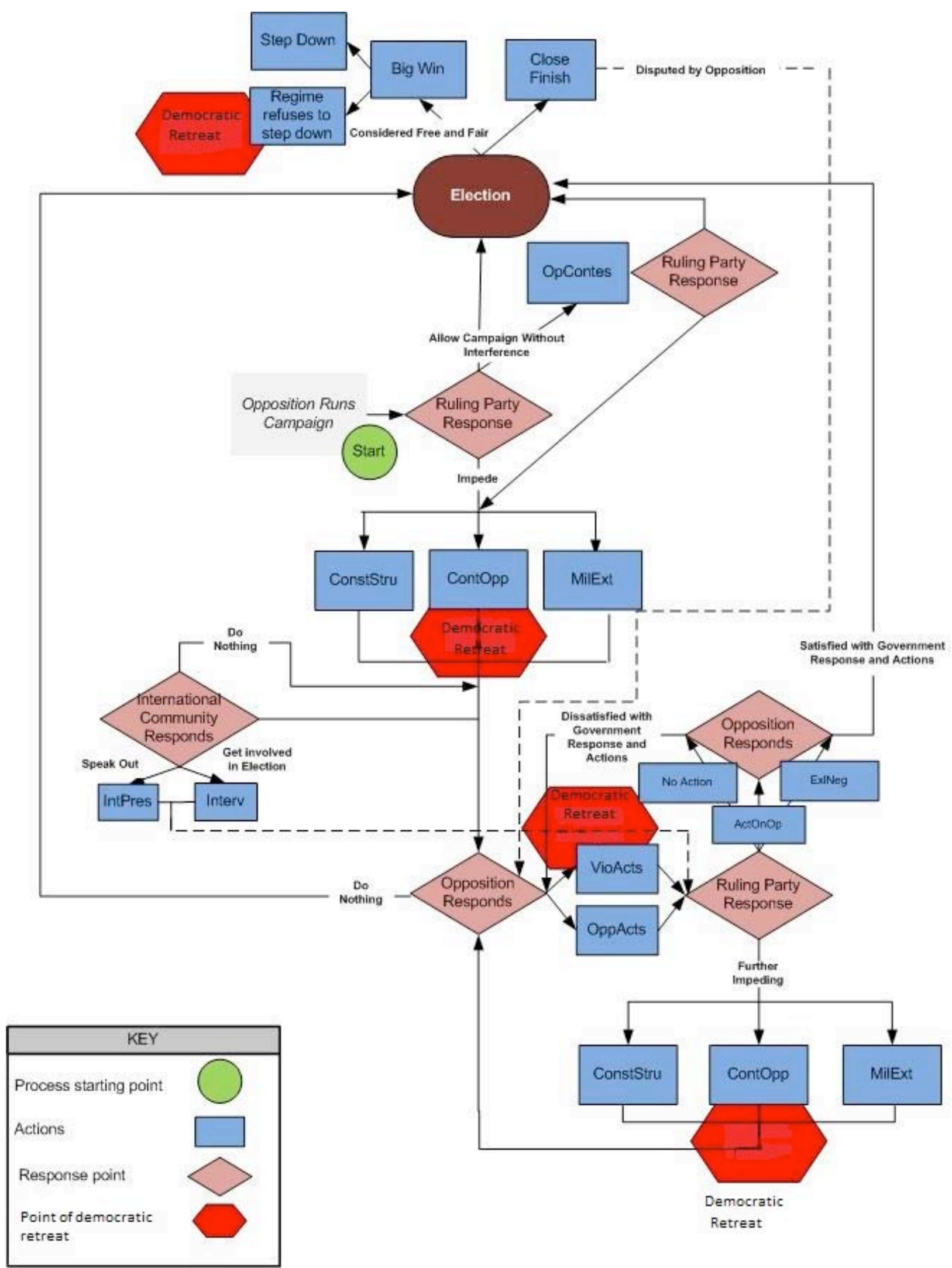




\title{
Towards a Genuine Economic and Monetary Union- Comments on a Roadmap
}

\author{
Ansgar Belke \\ Department for Macroeconomics, University Duisburg-Essen, Universitätsstraße 12, 45117 Essen, Germany; \\ E-Mail: ansgar.belke@uni-due.de; Tel.: +49 201183 2276; Fax: +49 2011834181
}

Submitted: 6 February 2013 | In revised form: 20 March 2013 | Accepted: 1 May 2013 |

Published: 17 May 2013

\begin{abstract}
The Van Rompuy Report and also additional proposals made by the European Commission outlined steps for a 'genuine Economic and Monetary Union'. This article explains, assesses and comments on the proposals made. Moreover, it outlines what could be recommendations in order to achieve a 'genuine Economic and Monetary Union'. For this purpose, details of the Interim Report are systematically evaluated. We also deal with different governance visions emerging from the ongoing euro area crisis and starts from different views of the 'North and the South' of the euro area on this issue. This contribution argues that there is an alternative option to the notion of cooperative fiscal federalism involving fiscal union, bailouts and debt mutualisation: competition-based fiscal federalism accompanied by a properly defined banking union. In order to be a successful one, any deal will have to come up with a successful recipe of how to (re-)create trust between European citizens and their elected governments.
\end{abstract}

Keywords: banking union; debt mutualisation; EU governance; Euro budget; Eurozone; genuine Economic and Monetary Union; North-South divide; shock absorber

\section{Introduction}

The June 2012 European Council invited the President of the European Council together with the Presidents of the Eurogroup, the ECB and the European Commission to develop "a specific and time-bound road map for the achievement of a genuine Economic and Monetary Union" [1]. The European Parliament launched an own-initiative procedure on this report [2]. On this basis, the European Commission delivered its ahead of mid-December EU Summit paper on 28 November 2012 [3].

The Interim Report was presented on 12 October 2012 [4] and the final report was published on 5 December 2012. The Interim Report, concentrating on the euro area Member States, lays down several proposals for the implementation of a real Economic and Monetary Union. This work programme is to be analysed in this paper and considers four main Building Blocks: 
1. Integrated financial framework (single European banking supervision, common deposit insurance and resolution framework);

2. Integrated budgetary framework (stronger economic governance, fiscal capacity and a safe and liquid financial asset for the euro area);

3. Integrated economic policy framework (reforms of the EU surveillance framework, promoting structural reforms through arrangements of a contractual nature, and strengthening macroprudential policy); and

\section{Ensuring democratic legitimacy and accountability of decision making.}

\subsection{Building Block 1-Integrated Financial Framework}

This Building Block essentially refers to the fragmentation of Eurozone financial markets, which has already been identified by ECB President Mario Draghi, on several occasions, as the most significant problem, due to its credit tightening effects. Hence, there is the necessity for an integrated financial framework which should consist (i) of a single supervisory authority, (ii) of a common resolution framework implemented by a common resolution authority, and (iii) of national deposit guarantee schemes erected on common standards. According to the Interim Report, all Building Blocks are logically intertwined. For instance, any method of sharing banking sector risks (Building Block 1) must rely on effective fiscal discipline (Building Block 2) if moral hazard of sovereigns is to be avoided.

Notably, the establishment of a single supervisory mechanism (SSM) has been labelled a priority goal. Moreover, the single supervisory mechanism should be hosted by the ECB, following a proposal by the EU Commission, and clearly separate the ECB's monetary policy from supervisory duties. It has to balance rights and obligations for all participating Member States. Finally, the SSM has to operate consistently with Single Market principles and is to be held accountable to the European public, i.e. the European Parliament. Since the deliberations of the Interim Report concentrate on the euro area Member States, it does not say anything about an extension to non-euro EU Member States, notably the UK.

Concerning resolution, the Interim Report heavily draws upon the EU Commission's Recovery and Resolution Directive. The resolution authority is intended to move from the national to the common level as soon as the SSM is set in place. Transitorily, banks have the possibility to be recapitalised directly by the ESM if they comply with 'appropriate conditionality'.

Finally, the Interim Report does not explicitly mention, but seems to suggest a common deposit insurance mechanism to ensure a level playing field. Again the Report is silent about the integration of non-euro EU members. At least it supports the view that even harmonising national guarantee schemes according to legislative proposal have a pre-emptive role in stabilising the financial system. As a basic principle, they should be funded by the financial sector itself to a sufficient extent.

\subsection{Building Block 2-Integrated Budgetary Framework}

The starting point for this section is the high degree of interdependence among Member States. For instance, the recent crisis has again dramatically shown that national budget policies can have euro area-wide (and beyond) spillovers. As a consequence, the Interim Report calls for complementing the current budget surveillance and coordination framework with a more ex ante focused scheme, for instance the 'Two-pack'. In the same vein, the euro area is to end up in a 'fully-fledged integrated budgetary framework'. The latter is hoped to "ensure sound budgetary policies at both the national and the European levels and, thus, sustainable growth and macroeconomic stability". Interestingly, the report sees EMU endowed with 'unique features', which necessitates a specific approach to the centralisation of budgetary instruments and fiscal insurance mechanisms ([4], p. 4). In passing, it introduces a clear macro policy assignment: whereas monetary policy is responsible for coping with symmetric shocks, fiscal policy is responsible for asymmetric shocks which are understood as country-specific but not region-specific.

In terms of a stronger economic governance, the ex ante coordination of Member States' annual budgets and their surveillance under financial distress have-according to the Interim Report-to be strengthened. In the short run, the main focus is on finalising and implementing the 'Two-pack' to strengthen fiscal governance in the euro area, starting from the 'Sixpack' and the Treaty on Stability, Coordination and Governance, which are already in force.

By gradually developing what will be decided at the December European Council no more closely specified than new fiscal capacity with new fiscal functions for the $E M U$, the authors intend to deliver an additional valve to relieve asymmetric shocks, i.e. shocks to specific Member States. As a first explanation, the Interim Report refers to "low levels of cross-country labour mobility and structural impediments to price flexibility (which) make economic adjustment mechanisms less effective than in other monetary unions" as a 'unique feature' of the EMU. A second rationale is to facilitate structural reforms which are beneficial for competitiveness and growth-surely a concession to the 'Northern', in particular the German, governments. More precisely: the report proposes funding the promotion of structural reforms through arrangements of contractual nature within the 'integrated economic policy framework' (i.e. Building Block 3). Put simply, even the possibility of the new fiscal capacity to borrow and, hence, a full-fledged treasury function is 
suggested-a clear concession to the 'South', but seemingly as no more than a vision for the future.

As a sub-block of Building Block 2, but again rather defensively, the Interim Report addresses a safe and liquid financial asset for the euro area in order to break the vicious circle among the fate of the banks and the fate of the Member States-again a concession to the 'South'. A redemption fund and eurobills (short-term maturities) are mentioned as measures for the medium term-but, for instance, the 50 page blueprint on future EMU released by the European Commission [3] acknowledges that both require a treaty change. Full eurobonds are for the long term. Collateral could be required for the redemption fund, but no details are given with respect to types of collateral (gold, etc.).

\subsection{Building Block 3-Integrated Economic Policy Framework}

Under this heading the Interim Report comes up with the need to revitalise the reforms of the EU surveillance framework, promoting structural reforms through arrangements of a contractual nature, and strengthening macro-prudential policy. While the first two serve to improve the global competitiveness of Europe and the internal competitiveness of euro area Member States, the latter enhances the ability to prevent asset and credit bubbles.

The newly implemented surveillance measures should be made more visible, authoritative and be endowed with more impact. At the same time, the single market should be completed. What is more, structural reforms should be promoted through arrangements of a contractual nature such as limited, temporary, flexible and targeted financial incentives for reform steps previously identified within subcomponent 1-the surveillance framework. Finally, the Interim Report proposes strengthening macroprudential policies-optimally through making macroprudential policy tools available to the single supervisor, the ECB, and granting the European Systemic Risk Board (ESRB) a larger role in this process.

\subsection{Building Block 4-Ensuring Democratic Legitimacy and accountability}

The fourth and last Building Block refers to the issues of democratic legitimacy and accountability of the proposed euro area/EU governance structures. The Interim Report also admits that it has to carefully weigh up the roles of the European Parliament versus the national parliaments. Its guiding principle is "democratic control and accountability should occur at the level at which the decisions are taken" ([4], p. 8). However, this does not exclude benefits from closer cooperation of the European Parliament with the national parliaments.

In the following, this paper assesses and comments the proposals made and outlines potential recommendations in order to achieve a 'genuine Economic and Monetary Union' also considering the 'four Building Blocks'. For this purpose, it distinguishes -where possible-between short-term, medium-term and long-term measures. In Section 2, details of the Interim Report are systematically evaluated with scrutiny. Section 3 concludes.

\section{Is Europe's Search for a Genuine Economic and Monetary Union Misguided?}

The main merit of the Interim Report is that it truly hits the core of the political debate on the future of the euro. The time has come to talk more frankly than before about questions such as whether a single currency really requires a significant pooling of national policies and which players in the euro area are really willing to follow this logic $[5,6]$. A first taste of these kinds of discussions was conveyed by Wolgang Schäuble's now-famous call for an EU Monetary Affairs Commissioner equipped with rights to punch-through on national budgetary policies, comparable to his colleague from DG Competition (see [7]).

\subsection{Member States and Participating Institutions Try to Impose Their Own Interests}

This note does not necessarily intend to go as far as, for instance, Mussler [8], who argues that such a fundamental debate in the euro area does not seem to be really desired, although the leaders in June 2012 asked a group of four, namely the Presidents of the European Council, the EU Commission, the European Central Bank and the Eurogroup to outline the way to a 'genuine' monetary union [9]. But the Interim Report, as outlined above, and also the current longenduring controversial discussion about the details of the banking union (Building Block 1) make it very clear that a true political consensus on the direction is still lacking. Along a clear 'North-South' divide visible in the Interim Report, the respective governments are still trying to enforce predominantly their own interests which are well-known from the debates about the 'correct' way to manage the euro crisis. Hence, the Report adopts the shape of a two-handed approach or, as some might express it more bluntly, as a not too coherent convenience store.

Moreover, it seems as if all four presidents involved in the Interim Report have also been successful, to a certain extent, in enforcing their own and independent interests in settling additional political competencies in their institutions. In a wide array of areas, market governance is in the Interim Report, substituted by a governance by institutions which are shifted upwards to the EU-level and are well-known to have their own life and vested interests [9]. What is more, interest groups, such as banks and real estate brokers, are then able to delocalise from the local 
voters, who are their main competitors in impacting government policies [10]. This substitution might be seen either as a reflex consistent with the genesis of the financial crisis or as a consequence of the attitude of politicians to shift additional competencies at the EU level [11]. But, from this political constellation, a sensible governance solution can hardly emerge. The reason is that the proposed governance structure and its four Building Blocks (which are not even compatible with each other in all cases) are not incentivecompatible for all actors from a politico-economic point of view.

\subsection{The Congenital Defects of the EMU Cannot Simply Be Defined Away Politically}

What is more, the congenital defects of the monetary union cannot simply be defined away politically by a resolution. The euro area is still far from forming an optimal currency area, as has also been suggested by the Interim Report ([4], pp. 4-5). It explicitly addresses the basic fact that the textbook-style adjustment mechanisms to external demand shocks work much worse than in other currency areas. Crossborder labour mobility is low, both national product markets and factor markets are not sufficiently flexible: "Low levels of cross-country labour mobility and structural impediments to price flexibility make economic adjustment mechanisms less effective than in other monetary unions" ([4], p. 5). But this precise pattern is given as the 'EMU's unique feature' in the Interim Report which justifies a 'specific approach', i.e. implementing a common budget as an asymmetric shock absorber ([4], p. 4).

Does this not mean that the report considers the rigidities as given, and thus gives in much too early by still sticking to fiscal transfers to distressed countries? This would be a dangerous position, since, at the same time, parallel adjustment programmes are working quite successfully in the Southern Member States, and especially dangerous in the programme countries. Fiscal accommodation might even feedback negatively to reform activity [12].

\subsection{Independent National Fiscal Policies Are Generally Preferable to a Common Budget Because They Allow Risk Diversification}

The Interim Report leaves the use of the 'Euro budget' as open as other obvious questions, for instance, the ratio of the 'Euro budget' in relation to the general EU budget, from which it would be financed and the 'Euro budget's scope [8].

"Asymmetric shock absorption at the central level would represent a form of limited fiscal solidarity exercised over economic cycles, improving the economic resilience of the EMU" ([4], p. 5). This is not a specific conclusion of the Interim Report. Instead, it is widely assumed that a common currency makes it desirable also to have a common fiscal policy. However, if fiscal policy is a source of shocks, independent national fiscal policies are said to be generally preferable because they allow risk diversification. "The variance of a sum of shocks is the lower the lower the covariance among the individual components". Otherwise, we have a leadership problem: one weak or bad leader in the euro area can suffice to hole the euro project below the waterline [13]. This is especially so in our context because fiscal transfers to (a lot of) financially distressed countries would be highly correlated, which would then lead to a higher variance of GDP in the euro area.

Also, a reference to the US case may help. Gros [14] finds that the US federal budget comes up with much less insurance against state specific shocks than generally presumed, as the US Banking Union acts as a strong shock absorber. From this angle, the longterm stability of the EMU depends significantly more on the completion of plans for a European banking union than on the instalment of a 'fiscal capacity' for the euro area. In addition, the US budget is not an instructive example in the context of the Eurozone budget since it redistributes significantly between US regions at an amount of 30 to 40 percent of income differences, but does not compensate for more than 10 to 15 percent of GDP shocks to specific federal states [14]. Finally, using the US unemployment insurance system as a blueprint for a European one using the European budget would be misleading since the US system is mainly active in nationwide business cycle troughs, and unemployment benefits are simply not large enough ( 2 to 3 percent of GDP) to cope with GDP shocks of 10 percent and more, as seen during the euro crisis [14]. Cases such as Spain, with (structural) unemployment rates approaching 30 percent, reveal that a European unemployment insurance scheme would clearly risk perpetuating long-term unemployment in such member countries ([5], hysteresis).

Hence, the more fundamental question to ask is: how useful is the outlined transfer union? And how to persuade the 'North' of the sense of a severe sovereignty loss, which is necessary to ensure an ever-inflating 'euro rescue' and, more importantly, what necessary financial expenses are involved [8].

\subsection{The 'South' Sees a 'Euro Budget' as an Instrument of Redistribution}

Theoretically, there are two possibilities beyond the unrealistic readmission of floating exchange rates to improve the euro area's capacity of adjustment to external shocks. The first amounts to an increase of labour mobility or economic reforms to strengthen competitiveness. The second option is well-known to be politically more convenient and attractive to euro area politicians: the shocks can be mitigated by financial transfers to hard-hit countries. The four 
presidents of the mooted 'fiscal capacity' for the euro area, i.e. the 'Euro budget', could be instrumental in both options (Building Block 2). The German government wants to see it mainly used as an incentive tool to implement painful reforms in individual countries. France, however, interprets it as a general European instrument of redistribution beyond the permanent crisis fund ESM.

Given this background let us now again ask how useful the outlined transfer union is. The German government, for example, maintains that these transfers are not necessary because the economic reforms in several euro countries are well advanced. However, this is at best a half truth. That the current reduction of the economic divergence means that they have melted away permanently may well be doubted [15]. And the new instruments with which the EU is to bring national economic policies back on the right path show little effect. This is not only due to the lack of enforcement of sanctions. This is also because a fine-tuning of various parameters of economic policy by pan-European actors and institutions is simply not possible [8].

Hence, we must fear that the euro area is further from a 'genuine' monetary union than ever before, and that is quite logical. The question now, is rather, how many compromises will the currency union be able to stand in its current form?

\subsection{On the Necessity of a European Supervisory Authority}

In Building Block 1 and also throughout the text, the Interim Report argues in favour of a supra-national European supervisory authority. The usual argument is that national supervision of banks leads to 'regulatory capture' (which is not necessarily weaker at the EU level, [10]), and thus to a vicious circle. However, this could also be prevented by limiting the share of domestic government debt in the domestic banks' portfolios (i.e. the Weidmann-proposal) (see [16]). Needless to say, the financial distress of most southern euro area governments cannot be traced back to any necessity to support their banks. What is more, a large extent of the knowledge relevant for supervisors is of local nature, and the internal effects of the financial crisis were significantly more devastating than the external impacts. Thus, national supervisors had a larger interest in adequate supervision than foreign authorities.

Finally, the Interim Report favours a 'level playing field' ([4], pp. 2-3). However, generally speaking, this is not at all optimal from an economic perspective. There are important reasons not to enforce equal conditions on these markets: national authorities are sometimes better informed, national banking systems have different profiles and needs. Finally, yardstick competition in regulation is well-known to foster innovation and contributes to diversification of regulat- ory risk, i.e. risks of regulatory error [17].

The Interim Report diametrically contradicts the recommendations of the De Larosière Report on Financial Supervision in the European Union: 'While the Group supports an extended role for the ECB in macro-prudential oversight, it does not support any role for the ECB for micro-prudential supervision', a report which has been requested by the 'EU' itself (see [18]).

\subsection{The Interim Report: Further Points of Discussion}

The Interim Report claims that monetary policy is overall responsible for common shocks ([4], p. 5). This might be true in the long run, but in the meantime we are stuck in a clear re-nationalisation of monetary policies in the euro area (see the debate organised by The Economist on the pros and cons of debt mutualisation as an element of future Eurozone governance among Belke, and de Grauwe [19]). The exit from these unconventional policies is probably more demanding than envisaged by the report, as argued earlier. What is more, the Interim Report is contradictory in itself by stating that '(in) the EMU, the response to a symmetric shock affecting all countries simultaneously should primarily be provided by monetary policy' ([4], p. 5) but at the same time it is well-known that the credit crunch has been very selective, i.e. 'South' bound and precisely for this reason, monetary policy has become re-nationalised. This immediately implies that the current monetary policy assignment, having monetary policy supporting structurally distressed countries for years [20], stands in sharp contrast to the recommendations of the Interim Report itself.

"One of the functions of such a new fiscal capacity could be to facilitate adjustments to country-specific shocks by providing for some degree of absorption at the central level" ([4], p. 5). This suggests that country-specific multipliers are of a reasonable size. The European Commission shows in its recent Autumn Forecast that the IMF World Economic Outlook statement that the fiscal multiplier is much higher than assumed up to now is not tenable as soon as one implements further control variables in the estimated equation $[21,22]$. It is well-known that the ECB fiscal experts also come up with very different estimation results from the IMF. Unfortunately, a policy of austerity is accompanied by hardship, but it is, by definition, not possible to grow out of a current account deficit. And, especially with respect to Spain, the Commission has already demonstrated huge flexibility in its magnitude and speed of fiscal adjustment. This much is clear: Without the EU-IMF programme (and the overly generous support by the ECB's monetary policy) fiscal adjustment would have had to happen much more quickly-due to the balance of payment restriction which is currently felt, for instance, by France. 
'Overall, the creation of an integrated financial framework (...) cannot be envisaged separately from steps towards more integrated fiscal and economic frameworks' ([4], p. 3). It is probably not correct to state that an integrated financial framework is not possible without more integrated fiscal frameworks. Here, the answer is to implement a kind of fiscal federalism as a form of EU governance structure [5].

'(A) fully-fledged integrated budgetary framework (...) will ensure sound budgetary policies at the national and European levels and thereby contribute to sustainable growth and macroeconomic stability' ([4], p. 4). Why and to what extent should a fullyfledged integrated budgetary framework necessarily ensure more sound budgetary policies at the national and the EU level, leading to growth, than it does in the status quo? A related point is the following: 'another important function of such a fiscal capacity would be to facilitate structural reforms' $([4]$, p. 5). Of course, the answer of the Interim Report is: positive incentives. But who guarantees that the rules of public choice and political economy do not apply in this setting? Why are the players on the EU-level which run all the new institutions proposed by the report more benevolent than the national ones, etc. [9]?

"(I)n the context of country-specific economic shocks, the response falls primarily on national budgets" ([4], p. 5). But the Interim Report does not take into account that asymmetric shocks emerging in a currency union should not and cannot be automatically absorbed by national budgets. Shocks are often regional but not necessarily national in nature. Exactly for this reason we advised against national stability funds when asked by the European Parliament in $1998[22,23]$. Hence, regionally flexible goods and factor markets are necessary ingredients.

'A well-functioning shock absorption function would require a further degree of convergence between economic structures and policies of the Member States' ([4], p. 5). Is this not an internal contradiction since the Interim Report argues that a new central shock absorber is needed because reforms are lacking and the degree of reform significantly differs among Member Countries? Expressed differently, I do not see any envisaged stop of the new centralised shock-absorber as soon as the necessary degree of reforms is reached by using this new fiscal capacity.

'(T)he pooling of some short-term sovereign funding instruments (e.g. treasury bills) on a limited and conditional basis could be examined further' ([4], p. 6). It can be argued in different contexts such as Eurobonds and/or OMTs that confidence in the conditionality of even temporary 'pooling' might be misguided $[20,24]$. Moreover, it potentially contradicts principles of democracy because it necessitates adhering to rules with which national parliaments are not necessarily compliant (Building Block 4).

"(A)n integrated economic policy framework contributes to avoiding the large and rapid buildup of im- balances" ([4], pp. 6-7). The ability to handle asset and credit bubbles through the proposed measures is not guaranteed with an eye on the commitment to a very accommodative monetary policy; this drawback is not necessarily compensated by more prudential policy tools (Building Block 3).

This is only a very selective choice of questions and caveats. There are certainly more of them, for instance, whether 'completing the single market' in the Interim Report means tax coordination instead of tax competition in view of the alleged Irish 'tax dumping' activities; or whether the integrated economic policy framework and the implied coordination mechanisms are explicitly said to be open to Member States that have not introduced the euro right now ([4], p. 7). Should this also be valid with respect to Building Block 1 , i.e., the components of a banking union? Even so, the UK and some non-euro Scandinavian countries had some incentive to financially support Ireland during the crisis.

Starting from the working assumption of the Interim Report ([4], p. 8) that "(t)he governance framework would also benefit from an active and open social dialogue", it appears overall worthwhile to have a detailed look at differences in the visions of EU governance between the 'North' and the 'South' of Member States [19].

\section{Different Governance Visions Emerging from the Ongoing Eurozone Crisis-The "North" and the "South"}

\subsection{Introductory Remarks}

The European summit that ended on 29 June 2012, declared that it was "imperative to break the vicious circle between banks and sovereigns". Markets revived on the hope that the leaders were finally ready to act to deal with the threat to the euro, and then soon lost heart amid the cacophony of rival interpretations about what had been agreed. Still, the leaders had identified the right issue: weak banks and weak sovereigns are like two bad swimmers that are pulling each other under water [25].

But which one should be saved first? Proponents of the "Southern view" like, for instance, Paul De Grauwe [19] tell us to start with the sovereigns, by throwing them the lifejacket of joint-issued debt. In effect, richer countries would guarantee at least part of the debt of weaker ones (Building Block 2).

Representatives of the "Northern", and especially the "German view", reckon instead that it is better to start by saving the banks (Building Block 1). This would be done through stronger central supervision and the mutualisation of some liabilities in the banking sector, for instance through a joint fund to wind up failing banks and provide a Europe-wide guarantee of bank deposits. In effect, depositors in solid banks would be guaranteeing the savings of those in more fragile ones. 
Following the identification of different and opposing views contained in the Interim Report above, this section finds it adequate to build upon a highly stylised, but widespread, definition of the "Southern" and the "Northern" view. The former usually comprises countries like Greece, Italy, Portugal and Spain and, quite frequently, also France. The latter is often used synonymously with the "German" view and also includes countries like Austria, Finland and the Netherlands and, to a lesser extent, also France. Since the exact characteristics of both views may still remain unclear, let us outline them in the remainder of this section more deeply.

Both sides-the "North" and the "South" agree on many things, such as the current threat to the survival of the euro. They both recognise the danger that debt mutualisation could bring moral hazard and higher costs for creditor countries. For representatives of the "Northern view" there is no getting around these problems. For the "South", though, these risks can be removed, or at least mitigated, through careful design of the system as expressed by the Interim Report. For instance, the Eurozone could impose conditions on countries seeking the benefit of jointly issued debt (Building Block 2).

The "South" sees the main threat to the Eurozone as coming from the fear and panic that can suddenly raise borrowing costs and push countries into insolvency. The "North", on the contrary, reckons the principal menace stems from removing this market pressure too quickly, which lets it dampen the need to reform.

Both speak of the political backlash that the crisis creates. For the "South" it is excessive austerity in debtor nations that will be resisted; for the "North" it is excessive liabilities in creditor states that can cause resentment.

In some ways, though, they are not so far apart. The "North" concedes that it is necessary to have some mutualisation of debt, if only to recapitalise banks [5]. The "South" accepts that debt mutualisation must be limited to avoid moral hazard [19].

\subsection{Opening-Contrasting the "Southern" and the "Northern" Views}

In the following, the basic ingredients of the "Southern" and the "Northern" views are contrasted with each other.

\subsubsection{The "Southern" View: Some Basics}

The main argument of the "South" runs as follows. Since the 1970s, economists have warned that a budgetary union would be a necessity for a sustainable monetary union. But the founders of the Eurozone had no ears for this warning. It is now patently clear that they were mistaken and that the governments of the euro area member countries face the following hard choice today: either they fix this design failure and move to a budgetary union; or they do not fix it, which means that the euro will have to be abandoned. Although analysts such as Paul de Grauwe were sceptics about the desirability of a monetary union during the 1990s (contrary to [26]), the same author now takes the view that we cannot properly manage a deconstruction of the Eurozone [19]. A disintegration of the Eurozone would produce huge economic, social and political upheavals in Europe. If the euro area governments want to avoid these, they have to look for strategies that move us closer towards a budgetary union (Building Block 2).

A budgetary union, like that in the US, appears to be so far off that there is no reasonable prospect of achieving this in the Eurozone "during our lifetimes". Does that imply that the idea of establishing a budgetary union and thus a 'genuine Economic and Monetary Union' is a pure chimera? De Grauwe [19] argues that this drastic assessment is not at all valid and that there is a strategy of taking small steps that can guide us in the right direction. But before this strategy can be outlined and compared to the Interim Report, it is-according to the "Southern" viewimportant to understand one of the main design failures of the Eurozone. This will deliver some information about what exactly has to be fixed.

The "Southern" argument starts from the basic idea that Eurozone governments issue debt in euros which is a currency they cannot control. As a result, and in contrast to "stand-alone" countries like Britain, they endow bondholders with a guarantee that the cash to pay them out at maturity will always be available [27].

The fact that governments of the Eurozone are not able to deliver such a guarantee to bondholders makes them vulnerable to upsurges of distrust and fear in the bond markets. These can trigger liquidity crises that, in a self-fulfilling way, can drive countries towards default, forcing them to apply austerity programmes that lead to deep recessions and ultimately also to banking crises [19]. According to the "Southern" view, this is not to say that countries that have overspent in the past do not have to apply austerity. They will have to. It is rather that financial markets, when they are driven by panic, force austerity on these countries with an intensity that can trigger major social and political backlashes that policymakers may not be able to control. The effects are there to see in a number of Southern European countries [19].

Their previous diagnosis of a design failure of the Eurozone leads proponents of the "Southern view" to the idea that some form of pooling of government debt is necessary to overcome this failure (Building Block 2). By pooling government debt, the weakest in the union are shielded from the destructive upsurges of fear and panic that regularly arise in the financial markets of a monetary union and that can hit any 
country. "Those that are strong today may become weak tomorrow, and vice versa" [19].

Representatives of the "South" agree that, of course, not just any type of pooling of national debts is acceptable. They acknowledge that the major concern of the strong countries that are asked to join in such an arrangement is moral hazard-that is, the risk that those that profit from the creditworthiness of the strong countries exploit this and lessen their efforts to reduce debts and deficits. This moral hazard risk is the main obstacle to pooling debt in the Eurozone. The Interim Report is silent in this respect; it does not refer to any form of pledges such as gold. The second obstacle is that, inevitably, the strongest countries will pay a higher interest rate on their debts as they become jointly liable for the debts of governments with lower creditworthiness. Thus, debt pooling must be designed in such a way as to overcome these obstacles.

Moderate proponents of the "Southern" view, apparently in agreement with the Merkel government, agree that there are three principles that should be followed in designing the right type of debt pooling [19]. First, it should be partia/-that is, a significant part of the debt must remain the responsibility of the national governments so as to give them a continuing incentive to reduce debts and deficits. Several proposals have been made to achieve this (among them [28] and [29]). Second, an internal transfer mechanism between the members of the pool must ensure that the less creditworthy countries compensate (at least partially) the more creditworthy ones [19]. Third, a tight control mechanism on the progress of national governments in achieving sustainable debt levels must be an essential part of debt pooling. The Padoa-Schioppa group has recently proposed a gradual loss of control over their national budgetary process for the breakers of budgetary rules [30].

Proponents of the "Southern" view acknowledge that the Eurozone is in the midst of an existential crisis that is slowly but inexorably destroying its foundations. They immediately conclude that the only way to stop this is to convince the financial markets that the Eurozone is here to stay [19]. Their main argument is that debt pooling which satisfies the principles outlined above would give a signal to the markets that the members of the Eurozone are serious in their intention to stick together. Without this signal the markets will-according to their argumentnot calm down and an end to the euro will be inevitable [19]. In the words of Angela Merkel: these policies are without alternative.

Materially, the "Northern" view described below represents the accumulation of a multitude of reactions of the "North" to these much more activist "Southern" proposals of several kinds of debt mutualisation, which have frequently been pushed forward since the start of the euro crisis.

\subsubsection{The "Northern" View: Important Facets}

One of the fundamental principles of the "Northern" view is that the mutualisation of the Eurozone's debt to bring about the convergence of interest rates as proposed within Building Block 2 of the Interim Report will not, in the long run, tackle the roots of the problems. Instead it has the potential to sow the seeds of an even larger crisis in the future [16,31]. They allude to what happened in the early years of the euro when interest rates largely converged. Paradoxically, perhaps, this paved the way for a greater divergence of national fiscal policies. A reckless lack of discipline in countries such as Greece and Portugalbe they more (Greece) or less (Portugal) insolventwas matched by the build-up of asset bubbles in other member countries such as Spain and Ireland, deemed merely illiquid. Structural reforms were delayed, while wages outstripped productivity growth. The representatives of the "Northern" view stress that the consequence was a huge loss of competitiveness in the periphery, which will by definition not be resolved by the mutualisation of debt as proposed in Building Block 2 of the interim report [5].

Debt mutualisation can take different forms. One is to mutualise new sovereign debt through Eurobonds ([28], more than 7 variants). Another is to merge part of the old debt, as advocated by the German Council of Economic Advisors [29] with its proposal for a partly gold-backed European Redemption Fund. A third means is to activate the Eurozone's "firewall" by using the rescue funds (either the temporary European Financial Stability Facility or the permanent European Stability Mechanism) to buy sovereign bonds on the secondary (or even primary) market, or to inject capital directly into distressed banks. Indeed, the ECB is already engaged in a hidden form of mutualisation-of risk if not (yet) of actual debtthrough its programmes of sovereign bond purchases (the Securities Market Programme, SMP, and the announced conditional Outright Monetary Transactions, OMTs) and its long-term refinancing operations for banks.

The view of the "North" is that almost all of these are bound to fail either for economic or political reasons, or both. The governments of even financially strong countries cannot agree to open-ended commitments that could endanger their own financial stability or, given that they are the main guarantors, that of the bailout funds. And the danger of moral hazard is ever-present [5].

Proponents of the "Northern" view, point to the fact that any form of mutualisation involves an element of subsidy (the Interim Report speaks of an element of limited solidarity), which severely weakens fiscal discipline: the interest rate premium on bonds of fiscally weaker countries declines and the premium for stronger countries increases. Fiscally solid countries are punished and less solid ones, in turn, are 
rewarded for their lack of fiscal discipline and excess private and public consumption.

If yields are too low, there is no incentive for private investors to buy sovereign bonds. The countries risk becoming decoupled from the capital markets permanently, and the debt problems become increasingly structural.

This is true also for the ECB's bond-buying announcements and activities. The credit risk is thus simply rolled over from the bonds of the weaker countries to those of the stronger ones (depending on the buyback price), and the ECB is made responsible for its liability. Over time, the ECB's measures might even be inflationary. Having the rescue funds to buy bonds is little different, except that they lack the landing capacity to be credible. If they are given a banking license, as demanded by the "South" (for instance, by French President Hollande), it would be no different from having the ECB buy bonds directly.

What about the European Redemption Fund (ERP) from the "Northern" perspective? This type of fund could be of particular help to Italy, which could unload half of its debt. But its partners could not force Italy to tax its citizens to ensure it pays back the dormant debt. And with the assumption of debt, the credit rating of Germany might drop due to the increase of the German interest burden. The pressure on Italy and Spain to consolidate their budgets sustainably would be reduced. The problems of Greece, Ireland and Portugal would not be resolved, since these countries are unlikely to qualify for the ERP.

On top of moral hazard, there are the political obstacles, which would be most acute in the case of Eurobonds-the "genuine euro area safe and liquid asset" proposed by the Interim Report on p. 6. For instance, Germany demands political union before Eurobonds can be considered. But this is sometimes said to put the cart before the horse: a political union would be created simply to justify Eurobonds [32]. Advocates from the Merkel government like Finance Minister Wolfgang Schäuble say that treaty changes and high-level political agreements would be sufficient to ensure that euro area member countries comply with all decisions taken at the euro area level (see again his recent "Waehrungskommissar" proposal). But the experience with Greece's adjustment casts severe doubt on such optimism. (Although recently, after Angela Merkel came back from a visit to China, surprisingly, some optimism towards the Greek case re-emerged in German politics as reflected in concerted media action in early autumn 2012).

Even a quick glance at the World Bank's databank of "governance indicators" shows that differences between Eurozone members, on everything from respect for the rule of law to administrative capacity, are so great that political union is unlikely to work, at least in the next couple of years. It follows from the perspective of the "North" that the case for Eurobonds is extremely weak.
According to the "Northern" or "German" view, the introduction of Eurobonds would have to, in principle, be backed by tight oversight of national fiscal and economic policies. This is correctly reflected in the Interim Report under the heading "Integrated economic policy framework", i.e. Building Block 3. But this view neglects that there is no true enforcement as long as the Eurozone members remain sovereign. The Interim Report argues accordingly that in this case the pivotal role of national parliaments has to be maintained ([4], p. 8, President of the European Council).

Intervening directly in the fiscal sovereignty of member states would require a functioning panEuropean democratic legitimacy, but we are far from that (Building Block 4). Voters in Southern countries can at any time reject the strong conditionality demanded by Brussels, while those of Northern countries can refuse to keep paying for the south. And either can choose to exit the Eurozone [32].

The emphasis on pushing through a fiscal union as a precondition for debt mutualisation means the debate, at least in Germany, has become a question of "all or nothing": either deeper political union (i.e. Building Block 2) or deep chaos [5]. This unnecessarily narrows the strategic options for the players and causes the permanent "North-South" divide described in this section (which is also mirrored in the Interim Report), which is severely hampering the realization of a "genuine" monetary and economic union.

But this paper argues that there is in fact an alternative option to the notion of cooperative fiscal federalism involving bailouts and debt mutualisation: competition-based fiscal federalism, of the sort successfully operating in the US, Canada and Switzerland, among others. These countries have largely avoided serious and sustained public debt in their component states. The sub-federal entities faced with insolvency have a great incentive to take early corrective actionwithout having to force the member-states into a corset of centralised fiscal policy coordination. This view seems to be a good compromise between the "Southern" and the "Northern" view.

To achieve this sort of federalism, it is necessary to separate the fate of the banks from that of the sovereigns. What is needed is not a fiscal union in first instance, but a banking union (Building Block 1). It should be based on four elements: a reformed banking regulation with significantly higher equity capital standards; a European banking oversight with farreaching powers to intervene; a banking resolution fund; and a European deposit insurance scheme. This has also been recognized and acknowledged by the Merkel Government.

A banking union-a less comprehensive, more clearly delineated and rather technical task-should be far better accepted in the "North" than the Europeanisation of fiscal policy as a whole. This is precisely because it touches upon only a small fraction of the 
fiscal policy areas which have to be subordinated to central control in a fiscal union.

Obviously, a central resolution authority has to be endowed with the resources to wind up large crossborder banks. Where does the money for this come from? In the long run, the existence of a resolution authority goes along with a deposit insurance scheme for cross-border banks. This should be-according to the "German" view-funded partly by the banking industry. But there should also be a backstop by the euro area governments provided through the EFSF or the ESM in order to cope with situations of systemic bank failure [33].

As a temporary transition measure, however, limited debt mutualisation may then be necessary-but only to recapitalise banks that cannot be sustained by their sovereigns. However, the amounts required are much smaller than for, say Eurobonds [33].

With the banking system and the debt crisis thus disentangled, banking-sector losses will no longer threaten to destroy the solvency of solid sovereigns such as Ireland and Spain. Eurobonds will then not be needed, and neither will the bailout of sovereigns. The debt of over-indebted states could be restructured, which means that the capital market could exert stronger discipline on borrowers [5].

\subsubsection{Summary}

There are at least two questions left which have not yet been covered in this paper and will be answered in the following sections. If the banking sector really is to be stabilised, a solution will surely have to deal with the devalued sovereign debt that some are holding. Would the banks not be better off holding at least some Eurobonds instead of, say, Greek or Spanish bonds? That said, "Southern" economists who advocate Eurobonds need to find a way of making them politically acceptable. And how much political union is feasible, or even desirable, just for the sake of a single currency that many never loved? (and also, where does the burden end up?).

\subsection{Rebuttal-Banking Union and Other Issues}

\subsubsection{The "Southern" View: Fiscal Debt Mutualisation to Protect Banks from Sovereign Failures}

It is quite surprising to find the German government on the "against the debt mutualisation" side in this debate. In fact, for instance, de Grauwe [19] argues that a couple of German politicians develop an eloquent plea for mutualising the debt in the context of a banking union [5]. As proponents of the "Southern" view recognise, the banking union that the "North" defends (and that the "South" also defends) requires "a backstop provided by the euro-zone governments". This is nothing but an implicit joint liability of the Eurozone governments to commit future taxpayers' money to a systemic banking crisis.

A second surprise for "Southern" governments is that Germany is not be willing to apply all the objections it has levied against the issue of Eurobonds to his proposal for an implicit Eurobond issue to defend the banks.

The "Southern" policymakers emphasise that promising future support to banks (Building Block 1) surely creates similar moral hazard risks as promising future support to sovereigns. There is no reason to assume that the latter are more serious than the former. According to their view, they find it strange that proponents of the "Northern" view do not apply his stern moral hazard analysis to banks in the same way as they do to the sovereigns. They seem to believe that bankers are more trustworthy than sovereigns [19].

"Southern" euro area governments acknowledge that there is a serious problem of democratic legitimacy in any scheme that ties the hands of future European taxpayers (Building Block 4). But they claim that the same problem arises if such taxpayers are called upon to save banks or sovereigns. In this vein, de Grauwe [19] represents the "Southern" view and argues that the "North" tries to extricate itself from this difficult problem by stating that the bank-related debt mutualisation it proposes will have only small consequences for future taxpayers [5]. What is more, the total bank debt in the Eurozone is three times the government debt. Potential future liabilities are certainly not small in his scheme, de Grauwe argues.

Finally, there is the "putting the cart before the horse" argument often heard in Germany: that we have to wait for a political union before we can start issuing Eurobonds. But why does that argument not count when, in the absence of a political union, Germany, for instance, proposes setting up a banking union in which one of the first steps is installing a banking oversight mechanism? A banking union is not just a technical matter, as the "North" often states (see Section 3.2.2). The "South" claims that it requires the same political infrastructure to enforce decisions taken at the European level and to give taxing powers to the European institutions that will be called upon to sustain the banking sector [19].

Proponents of the "Southern" view permanently emphasise that they do not want to be misunderstood on this issue. They concede that the problems that their "Northern" counterparts evoke are real ones [19]. However, their criticism is that the "North" emphasises these problems when discussing one form of debt mutualisation-the issue of Eurobonds-and ignores them when proposing its own form of debt mutualisation [19]. It might also be worth mentioning the German opposition to a third form of mutualisation, namely deposit insurance.

Moreover, the "South" argues that "problems are there to be solved". The moral hazard problem is acknowledged to be a difficult one, but the "South" claims that its impact can be minimised. In Section 
3.2.1, some principles have already been formulated to reduce this moral hazard risk. One was that the mutualisation should be partial; the other was that it should be linked to transfers of sovereignty. These are the conditions the "North" seems to stress while despairing that they can be met today [19].

The "Southern" Eurozone governments call it a fundamental problem that-in compliance with the German view-the community of euro area member states must wait for a political union before it can think of mutualising the debt [19]. But how do we start a political union? The "South" argues that "just waiting will not make it happen". Hence, there is only one other approach from the "Southern" perspective: taking small steps towards political union [19]. At some point the content of political union should be explained-as is done in the Interim Report. The interesting point from the perspective taken in this paper is that it could be seen as the fourth dimension of the October 2012 report by the 'four presidents' i.e. the legitimacy and accountability dimension (Building Block 4).

The "South" concedes that "North" and "South" can disagree on what these steps should be. But the "North" tells it that the first and only step should be a limited mutualisation of the debt so as to sustain a banking union. The "South" is in favour of the "North's" banking union (Building Block 1). But it disagrees when the "North" claims that this is all that is needed and that the capital markets will take care of the rest by "exerting stronger discipline on borrowers" [31] -the efficient market theory is a deus ex machina to save the euro.

Once we take the first step, we will be confronted with the need to take other steps, the "South" further argues. According to the "Southern" view, the banking union protects the sovereigns from bank failures, which is a good thing. But it does not protect the banks from sovereign failures. These will continue to occur in the Eurozone with or without efficient markets [19]. Thus by hitting the banks, a sovereign debt crisis will force other Eurozone governments to support the banks, and thus the sovereigns. Then, the "South" argues, we will have come full circle. In order to support the banks, sovereigns will be forced to support each other. One step, i.e. Building Block 1, necessarily leads to a second step, i.e., Building Block 2. The "South" is iteratively proposing that we may as well take that second step now (see most recently French President Hollande at the EU Summit in Brussels on 18 October 2012).

3.3.2. The "Northern" View: No Debt Mutualisation as Long as "South-North" Divide Is Structural

As pointed out in Section 3.2.1, the "Southern" view regrets that Eurozone countries do not have the control over the European Central Bank which countries such as Britain and America have over their central banks. But according to the "Northern" view, that is not a flaw in the system. Instead, it was designed that way in order that governments should not be able to inflate their way out of trouble. In Britain and America there is-according to the "Northern" view a tango between the central bank (which cannot become illiquid because of the possibility of inflating) and with the government (which cannot become insolvent, given the possibility of imposing and increasing taxes). De Grauwe [19] implicitly unveils the "Southern" view of the role monetary policy should play in accompanying debt pooling when he says that the main task of a central bank is to "give a guarantee to bondholders that cash is always available to pay them out..." According to the proponents of the "Northern" view, he thus directly complies with the wishes of the rating agencies and US-portfolio managers to orchestrate sovereign bond purchases and bazookas in the form of long-term refinancing operations by the ECB.

As a starting point, the "North" points to the fact that macroeconomic evidence is clearly not compatible with the "Southern" view that those "who are strong today may become weak tomorrow and vice versa". In practice, the opposite has happened. This is because of diverging long-term trends between Southern and Northern Eurozone countries in the quality of governance, the rule of law, labour market performance, growth and current account imbalances (Building Block 3). These differences have become structural and long-lasting in the case of several Eurozone countries. Spain, for instance, has arguably been suffering from very high structural unemployment for decades and will be additionally hampered in the decades to come by its excessive investment in construction [14].

The main problem debt pooling is supposed (by the "North") to solve is that, given the 'sudden stop' in cross border capital flows, some Southern member states must close their current account deficits as they have actually started to do in recent months. So, in the short run, they need to reduce consumption, and in the long run, they need a shift of resources to exports via lower wages and structural reform (Building Block 3). But debt pooling will not help them make these adjustments (Building Block 2).

In the same vein, the "North" notes that the relatively good performance of the Spanish economy in the years 2010 to 2011 was due to the slowdown of the adjustment in both the government accounts and the housing sector. This delay was thus the result of a lack of leadership, and is not an argument for debt pooling. Its long-term costs are now becoming apparent. The huge construction overhang implies losses that the banking sector may be facing once adjustment is complete (see the macro-prudential policies proposed in Building Block 3). It corresponds with the amount of real resources wasted by expenditure that was financed mostly by loans. It far exceeds the 
provisions and the write-downs as yet accumulated by the Spanish banking system. If debt-pooling were in place, Spain's banks might still be making those loans.

The "South" on some occasions outlines hard budget constraints to accompany debt pooling [19]. Its representatives propose binding mechanisms of compensating the more creditworthy countries and controlling the behaviour of those that are less so. But, according to the "Northern" view, historical experience gives reason to doubt that this will work-for several reasons.

One reason is that Spanish foreign debt is currently the greatest risk to the Eurozone, and it is essentially private. As long as the private sector has access to the ECB system at interest rates that are below the market rate, the correction of external imbalances through real internal devaluations will not take place, or if it does, at least not in sufficient quantities. The "South's" approach would require not only public debt limits but also private debt barriers to bring about such a correction, but that would be an absurd endeavour.

The "South" should draw some lessons from the current conduct of monetary policy. The latter already uses debt pooling, of a sort. The quality of the collateral that the ECB accepts varies considerably from country to country. In the case of the ECB's lending to Greek banks, it consists of doubtful private Greek assets and Greek government debt whose value depends on election results, as has been recently observed. Thus the ECB acts as a central counterparty for cross-border lending which incurs risks along national lines [34]. Risk mutualisation could well, if things go wrong, turn into full debt mutualisation, and lead to conflicts between member states. It provides an advance warning of how debt pooling could lead to the disintegration of the Eurozone.

This is precisely why the Interim Report argues with respect to its Building Block 2 that in the long run "...(i)n the EMU, the response to a symmetric shock affecting all countries simultaneously should primarily be provided by monetary policy, whereas in the context of country-specific economic shocks, the response falls primarily on national budgets" ([4], p. 5, President of the European Council).

\subsubsection{Summary}

For "Northern" governments like the German one, the mutualisation of debt is just another form of subsidy and bail-out for which markets clamour, be it the overt help given to Greece, or the more discreet liquidity provided by the European Central Bank.

The fact that there is a loud chorus demanding subsidies does not, in Germany's view, make it right [5]. The Merkel government argues that assistance does not help countries make the necessary macroeconomic adjustment in either public or private borrowing. Safeguards and conditions as stand-alone measures will not work. Anything that puts off the rebalancing of the current-account deficit only builds up the forces for the disintegration of the Eurozone. Watching the "South" borrow and spend themselves into bankruptcy and then bailing them out is both immoral and irresponsible.

In their rebuttal, "Southern" governments target what they regard as the contradiction in the "North's" position, rejecting debt mutualisation while supporting a joint Eurozone backstop for the banking sector [19]. Are banks any more trustworthy than sovereigns?

The "South" usually argues, moreover, that mutualisation of banking liabilities will inevitably be followed by the pooling of debt. Banking union on its own, for instance de Grauwe [19] notes, would protect the sovereigns from banking crises. But it would not protect banks from sovereign-debt crises. If banking union (Building Block 1) must be followed by the fiscal sort (Building Block 2), it would be best to do it at the same time, the "South" argues.

But many questions remain unanswered-the Interim Report is also no exception to this rule. Some German politicians identify the tendency of the single currency to push the economies of its members apart [5]. If all countries are to fend for themselves, as some proponents of the "German" view assert, would they not be better off restoring their own national currencies so that macroeconomic adjustment can take place more painlessly (a point directly related to Building Block 3)? As a blogger in The Economist Online puts it, "The south will end up having to leave the euro to save what's left of its economy" (see [35]).

For its part, the "South" indicates that more steps will have to be taken beyond the mutualisation of debt and banking liabilities, including the transfer of sovereignty to Brussels [19]. But what is the limit of all this? "This is not an economic problem. It is a cultural problem. We are experiencing mutinies by various groups among the passengers and deck and engine room crews" (see [36]). If Southern governments are right in saying that the banking union should be the first step towards the eventual creation of the United States of Europe, when will the citizens be asked to give their opinion of the whole project? Clearly, Building Block 4 is addressed here.

\subsection{Closing-The Way Forward}

3.4.1. "South": A Monetary Union Cannot Last without Debt Mutualisation to Avoid Deflation

The key issue is this: can a monetary union last without some form of fiscal union? Economists have been debating this issue for decades. It seems at least to the "South" that the consensus among them is that a monetary union without some form of fiscal union will not last. This view is clearly shared by the Interim Report.

What kind of fiscal union is necessary to sustain a 
monetary union (Building Block 2)? "Southern" governments tend to argue that such a fiscal union must have two components. First, it must have some insurance component, i.e. there must be some transfer mechanism from regions (countries) that experience good economic times to regions (countries) that experience bad times (the Interim Report alternatively proposes a central budget with similar functions). According to the "South", the US is often seen as a successful monetary union, partly because the federal government's budget performs the role of insurance. "Southern" governments are also eager to point out that the opponents will not cease to stress that such an insurance mechanism creates moral hazard issues. But that is the case with all insurance mechanisms. Representatives of the "Southern" view argue, as an analogy, that one generally also does not conclude that people should not have fire insurance because such insurance creates moral hazard, i.e. it will lead to more fires.

The second component of a fiscal union is some degree of debt pooling. Economist defending the "Southern" view have argued that this is necessary because in becoming members of a monetary union countries have to issue debt in a "foreign" currency and therefore become more vulnerable to upsurges of distrust and fear in financial markets. These can, in a self-fulfilling way, push countries into a bad equilibrium that makes it more difficult for them to adjust to imbalances [19]. Of course, debt pooling does not solve these fundamental problems (as "Northern" governments suggest that the "South" believes), but it avoids pushing countries, like Spain today, into a deflationary spiral that causes their debt problems to deteriorate, not improve.

Thus monetary union and fiscal union (including some degree of debt mutualisation) are the opposite sides of the same coin. As was made clear earlier in this paper, the proponents of the "Northern" view like to refer to history. The "Southern" economists also do this. According to them, there are no successful monetary unions that are not embedded in a fiscal union that includes debt mutualisation.

Some economists, especially in Northern Europe, continue to argue that one can have a monetary union without a fiscal union. Paul de Grauwe [19], for instance, reduces the "Northern" view to something like "all we need is discipline (a fiscal compact?), including a credible no-bail-out clause. If we allow governments to default, financial markets will do their work in disciplining these governments". According to both the "South" and the Interim Report, this view can certainly not be taken seriously any longer [19]. This is because financial markets are utterly incapable of applying the right discipline to governments. When markets are euphoric, as they were during the ten years before the crisis, they intensify indiscipline by giving incentives to borrowers and lenders alike to create excessive debt and credit. Since the crisis erupted, financial markets have been in a continuous state of fear and panic, leading them to apply excessive discipline that has led nowhere except to increasing debt burdens [19].

When the dust in this debate has settled, it willaccording to the "Southern" view-be clear that the greatest obstacle to debt mutualisation and the continuing existence of the Eurozone is a lack of trust -which has not yet been eliminated, as the Interim Report clearly proves. "Northern European countries distrust southern European countries and have propagated the myth that the North is morally superior compared with the corrupt regimes in the South. In Northern mythology, Southern European countries are seen as utterly incapable of setting their house in order. Lending money to these countries is pouring the hard-earned money of virtuous German savers into a bottomless pit. Southern European countries distrust the North and have propagated the myth that Northern European countries are out to dominate them and to impose a harsh and inhumane regime on helpless people. Mutual distrust is growing and is left unchecked because in all these countries few people stand up to call these myths just myths" [19].

The idea that a successful monetary union needs two essential ingredients is common to the "North" and the "South". One is mutual support, the other is a mutual control system. "Mutual support is essential to create a sense of belonging, without which no union can survive. In that sense a monetary union is like a marriage" [19]. It cannot survive if the partners tell each other that they should not count on help when they are in trouble. Mutual control is also essential in order to avoid opportunistic behaviour by those who receive help [19]. Unfortunately, the Interim Report claims that this control should take place by way of plans and newly designed mechanisms, but not through markets.

Mutual support and control can only be organised effectively in the context of a political union, the "South" claims. That is the institutional environment in which support and control can acquire democratic legitimacy (Building Block 4) and become sustainable. Thus, the choice is clear: either the euro area becomes a country, or it disappears. There is nothing intermediate option. This view is also shared among the "South" and the "North".

\subsection{2. "North": Towards a Concept of Competition- Based Fiscal Federalism in the Eurozone?}

In Section 3.2.2, I set out the most important components of a competition-based fiscal federalism that would probably make Eurobonds (Building Block 2) unnecessary. These relate mainly to Building Block 1 . This is not because banking union is equivalent to Eurobonds (as claimed by de Grauwe [19] but because it would disentangle a banking and a sovereigndebt crisis. With a solid banking system in place, 
banking-sector losses would no longer threaten the solvency of solid sovereigns (such as Ireland and Spain), and the bail-out of less reliable sovereigns would no longer be necessary. That means there would be a lower chance that fundamentally sound sovereigns would suffer from a confidence crisis and rocketing risk premiums.

Proponents of the "Northern" view do not accept the argument of the "South", coined for instance by de Grauwe [19], that a banking union does not protect the banks from sovereign failures. In a banking union, the capital market could exert its disciplining influence more effectively than it does now. Debt restructuring for insolvent states would become more probable. The debtor state would lose its strongest asset (the claim that default would cause huge damage to the entire financial system) and creditors could not rely on taxpayers to recoup their money. This, in turn, would put governments with unsound finances under pressure to curb their deficits.

Instead they hint at a wide array of econometric studies showing a systematic relationship of sovereign bond yields and the anticipated sustainability of a country's public debt-at least in the medium term. They leave it to the Banca d'Italia's research department to come up with convertibility risk (measured by google-nomics counting google searches for euro area breakup), as an explanatory variable of Southern sovereign bond yield spreads over the German yield [37]. Only recently, the spread on Spanish bonds moved up after Mariano Rajoy, the Spanish prime minister, announced that he intended to relax Spain's deficitadjustment path; as when Italy decelerated its pace of reforms. Hence, proponents of the "Northern" view can sleep quite well with the idea that "capital markets will take care of the rest".

To eliminate the fragility from the banking system, we must establish a temporary, or even permanent European Resolution Authority (ERA), whose task would be to rehabilitate fragile banks across Europe, regardless of size. Weaker banks would receive a onetime injection of capital or be wound down, wholly or partly. This body should have the power to turn bank debt into equity capital. Creditors of ailing banks-but not the taxpayers, as de Grauwe [19] assumesshould, as far as possible, be made liable for their risky investments. In contrast with Eurobonds, which tend to cover many bad risks, a European deposit scheme based on funding from the banks themselves (in order to avoid taxpayers bearing the risk) would in the end embrace only stronger banks [33].

The "North" admits to the "South" that it is right to argue that the lack of a budgetary union, akin to the American system, is a design failure of the Eurozone. Proponents of the "Northern" view also strongly support the "South's" view that a proper application of the American system would prevent a costly disintegration-but most probably for different reasons. Since the US system prevents central-bank loans from being more attractive than market loans, it avoids permanent balance-of-payment imbalances between member states. In America, neither the individual state nor the private sector has access to the printing press to finance itself and can default. If the inhabitants of a state need to finance their currentaccount deficits, they have to offer attractive interest rates and provide sufficient collateral to private lenders from other American states [5].

Yet the "South" argues, essentially, that Eurozone countries' main problem is that they do not have direct access to the printing press [19]. According to the "North", and, thus, following the strange behaviour of rating agencies, which penalise members of the Eurozone simply for being part of the single currency. For too long the agencies rated countries too generously, pricing in a potential bail-out rather than basing ratings purely on macroeconomic fundamentals. This pattern made risk-free profits possible from risk-free speculation against sometimes hopelessly non-competitive member states. The "South" reinterprets this as a question of "panicked financial markets" in its mother of all arguments for debt pooling [19].

Especially according to the "Northern" view, the members of the Eurozone are intentionally kept away from the ECB to avoid them activating the inflation tax to finance themselves. The scope for an individual country to incur government debt is simply lower within a currency union than outside. This scope cannot be extended through debt pooling without risking the disintegration of the Eurozone [5].

But the "Northern" view contains a lot more. As a rule, the burden on bank balance sheets should be borne by the country of domicile and not-as in the case of Eurobonds-be passed on to other countries (Building Block 2). However, it is not clear whether and to what extent over-indebted countries will be capable of doing this. Using the rescue funds would make sense as a fiscal backstop. Subject to negotiation, a temporary debt mutualisation to cover the cost of bank recapitalisation would make sense, to avoid a larger and permanent mutualisation of sovereign debt. But only after a proper pan-European banking oversight has been finalised and implemented (Building Block 1 and [5]).

\subsubsection{Summary}

Throughout the Eurozone's debt crisis, many Europeans have looked across the Atlantic for lessons on how to run a successful monetary union. The European Commission boasts that, taken together, the Eurozone's fiscal deficit and debt are lower than America's. Yet the euro faces an existential crisis while the dollar, despite the troubles of the American economy, still remains a shelter.

So, how much banking and fiscal integration does the Eurozone need to restore stability (Building Blocks 
1 and 2)? And how much political unity does it need to maintain checks and balances, and democratic legitimacy (Building Block 4)? Looking at the US, "Southern" and "Northern" economists and politicians more or less agree on the need for some kind of federalised system to recapitalise, restructure or wind down ailing banks. That is where the "North" thinks integration should stop-in contrast to the Interim Report. The key lesson from the US is, in its view, that it pays to enhance market discipline on the states: as long as the banking system is stabilised at minimal cost to the taxpayer, over-indebted states can be allowed to go bust.

But proponents of the "South" (as well as the drafters of the Interim Report) think that this deals with only half of the vicious circle between weak banks and weak sovereigns, and therefore cannot work in the long run. In his view, what makes America and other monetary unions stable is a system of joint bonds and other forms of mutual insurance and internal transfers to redress economic imbalances [19].

Drawing a parallel with the US case inevitably leads one to consider the obvious difference: the US is a federal country; the Eurozone however is a collection of 17 separate states. De Grauwe [19] vividly addresses this point, which is an essential ingredient of the "Southern" view, directly in his final sentence: "The choice is clear: either the euro zone becomes a country, or it disappears. There is nothing in between." Section 3.4.2 does not speak much about the desirability of political union, but the "North's" vision implies that the Eurozone should remain a collection of sovereign countries, each guarding its taxpayers' interests by limiting their exposure to others.

Many in the active and engaged audience of European citizens reflect on the loss of national sovereignty and discretion that may be necessary to make the single currency work. From the floor we hear bloggers state: "the only way this could work is if all the countries agree on a common retirement age, welfare, unemployment, etc.", "Mutualisation of debt has to be tied to a real surrender of fiscal sovereignty. The reason is obvious: Only a complete fool would share his unlimited credit card with someone if he had no control over their spending", and "As long as there is no European army to force European countries to comply with directives (on budgets and spending) of a central authority, it will always be a game of bluff and brinkmanship." (see [38]).

\section{Conclusions}

We can only hope that most of the panic selling of the 'Southern' sovereign bonds has already taken place and that the crisis is now slowly easing by itself, now that the 'Southern' countries have gone through the necessary adjustment recession. We should note that, currently, only financial institutions that are able to bear some risk still hold these bonds. This is rational since optimally a (risk-weighted) portfolio of (all available) sovereign bonds is held, a behaviour which is often intended to be mimicked by Eurobonds. For just this reason, these holders will not suddenly release the entirely of their bonds to the market, even if difficulties emerge. The current account imbalances will then recede, and the public sector will strengthen. But, admittedly, a perfect 'genuine' Economic and Monetary Union seems impossible in the future, too, due to country-specific interests along a 'North-South' divide [19]. It could, however, be more stable than at present, with a strong banking union that also enforces the fully justified Maastricht vision of hard budget constraints [14,32]. A European Monetary Fund would certainly be another important component of a more stable currency zone [39-41].

This article has identified two principal, but competing, ways to stabilize the Eurozone. With centralized control over fiscal policy and also over some economic policy areas one could introduce a joint liability for government debt to exclude bankruptcies of individual states. In this note we were not able to identify any current willingness and/or democratic legitimacy to proceed in this manner in the short to medium run. Alternatively, one may thus feel forced to leave the decision-making power over public debt to national parliaments. But then it must be possible as a conditio sine qua non that countries become insolvent, and private creditors are held fully responsible-a clear complement to a European Monetary Fund $[39,41]$. However, this is only possible if the financial sector is changed in such a way that government insolvency no longer affects the stability of the banking system. This could be achieved by a banking union. The fundamental problem to be resolved consists of the skeletons that have remained in the cupboards of some countries' banking systems, and which must not be passed on to the community [5].

The emphasis on pushing through a fiscal union as a precondition for debt mutualisation means the debate, at least in Germany, has become a question of 'all or nothing': either deeper political union (i.e. Building Block 2) or deep chaos. This unnecessarily narrows the strategic options for the players and causes the permanent 'North-South' divide described by Belke [5] - which is also mirrored in the Interim Report-severely hampering the realisation of a 'genuine' monetary and economic union.

However, the European Central Bank (ECB) has bought only some time with its Securities Markets Programme (SMP), Longer-Term Refinancing Operations (LTROs) and Outright Market Transactions (OMTs) and it is vital that the fundamental problems are addressed through a concept of a 'genuine' Economic and Monetary Union. A major problem is that many losses are passed on the ECB and redistribution policy is carried out primarily by monetary policy. It would be better if fiscal authorities restructured banks in a targeted fashion. In the medium run, a way must 
be found to protect the ECB and to guarantee a truly financially and politically independent monetary policy. The Interim Report correctly stresses in this respect 'a clear separation between ECB monetary policy and supervisory functions' [4].

The "South" is right in stating that the lack of a budgetary union like that in the US is a design failure. This paper also strongly supports the view that a proper application of the US system would prevent a costly disintegration process of the Eurozone-but maybe for different reasons. In order to assess the "Southern" euro area governments' proposals of debt pooling and compare them with the US benchmark it is necessary to look at the main ingredients of the rules of the game of the US federal system which became clear only after nine defaults by the 1840s.

Since the US system (unlike the current situation in the Eurozone) prevents central bank loans from being more attractive than market loans, it avoids permanent balance-of-payment imbalances between member states and, in this way, current account deficits which fail to be backed by credible and solid investment projects. In the US, neither the individual, federal state nor the private sector has access to the printing press to finance itself. If the inhabitants of a federal state require financing for their current account deficits, they must offer other states attractive interest rates and provide sufficient collateral to private

\section{References and Notes}

1. European Council. European Council 28/29 June 2012-Conclusions; 2012. Available from: http://www. consilium.europa.eu/uedocs/cms_Data/docs/pressdata /en/ec/131388.pdf (accessed on 9 May 2013).

2. European Parliament. EP resolution of 20 November 2012 with recommendations to the Commission on the report of the Presidents of the European Council, the European Commission, the European Central Bank and the Eurogroup 'Towards a genuine Economic and Monetary Union' (2012/2151(INI)); 2012. Available from: http://www.europarl.europa.eu/ oeil/popups/ficheprocedure. do?reference $=2012 / 2151$ ( INI)\&l=en (accessed on 9 May 2013).

3. European Commission. A blueprint for a deep and genuine economic and monetary union-Launching a European debate. Communication from the Commission. COM(2012) 777 final. Brussels, Belgium: European Commission; 2012.

4. European Council. Towards a genuine Economic and Monetary union. Interim Report. 12 October 2012. Brussels, Belgium: European Council. Available from: http://www.consilium.europa.eu/uedocs/cms_d ata/docs/pressdata/en/ec/132809.pdf (accessed on 9 May 2013).

5. Belke A. Euro Debt: Should the Eurozone's debt be mutualised? Economist Debates. The Economist outside lenders. If they fail, they simply dispense with borrowing and current account imbalances do not spread in the first place.

This contribution is in strong accordance with "Southern view" that the instalment of a US-type budgetary union remains illusionary. The best proof of this is the over-indebted euro area governments crowding, sometimes massively, to reach a substantial increase in the guarantees for excessive national debt contained in the ESM, typically in advance and without conditionality, and more or less hidden through offering the South's "right types" of debt pooling. Experience shows that the latter must suffer from the noncredibility of all variants of rules proposed to prevent moral hazard-which is simply due to a lack of availability of forfeit in terms of gold, foreign exchange reserves or other hard assets involved and to de-activating the interest rate mechanism (by fixing upper bounds for "tolerable" rate movements) which, however, is a central ingredient of the US-system.

\section{Acknowledgements}

This paper heavily relies on [42]. I am grateful for valuable comments to Iain Begg, Christian Deubner, Daniel Gros, René Smits, Guido Traficante and Wolf Schäfer.

online. 11-23 July 2012. Available from: http://www.e conomist.com/debate/days/view/856 to 858/print (accessed on 9 May 2013).

6. Gros D. Banking Union: Ireland vs. Nevada, an illustration of the importance of an integrated banking system. CEPS Commentaries. Brussels, Belgium: Centre for European Policy Studies; 18 October 2012.

7. Mario Draghi backs Wolfgang Schaeuble's 'super commissioner' plan. The Telegraph. 28 October 2007. Available from: http://www.telegraph.co.uk/finance/fi nancialcrisis/9638725/Mario-Draghi-backs-Wolfgang-S chaeubles-super-commissioner-plan.html (accessed on 9 May 2013).

8. Mussler W. Das Phantom der echten Währungsunion. Frankfurter Allgemeine Zeitung, 18 October 2012, p. 9.

9. Belke A, Potrafke N. Does government ideology matter in monetary policy? A panel data Analysis for OECD countries. Journal of International Money and Finance. 2012;31(5),1126-1139.

10. Andersen SA, Eliassen KA. European community lobbying. European Journal of Political Research. 1991;20(2),173-187.

11. Quite consistently, Wolfgang Schäuble argues: "We can only achieve political union if we have a crisis". See: Seeing in Crisis the Last Best Chance to Unite Europe. New York Times, 18 November 2011. Available from: http://www.nytimes.com/2011/11/19/world/euro pe/for-wolfgang-schauble-seeing-opportunity-in-europes 
-crisis.html?pagewanted=all (accessed on 9 May 2013).

12. Belke A, Herz B, Vogel L. Reforms, exchange rates and monetary commitment: A panel analysis for OECD countries. Open Economies Review. 2006;18 (3),S369-S388.

13. Belke A, Gros D. Is a unified macroeconomic policy necessarily better for a common currency area? European Journal of Political Economy. 2009;25(1),98101.

14. Gros D. The false promise of a Eurozone budget. CEPS Commentaries. Brussels, Belgium: Centre for European Policy Studies; 7 December 2012.

15. Belke A, Dreger C. Current account imbalances in the euro area: Does catching up explain the development? Review of International Economics. 2012;21(1),6-17.

16. Bundesbank warms to banking union. Financial Times. 19 November 2012. Available from: http:// www.ft.com/intl/cms/s/0/cc55f4d2-3241-11e2-b891-0 0144feabdc0.html\#axzz2ENuSVL6S (accessed on 9 May 2013).

17. Vaubel R. Why the current plans for European Banking Supervision are not well founded. 2012. Available from: http://www.openeuropeberlin.de/Cont ent/Documents/121203_Roland_Vaubel_-_Gastbeitrag .pdf (accessed on 9 May 2013).

18. The de Larosière Group. The High-Level Group on Financial Supervision in the EU Report. Brussels, Belgium: European Commission; 25 February 2009, p. 43. Available from: http://ec.europa.eu/ internal_market/finances/docs/de_larosiere_report_en .pdf (accessed on 9 May 2013).

19. De Grauwe P. Euro debt: Should the Eurozone's debt be mutualised? Economist Debates. The Economist; 11 to 23 July 2012. Available from: http:// www.economist.com/debate/days/view/856 to 858/pri nt (accessed on 9 May 2013).

20. Belke A. A more effective euro area monetary policy than OMTs-Gold-backed sovereign debt. In: ECB Intervention in the Euro Area Sovereign Debt Markets, Compilation of Notes. Brussels, Belgium: European Parliament; October 2012. Available from: http://www.europarl.europa.eu/committees/en/econ/st udiesdownload. html? languageDocument $=E N \&$ file $=76$ 695 (accessed on 9 May 2013).

21. International Monetary Fund. World economic outlook-Coping with high debt and sluggish growth. Washington, DC, USA: IMF; October 2012.

22. European Commission. Autumn economic forecast 2012-14: Sailing through rough waters, Brussels, Belgium: European Commission; 7 November 2012.

23. Belke A. Expert-Statement in the Public Hearing on 'Asymmetric Shock or Shock Specific to One Country: On the Need of a Stability Fund under EMU'. Brussels, Belgium: European Parliament, Committee on Economic and Monetary Affairs and Industrial Policy; 2 September 1998. Re-printed in: European Parliament. DB IV Publications, Economic Affairs Series ECON 104,
09/1998. Brussels, Belgium: European Parliament; 1998.

24. Belke A, Gros D. Asymmetric shocks and EMU: Is there a need for a Stability Fund? Intereconomics. 1998;33(6),274-288.

25. This section heavily relies on the debate between Paul de Grauwe and myself on "Euro Debt: Should the Eurozone's Debt Be Mutualised?", Economist Debates, The Economist online, 11-23 July 2012. Needless to say then, the author of this paper feels inclined to support the 'Northern' view more than the 'Southern' view-although he outlines that both approaches are reconcilable, building upon a solution which combines a banking union with fiscal federalism.

26. Gros D, Thygesen N. European monetary integration, 2nd ed. London, UK: Longman; 1998.

27. Belke A, Burghof H-P. Stand-alone ratings for countries-Remedial action in case of market failure. EuroIntelligence. 24 November 2010. Available from: http://www.eurointelligence.com/eurointelligence-new s/archive/single-view/article/stand-alone-ratings-for-co untries-remedial-action-in-case-of-market-failure.html (accessed on 9 May 2013).

28. Delpla J, Weizsäcker J. The Blue Bond Proposal. Breugel.org. 11 May 2011. Available from: http://www.bruegel.org/fileadmin/bruegel_files/Event s/Presentations/2011-03-16_Blue_Bonds_Weizsacker_ Delpla_11th_May_final_Compatibility_Mode_.pdf (accessed on 9 May 2013).

29. German Council of Economic Experts. After the Euro Area Summit: Time to Implement Long-Term Solutions. Wiesbaden, Germany: German Council of Economic Experts; 2012.

30. Padoa-Schioppa Group. Completing the EuroA roadmap towards fiscal union in Europe. Notre Europe. 2012. Available from: http://www.eng.notreeurope.eu/011-3024-Tommaso-Padoa-Schioppa-Group .html (accessed on 9 May 2013).

31. Sinn H-W, Wollmershäuser T. Target loans, current account balances and capital flows: The ECB's rescue facility. International Tax and Public Finance. 2012;19(4),468-508.

32. Gros D. Eurobonds: Wrong solution for legal, political, and economic reasons. VoxEU. 2011. Available from: http://www.voxeu.org/article/eurobon ds-are-wrong-solution (accessed on 9 May 2013).

33. Gros D, Schoenmaker D. A European deposit insurance and resolution fund-An update. CEPS Policy Brief. Brussels, Belgium: Centre for European Policy Studies; 11 September 2012.

34. Gros D, Alcidi C, Giovannini A. Central banks in times of crisis: The FED vs. the ECB, CEPS Policy Briefs. Brussels, Belgium: Centre for European Policy Studies; 11 July 2012.

35. Comments by turbatothomas. The Economist. Available from: https://www.economist.com/users/tur batothomas/comments?page $=1$ (accessed on 9 May 2013).

36. Reply to comment. The Economist. Available from: http://www.economist.com/comment/reply/215 
58392/1521375 (accessed on 9 May 2013).

37. Di Cesare A, Grande G, Manna M, Taboga M. Recent estimates of sovereign risk premia for Euroarea countries. Occasional Papers 128. Rome, Italy: Banca d'Italia; September 2012.

38. Economist Debates: Euro debt: Statements. The Economist. Available from: http://www.economist. com/debate/days/view/856 (accessed on 9 May 2013).

39. Plenum der Ökonomen. Stellungnahme zur Bankenunion. 2012. Available from: http://www.wiso. uni-hamburg.de/lucke (accessed on 9 May 2013).

40. Gros D, Mayer T. How to deal with sovereign default in Europe: Create the European Monetary Fund now! CEPS Policy Brief. Brussels, Belgium:
Centre for European Policy Studies; 17 May 2010.

41. Belke A. Reinforcing economic governance in EMU: The case for a European Monetary Fund. Paper presented at the Panel 'Responses to Potential National Insolvency', Global Economic Symposium (GES), Istanbul, Turkey, 27-29 September 2010.

42. Ansgar B. Towards a Genuine Economic and Monetary Union-Comments on a Roadmap. Briefing paper prepared for presentation at the Committee on Economic and Monetary Affairs of the European Parliament for the quarterly dialogue with the President of the European Central Bank. Brussels, Belgium: European Parliament; December 2012. 


\title{
Campaign Duration and Election Outcomes
}

\author{
Costas Panagopoulos \\ Department of Political Science, Fordham University, Bronx, NY 10458, USA; E-Mail: costas@post.harvard.edu; \\ Tel.: +1 7188173967; Fax: +1 7188173972
}

Submitted: 15 January 2013 | In revised form: 28 March 2013 | Accepted: 2 May 2013 |

Published: 23 May 2013

\begin{abstract}
Does campaign duration affect election outcomes? To date, this question has largely evaded political scientists, but it is reasonable to expect systematic links between campaign length and candidate performance in elections. We hypothesize that longer campaigns would help challengers' electoral fortunes, thereby curbing incumbency advantage and potentially boosting competitiveness in elections. Using two data sources, aggregate data from U.S. House elections between 1994 and 2006 and ANES survey data from the 2002 election cycle, we find little evidence to support contentions that campaign length affects election outcomes or candidate familiarity. The results we report suggest the political consequences, intended or not, to choices about election timing are likely minimal.
\end{abstract}

Keywords: campaign duration; campaign length; campaign spending; campaign timing; candidate familiarity; election outcomes; vote choice

\section{Introduction}

On 28 October 2009, President Barack Obama signed into law the Military and Overseas Voter Empowerment (MOVE) Act, an initiative designed to help military serving overseas and citizens who live abroad to vote in U.S. elections. Among other provisions, the law requires states to send absentee ballots to voters overseas at least 45 days in advance of any federal election, including special, primary and runoff elections. As a practical matter, this provision has been problematic for several states which have typically held late congressional primary elections, often in September, to determine general election candidates for Congress. The Department of Defense has been reluctant to grant states waivers to this requirement, so states have revamped their electoral calendars to hold primary elections earlier in the election cycle.

Ostensibly, MOVE was designed to enfranchise American voters living or serving in the military abroad, but the Act, which went into effect during the November 2010 elections, will undoubtedly have other consequences, intended or otherwise. One implication linked to this policy reform, and alluded to above, is that general election periods are likely to be lengthened, at least for some elections in several states. But what are the political consequences potentially associated with longer campaigns? To date, this question has largely evaded political scientists, but it is reasonable to expect systematic links between 
campaign duration and candidate performance in elections. One possibility is that longer campaigns would help challengers' electoral fortunes, thereby curbing incumbency advantage and boosting competitiveness in elections. In this paper, we investigate this possibility empirically by examining data from U.S. House elections between 1994 and 2006. Previewing our main findings, we find evidence that campaign duration does impact election outcomes, suggesting there are important consequences, intended or not, to choices about election timing. We also speculate about the underlying mechanism that potentially gives rise to this pattern. We analyze survey data from the 2002 American National Election Study to demonstrate that longer campaigns may advantage candidates at the polls by raising awareness about them and elevating name recognition. This effect appears to be moderated by levels of campaign spending.

\section{Incumbency and Campaign Length}

Incumbent dominance at the polls has long been a central and enduring feature of American elections. Scholars have traced incumbent strength to a number of sources [1-3], but an advantage in incumbent name recognition has emerged as a leading explanation [4]. As Jacobson notes, "people hesitate to vote for candidates they know nothing at all about. Among the most consistent findings produced by studies of congressional voters over the past generation is that simple knowledge of who the candidates are is strongly connected to voting behavior" [4].

Discussions about the impact of name recognition on voting preferences are often closely linked to ongoing debates about the deployment of candidate resources, most notably campaign funds. On this score, researchers have been somewhat equivocal. Some [5-8] argue that spending by challengers is more effective than spending by incumbents, perhaps reflecting the relative obscurity of challengers. Others [9-12] find incumbent and challenger spending to have similar effects, with challengers enjoying a smaller edge in spending efficiency than suggested initially by Jacobson [5]. The problem of reciprocal causation resulting from strategic behavior by candidates and donors alike makes the precise relationship between spending and election results difficult to pin down, but most studies suggest marginal returns are greater for challengers than for incumbents [4]. Taken as a whole, these findings imply that policies that grant equal resources to both incumbents and challengers would advantage challengers because of diminishing marginal returns, a hypothesis that finds supports in recent field experimental work [13].

Despite an abundance of studies published over several decades devoted to disentangling the impact of campaign spending on election outcomes, examinations of the impact of access to other important resources, like time, are scarce. After all, time can facilitate information acquisition, and scholars have shown the length of a campaign helps voters to make use of important electoral information [14]. Moreover, unlike campaign spending, whose causal effects are methodologically challenging to isolate because they can be linked to expected outcomes, the duration of a campaign is exogenously determined and assigned in an even-handed manner to all candidate types in a given state. As we demonstrate below, the duration of campaigns varies considerably over time and across states, and this variation can be exploited to gauge the effects of this important resource on candidate voteshares.

Given the discussion above, we hypothesize that longer campaigns would disproportionately advantage challengers over incumbents. Longer campaigns would conceivably afford challengers greater opportunities to build awareness of their candidacies and to cut into incumbents' name recognition advantages. In this study, we investigate this possibility using data from elections for the U.S. House of Representatives between 1994 and 2006. We find support for the contentions that campaign duration affects election outcomes and that longer campaign cycles benefit challengers over incumbents. We also find that the impact of campaign duration is moderated by the level of campaign funds.

We proceed as follows. In the next section, we develop more fully our ideas about the impact of campaign duration on election outcomes and provide a more nuanced set of hypotheses. We then describe the variation in campaign duration in states across the country over the period of our study. In the following section, we develop and estimate an empirical model to test our hypotheses and present the results. We conclude with a discussion of the implications of our findings.

\section{The Impact of Campaign Length: Theory and Hypotheses}

Evidence from studies of presidential elections has demonstrated that candidate preferences rarely shift dramatically over the course of a general election campaign, but that meaningful change can, and typically does occur [15]. Preferences form, crystallize or change as a result of learning that is facilitated over the course of a campaign [16]. As Gelman and King [17] argue, campaigns convey information about the values of "fundamental" variables; campaign activities increase the amount of information accessible to voters about candidates' true positions on issue priorities as well as about the real conditions of important considerations (like economic performance). The authors assert that campaigns help to "enlighten" voters, but such an educating process takes time [17]. As Stevenson and Vavreck ([14], p. 223) argue, "[w]ithout sufficient time for this kind of process, voters will be hard pressed to correct distortions in their initial assessments which may be based on a very limited amount 
of information and only a few campaign messages. [E]nlightenment should be less successful in very short election campaigns than it is in campaigns of sufficient length."

A condition that, according to [17], is essential to facilitating enlightenment is competition. Competitive elections, like the presidential contests that the authors study, ensure that biased information cannot systematically misinform voters. But Stevenson and Vavreck ([14], p. 222) argue that symmetry and pervasiveness are linked to competitiveness. "Without symmetry, resource-rich candidates can dominate the information that is conveyed to voters and so might be able to mislead them systematically about the true values and weights for fundamental variables that are unfavorable to them." Related is pervasiveness, which the authors conceive of as the ability to reach the bulk of the electorate with their campaign messages. Using data from 113 elections in 13 democracies, Stevenson and Vavreck show that voters rely more heavily on the true values of economic conditions to inform their preferences in relatively lengthy campaigns of at least six weeks while these effects are largely absent in shorter campaigns; they conclude campaign length matters for voter learning [14].

If it is the case that campaign length helps voters to learn about important aspects of a campaign, like candidate qualities and positions on key issues, then longer campaigns presumably afford challengers greater opportunities to make up for deficits in familiarity or name recognition they typically start off with [4], relative to incumbents; sufficiently long campaigns should, all else equal, disproportionately favor challengers. This is the main hypothesis we investigate below.

But longer campaigns, in and of themselves, are not necessarily sufficient to accrue benefits to challengers. Unlike the presidential contests that Gelman and King [17] study, congressional elections are typically lopsided affairs characterized by resource imbalances: "symmetry", at least with respect to financial resources, is uncommon in races against incumbents in particular [4]. Above we argue that sufficient campaign length has the capacity to afford nonincumbents the time to become more familiar to voters, but even challengers with the luxury of longer campaign periods may not necessarily be able to capitalize on these without adequate resources. It is also conceivable that any potential benefits associated with longer campaigns may be less influential for well-funded challengers. Considerable financial resources at their disposal may render campaign duration less consequential with respect to its influence on eventual levels of support at the polls. Conversely, challengers with scant financial resources may benefit more so from longer periods during which to promote their candidacies. Accordingly, we argue the effect of campaign duration on candidate performance will be moderated by the level of campaign spending, a conditional hypothesis we examine empirically below.

\section{Measuring Campaign Duration}

The measurement of campaign duration can itself be a debatable matter. In contemporary presidential nomination contexts, the notion of an "invisible primary" that often begins long before any votes are cast in an actual election is an established regularity. For the purposes of the current study, we are concerned primarily with the length of the formal general election campaign period, which we define as the total number of calendar days between the primary election and the general election. This choice is arbitrary, and it is not intended to discount the significance of the informal campaign period that typically unfolds in advance of primary Election Day, sometimes over a span of months or even years. Admittedly, this is a crude measure that does not take into account a myriad of other factors that could include whether eventual nominees faced contested primaries, how soon before the primaries candidates declared their candidacies or actually began to campaign, or variation in convenience voting or levels of early, absentee or mail-in voting in each jurisdiction. While research examining the effects of these factors is worthwhile in its own right, we acknowledge these limitations and view the current study as a first-cut in examining the heretofore unexplored relationship between campaign duration and outcomes. As such, we are mainly interested here in the period beyond the primary election, when candidates have secured party nominations and are assured positions on general election ballots.

Despite the fact that a uniform date for congressional general elections has been statutorily set by Congress since 1872 (for the Tuesday after the first Monday in November of even-numbered years), regulations concerning primary elections, including dates on which these contests are held, are reserved for the states. As a result, there is considerable variation, both over time and across states in terms of primary election dates. Researchers have observed that, over the past few decades, states seeking greater influence in presidential nomination contests have moved their primary dates earlier and earlier in the process [18], resulting in the so-called frontloading phenomenon, but primary elections for congressional candidates need not necessarily coincide with presidential primaries; they often do not. As a result, the duration of the general election campaign period, in terms of total number of calendar days, for congressional races varies considerably both across states and within states over time.

Table 1 presents further evidence about the variation in the mean duration of the general election period, as well as the range, for congressional election cycles between 1994 and 2006. The data for the period we examine indicate that general election candidates 
Table 1. Congressional general election duration (days), 1994-2006.

\begin{tabular}{cccc}
\hline Year & Mean (Days) & Minimum & Maximum \\
\hline 1994 & $122(60)$ & 14 & 245 \\
1996 & $118(58)$ & 21 & 239 \\
1998 & $114(55)$ & 45 & 238 \\
2000 & $129(64)$ & 45 & 245 \\
2002 & $116(57)$ & 43 & 245 \\
2004 & $125(63)$ & 45 & 245 \\
2006 & $122(54)$ & 45 & 245 \\
\hline
\end{tabular}

Note: Standard deviations in parentheses.

have consistently had about four months on average to campaign, but this span of time varies widely. In the 1990s, congressional candidates in Arkansas, for example, had only two or three weeks to campaign against their general election opponents, while candidates in states like Ohio, Texas and Illinois had almost eight months to do so. In the most recent cycles we examine, the length of the general election period ranges from about six weeks to eight months [19].

Above we argue that this variation may have important consequences for election outcomes. Candidates, namely challengers, may be able to take advantage of longer campaign periods to build name recognition and awareness and to promote their candidacies, while incumbents would presumably have an advantage in shorter campaign cycles. We also expect the impact of campaign duration will be moderated by the level of campaign funds accessible to a challenger. Next we proceed to estimate the impact of campaign duration on candidate performance.

\section{Estimating the Impact of Campaign Duration on Candidate Performance}

Previous research has established that candidate voteshares in general elections are a function of a number of factors including resource levels, district partisan strength and candidate quality [4]. As we discuss above, reciprocal causation between campaign spending and expected voteshares make empirical examinations of the impact of campaign spending on election outcomes a methodologically thorny issue. Scholars have grappled with this issue for decades [4-7,9-12] offering a range of solutions. Most of these studies advocate, and several adopt, an instrumental variables approach to addressing the issue of reciprocal causation, although the range of instruments for spending variables is diverse across studies. In the current study, we adopt an empirical strategy similar to the one proposed by Green and Krasno $[9,10]$. Specifically, we use lagged incumbent spending as an instrument for current incumbent spending in two-stage least squares analyses. To be consistent with previous work in this field, we also adopt the following conventions: first, we convert all spending figures to 2006 dollars; as in previous studies, a log transformation of campaign spending (in thousands of 2006 dollars) is used to simulate diminishing marginal returns; to make this assumption less drastic, $\$ 5,000$ is added to all candidate expenditure levels (see [7] for details). A similar transformation was performed on the incumbent spending instrument (incumbent spending in the previous campaign). Two-stage least squares purges the independent variables of their covariance with the disturbance term; the procedure involves estimating a predicted score for the endogenous regressor (the incumbent spending variable), in this case, from its lagged values, and using this as instruments in a second-stage regression instead of the original value.

To isolate the impact of campaign duration on candidate performance in general elections, we include measures of campaign duration in a more fully specified model that simultaneously accounts for other variables, as discussed above, known to influence candidate voteshares in elections. We estimate a series of two-stage least squares regression models using the instrument for incumbent spending described above [20]. The basic model presents the challenger's share of the two-party vote in contested general elections as a function of incumbent (instrumented) and challenger campaign spending, challenger quality, and incumbent party strength in the district and campaign duration. We also include a dummy variable in the model to account for presidential election years as well as indicators to denote the party of the challenger and redistricted districts; we interact the challenger party indicator with dummy variables for each year included in our study to account for national, partisan trends. Consistent with previous work, we adopt a dichotomous categorization for challenger quality [4]; admittedly, a more refined measure of quality would have been preferable, however this was unavailable. Studies have repeatedly demonstrated such dichotomous conceptualizations of challenger quality to be quite robust and very highly correlated with alternative, more refined measures of quality [7]. Accordingly, we consider challengers with prior elective experience to be high-quality challengers while those with no prior elective office are low-quality.

The results of the initial estimation, model 1 presented in Table 2, column 1, reveal patterns that are familiar given extant work in this field. We find evidence that challenger performance is strengthened by higher levels of both incumbent and challenger spending as well as challenger party strength in the district and challenger experience. The results also suggest challengers are disadvantaged somewhat in presidential years.

Our key variable of interest, however, is the duration of the general election period, operationalized as the total number of calendar days between the primary and general elections. We estimate a second model (model 2 ) that adds this variable to the equation. The results of the estimation are presented in Table 2, column 2. The estimates reveal that the inclusion of the additional 
Table 2. Estimating the impact of campaign duration on candidate performance.

\begin{tabular}{|c|c|c|c|}
\hline \multirow[b]{2}{*}{ Variable } & \multicolumn{3}{|c|}{ Model Specifications } \\
\hline & (1) & (2) & (3) \\
\hline $\begin{array}{l}\text { Challenger Party Strength in } \\
\text { District }\end{array}$ & $0.384(0.012)^{* * *}$ & $0.384(0.012)^{* * *}$ & $0.386(0.012)^{* * *}$ \\
\hline Experienced Challenger & $1.143(0.303)^{* * *}$ & $1.160(0.303)^{* * *}$ & $1.142(0.304)^{* * *}$ \\
\hline $\begin{array}{l}\text { General Election Duration } \\
\text { (days) }\end{array}$ & & $0.002(0.002)$ & $0.003(0.026)$ \\
\hline $\begin{array}{l}\text { Incumbent Spending (log) } \\
\text { (instrument) }\end{array}$ & $1.281(0.278)^{* * *}$ & $1.309(0.278)^{* * *}$ & $1.158(0.663)$ \\
\hline $\begin{array}{l}\text { Incumbent Spending (inst.) } \\
\times \text { Duration }\end{array}$ & & & $0.001(0.004)$ \\
\hline Challenger Spending (log) & $2.384(0.073) * * *$ & $2.380(0.073)^{* * *}$ & $2.630(0.150)^{* * *}$ \\
\hline $\begin{array}{l}\text { Challenger Spending (log) } \\
\times \text { Duration }\end{array}$ & & & $-0.002(0.001)^{* *}$ \\
\hline Challenger Democrat & $1.606(0.575)^{* * *}$ & $1.592(0.574)^{* * *}$ & $1.592(0.574)^{* * *}$ \\
\hline Presidential Election Year & $-5.898(0.540) * * *$ & $-6.032(0.518) * * *$ & $-6.023(0.518) * * *$ \\
\hline Redistricted & $0.925(0.613)$ & $0.891(0.612)$ & $0.900(0.613)$ \\
\hline Constant & $2.918(1.783)$ & $2.394(1.807)$ & $2.263(4.258)$ \\
\hline$N$ of individuals & 1,666 & 1,663 & 1,674 \\
\hline Adjusted R-squared & 0.771 & 0.772 & 0.773 \\
\hline $\begin{array}{l}\text { Notes: Two-least least squares re } \\
\text { estimated as a function of lagged } \\
\text { instruments for incumbent spenc } \\
\text { challenger's share of the two-part } \\
\text { statistical significance at the } p< \\
\text { models include dummy variable } \\
\text { available upon request). Redistr } \\
\text { spending and other variable meas }\end{array}$ & $\begin{array}{l}\text { ssion (TSLS). In the } \\
\text { cumbent spending } \\
g \text { in the second sta } \\
\text { vote in the district. } \\
11 \text { level, and } * * \text { at t } \\
\text { or years and year } \\
\text { ing years (1992, } 2 \\
\text { ement or constructio }\end{array}$ & $\begin{array}{l}\text { irst stage, incumbent } \\
\text { gged). These estimat } \\
\text { in which the depen } \\
\text { andard errors in paren } \\
p<0.05 \text { level, using } \\
\text { nallenger party interc } \\
\text { 2) excluded. See te }\end{array}$ & $\begin{array}{l}\text { spending (logged) is } \\
\text { es are then used as } \\
\text { dent variable is the } \\
\text { theses. } * * * \text { denotes } \\
\text { two-tailed tests. All } \\
\text { ctions (not shown; } \\
\text { kt for details about }\end{array}$ \\
\hline
\end{tabular}

variable denoting the duration of the general election campaign does not substantively alter the impact or statistical significance of any of the other variables. The coefficient for the campaign duration variable is positive, implying longer campaigns may boost challenger voteshares relative to incumbents, but the effect is not statistically significant; moreover, it is, at best, substantively modest. Extending the general election period by 100 days would only add 0.2 percentage points on average to the challenger's voteshare, all else equal.

We remind readers, however, that we expect the impact of the length of the campaign to be conditioned by the level of campaign spending. Thus, we estimate a third model (model 3) to include interaction terms in our model to capture the effects of campaign duration as conditioned by candidate spending levels in addition to the individual constitutive terms accordingly. The estimates reveal some familiar results: support for challengers is positively and significantly influenced by prior experience and partisan strength in the district, as in the other two models. However, neither incumbent spending (instrumented) nor the interaction between campaign duration and incumbent spending are statistically significant, suggesting incumbent spending levels are statistically unrelated to challenger performance once the other ingredients are included in the model. The positive and significant impact of challenger spending persists, however. The direct effect of the campaign duration variable remains insignificant, however the interaction between challenger spending and campaign duration is statistically significant at conventional levels, implying the impact of campaign length is moderated by the level of challenger spending, as hypothesized above. The negative and statistically significant coefficient on the interaction term, however, suggests the effect of campaign duration declines as challenger spending grows. We interpret this to suggest the marginal impact of campaign length declines with growing levels of campaign spending, a result that is also consistent 
with the hypothesis we develop above. Still, the substantive effects are quite small. Figure 1 presents a visual depiction of the impact of campaign duration on challenger voteshares across ranging of levels of logged challenger spending. The solid line displays the marginal impact of campaign duration on challenger support at the polls, with dashed lines representing the 95 percent confidence intervals associated with the impact of campaign duration for the corresponding spending levels. Taking uncertainty levels into account, the evidence indicates the marginal impact of campaign duration is indistinguishable from zero. Although there are indications the marginal effect of campaign length likely declines somewhat as spending grows, the overall effect is negligible. Next, we proceed to examine the impact of campaign length on candidate familiarity.

\section{Estimating the Impact of Campaign Duration on Candidate Familiarity}

Above we argued that the length of congressional general election campaigns likely influences challenger performance at the polls on Election Day. The analyses we present, however, provide only limited empirical evidence for this contention; for the most part, the effects are likely substantively small, at best. To the extent that longer campaigns may influence candidate voteshares in elections, however, what could be the driving force behind any such effects? One possible underlying mechanism that could give rise to the hypothesized effect is that longer campaigns facilitate voter learning and raise familiarity with challengers. Previous research has established a link between familiarity and vote choice and demonstrated that greater familiarity increases the likelihood of voting for a candidate $[4,21]$. If the likelihood of voting for a challenger is enhanced because longer campaigns raise challenger familiarity, we should be able to detect empirical evidence for the latter. Accordingly, we expect that longer campaigns raise voters' familiarity with the candidates, especially challengers, cutting into the recognition advantage incumbents typically enjoy [4] and that this is the causal mechanism that may help to explain even the muted effects on electoral support we identify above. Next, we seek empirical evidence for the contention that longer campaigns raises candidate familiarity, even after controlling for other key factors like candidate quality and campaign spending.

We rely on data collected for the 2002 American National Election Study for these analyses. The 2002 ANES probed respondents about their ability to recognize congressional candidates in the November 2002 elections. Analysis of the unweighted data confirms incumbents' recognition advantage compared to challengers: 89 percent of respondents recognized incumbents, compared to only 58 percent who could recognize challengers. We expect longer campaigns could conceivably boost levels of recognition for incumbents, but we argue that longer campaigns should elevate challenger recognition levels even more so.

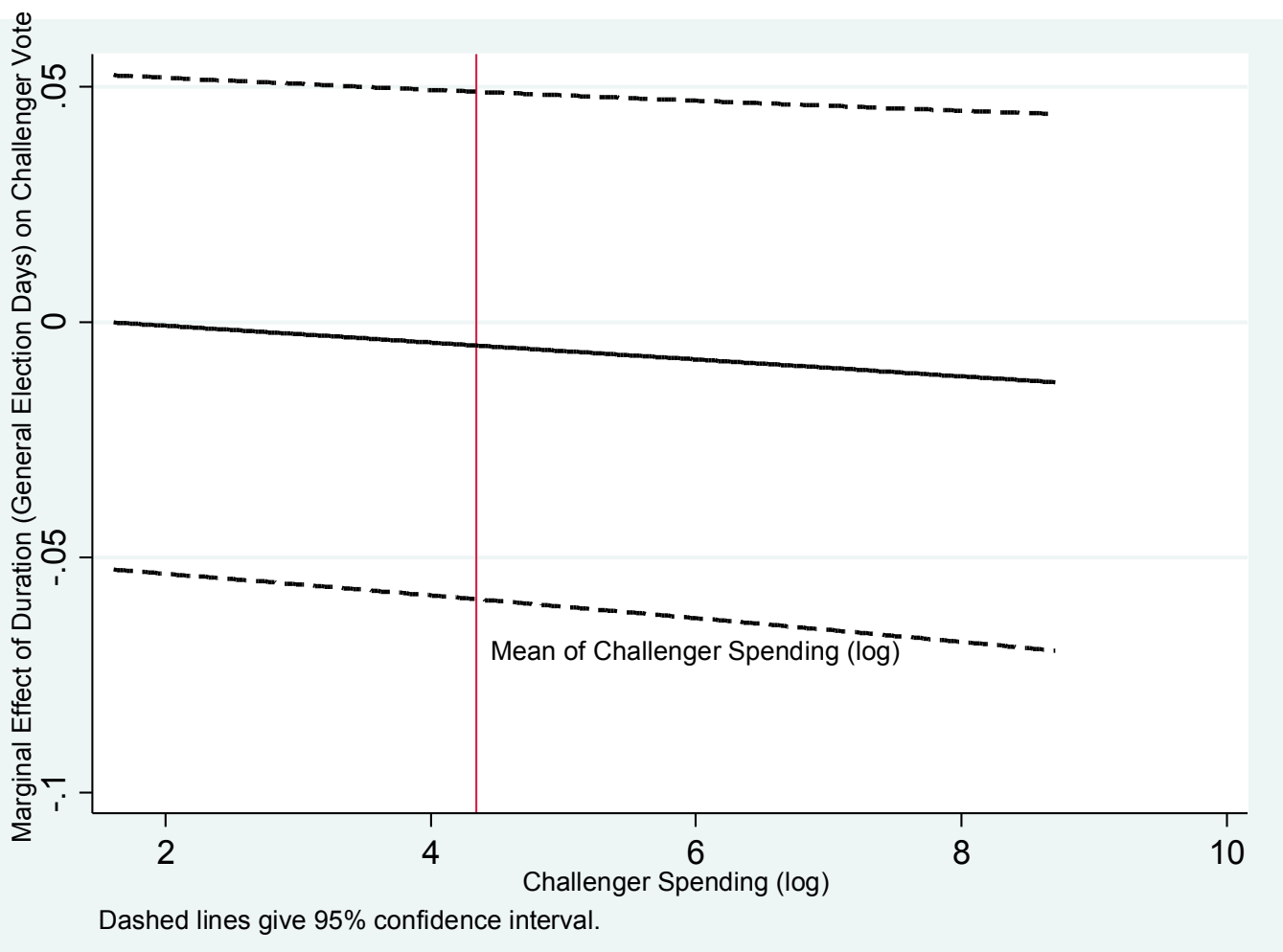

Figure 1. Marginal impact of campaign duration on challenger voteshares across range of challenger spending (logged) levels. 
Table 3. Estimating the impact of campaign duration on candidate familiarity.

\begin{tabular}{|c|c|c|}
\hline & Recognize Challenger & Recognize Incumbent \\
\hline \multicolumn{3}{|l|}{ Variable } \\
\hline $\begin{array}{l}\text { Incumbent spending } \\
\text { (thousands of dollars, logged) }\end{array}$ & $0.031(0.323)$ & $0.134(0.423)$ \\
\hline $\begin{array}{l}\text { Challenger spending } \\
\text { (thousands of dollars, logged) }\end{array}$ & $0.209 * *(0.103)$ & $0.015(0.139)$ \\
\hline Experienced challenger & $0.489 * * *(0.163)$ & $-0.066(0.211)$ \\
\hline $\begin{array}{l}\text { Candidate Party Strength in } \\
\text { District }\end{array}$ & $0.019 * * *(0.007)$ & $0.004(0.009)$ \\
\hline $\begin{array}{l}\text { General Election Duration } \\
\text { (days) }\end{array}$ & $-0.001(0.013)$ & $-0.003(0.016)$ \\
\hline $\begin{array}{l}\text { Duration } \times \text { Incumbent } \\
\text { Spending }\end{array}$ & $0.0005(0.002)$ & $0.0003(0.003)$ \\
\hline $\begin{array}{l}\text { Duration } \times \text { Challenger } \\
\text { Spending }\end{array}$ & $-0.0001(0.0006)$ & $0.00003(0.001)$ \\
\hline Constant & $-2.606(2.065)$ & $-0.025(2.691)$ \\
\hline$N$ & 509 & 537 \\
\hline Pseudo R-squared & 0.16 & 0.11 \\
\hline Log likelihood: & -278.972 & -147.119 \\
\hline $\begin{array}{l}\text { Notes: Probit regression (unweight } \\
\text { coded } 1 \text { if respondent accurately } \\
\text { statistical significance at the } p<.01 \\
\text { include the following political and d } \\
\text { gender, race, income, education, } \\
\text { partisanship of the challenger (as we } \\
\text { upon request). Source: [22] }\end{array}$ & $\begin{array}{l}\text { Standard errors in parent } \\
\text { ognized challenger/incumbe } \\
\mathrm{l}, * * \text { at the } \mathrm{p}<05 \text { level, usin } \\
\text { ographic control variables ( } \\
\text { ther respondent was marr } \\
\mathrm{s} \text { its interaction with respon }\end{array}$ & $\begin{array}{l}\text { eses. Dependent variable is } \\
\text { t, } 0 \text { otherwise. } * * * \text { denotes } \\
\text { two-tailed tests. Models also } \\
\text { t shown): partisanship, age, } \\
\text { d or resided in the South; } \\
\text { ent party ID; details available }\end{array}$ \\
\hline
\end{tabular}

We append the ANES data to include campaign variables shown to influence familiarity (campaign spending levels (logged) [23], candidate quality, partisan composition of district) as controls (see [4]); we also control for key political and demographic attributes including a dummy variable to denote the challenger's party (in addition to its interaction with a respondent's partisan identification), partisanship, age, race, gender, income, education, whether respondents were married or resided in the South. The key variable of interest is the length of the general election campaign, measured in total number of days between the primary and general elections as above. Again, we expect recognition to be positively related to campaign length; consistent with arguments developed above, we hypothesize further that the impact of campaign duration will depend on the level of campaign expenditures. We include terms in our models to test these hypotheses, including interactions. We use probit regression to estimate models to predict respondents' ability to recognize a candidate (incumbents and challengers separately) as a function of these variables and the interactions.

The results of the estimations are presented in Table 3. We find that challenger recognition is explained by challenger spending and experience and the district's partisan tendencies. The estimates reveal that neither challenger nor incumbent recognition is influenced by campaign duration; the interactions are also statistically insignificant, suggesting there is no heterogeneity in the impact of campaign length attributable to spending levels. Jacobson demonstrated that support for U.S. Senate challengers in the 2000 elections grew over time during the course of the campaign cycle in direct proportion to spending, but the author did not examine elements related to campaign duration [20]. Jacobson also demonstrated that incumbent familiarity and favorability were not linked to levels of incumbent spending, a result that is consistent with the estimates reported in column 2 of Table 3 [21]. In fact, we find that incumbent recognition is unrelated to the key factors we investigate including spending, candidate quality, district partisanship or campaign duration, suggesting that sources of familiarity with incumbents differ considerably from forces that influence challenger recognition.

\section{Conclusion}

Overall, the preponderance of empirical evidence we report suggests campaign length may matter little for election outcomes once the effects of other, relevant factors are taken into account. That said, there are hints that campaign duration could exert the hypothesized effects, but additional research is necessary to demonstrate this connection more definitively. We acknowledge the substantive impact of campaign duration is likely quite small, at best, but it may not be wholly irrelevant to candidate performance. Even so, there is scant evidence that 
campaign duration is related to familiarity with the candidates, so the identification of a mechanism by which longer campaigns may help challengers, if it does turn out to be the case, remains elusive. One sobering conclusion readers may reach from the current study is that if a pattern of longer campaign periods emerges in American elections, precipitated by recent policy reforms or otherwise, there are unlikely to be significant electoral consequences. For observers who decry anemic competition in races like congressional contests, longer campaigns will likely not offer a glimmer of hope.

We conclude by acknowledging that the current study and the theoretical arguments we develop raise some intriguing possibilities, but it is beyond the scope of this paper to explore all of the nuances associated with campaign duration. Further research

\section{References and Notes}

1. Erikson RS. The Incumbency Advantage in Congressional Elections. Polity. 1971;3(3):395-405.

2. Carson JL, Engstrom EJ, Roberts JM. Candidate Quality, the Personal Vote, and the Incumbency Advantage in Congress. American Political Science Review. 2007;101(2):289-301.

3. Mayhew DR. Congressional Elections: The Case of the Vanishing Marginals. Polity. 1974;6(3):295-317.

4. Jacobson GC. The Politics of Congressional Elections. 6th ed. New York, NY, USA: Pearson Longman; 2004.

5. Jacobson GC. The Effect of Campaign Spending in Congressional Elections. American Political Science Review. 1978;72(2):469-491.

6. Jacobson GC. Money and Votes Reconsidered: Congressional Elections 1972-1982. Public Choice. 1985;47(1):7-62.

7. Jacobson GC. The Effects of Campaign Spending in House Elections: New Evidence for Old Arguments. American Journal of Political Science. 1990;34(2): 334-362.

8. Abramowitz AI. Incumbency, Campaign Spending, and the Decline of Competition in U.S. House Elections. Journal of Politics. 1991;53(1):34-56.

9. Green DP, Krasno JS. Salvation for the Spendthrift Incumbent: Reestimating the Effects of Campaign Spending in House Elections. American Journal of Political Science. 1988;32(4):884-907.

10. Green DP, Krasno JS. Rebuttal to Jacobson's 'New Evidence for Old Arguments'. American Journal of Political Science. 1990;34(2):363-372.

11. Levitt SD. Using Repeat Challengers to Estimate the Effect of Campaign Spending on Election Outcomes in the U.S. House. Journal of Political Economy. 1994;102(4):777-798.

12. Erikson RS, Palfrey TR. Equilibria in Campaign Spending Games: Theory and Data. American Political Science Review. 2000;94(3):595-609.

13. Panagopoulos C, Green DP. Field Experiments could propose a more refined measure of campaign duration that takes into account the dynamics of the primary period or early voting. Additional work could also contribute deeper insights about how campaign length operates with other aspects of elections to influence outcomes. For instance, does the timing of campaign appearances differ depending on campaign length? How does news coverage of challengers and incumbents vary depending on campaign length? How does having a contested primary interact with these other factors? Do contested primaries give challengers a leg up by getting them early media exposure? Or do contested primaries prevent candidates from beginning their general election campaigns, ultimately hindering their chances of success? The central mechanisms linking campaign length and candidate success are complicated and beg further scholarly examination.

Testing the Impact of Radio Advertisements on Electoral Competition. American Journal of Political Science. 2008;52(1):156-168.

14. Stevenson RT, Vavreck L. Does Campaign Length Matter? Testing for Cross National Effects. British Journal of Political Science. 2000;30(2):217-235.

15. Wlezien C, Erikson RS. The Timeline of Presidential Election Campaigns. Journal of Politics. 2002;64(4):969-993.

16. Erikson RS, Panagopoulos C, Wlezien C. The Crystallization of Voter Preferences during the 2008 Presidential Campaign. Presidential Studies Quarterly. 2010;40(3):482-496.

17. Gelman A, King G. Why Are American Presidential Election Polls So Variable When Votes Are So Predictable? British Journal of Political Science. 1993;23(4):409-451.

18. Mayer WG, Busch AE. The Front-loading Problem in Presidential Nominations. Washington, DC, USA: Brookings Institution Press; 2004.

19. We note there do not appear to be any firm patterns over time; if anything, general election campaign periods appear to be growing slightly over the time horizon we examine, but this trend is not statistically significant at conventional levels. Data available upon request.

20. We note we obtain substantively similar conclusions for the analyses using ordinary least squares without instrumented incumbent spending. Details available upon request.

21. Jacobson GC. Campaign Spending Effects in U.S. Senate Elections: Evidence from the National Annenberg Election Survey. Electoral Studies. 2006;25(2):195-226.

22. The American National Election Studies. The 2002 Time Series Study. Ann Arbor, MI, USA: University of Michigan; 2002.

23. We do not adopt a two-stage least squares estimation approach using lagged incumbent spending as an instrument in these analyses given 2002 was a redistricting year and district. 


\title{
From Needs to Rights-A Socio-Legal Account of Bridging Moral and Legal Universalism via Ethical Pluralism
}

\author{
Andrej J. Zwitter
}

Department of Legal Theory, University of Groningen, Oude Kijk in 't Jatstraat 26, 9715 EK Groningen, The Netherlands; E-Mail: a.zwitter@rug.nl; Tel.: +31 503635991; Fax: +31 503637253

Submitted: 26 November 2012 | In revised form: 10 May 2013 | Accepted: 15 May 2013 |

Published: 30 May 2013

\begin{abstract}
The question of the universality of human rights has much in common with the question of the universality of ethics. In the form of a multidisciplinary reflexive survey, the aim of this article is to show how human rights discourses derive from more basic principles related to basic needs. These needs are the universal grammar for moral principles, which will be distinguished from ethical norms. Ethical norms, I will argue, are rules that develop in social groups to put into effect moral principles through communicative action and therefore develop as culturally specific norms, which guide behaviour within these social groups. This will explain why ethical norms contain some universal principles, but are largely culturally specific. In order to shed some light on the universality debate, I will show how moral principles translate into ethical norms and might manifest through communicative action in human rights law. For this purpose the article develops a socio-legal account on social norm-creation that bridges moral universality and legal universality via ethical pluralism, which in effect explains why despite the universality of moral principles, the outcomes of ethical rationales can vary extremely.
\end{abstract}

Keywords: discursive action; ethical pluralism; human rights; moral universalism

\section{Introduction}

In many ways natural rights have found their way back into common discourse. Statements of politicians and even court decisions account for that. This trend parallels the belief that human rights are universal. Such a conviction is fundamentally rooted in the belief of an existence of universal moral principles. However, cultural pluralists reject the belief of universality of morals; their most lenient position is that, although morals are different all over the world, in discourse we might find some common principles on which we all can agree. This article aims to give a socio-legal account of these positions that bridges moral universalism understood in relation to basic needs and legal universalism based on universal agreement between states in an interdisciplinary manner. While the individual debates traced herein are quite well known, they usually take place apart from each other. This article tries to place these debates in a broader socio-legal framework functioning as a conceptional link. The argument that this socio-legal account puts forth is then that due to our commonness in needs and vulnerabilities we all share common moral principles (moral universalism); but due to different mechanisms to protect from threats to needs and to alleviate vulnerabilities, which developed differently within different cultures, ethical 
norms are not universally the same, but on the contrary are very different (ethical pluralism); eventually, through international ethical discourse states are able to negotiate norms that are universally valid on legal grounds based on the acceptance of all states (legal universality). In this manner, this essay creates a link between these three conceptions about universality versus plurality and thereby constitutes a reinterpretation of Thomas Paine's distinction between natural rights and civil rights adapted to a globalized world. The arguments will refer to advancements in cognitive psychology concerning empathy and will be placed in a socio-legal framework on social norm-creation.

Section 2 will use human rights to exemplify three things: (a) that human rights are not themselves universal moral principles, but are based on culturally specific ethical norms; (b) that human rights can only claim legal universality based on acceptance by states; and (c) that human rights by themselves have become a culture for human rights lawyers and activists. This results in the phenomenon that even within the same culture, human rights advocates have distanced themselves from the popular opinion of large portions of society and/or from politicians about what constitutes ethical conduct. Section 3 will then briefly elaborate on norms that some authors accept as universally valid and continue with the example of "the prohibition of torture". Building on Wittgenstein's conception of depth grammar, the cultural grammar underlying the very foundations of language, the article will explain how cultures give their own coloration to discourses, which leads to a differentiation between universal moral principles and culturally specific ethical norms (a distinction between morals and ethics) [1]. Based on psychology of human motivation (related to needs) and cognitive research on neurological foundations of language acquisition, empathy and moral development (i.e. mirror neurons), Section 4 will explain how social-norm creation can be seen from a socio-legal perspective. Section 5 will then develop the socio-legal account based on the case of the prohibition of torture. Eventually, this article will contribute to the larger debate with a structural explanation on how societies tend to re-evaluate already established ethical norms in the face of events with great moral impact.

Moral principles and ethical norms, be it their universal application, their ethnocentric roots or their cultural interpretations, are a product of an extensive canon of post-Enlightenment ideas drawn from a rich variety of sources. This article reflects on these sources and tries to revisit the salient parts of some of these ideas by tying them together into one larger account of social norm-creation. By having to draw on a variety of abiding debates and case material, exploring their inner logic, and testing them against their equally colourful background from which they derive, this essay obviously faces the challenge to revive well known themes without becoming to superficial, while at the same time drawing the bigger picture of how, in the author's account, societies come from a priori morals to human rights. Thereby, this essay essentially aims to reconcile the universalist with the pluralist worldview through the use of theoretical elaborations on language, empathy and social norm-creation. The here presented account is then one of how initially universal moral principles pertaining to the protection of individuals and of social groups from harm become culturally coloured and emerge as culturally specific ethical norms. These ethical norms can become universal again only through international consensus. At this stage these ethical norms have absorbed many culturally specific assumptions that their acceptance is often disputed. The overarching objective of this essay is to lay the groundwork for future questions in the study of politics and ethics that aim to go beyond the contemporary tendency of scholarship to give priority to certain ethical concepts such as justice, whilst ignoring the canon of other concepts such as beneficence, magnanimity, mercy etc. as well as the pertaining question of vices and evil in international politics.

\section{Non-Universality of Human Rights}

Let me now turn the attention to the legal debate about universality, specifically with regard to human rights. Although this generalizes the subject greatly, one can make the classic distinction between natural law and positive law with regards to human rights as well. Thomas Paine made the distinction between $a$ priori given natural rights of persons and of a posteriori given civil rights (read: human rights) when stating:

\footnotetext{
"Natural rights are those which appertain to man in right of his existence. Of this kind are all the intellectual rights, or rights of the mind, and also all those rights of acting as an individual for his own comfort and happiness, which are not injurious to the natural rights of others. Civil rights are those which appertain to man in right of his being a member of society. Every civil right has for its foundation some natural right pre-existing in the individual but to the enjoyment of which his individual power is not, in all cases, sufficiently competent. Of this kind are all those which relate to security and protection." [2]
}

In response to an attack on the principles of the French Revolution in the House of Commons by Edmund Burke, Thomas Paine formulated the first part of the Rights of Man. He postulated civil rights as having their basis in natural rights; but he was also clear that these rights may not be fully enjoyed unless supported and protected by the state. This perspective 
is very representative of the 'natural law branch' of legal scholarship, which assumes that humans are to the same extent entitled to the same rights. The natural law approach argues in different ways for a common morality that is enshrined either in human nature, human dignity, nature, or god given law, which in turn results in natural rights [3]. The natural law discourse is particularly tempting nowadays as it assumes a close connection to human rights. This is apparent in many writings and a very common statement is: "we are all humans thus we all have the same human rights" (for similar statements and annotations see [4]). The statement demonstrates how language is used to connect two concepts, which are not necessarily married, by bridging the logical gap between being human and having rights through attaching the label 'human' to rights. Such rhetoric can lead to a wrong explanatory mechanism of why natural rights may result in human rights. Paine's perspective is particularly valuable with regard to the social mechanism pertaining to security and protection. Paine's perspective is different from Henry Shue's consequentialist argument for universality that certain rights (three in his case, eight in the case of Talbot [5]) are prerequisites because they ensure the enjoyment of other rights and protect against standard threats [6].

To a large extent this concealed retreat to natural law via rhetorical logic follows the intuitive feeling that there is some commonness-a universal morality. Many contemporary legal scholars (particularly of a continental European legal tradition) have, concerning universality of human rights, assumed the perspective of legal positivism, since natural law is considered to be outdated [7]. On the other hand, one of the most common references of 'legal rationalists' to be found derives from Kant's categorical imperative in one way or the other. Legal positivism essentially states that law is distinct from morality as it is simply a result of a process rooted in the legal system. Law does therefore not derive its validity from being morally right or just, but from being the result of a correctly followed procedure. Hart strongly defended this position and the need for a distinction between 'law as is' and 'law as ought', trying to separate the legal sphere from the moral sphere. He reiterates his position by the help of two utilitarians, Austin and Bentham, who "insisted on the need to distinguish firmly and with the maximum of clarity, law as it is from law as it ought to be. This theme haunts their work, and they condemned the natural-law thinkers precisely because they had blurred this apparently simple but vital distinction" [8]. Even though one of the major works on legal positivism, Kelsen's Pure Theory of Law, is a tribute to Kant's Critique of the Pure Reason, Kelsen rejects what he calls empty formulas ('inhaltsleere Formeln') such as the categorical imperative and the golden rule as basis of a principle of justice, because these formulas make justice subject to what one is willing to accept for oneself [9].

However, the principle of justice, which is commonly filled with natural legal assumptions, always finds its way back even into positive law through legal principles and the margin of appreciation of judges. One could further argue that law, because it is a matter of social agreement (within the right procedures and ultimately also about the right procedures), is always culturally specific. Such an argument would make legal positivism a relative of moral pluralism. Nevertheless, the difference is that legal positivism can explain universal human rights by referring to its universal acceptance through ratification by states. This is quite important because it distinguishes morality from law and introduces the idea of a universal discourse, which can result in consent about the formulation of a treaty and in acceptance by ratification. The universality then results not from being universally true but from being universally accepted-a legal universality.

With regard to cultural relativism in legal discourses the following arguments can be seen as examples of the overall perspective on Non-Western critique of human rights law (for a very elaborate account on different arguments why human rights are a particularly Western concept see [10]). In Vedic and Confucian traditions, critics of universality of human rights contend that duties towards the group are more important than rights of the individual against the group. In other words, Confucian virtues of order, obedience, and respect for authority are seen as justly limiting human rights as a sacrifice of a few for the benefit of many [11]. The Singapore School on Human Rights does not reject human rights per se, but it rejects the Western values in them that derive from cultural and historical developments of Europe and the US. At the same time, the Singapore School criticizes the West for applying double standards and pursuing its own political and economic agenda in the fight for human rights ([12], pp. 36-37). Out of the desire to "Africanize" human rights, African states established their own human rights regime. The African human rights discourse as manifest in the African Charter of Human and Peoples' Rights is very explicit about collective rights of groups and peoples: Art. 18-family rights to protection, Art. 19-equality of peoples, Art. 20-right to self-determination, Art. 21-peoples' right to freely dispose of their wealth and natural resources, Art. 22-peoples' right to economic, social and cultural development, Art. 23right to peace and security, Art. 24-right to a satisfactory environment ([12], p. 93). In terms of mechanisms of community survival it reflects a complex of communal entitlements and obligations, which are grouped around concepts such as respect, restraint, responsibility and reciprocity [11].

Another non-Western approach would be the Islamic discourse on the universality of human rights, 
which can be divided into three branches: (1) one that sees Islamic law as the perfect protection against human rights violations; (2) another approach that is aware of the differences and claims impossibility of full compatibility; and (3) yet another approach that suggests the possibility of applying the concept of margin of appreciation, i.e. a measure of discretion allowing states to take into account particular national circumstances [13], in human rights law and also proposes applying the Islamic equivalent to this concept (welfare: maslahah) to mitigate between cultural differences (for more detailed elaborations see [12,14, 15]). Radical cultural relativism finds support in the second position: "Western condemnations of discrimination against women in other regions are said to reflect an insensitive, ethnocentric approach to rights issues, which is linked to cultural imperialism" [16]. One of the less obvious (but very important) differences is that Islamic law is a combination of individual duties and community duties (five pillars of Islam, e.g. charity enforced by a poor-due tax, zakat) and entitlements of classes (for zakat the destitute and needy) that try to ensure a stable society and not the assertion of individual rights and freedoms [17].

There is one particularly strong argument against the universality-of-principles perspective on human rights: what a social group perceives as right and wrong in terms of human rights might differ from universally accepted human rights based on different values that are applied in a local cultural setting. These values of the social group are derivatives of its own social and historical context. In this regard universality of human rights can thus only be understood as the consent of states as representatives of their citizen to be bound by certain norms. Different cultures, the argument continues, do not intrinsically nor inherently refer to a common conception of human rights but rather to what Donnelly alludes to as human dignity, which makes them only seemingly the same [18]. Using similar labels, such as morality and human rights or even the same term such as 'human dignity' does not necessarily result in a compatibility of the underlying value hierarchies that try to ensure need fulfilment of a social group and the protection from harm in different cultural contexts. Even within the same state the ordinary citizen and the human rights lawyer might come into dispute over human rights that are not in harmony with the moral sentiment of the public, as the following cases demonstrate.

As a concrete example of the difference between popular ethical intuition and legal argument serves the protest of politicians with regards to a decision of the German Constitutional Court that shooting down a plane which aims at a populated area would violate the individual right to life and human dignity of the passengers. The court defended its anti-utilitarian perspective with the argument that one could not assume that innocent passengers would consent to give their life for others just by boarding a plane [19] (see also [20]). Another example is the "Mauerschützen" trials (the Berlin wall shooting trials) in Germany. After the German reunion, the German Highest Court circumvented the prohibition of retroactive penal law by arguing that East-German soldiers, who shot people trying to cross the Berlin wall (before the reunification) and went unpunished in Eastern-Germany, violated law common to all nations. Obviously, this law was not common to all nations; thus legal scholarship (contrary to the general public) criticized the court of having brought back natural law into the legal positivist tradition of Germany and connecting it with human rights law through the backdoor of Radbruch's formula ([21]; concerning the natural law argument see also [22]). Eventually the European Court of Human Rights followed the German Highest Court in its opinion [23].

Yet another instance of how different national courts in comparison to the popular opinion might argue is the following trial, in which the German Highest Court came to a conclusion that was contrary to the popular moral sentiment. The Daschner criminal trial concerned the former deputy police chief of Frankfurt, Wolfgang Daschner, who threatened Magnus Gaefgen, the suspect who had already confessed to the kidnapping of a boy, with torture if he would not reveal the boy's location. In the criminal procedure against the deputy police chief, the court came to the conclusion that human dignity (Article 1 paragraph 1 sentence 1 German Grundgesetz) is an untouchable principle without exception, which corresponds with the absolute prohibition of torture of Article 3 European Charter of Human Rights [24]. This case resulted in a heated discussion about the permissibility of 'rescue torture', a variant of the ticking bomb scenario, among scholars, the German press and the German public [25].

All the above cases have in common that due to different conceptions underlying the same label ('human rights') a fierce disagreement within even the same state occurred. It seems that the legal conceptions underlying the argument of universality have changed to that extent that common moral sentiments cannot consent to the results of law application in extreme cases. The limits of a semantic incompatibility of human rights with general ethical beliefs become apparent in these cases. That the fault lines of this disagreement open up between the wider, not legally trained public, politicians with certain responses in mind, and human rights lawyers suggests that human rights have emerged as a fairly specific kind of ethical norms within a legal culture that does not always correspond with the public opinion about morality and by extension of how law should work. 
This is, however, not the whole story. People might disagree in these extreme cases where human rights seem to violate utilitarian moral logics, but such logics come under attack where the level of cruelty, the systematic nature of the deed and its proportions are clearer as with torture in Abu Ghraib and Guantanamo Bay. In other words, there seems to be some consensus concerning the existence of very basic moral principles. This is not to say that there is consensus on the justifications applicable to deviate from moral principles such as: what constitutes the greater good, avoiding a terrorist attack by retrieving information from suspects through torture or not living in a society in which torture is the sword of Damocles hanging over everyone's head who might be identified as a potential bearer of valuable information? The next section will discuss moral universalism and relativism to shed some light on what could constitute the universal core and what the relativist elements of human rights.

\section{Language and Morals}

One can distinguish between two contrary theoretical positions regarding ethical norms, moral principles and cultures which one can label 'radical cultural relativism' and 'radical universalism'. The former sees culture as the sole source of validity of a moral right or wrong, while the latter holds that cultural perspectives are irrelevant to moral validity as moral principles are universally valid [26]. The radical cultural relativist's main argument claims that there are no rights that everyone is entitled to equally because humans are different [27]. The following explanatory argument underlies this ethical relativism: people differ in their basic moral beliefs; "there are or there can be no value judgements that are true, that is, objectively justifiable independent of specific cultures" ([28], p. 782); "in every case the rightness of any act or goodness of anything for a member of culture $A$ is justified by reference to what in fact is considered right or good in culture A" ([28], p. 786). Radical cultural relativists, therefore, deny common values that all cultures share, such as human rights. In response Donnelly argued, that "if human nature were infinitely variable, or if moral values were determined solely by culture, there could be no human rights (rights that one has "simply as human being") because the concept of "human being" would have no specificity of moral significance" [29]. Radical universalism essentially turns these arguments around, claiming that all humans are the same and therefore the same moral principles apply to everyone. The reasons can range from natural law, to a Humean inherent moral sense [30], to rational Kantian reasoning [31], or combining moral sentiments with rational reasoning [32].

In between these two extremes, one can locate two branches of moral philosophy that argue for a middle path and agree on some degree of commonness: 'weak cultural relativism' and 'soft moral universalism'. Donnelly advocated weak cultural relativism as an explanation that integrates both the 'undeniable fact' of cultural relativism and the universality of some norms by resorting to the human rights discourse as follows:

"Rights held equally by all against the state, both limiting its legitimate range of actions and requiring positive protections against certain predictable economic, social, and political contingencies, are a seemingly natural and necessary response to typically modern threats to human dignity, to basic human values, traditional and modern alike" [33].

Donnelly's approach, which he later terms "functional universality" attributes universality of ethical norms to the fact that the same constraints are being posed to the individual in the modern state. Moreover, when using the terms 'human dignity' and 'basic human values' he assumes that there is indeed some commonness to be found. The mere fact that modern states pose similar threats does not yet mean that similar values are threatened. Thus, this perspective is only plausible if these similar threats are directed against similar values. This means a necessary presumption of same threats is that people are the same in what can be threatened in the first place. Earlier in his writings Donnelly, however, seems to suggest that the principle of human dignity is to some extent universal but realized in different ways [18]. This sociolegal perspective in his earlier writing does not come back in Donnelly's 2007 article The Relative Universality of Human Rights and the following debate with Goodhart, which discusses a wide range of different forms of universality (functional, legal international, overlapping consensus, anthropological, and ontological universality of human rights) [34-36]. However, exactly the commonness of human faculty is what seems to be the initiating factor for social normcreation as will be elaborated in Section 5 .

Soft moral universalism assumes that there are some basic moral principles that are shared by all cultures such as human dignity or the prohibition of murder, but also assumes that different cultures may apply or ensure these principles differently. When looking into diverse cultures at various points in times, some scholars found that there are some basic principles that where valid in all cultures. Gert and Lewis described a set of common moral principles one might regard as universal (and which will illustrate how the use of labels and categories leads to a semantic incompatibility, but not a factual one). Following Gert's account of universal moral principles there are ten norms the violation of which without justification is universally prohibited as immoral action (see Table 1). 
Table 1. Gert's ten universal moral principles [37].

1. Do not kill.

3. Do not disable.

5. Do not deprive of pleasure.

7. Keep your promises.

9. Obey the law.
2. Do not cause pain.

4. Do not deprive of freedom.

6. Do not deceive.

8. Do not cheat.

10. Do your duty.

Table 2. Lewis' illustration of the Tao [38].

1. The Law of General Beneficence: 'I have not caused hunger. I have not caused weeping.' (Ancient Egyptian. ERE v. 478)
2. The Law of Special Beneficence: 'Part of us is claimed by our country, part by our parents, part by our friends.' (Roman. Ibid. i. vii)

a. Duties to Parents, Elders, Ancestors

b. Duties to Children and Posterity

3. The Law of Justice

a. Sexual Justice: 'Thou shalt not commit adultery.'

b. Honesty: 'Has he drawn false boundaries?'

(Babylonian. List of Sins. ERE v. 446)

c. Justice in Court, \&C.

5. The Law of Mercy [37]: 'You will see them take care of... widows, orphans, and old men, never reproaching them.' (Redskin. ERE v. 439)

4. The Law of Good Faith and Veracity

'A sacrifice is obliterated by a lie and the merit of alms by an act of fraud.' (Hindu. Janet, i. 6)

6. The Law of Magnanimity: 'There are two kinds of injustice: the first is found in those who do an injury, the second in those who fail to protect another from injury when they can.' (Roman. Cicero, De Off. I. vii)

In a similar way, but more on the level of principles, Lewis distils eight principles of natural law, which he calls Tao, out of 119 examples (covering Australian Aborigines, Native Americans, Christian, Hindu, Chinese, Norse, Egyptian, Greek, Jewish, Roman, Germanic, and other traditions) that all cultures can account for without known exception (see Table 2).

The difference between Gert's and Lewis' account of universal norms might at first sight be interpreted as an argument against universality as such. Both try to prove the same point but come to different categories, which seem hardly compatible, because they categorize elements of the same object of inquiry ('social interaction') into other categories of moral principles. Gert formulates a prohibiting norm in the form of a commandment ("Do not cause pain!"). The physiological and psychological makeup of a human being that enables it to experience pain is implicitly assumed in both accounts. Lewis chooses not to formulate the norm in the form of a prohibition against the vice of cruelty, but in a commandment in the form of the virtue of general beneficence.

When looking closer, the laws of general and special beneficence describe Gert's first five norms by adding a psychological mechanism to it, namely that there is a difference between the compassion towards friends, family and strangers. Lewis' laws 3 and 4 do not appear in a special way in Gert's account as he does not reflect on the difference between the closeness of relationship in the first place. The law of justice relates to the principle 'obey the law' and 'do your duty'. And finally, good faith and veracity are reflected in keeping promises, not cheating and not deceiving. Magnanimity and mercy are, according to Gert, virtues that more describe the moral identity of a person than a moral principle ([37], pp. 76-79). Most of all, the reason for coming to different categories and labels might be that Lewis includes an element intrinsic to social behaviour that Gert blends out, namely the difference of compassion depending on the specific relationships involved. It is the phenomenon that in moral terms we do not only differentiate between me and the other but also between me, people that I am close to and the other. This is expressed by the law of special beneficence, which does not only relate to one's own preferences that we have in fulfilling moral obligations towards people who are emotionally closer to us. It seems to be also a bigger principle that a judging observer applies when (s)he sees a violation of moral principles regarding 
two actors that are either close to each other or not. This changes also the perception of severity of the breach of a moral principle [40]. The expression of special beneficence is not so much manifest in Human Rights Law (protection of the family and rights of the child merely acknowledge the specific importance of the family in social life and the increased vulnerability of children). It is, however, commonly found as an attribute in criminal law (e.g. different punishment for perpetrators who misused a relationship of trust). Also general beneficence exists regarding people that do not belong to the in-group quite commonly, for example as the principle hospitality in international legal discourse since Vitoria [41]. A modern view of Human Rights and particularly the concept of the Responsibility to Protect seem to also confirm growing international acknowledgement of general beneficence not only as a moral but also as an emerging legal duty.

Looking at common principles it is immediately apparent that (1) all principles mentioned by Gert and Lewis relate to social interaction, which is also the field of culture, and that (2) most of the principles mentioned relate directly or indirectly to the causation or the prevention of harm. Concerning (2), Linklater found that the principle of harm follows similar narratives across cultures because of the universality of the human condition to experience pain, which puts cruelty, i.e. causing harm without justification and simply for the sake of making someone suffer, to rank highest in the vices one can commit [42]. Harm and multiple general forms of how it can be inflicted through commission and omission reside in the psychology and physiology that compose together the human condition and its ability to experience suffering.

Next to that, some norms shape a basic structure of what communities in general need to be able to survive as communities (Gert: 6-10; Lewis: 2, 4, 5, $6)$. Norms such as veracity and justice are considered universal, not because they are relevant for individual survival, but for group survival. Social groups require some degree of trust and/or control to benefit from the advantages of cooperation among its members.

If the object of inquiry changes only marginally, it can happen that many implicit assumptions change as well or are added. Let us assume for now that the norm of general beneficence is based on the same assumptions as the prohibition of causing pain, namely the physiological and psychological makeup of a human being's ability to experience suffering. If we compare this norm with its equivalent norm in the Universal Declaration of Human Rights (UDHR), we find in the latter that many more assumptions are tacitly added: "No one shall be subjected to torture or to cruel, inhuman or degrading treatment or punishment" (Article 5). The basic assumptions that make the breach of this norm possible are the same (the human ability to experience pain). The difference lies not in the offence but in the formulation of the Article 5 and the logic of the UDHR as such. General beneficence and the prohibition of causing pain concern a perpetrator and the offence, and are valid independently from the culture in which they happen (as long as we do not include justifications). These general moral principles derive directly from a violation of human integrity. Therefore, they do not assume a conception of individual rights and freedoms or, for example, structures where norms oblige or give rights to communities instead of individuals. That means they do not contain secondary (executive) norms of how the violation relates to the victim with regards to rights. They only relate to the perpetrator in the form of a duty. Compliance mechanisms are also omitted. In the UDHR's view "no one" refers to an individual right of a subject to such a treatment (which is more clearly expressed in Article 2: "Everyone is entitled to all the rights and freedoms set forth in this Declaration..."). Thereby, the same norm implies much more in the latter case by adding the concept of entitlement. It additionally tacitly assumes that the same human is equipped with rights and freedoms that stem from its individuality. Thus, the shift from obliging the duty bearer to give rights to an individual is a step that changes the object of inquiry from a moral principle stemming from basic physiological and psychological experiences of pain to the rights of human beings as individualized entities. It furthermore assumes that humans are entitled to exercise these rights and freedoms against a state entity with corresponding duties.

Therefore, in the light of the discussion above one can see that semantic incompatibilities do not necessarily result in factual incompatibilities concerning the protected value. However, as soon as additional assumptions (about the rights/duty relationship between rights-holder and duty-bearer; the relation between state, groups and individuals; the forms of suffering; the relationship between in- and out-groups) are implicitly introduced, one creates norms that presuppose certain cultural-normative structures. This is what always happens in social norm-creation and which creates the impression that there is no universality. Nevertheless, the underlying reason for creating the norms "Do not cause pain"/General beneficence/ Article 5 UDHR is originally the same and universalto protect people from harm. Thus, language has two effects: (a) using different categories and labels seemingly leads to an incompatibility based on semantics; and ( $\beta$ ) attaching tacit procedural and cultural assumptions leads to a real incompatibility. The next section differentiates between principles that can claim universality and the tacit procedural and cultural assumptions leading to culturally specific ethical norms. 


\section{Cultural Specificity of Ethics}

Since Maslow many scholars have attested that needs can create an impetus for human motivation (see for example [43-45]; [46]). One can essentially summarize that when people feel that their needs are threatened, this dominates their behaviour. My hypothesis in this regard is that the violation of fundamental needs leads people to identify moral principles. I use the term 'fundamental needs' to avoid the postulate of a biological essentialism, which would be caused by using the Maslowian term 'basic needs'. Maslow himself doubted that the hierarchical structure of needs reflects an order of importance of needs to the individual considering the fact that people go on hunger strike for their beliefs, i.e. are willing to risk physiological (basic) need fulfilment for psychological or transcendental needs [43]. 'Fundamental needs' mean to reflect the fulfilment of needs necessary to human faculty and without which life cannot thrive sustainably. In this sense transcendental needs (the need for an overarching framework that helps the individual to make sense of the world) are just as fundamental as the need for food, shelter and love. With the inclusion of transcendental needs one however includes philosophical frameworks, such as religions which are highly culturalized. Fundamental about it is then not the specific world view itself, but the need for such a world view whatever shape it might take (philosophy, religion etc.). One experiences this fundamental nature of transcendental needs when ideas and events cannot be explained by one's current world view and thus threaten the very fabric of one's sanity if one does not modify her/his world view.

Therefore, although the violation of fundamental needs is universally comprehensible in the same way, different mechanisms evolved in different cultures and social groups to ensure the fulfilment of these needs leading to a differentiation of expression of safety needs. Furthermore, higher value is attributed to value categories of subsistence of fundamental needs than to object categories that ensure survival to a lesser degree. These value categories of subsistence differ from culture to culture because they are based on different forms of survival. An example can illustrate the basic problem with regard to different value categories of subsistence and how it links to fundamental physiological needs: Stealing is forbidden in every culture. However the punishment for stealing varies. Stealing a cow in Western Europe nowadays might be seen as a petty crime punished with a relatively low sentence in comparison to the punishment that would result from the same act in a Muslim South Sudanese herding community (e.g. cutting off limbs) [47]. The difference in the punishment can be explained by the difference in what a cow means for the fulfilment of fundamental needs in one or the other community and culture. Thus, the same object (the cow) falls in the South Sudanese case into a value category of subsistence higher in the value hierarchy than it is placed in Western European cultures, although all do agree that it is a wrongdoing. Stealing a cow in Western Europe threatens the survival of the community less than in a South Sudanese herding community.

Cultural specificity is also reproduced in language. Some philosophers see herein an absolute hurdle. I will, however, elaborate that there are common denominators that allow overcoming this problem. Hudson's example of a small party of Martians coming to earth telling people what they ought to do illustrates the argument of some philosophers that we would not recognize an alien moral discourse as moral discourse, because the depth grammar of Martians would be fundamentally different to ours. According to Wittgenstein's theory of surface and depth grammar, language is woven into our lives and our culture. Therefore, the argument continues, we would not understand the depth grammar (telling us that if "x is red" one assumes that $x$ is an object with the physical attributes of 'red' that are visible to the normal sighted) underlying a Martian moral discourse [48]. My argument is that although language is woven into life and by extension into culture, the ultimate determinant and presumption of language is social interaction and therefore life itself. If moral is "what prevents harm to life", then one assumes that "harm to life can be caused by depriving life of fundamental needs". This is universally valid to all forms of human life and alien life to the extent of the similarity of fundamental needs and under the condition that the Martians possess the faculty of rational reflection.

Without a social counterpart language is not necessary and without the concept of life morality has no meaning in a discourse. This becomes evident when trying to come up with examples that try to disprove this assumption, e.g.: what is the moral property of disassembling an inanimate object that nobody is emotionally attached to and that serves no purpose to individuals and or social groups? This question becomes a moral question only once a sentient being fosters any kind of relationship to that object. The moral question becomes then whether the effect of disassembling the inanimate object leads to negative effects for the sentient being or a group. Most basic and thus universally understandable moral discourses can therefore be said to have at least 'life' as the universally common reference point, and in their prescriptive form the prohibition to harm life by prohibiting privation of fundamental needs necessary to sustain life. This means that if the Martian discourse was indeed about morality, then 'life' and the violation of it through causing harm would also feature in their moral discourse as a reference point, 
at least when talking about their most fundamental moral principles. Because we share this reference point, we would recognize their discourse as a moral discourse notwithstanding that we might disagree about the outcome of their ethical reasoning. Suggesting that moral discourse can ultimately (with regard to the reference point 'life' and by extension fundamental needs) always be recognized as such does not imply that all facets of a Martian ethical reasoning would disclose themselves to our comprehension. Because of a different depth grammar we might be unable to recognize a Martian moral discourse with regard to cultural specificities (e.g. if there were no concept of property in Martian culture, there would be no concept of stealing). Parallel to the punishment of theft of a cow in the South Sudanese herding community case, the elaborations on depth grammar also help to distinguish ethical norms from moral principles. The moral principles recognizable in a Martian discourse would be those that relate to harm by depriving of fundamental needs in various derivative forms of action (e.g. the act of stealing what someone needs to fulfil fundamental needs). The ethical norms reflect the culturalized specificities of social interaction, compliance mechanisms, ways in which a group ensures that fundamental rights are protected, and the hierarchy of values that determines the proportionality between violation of a prohibition, appropriate defence against such a violation and punishment. In the South Sudanese case ethical norms would be the value that livestock represents, the punishment attributed to stealing livestock, and the enforcement mechanisms attached.

I suggest that the more a moral discourse diversifies and departs from the common points of reference 'life' and fundamental needs, which make life possible and sustainable, and moves on to culturally coloured specificities of social life (diminutive derivations, e.g. social integrity, honour, property, importance of family, etcetera), the more depth grammar makes different cultures unable to recognize that the other's moral discourse and ethical reasoning is based on the same moral principles. The same mechanism of cultural coloration would make moral discourses between cultures that recognize different value hierarchies on top of the commonly shared value of life potentially incompatible. This becomes particularly apparent when looking at the order of value hierarchies. The question "is it justifiable to kill, inflict physical or psychological pain, offend or not to do anything if one's honour is violated?" results in different answers depending on the culture that is asked. The social mechanism of honour developed in some societies as a social mechanism to prevent crimes, while in others to protect one's honour was not necessary. This can be explained by evolutionary psychology: "A key element of cultures of honor is that men in these cultures are prepared to protect with violence the reputation for strength and toughness. Such cultures are likely to develop where (1) a man's resources can be thieved in full by other men and (2) the governing body is weak and thus cannot prevent or punish theft" ([49], pp. 48-49,51). To see honour as a value embedded in the social context helps understand how depth grammar might prevent members of one culture from understanding the actions of another culture as ethical.

How the respect for the other is expressed takes an even stronger cultural coloration. A female American student accompanying her professor on a field research through Islam expressed on one occasion her anger about an Islamic scholar they interviewed, because he would not even have the audacity to look in her eyes when talking to her. Her professor, familiar with both cultures, explained that the Islamic scholar, in accordance with his cultural expression of honour, would have dishonoured her by looking into her eyes [50]. In traditional Japanese culture honour was of highest importance and connected strongly with loyalty. For example, the Hagakure (the code of the samurai) describes how 36 samurai wanted to give their lives (seppuku) to honour their deceased master and show their loyalty. The clan leader, Mitsushige, heard of it and issued a decree that seppuku to show loyalty beyond life would be dishonourable and disloyal [51]. If such abiding loyalty as a value is alien to another culture, it has a hard time understanding the ethical rationale of the 36 samurai and it might simply call it craziness. Loyalty and subordination to superiors in traditional Japanese culture, however, were the foundation to the functioning of this society. Loyalty was not blind, but it also demanded from the samurai to tell his master if he was wrong, even if the samurai would be punished for it. In that way, the values of loyalty and courage to do the right thing enabled stability of the societal structures, which is why loyalty and courageous integrity cannot be separated from each other in the Japanese context without having destabilizing effects on the social system. This further indicates that fundamental needs of life might be at the centre of moral principles, but also that the functioning of the social system and the survival of the social group are at the heart of ethical reasoning, bearing the distinction between the two in mind.

As one can see with the example of honour, the role and place of values in the value hierarchy of a society enables its members to make conscious choices about moral questions concerning the rationale of their deeds in accordance with what the society would accept. This hierarchy of values is inherent in all principled moral arguments, and also in the previously discussed value of the prohibition of torture. The Human Rights Committee made the value 
hierarchies that guide the logics concerning torture explicit in is General Comment 20 on Article 7 International Covenant on Civil and Political Rights (ICCPR):

"The text of article 7 allows of no limitation. The Committee also reaffirms that, even in situations of public emergency such as those referred to in article 4 of the Covenant, no derogation from the provision of article 7 is allowed and its provisions must remain in force. The Committee likewise observes that no justification or extenuating circumstances may be invoked to excuse a violation of article 7 for any reasons, including those based on an order from a superior officer or public authority" [52].

The only reason of why human rights treaties were established in this way was given in a very short sentence in General Comment 7: "Its purpose is to protect the integrity and dignity of the individual" [53]. What remains implicit is the reason why dignity trumps life concerning torture in all circumstances. For finding out what reasons could be put forward, one would have to study the relevant case law and the materials to Article 5 UDHR and Article 7 ICCPR respectively.

We have now established that the norms we discuss in ethical discourse are culturally specific expressions of moral principles coloured by the depth grammar of a specific culture, which I call 'ethical norms'. I refer to 'moral principles' as those that can be considered universally common to all people and universally recognized as belonging to moral discourses - the tacit presuppositions of life itself, i.e. the ability to suffer (physiologically, psychologically or transcendentally) and to die or to lose the will to live as a cause of deprivation of fundamental needs. As soon as language is involved, moral principles become immediately tainted by cultural specificities, the order of values in the value hierarchy, by assumptions about how a social group ensures its survival, and by the relation between rights and duties as well as between individuals and the social group.

Habermas' term of discourse ethics takes a similar meaning with regard to ethics in the sense of a result of communicative action on which discourses are superimposed. Habermas assumes that moralities coincide because linguistic action is the source of and the solution to mutual vulnerabilities of socialized persons. In a discourse, the more exacting form of communication, he sees the potential of universalizing moral principles beyond the provincial limits of particular forms of life [54]. Habermas himself calls this a scaling down of the categorical imperative to a universality agreeable to all parties in the discourse (a biggest common denominator) ([54], pp. 201-202).
However, Habermas' argument of an agreeable universality works only, if one assumes that, as for example concerning human rights, there is a common denominator such as found in a priori existent moral principles deriving from fundamental needs. Because under the conditions set forth by different cultures to ensure these principles for the society in manifold ways, language has two more effects: $(Y)$ it connects ethical discourses and makes them potentially compatible within the same social group that shares the tacit cultural assumptions; $(\delta)$ it also separates different cultures from each other because they do not share these assumptions and the depth grammar would indeed result in the Martian dilemma. If there were no common moral principles, different cultures might try to negotiate, but they would never find a common ground. That agreement about human rights is possible, is the effect of a priori existent moral principles that derive from the human condition and fundamental needs.

In summary, a priori universality of the moral principles is given only in an early stage of when the moral norm is identified. This a priori universality derives from the human condition of being able to experience pain and suffering (through the privation of fundamental needs) and ultimately to die. After that initial stage of identifying the relevant moral principle, ergo as soon as discourse starts, language attaches many cultural specific elements to these principles. Most of them remain tacitly assumed. Furthermore, executive norms are attached to ensure compliance with the norm. These executive norms incorporate societal structures and the respective hierarchy of values. Once we reach this stage, we find a fully developed ethical norm as demonstrated with Article 5 UDHR in the previous section. This section used the concept of honour to explain the value hierarchies that are implicitly attached by cultures. It showed that these assumptions remain just as implicit in the Human Rights Committee's General Comments concerning torture.

The next section gives a sociological account to social norm-creation and continues on to a different form of universality (through universal acceptance-a posteriori) that can be achieved through international discourse-legal universality.

\section{Connecting Needs, Empathy and Morality}

With regard to depth grammar one might raise the question of what are, as Wittgenstein calls it, the tacit presuppositions of life and culture in moral discourse ([55], p. 197). Being part of the language game, such tacit presuppositions are assumptions of cognition that do not need to be expressed in order to be understood. Describing the scene of a patient and a doctor Wittgenstein explains that depending on whether 
it is a scene in a play or a psychology book our understanding changes: "If this experiment were described in the same way in a book on psychology, then the behaviour described would be understood as the expression of something mental just because it is presupposed that the subject is not taking us in, has not learnt the replies by heart, and other things of the kind" ([55], pp. 179-180, Section V). In similar terms when talking about ethics tacit presuppositions are constantly present, those about what constitutes life and those about what constitutes the norm in a culture. E.g. for stealing a cow his limb was cut off. The tacit presupposition of life is twofold in this case; both the cutting off of the limb is an infringement of life, and so must be the deed of stealing for which the retribution was cast. The tacit presupposition of culture in social life is the proportionality of the retribution in relation to the deed, the value hierarchy that relates to stealing of a cow and cutting off of limbs, and the assumption of an ethical system of norms regulating both the idea of property and the relation between actors. These tacit presuppositions thus rest on assumptions connected with the object of investigation, and ethics is the language game to form rules based on the tacit presuppositions of life and culture.

One tacit presupposition is revealed by the use of the word 'good' in all discourses. 'Good', or as Warnock translates it "human happiness or interests, needs, wants, or desires" ([48], p. 59), is obviously something that all moral discourses are concerned with. The tacit presuppositions we do all have in common is the fact that life in order to be sustained requires the fulfilment of fundamental needs. Another tacit presupposition of moral discourse is the fact that life can only be sustained in social interaction, which happens among humans to a large degree through speech-acts. Thereby, language becomes indispensable for the creation of a complex of moral principles, ethical norms and value hierarchies.

In terms of social norm-creation, if there were no conception of the wrongness of depriving somebody of his life without justification, human life would be without protection and open to attack any time. Since human life is, however, not possible without mutual social exchange, i.e. a society of humans, trust of not being killed by anyone randomly is a prerequisite of any society. Furthermore, since social norm-creation is a social process and the human being is socially embedded and dependent on the other members of the group, one possible justification of killing is logically when the existence of the larger group is at stake. The continuation of human existence in a society therefore requires the right to exist as a norm within this society. Likewise the society will claim a right to existence and therefore self-defence against external threats as well as individual members threatening the social structure that ensures survival.
In order for a group to survive, the first principle of the preservation of life is not to murder any member of the group without justification. This does, however, not preclude that value hierarchies might differ from culture to culture and that the values inherent in the justifications for killing a member of the group might differ.

How does social norm-creation relate to fundamental needs? With regard to social interaction one can postulate the following three points:

a) Actors derive moral principles (primary norms) from the violation of tacit presuppositions of life itself reflecting the fulfilment of fundamental physiological, psychological, and transcendental human needs.

Why would actors derive moral principles from violations of tacit presuppositions of life? From Adam Smith's [32] elaboration on moral sentiments based on sympathy to modern neurological and cognition research, many scholars agree that humans are equipped with moral faculty based on empathy [5659]. There is increasingly evidence that mirror neurones are responsible for empathy. Mirror neurones are neurones that fire when an individual acts and also when it observes action. Interestingly, originally attributed to the acquisition of both language and grammar, mirror neurones seem to be also largely responsible for empathy with the suffering of others and the imitation learning of moral principles as well (see for example $[60,61])$. In layman's terms, observing the suffering of others results in mirror neurons firing in the brain of the observer and thereby resulting in empathic compassion.

b) By abstraction based on these higher ranking principles (a) a group can envision certain actions as threatening to its own existence, which leads the members to engage in ethical discourse and to formulate prescriptive norms (e.g. protection of life, prohibition of harm, prohibition of stealing).

It is only natural that within social groups the drive to avoid both direct and indirect experience of harm will result in the exchange of opinions on how to achieve this. This results in what Habermas terms 'discursive action' trying to formulate principles of harm prevention. At the same time, how to ensure the preservation of life and the fulfilment of needs would strongly depend on how groups learned to survive together efficiently. This can be different based on the value categories of subsistence present in a culture resulting by and large from different cultural systems and technologies of production, the availability of sources of need fulfilment (food etc.), and the form of government and procedural order guiding the society's dispute settlement and norm enforcement. Therefore, one would learn different ethics in one culture than in another.

c) In order to protect moral principles (a) through 
these ethical norms (b) from future violations the group creates secondary norms ensuring compliance, i.e. norms that regulate the relation among individual members and between the group and its individual members (in the form of obligations or rights of the group and/or of the individual).

Eventually, discourses about human rights have long ago transcended the nation state through globalization, informal pressure by non-state actors with the aim to protect human rights and through states agreeing upon common laws in the form of international covenants on human rights. This universal agreement was already discussed above. But now it becomes apparent that the moral a priori universality in this last stage has diminished and made room for a legal a posteriori universality based on the international discourse between states. In this last step, as observed above with the Gaefgen torture case and the plane shooting debated in Germany, when states agree upon principles to become international law, there seems to be a disconnect between the moral sentiment of the public which remains in its own sphere (national, sub-national, local). States will have to trade off cultural specificities that are unique to the cultures they encompass in order to make agreement possible. This compromise might be between local cultural values and values accepted in international law either concerning mechanisms of ensuring survival (such as the role of the individual vis-à-vis groups and vis-à-vis states), or concerning the content of a norm in relation to justifications and aggravations.

The Kantian idea that morality strives for the highest good, which is an immanent and transcendent, but necessary and therefore possible object of volition [62], as Kohlberg interprets, has its own autonomous sphere. That means that a moral argument is distinct from other forms of argument as it uniquely establishes the tacit presupposition, which by the very nature of moral discourse asks questions about the relation between sentient beings and the effect of an event or act on their fundamental needs, at the same time with relation to the individual as well as to the social group. The question "Is it morally right?" [54] as Habermas puts it or the Kantian "What ought I to do?" has its autonomous sphere, if we can agree that morality is ultimately and minimally always about the reduction or prevention of harm through any privation of fundamental needs. This makes the discourse about morals recognizable for every culture, but not at the same time compatible, because the outcome of how to ensure moral principles needs to be formed along the lines that societal and cultural specificities require. Looking from this perspective back at Habermas' discourse ethics, it appears that the process of ethical norm-creation does not necessarily happen in a rational act of the individual moral agent but is rather the result of discourse among the members of a social group. The perspective of the social construction of ethical norms based on universal moral principles deriving from a discourse that acknowledges fundamental needs of the individual as member of a group as well as the group's overall needs thus leads to highly specific and culturally coloured ethical norms that contain: compliance mechanisms, justifications for violation, and aggravating elements (circumstances under which a violation is worse).

This then seems to also put into perspective that the argument that liberty in the form of individual autonomy constitutes the basic principle of morals is a highly culturally embedded argument (see for example $[63,64])$. Because individualistic liberty and rights are but one way of ensuring fundamental needs, another would be via group obligations towards the individual in mutual correspondence with individual duties towards the group. This has been illustrated with the non-Western critique to Human Rights above. Thus individual liberty is just one form of ensuring basic moral principles and not a basic moral principle by itself. It is an ethical norm, more exactly an executive norm, describing the relation between members of the community and the community itself, because it is a culturally specific mechanism that derives from the value hierarchies the community established. Following this perspective allows for natural law and positive law to exist in parallel as long as natural law remains a subject of need fulfilment and harm prevention, and positive law belongs to the area of ethical discourse about secondary and executive norms, i.e. culturally specific mechanisms to ensure these basic principles.

Figure 1 illustrates the here presented account of bridging moral universality and legal universality via cultural pluralism: the path from an offence against an individual or a group of individuals, via identification of the associated moral norm in different social groups (local and national), the attaching of culturally specific elements (compliance mechanisms, justifications and aggravating factors), which results in ethical norms and the negotiation on the formulation of ethical norms internationally and the necessary trade-offs to come to an agreement. In between the boxes the mechanisms empathy, national/local discourse and international discourse that have been discussed above are indicated.

International agreement found that the prohibition of torture would have to become an absolute prohibition in order to protect the inviolable dignity of the human being. This led over the years to many different international laws (Article 5 UDHR 1948, Article 7 ICCPR 1966, Torture Convention 1984, Art. 7(1)f, 8(2)a/ii Rome Statute 1998). If this happens in a public debate and the national authorities feel 


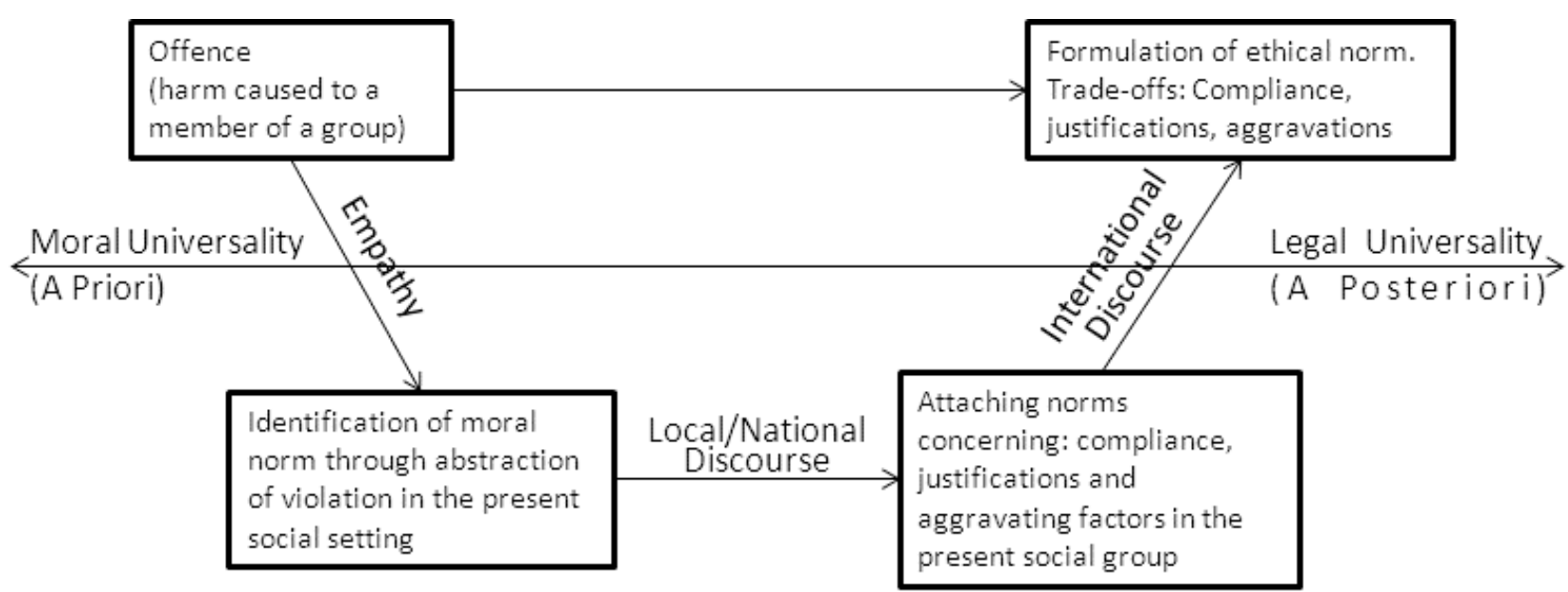

Figure 1. Socio-legal framework bridging moral and legal universality via cultural pluralism.

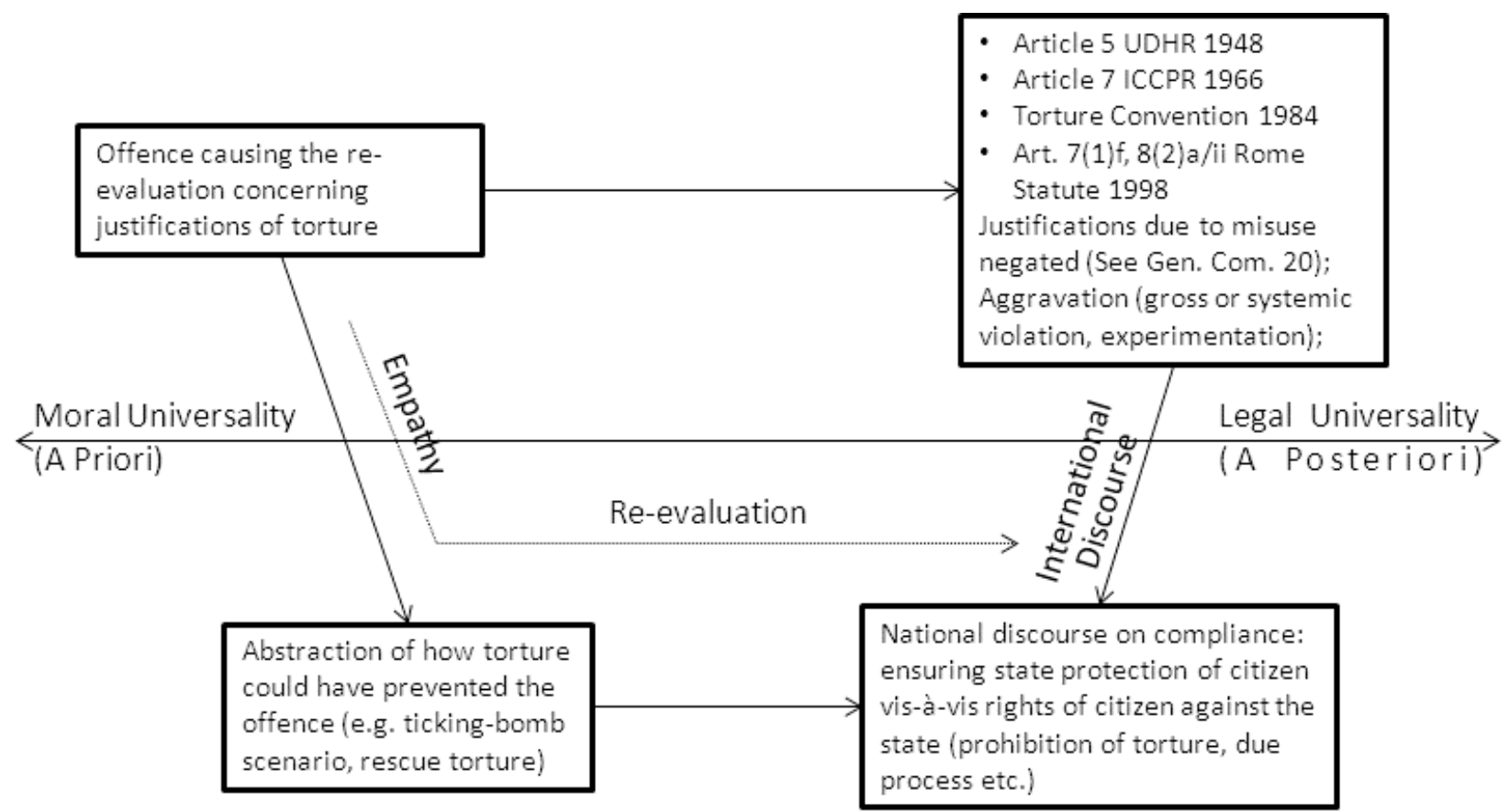

Figure 2. Process of re-evaluation of torture regulations within the socio-legal framework.

obliged to continue to comply with international law previously accepted, they will face criticism from those who support 'rescue-torture'. If national authorities would follow the rescue-torture argument, they might detach themselves from the international norm. This would cause a debate with the adherents to the internationally agreed norms (both within the country and internationally). In other words, social norm-creation might result in a re-evaluation in extreme circumstances and in effect might reduce de facto legal universality.

The Daschner case caused the German society to re-evaluate the value hierarchy between the right to life (of the kidnapped child) and torture (or the threat of it against Gaefgen to surrender the details of the child's whereabouts). Furthermore, among the population the justifications of rescue-torture were discussed. If the society would have had the choice and the state no pre-existing absolute obligations, rescuetorture might have become a reality. A similar path can be observed in the United States within governmental circles, where after the tragic events of $9 / 11$ the justifications concerning torture were indeed reevaluated. This came to be known as the infamous torture memos and John Yoo's legal justifications for why harsh interrogation techniques would not amount to torture. It resulted in an international debate led by governments, the ICRC, NGOs, and human rights activists, who invoked international law and finally led to a course correction of the United States. In this 
case the course correction came by pressure from adherents to the international norms but not without causing other governments (among others Poland, Romania, Germany) to tacitly support the United States' practices as became evident in the Council of Europe report "Alleged Secret Detentions and Unlawful Inter-State Transfers Involving Council of Europe Member States" [65]. This reduced the a posteriori legal universality. Figure 2 illustrates this within the elements and processes of the account given in this essay.

This socio-legal account of universality of moral principles and cultural specificity of ethics suggest something else: despite the fact that a priori moral principles are universally the same, cultural colorations and re-evaluations can lead to the modifications of value hierarchies (for example from human dignity to homeland security) that can not only weaken $a$ posteriori legal universality, but in extreme circumstances even reverse the outcome of the ethical reasoning. This means that moral principles are less determinative of the outcome of ethical reasoning than the respective value hierarchy applied. As paradox as this sounds, one has to consider that the hierarchy of values determines the proportionality between deed and response. Thus, while the moral principles remain the same (e.g. 'do not unjustifiably cause harm'), the justification might just tip the scale in favour of arguing that a certain harm caused is justified. Practically this can mean in the case of torture that if in ethical discourse issues such as homeland security, individual liberty, the hypothetical threats of terrorism, and other similar arguments become stronger, value hierarchies might just be modified enough to blur the lines between interrogation and torture so much that we can no longer speak of an absolute prohibition in the sense of an $a$ posteriori universality. Figure 2 above shows how reevaluation of justifications can diminish the a posteriori universal validity of the prohibition of torture.

\section{Conclusion}

This article demonstrated that moral universality and legal universality interact with ethical pluralism. Concerning moral universality, what connects human beings is the principle that fundamental needs of individuals and of a social community need to be ensured and that harm to them needs to be prevented. The universality of this moral principle is only inherently present and hardly observable as universality ends as soon as communities start a discourse on the different ways in which they want to ensure these needs. Depending on the culturally specific mechanisms (such as the role of duties and/or rights of the group and/or its individuals) and the diverse value categories of subsistence, their hierarchy and the weight of values are different. I called them culturally specific mechanisms, since they pertain to social groups within which through custom, practice and discourse certain enforcement mechanisms developed. This might call for further research on how cultures and practices relate to social mechanisms of normcreation and to the elements of subsistence (farming, herding etc.) certain social groups have adopted. There is no doubt that globalization and the interaction between different social groups, just as much as the reassembling of social groups for different purposes (economic, religious, etc.) over the course of human history makes this task tremendously difficult. This is particularly challenging also because every newly formed social group will develop new customs pertaining to its purpose and therefore new ethical norms.

From this perspective, what pluralist human rights debates actually criticize are not the basic moral principles underlying human rights but (1) the culturally coloured way human rights try to achieve the safeguarding of fundamental needs and (2) a certain hierarchy of values (and their weight) which is implicitly introduced. This can lead people to reject human rights because they feel that they do not fit the system of enforcement mechanisms, which their own social group has developed and to which they have grown accustomed. Thereby Donnelly's "functional universality" gets another turn. According to the elaboration above, moral universality does not primarily derive from the same constraints and the ways of how to deal with these constraints. It derives from the most basic reference point of moral discourse being 'life' and the physiological, psychological and transcendental unity of human faculty with its intrinsic capability to suffer and to have empathy with the suffering of others through the effect of mirror neurones. This potentially connects every culture due to the use of the same reference points: human life, fundamental needs, and corresponding violations. These same reference points make a global discourse about common ethical norms possible.

I have therefore argued for a distinction between universal moral principles and ethical norms. Moral principles are universal on the basis of the principal ability of all humans to physiologically, psychologically and transcendentally experience suffering. Ethical norms are culturally specific because, as soon as social discourse engages with an offence, elements typical to the social group are naturally added through depth grammar and through discussing enforcement mechanisms, justifications, and aggravating factors. Values and value hierarchies derive from the categories of objects that a group requires for subsistence and from the societal norms that ensure an efficient social interaction. That means cultural values also become a subject of ethics, not because they represent 
fundamental needs of individuals, but because they ensure these fundamental within and for a community. The role of honour was used as an example in this respect.

Universality can again be reached in the form of legal universality, which is dependent on universal agreement. That the negotiations and compromises which led to the formulation of the "universal" Human Rights documents took place particularly among Western powers is no legal argument against legal universalism. However, it is a strong political argument that derives from the fact that other states joined these treaties later and without the chance for a renegotiation in relation to the ethical norms of their own cultures. From their perspective, scholars rightfully argue that human rights contain particularly culturally coloured secondary norms derived from the ethical discourse of certain (mostly Western) social groups. They can never be factually universal as long as different social groups have different value hierarchies and diverse mechanisms of ensuring subsistence of individuals and groups. This socio-legal account presented here does not only explain the process from moral universality via ethical pluralism to legal universality, but also elucidates how and why there is just as much disagreement as there is agreement on the universality of human rights. Furthermore, it explains how (and to some degree why) societies constantly re-evaluate their relation to these universally agreed norms and why universal moral principles are no guaranty for similar outcomes of ethical questions.

This essay raises as many questions as it tries to answer. It shows that there is a strong relationship between culture, traditional elements of subsistence of social groups and social norm-creation. How this relationship exactly works, however, still remains open for further research. In addition, the socio-legal framework presented would require further research in the nature of the offences that trigger re-evaluation of established norms. This undertaking might well benefit from cognitive psychological research on morality and decision-making. As mentioned in the introduction, this article also wants to prepare the ground for further theoretical investigations concerning an extended canon of ethical concepts commonly derived from virtue ethics. C.S. Lewis' description of universal moral

\section{References and Notes}

1. Usually, the distinction between 'ethics' and 'morality' is rather unclear. Mostly 'ethics' is regarded as the philosophical study of morality, and morality is the issue of everyday practice. See, for example: Gert B. The Definition of Morality. In: Zalta EN, editor. The Stanford Encyclopedia of Philosophy. Summer 2011 Edition. Available from: http://plato.stanford.edu/arch principles has already highlighted universal norms (magnanimity, beneficence, veracity, good faith, and mercy) that hardly feature in contemporary debates in political philosophy, law and international relations. Theoretical investigations concerning the universality of virtues might shed even more light on the socio-legal function of ethics and the workings of ethical reasoning. Additionally, a virtue ethics perspective on international politics would also ask for the study of what constitutes vices in contemporary legal and political discourses on ethics.

For the practice of international politics the discussion in this paper shows that the current human rights system (that includes social, economic, cultural, civil, and political rights) as well as its enforcement mechanisms are indeed not at all suited to accommodate differences between different legal cultures and approaches to compliance with prohibitions against harming the survival of individuals and groups. The mere fact that the conception of human rights focuses on rights of the individual against the state ignores all other possible combinations of individuals, groups and states on the one hand and of rights and duties on the other. Five possible strategies for advocates of the current international human right system seem to emerge from this: (1) top-down: the carrots and stick approach to convince all states of the current international normative system; (2) bottom-up: the soft power approach to convince local populations of the importance of individual rights and of the benefits of this system for their wellbeing; (3) emphasizing those elements of international human rights in domestic discourses that are closer to moral principles, i.e. that are less value laden; (4) extending the margin of appreciation for the interpretation of international human rights norms to facilitate the ease of which the previous three strategies can lead to a greatest common denominator; (5) providing alternative legal mechanisms concerning the right-duty and the individual-group-state relationship.

\section{Acknowledgments}

The author is in debt to the VIEW group, Christopher Lamont and Joris Kocken as well as the reviewers for their invaluable comments.

ives/sum2011/entries/morality-definition (accessed on 25 November 2012).

2. Paine T. Rights of Man. Hertfordshire, UK: Wordsworth Editions; 1996. p. 33.

3. For example, the philosophies of: Thomas Aquinas, Francisco Suárez, Thomas Hobbes, Hugo Grotius, Samuel von Pufendorf, John Locke, Francis Hutcheson, and Emmerich de Vattel.

4. Gardner J. Simply in Virtue of Being Human: 
The Whos and Whys of Human Rights. Journal of Ethics \& Social Philosophy. 2008;2(2):1-22.

5. Talbott W. Which Rights Should Be Universal? Oxford, UK: Oxford University Press; 2005.

6. Shue H. Basic Rights: Subsistence, Affluence, and U.S. Foreign Policy. Princeton, NJ, USA: Princeton University Press; 1996. pp. 29-34.

7. Dreier H. Gustav Radbruch und die Mauerschtützen. Juristen Zeitung. 1997;52(9):421-434.

8. Hart HLA. Positivism and the Separation of Law and Morals. Harvard Law Review. 1958;71(4):594.

9. Kelsen H. Was ist Gerechtigkeit? Stuttgart, Germany: Reclam; 2000.

10. Sharma A. Are Human Rights Western? Oxford, UK: Oxford University Press; 2006.

11. Tharoor S. Are Human Rights Universal? World Policy Journal. 1999/2000;16(4):1-6.

12. Brems E. Human Rights: Universality and Diversity. The Hague, The Netherlands: Martinus Nijhoff Publishers; 2001.

13. "The term 'margin of appreciation' refers to the latitude a government enjoys in evaluating factual situations and in applying the provisions enumerated in international human rights treaties." Arai-Takahashi Y. The Margin of Appreciation Doctrine and the Principle of Proportionality in the Jurisprudence of the ECHR. Antwerp, Belgium: Intersentia; 2002. p. 2.

14. Baderin MA. International Human Rights and Islamic Law. Oxford, UK: Oxford University Press; 2003.

15. Al-Jabri MA. Democracy, Human Rights and Law in Islamic Thought. London, UK: I B Tauris; 2009.

16. Mayer AE. Cultural particularism as a bar to women's rights: Reflections on the Middle Eastern experience. In: Peters JS, Wolper A, editors. Women's rights, human rights: International feminist perspectives. New York, NY, USA: Routledge; 1995. pp. 176-188.

17. Bakhtiar L. Encyclopedia of Islamic Law-A Compendium of the Major Schools. Chicago, IL, USA: ABC International Group; 1996. pp. 229-241.

18. Donnelly J. Human Rights and Human Dignity: An Analytic Critique of Non-Western Conceptions of Human Rights. American Political Science Review. 1982;76(2):303-316.

19. BverfG. 1 BvR 357/05. 15 February 2006. Para. (1-156):131. Available from: http://www.bverfg. de/entscheidungen/rs20060215_1bvr035705.html (accessed on 25 November 2012).

20. Debatte über Flugzeug-Abschuss: Die Scheinwelt eines Verteidigungsministers. Spiegel Online. Available from: http://www.spiegel.de/politik/deutsch land/0,1518,506562,00.html (accessed on 25 November 2012).

21. "Preference is given to the positive law, duly and secured by state power as it is, even when it is unjust and of no benefit to the people, unless its conflict with justice reaches so intolerable a level that the statute becomes, in effect, 'false law' and must therefore yield to justice" ("Der Konflikt zwischen der Gerechtigkeit und der Rechtssicherheit dürfte dahin zu lösen sein, daß das positive, durch Satzung und Macht gesicherte Recht auch dann den Vorrang hat, wenn es inhaltlich ungerecht und unzweckmäßig ist, es sei denn, daß der Widerspruch des positiven Gesetzes zur Gerechtigkeit ein so unerträgliches Maß erreicht, daß das Gesetz als ,unrichtiges Recht' der Gerechtigkeit zu weichen hat"). Radbruch G. Gesetzliches Unrecht und übergesetzliches Recht. Schweizerische Juristen-Zeitung/Revue Suisse de Jurisprudence. 1946:107. In: Radbruch G. Gesamtausgabe. Vol. 3. Heidelberg, Germany: Müller, Juristischer Verlag; 1988. p. 89. Translated in: Paulson SL. Radbruch on Unjust Laws: Competing Earlier and Later Views? Oxford Journal of Legal Studies. 1995; 15(3):490.

22. Dreier H. Gustav Radbruch und die Mauerschützen. Juristen Zeitung. 1997;52(9):427.

23. K.-H. W. v. Germany (Berlin Border Guard Case). European Court of Human Rights (Grand Chamber). Application no. 37201/97. Judgment on the Merits (22 March 2001).

24. Landesgericht Frankfurt am Main. Press Release: Schriftliche Urteilsgründe in der Strafsache gegen Wolfgang Daschner. 15 February 2005. Available from: http://www.lg-frankfurt.justiz.hessen.de/irj/servl et/prt/portal/prtroot/slimp.CMReader/HMdJ_15/LG_Fr ankfurt_Internet/med/acb/acb50880-b973-6411-aeb6df144e9169fc, 222222222-2222-2222-2222-2222222222 222,true.pdf (accessed on 25 November 2012).

25. For a collection of links to the German press covering this topic in the aftermath of the Daschner trial see: http://www.stop-torture.de/presse.html and http://www.stop-torture.de/presse-neu.html.

26. Donnelly J. International Human Rights. 3rd ed. Boulder, Colorado, USA: Westview Press; 2007. p. 37.

27. Renteln $A D$. International Human Rights: Universalism versus Relativism. Newbury Park, CA, USA: Sage; 1990. pp. 69-72.

28. Schmidt PF. Some Criticism of Cultural Relativism. Journal of Philosophy. 1955;52(25):780-791.

29. Donnelly J. Universal Human Rights: In Theory and Practice. 2nd ed. New York, NY, USA: Cornell University Press; 2003. p. 91.

30. Hume D. An Enquiry Concerning the Principles of Morals. Indianapolis, IN, USA: Hackett Publishing; 1983.

31. Kant I. Kritik der reinen Vernunft. Ditzingen, Germany: Reclam; 1986.

32. Smith A. The Theory of Moral Sentiments. Mineola, NY, USA: Dover Publications; 2006.

33. Donnelly J. Cultural Relativism and Universal Human Rights. Human Rights Quarterly. 1984;6(4): 415.

34. Donnelly J. The Relative Universality of Human 
Rights. Human Rights Quarterly. 2007;29(2):281-306.

35. Goodhart M. Neither Relative nor Universal: A Response to Donnelly. Human Rights Quarterly. 2008; 30(1):183-193.

36. Donnelly J. Human Rights: Both Universal and Relative (A Reply to Michael Goodhart). Human Rights Quarterly. 2008;30(1): 194-204.

37. Gert B. Common Morality: Deciding what to do. New York, NY, USA: Oxford University Press; 2004.

38. Lewis CS. The Abolition of Man. New York, NY, USA: HarperCollins Ebooks; 2001. pp. 83-101.

39. The law of Mercy is one of the best counter examples for the evolutionary theory of morality that claims that moral behaviour developed out of the need to cooperate to better survive. Because the criterion of survival of a group is violated by taking care of lethally wounded and deadly sick-they would only drain valuable resources and do not give any benefits to the group. The only explanation could be to say that those taking care could hope for the same treatment, but then again they would have to be afraid of defectors. In this case defection is particularly plausible because no emotional bond (such as between parents and children) of reciprocity exists.

40. For example, a child hitting its mother has a different moral quality than a person hitting a stranger.

41. Cavallar G. The Rights of Strangers: Theories of International Hospitality, The Global Community and Political Justice since Vitoria. Aldershot, UK: Ashgate; 2002.

42. Linklater A. The Problem of Harm in World Politics. Cambridge, UK: Cambridge University Press; 2011. p. 105.

43. Maslow A. A theory of human motivation. Psychological Review. 1943;50:370-396. Classics in the History of Psychology. Available from: http://psych classics.yorku.ca/Maslow/motivation.htm (accessed on 25 November 2012).

44. Gurr TR. Why men rebel. Princeton, NJ, USA: Princeton University Press; 1970. pp. 25-26.

45. Deci EL, Ryan RM. The 'What' and 'Why' of Goal Pursuits: Human Needs and the Self-Determination of Behavior. Psychological Inquiry. 2000;11(4): 227.

46. One should mention that "self-transcendence: to connect to something beyond the ego or to help others find self-fulfilment and realize their potential" is frequently included in the hierarchy but is not found in Maslow's original article on human motivation. See: Huitt W. Maslow's hierarchy of needs. Educational Psychology Interactive. Valdosta State University. 2004. Available from: http://www.edpsycinteractive.org/topi cs/conation/maslow.html (accessed on 25 November 2012). The hierarchical structure of these needs has been doubted by Maslow himself and is frequently disputed. See for example: Wahba MA, Bridwell LG. Maslow Reconsidered: A Review of Research on the
Need Hierarchy Theory. Organizational Behavior and Human Performance. 1976;15(2):212-240.

47. In accordance with statutory domestic and Sharia law the crimes of murder and robbery could be punished by death, and theft according to Sharia law would be punishable by cutting off limbs. See: Jok AA, Leitch RA, Vandewint C. A Study of Customary Law in Contemporary Southern Sudan. World Vision International and the South Sudan Secretariat of Legal and Constitutional Affairs. 2004. Available from: http://site resources.worldbank.org/INTJUSFORPOOR/Resources /JoketalStudyofCustomaryLawinContemporarySouthSu dan.doc (accessed on 25 November 2012).

48. Hudson WD. Modern Moral Philosophy. 2nd ed. New York, NY, USA: Palgrave Macmillan; 1983.

49. Shackelford TK. An Evolutionary Psychological Perspective on Cultures of Honor. Evolutionary Psychology. 2005;3:381-391.

50. Ahmed A. Journey into Islam: The Crisis of Globalization. Washington, DC, USA: Brookings Institution Press; 2009.

51. Yamamoto T. Hagakure-Der Weg des Samurai. Kabel, Germany: 2007. pp. 164-166.

52. Human Rights Committee (CCPR). General Comment No. 20. Replaces general comment 7 concerning prohibition of torture and cruel treatment or punishment (Art. 7). 03/10/1992.

53. Human Rights Committee (CCPR). General Comment No. 07. Torture or cruel, inhuman or degrading treatment or punishment (Art. 7). 05/30/1982.

54. Habermas J. Moral Consciousness and Communicative Action. Cambridge, MA, USA: Polity Press; 1993.

55. Ludwig Wittgenstein. Philosophical Investigations. Oxford, UK: Blackwell; 1986.

56. Lamm C, Batson CD, Decety J. The Neural Substrate of Human Empathy: Effects of PerspectiveTaking and Cognitive Appraisal. Journal of Cognitive Neuroscience. 2007;19(1):42-58.

57. Preston SD, de Waal FBM. Empathy: Its Ultimate and Proximate Bases. Behavioral and Brain Sciences. 2002;25:1-72.

58. Decety J, Jackson PL. The Functional Architecture of Human Empathy. Behavioral and Cognitive Neuroscience Reviews. 2004;3(2):71-100.

59. Cheng $Y$, Yang $C Y$, Lin $C P$, Lee $P L$, Decety J. The Perception of Pain in Others Suppresses Somatosensory Oscillations: A Magnetoencephalography Study. NeuroImage. 2008;40(4):1833-1840.

60. Gallese V. The 'Shared Manifold' Hypothesis: From Mirror Neurons to Empathy. Journal of Consciousness Studies. 2001;8(5-7):33-50.

61. Botvinick M, Jha AP, Bylsma LM, Fabian SA, Solomon PE, Prkachin KM. Viewing Facial Expressions of Pain Engages Cortical Areas Involved in the Direct Experience of Pain. NeuroImage. 2005;25(1):312319. 
62. Silber JR. Kant's Conception of the Highest Good as Immanent and Transcendent. The Philosophical Review. 1959;68(4):469-492.

63. Williams BAO. In the Beginning was the Deed: Realism and Moralism in Political Argument. Princeton, NJ, USA: Princeton University Press; 2005. pp. 21-23. 64. Hodgson L-P. Kant on the Right to Freedom: A
Defense. Ethics. 2010;120(4):791-819.

65. Marty D. Committee on Legal Affairs and Human Rights. Alleged Secret Detentions and Unlawful Inter-State Transfers Involving Council of Europe Member States. Council of Europe. AS/Jur (2006). 16 Part II 7 June 2006. 


\title{
The Political Economy of Extraterritoriality
}

\author{
Paul B. Stephan
}

School of Law, University of Virginia, 580 Massie Road, Charlottesville, VA 22903-1738, USA;

E-Mail: pbs@virginia.edu; Tel.: +1 4349247098; Fax: +1 4349247536

Submitted: 10 April 2013 | In revised form: 30 April 2013 | Accepted: 14 May 2013 |

Published: 4 June 2013

\begin{abstract}
Near the end of the 2009 Term the Supreme Court decided Morrison v. Australia National Bank, Ltd., the strongest anti-extraterritoriality opinion it has produced in modern times. Not only is Congress presumed generally to prefer only territorial regulation, but lower courts that had carved out exceptions from this principle over a long period of time must now revisit their positions. Again this year in Kiobel v. Royal Dutch Shell Co. the Court relied on an aggressive use of the presumption against extraterritoriality to cut back on an important field of private litigation. The Court appears to have embraced two related stances: The imposition of barriers to extraterritorial regulation generally advances welfare, and the lower courts cannot be trusted to determine those instances where an exception to this rule might be justified. Implicit in the Court's position are intuitions about the political economy of both legislation and litigation. I want to use the occasion of the Morrison and Kiobel decisions to consider the political economy of extraterritorial regulation by the United States. International lawyers for the most part have analyzed state decisions to exercise prescriptive jurisdiction over extraterritorial transactions in terms of a welfare calculus that determines the likely costs and benefits to the state as a whole. Fewer studies have considered the political economy of the decision whether to regulate foreign transactions. No work of which I am aware has considered the political economy of deciding the extraterritorial question through litigation. This paper seeks to fill these gaps by sketching out what political economy suggests both about extraterritoriality and the role of courts as arbiters of extraterritoriality.
\end{abstract}

Keywords: international economic regulation; political economy of litigation; political economy of regulatory jurisdiction; regulatory jurisdiction 


\section{Introduction}

One sign of the United States' arrival as an international hegemon was the imposition of its economic regulation on foreign actors and transactions. Breaking with a tradition that had limited regulatory authority (prescriptive jurisdiction) to a state's territory and subjects, the United States at the end of World War II claimed the right as well as the capacity to regulate any transaction in which it had an interest [1]. Australia, Canada and the European powers pushed back, but failed to reverse this stance. Dynamic tension ensued. In 1988 the European Court of Justice accepted that EC competition rules could apply to overseas conduct [2]. Extraterritoriality of regulation has become a fact of life, albeit a controversial one.

The stakes are considerable. On the one hand, a state that fails to regulate offshore production of goods and services might allow its consumers to suffer (what it considers) injuries and its producers to lose international market share to under-regulated competitors. On the other hand, a state might impose offshore regulation to deprive foreign producers of an otherwise legitimate competitive advantage. They even can use regulation as a form of trade protection by imposing stricter standards on foreign firms than on domestic producers. There is every reason to think that national interest rather than global welfare will dominate what choices states make (see [3]).

Determining whether extraterritorial regulatory authority exists involves a complex dynamic among the three branches of government. The legislature must create regulatory authority, in the course of which it may or may not address the extraterritoriality issue. The executive, as either the exclusive regulator or in partnership with private litigants, may make assertions about the scope of authority. Courts will adjudicate claims made by both the executive and private actors. The pronouncement of courts in turn will inform the legislature about the kinds of signals it must send to permit extraterritorial regulation.

In 1991, the Supreme Court in EEOC v. Arabian American Oil Co. (Aramco) sought to clarify the law [4]. The decision articulated a presumption against extraterritoriality, making it more costly for Congress to authorize such regulation. In 2011, the Court, in Morrison v. Australia National Bank, Ltd., issued an even stronger anti-extraterritoriality opinion [5]. Not only was Congress presumed generally to prefer only territorial regulation, but lower courts that had carved out exceptions from this principle over a long period of time had to revisit their positions. Most recently, the Court in Kiobel v. Royal Dutch Shell invoked the presumption in a context that some (including four members of the Court) think inapposite, namely the application of international human rights law [6]. The last case repudiated a wide swathe of circuit court decisions [7].

Three data points may not support much social science, but lawyers and policy makers must cope as best they can. The Court appears to have embraced two related stances: The imposition of barriers to extraterritorial regulation generally advances welfare, and the lower courts cannot be trusted to determine those instances where an exception to this rule might be justified. Implicit in the Court's position are intuitions about the political economy of both legislation and litigation.

I want to use the occasion of the Morrison and Kiobel decisions to consider the interests that produce extraterritorial regulation by the United States. International lawyers and international relations scholars for the most part have analyzed state decisions to exercise prescriptive jurisdiction over extraterritorial transactions in terms of a welfare calculus that determines the likely costs and benefits to the state as a whole (e.g., [8,9]). Fewer studies have considered the political economy of the decision whether to regulate foreign transactions [10]. No work of which I am aware has considered the political economy of deciding the extraterritorial question through litigation [11]. This paper seeks to fill these gaps by sketching out what political economy suggests both about extraterritoriality and the role of courts as arbiters of regulatory scope.

\section{The Political Economy of Extraterritorial Regulation}

The conventional international political economy story starts with a strong assumption about states as internally homogenous actors. This "black box" approach posits national interests that states pursue in interactions with other states. Within this framework, states have incentives to pursue two general policies: to export their own negative externalities and to resist the importation of other states' negative externalities. Antitrust provides convenient examples: A state may encourage export cartels by its producers even as it punishes anticompetitive conduct by external actors that affect its economy. Confronted with these conflicting interests, a state has to pick a rule that maximizes the sum of protection for its export activities and authorization of its capacity to regulate unwanted imports. A country that only exports would opt for a strong rule against extraterritorial regulation. A state that imports goods that are likely to be cartelized might want the authority to regulate offshore producers (see [9], supra note 6).

A more sophisticated political-economy analysis would disaggregate the state to identify the discrete interests of institutional actors within the state sector. It would go beyond estimating overall national welfare to assess the interests of particular influential groups in the outcome of regulatory choices. A conventional model of U.S. political economy, for example, depicts the Executive as relatively more sensitive to foreign influences, including those of foreign producers represented by their states. The Executive is in an iterative 
game with foreign governments that opens the possibility for solving collective action problems. Senior policymakers within the Executive also are mostly political appointees that serve for relatively brief periods and thus are subject to revolving-door pressures. Foreign economic interests are likely to be in the mix of subsequent bidders for their services [12-14].

The Congress is more sensitive to domestic producers due to well recognized public choice effects. Producers tend to be local, concentrated, and homogenous in their interests, leading to natural alliances with their representatives in Congress. Consumers are dispersed and heterogeneous in their interests, raising organizational costs and impeding their ability to wield political influence. Moreover, members of Congress represent local rather than national constituencies, rendering these legislators less sensitive to general national interests. Legislators face no penalty at the polls when they pander to local hostility to foreign interests, and receive no reward when they pursue balanced policies that incorporate the interests of foreigners. In addition, because Congress does not have a permanent bureaucracy, or at least has much less of one than does the Executive, its capacity to participate in iterative interactions with foreign states is more limited. Finally, the leadership of Congress and their staff turn over less frequently than do senior Executive officials, diluting the revolving door effect compared to their Executive-branch counterparts. The net effect should be a body sensitive to the concerns of domestic producers, insensitive to the concerns of domestic consumers, and largely indifferent to the welfare of foreign producers and consumers.

Applying this simple, indeed rudimentary, model to decisions about extraterritorial regulation, one would predict that Congress would push both for immunity for domestic producers from foreign regulation and for extraterritorial application of U.S. regulation. The argument for the immunity is easy. Domestic producers would argue that foreign regulation is discriminatory and harmful to U.S. interests. The argument for extraterritorial extensions of U.S. regulation would rest on the assertion that foreign producer behavior undercuts U.S. producers both at home and abroad and also endangers U.S. consumers. Congress would have no particular reason to act consistently, as foreign interests do not participate in their elections. Moreover, because it lacks foreign interlocutors to challenge its choices, it would not focus on the indirect costs of such inconsistency, such as foreign retaliation against U.S. exporters.

The model predicts that the Executive would push back against these proposals. The ability of local producers to capture strong advocates in Congress does not translate into the same pressures on the Executive. The Executive should focus most on groups with effective power in marginal, large-electoral vote states. Moreover, the Executive must engage with foreign governments, and components of the Executive, not least the President himself, will be judged based on outcomes over which foreign governments have some influence. Finally, the Executive has a substantial permanent bureaucracy that interacts with foreign governments and wishes their exchanges to go smoothly. The bureaucrats, as well as senior Executive officials, might enjoy subsequent careers in the private sector working on behalf of foreign interests. For all these reasons, the Executive will be more sensitive to concerns about consistency than will Congress. It, rather than Congress, will confront the contradiction inherent in extending extraterritorial regulation while defending domestic producers from foreign regulation.

Anecdotal evidence is consistent with these conjectures. Initiatives to expand extraterritorial regulation tend to come from Congress. In trade law, Congress is a perennial source of protectionist measures, which the Executive tends to resist.

Examples of the tension between Congress and the Executive over protectionism, albeit not precisely in the form of extraterritorial regulation, include the 2000 Byrd Amendment, which increased the incentive of domestic producers to seek antidumping and countervailing duties on imports and which the Clinton Administration unsuccessfully battled, and the 2007 broadening of Exon-Florio regulation of inbound investment following the Dubai Ports World kerfuffle, which the Bush II Administration unsuccessfully resisted [15]. Both these measures restricted imports (goods in the case of the Byrd Amendment, capital in the case of the Dubai Ports World legislation) in ways that invite retaliation and probably reduce overall U.S. welfare. The laundry list of protectionist legislation that never gets out of Congress, often because of Executive opposition, is extensive and well known. A more systematic review of the evidence, I suspect, would produce conclusions broadly consistent with the simple model, but I do not pretend to have conducted that study.

Finally, courts have complex incentives. One might postulate two general forces shaping their preferences. First, one would expect some correlation between their policy preferences and those of the President who selected them. Second, judges react to litigation and the way it frames choices as much, if not more, as they proactively seek to shape legal policy. One, thus, would anticipate some influence over their choices by litigants that appear before them.

It seems plausible that the effect of Presidential preferences on judicial behavior might increase as one moves up the judicial hierarchy. While personnel in the Executive might investigate the careers of judicial candidates to predict future voting behavior, they would know that such research is costly relative to the value of the data derived. It is notoriously difficult to predict the future voting patterns of judges, especially with respect to issues that may become important but have not yet arisen (the known unknowns). The willingness of the Executive to incur these costs likely 
increases with the importance of the position. Accordingly, the odds that a judge will vote consistently with the preferences of the nominating President may increase as one goes up the hierarchy, with Supreme Court nominees subject to the greatest investment in selection [16].

Conversely, one would expect the effect of litigant framing to be greatest in the lower courts. First, federal district courts and courts of appeals, unlike the Supreme Court, have no control over their docket. Second, lower federal judges tend to have strong local ties, including repeat interactions with the lawyers who bring suits. Third, relative to the Supreme Court, lower federal judges have fewer resources to conduct independent research into the matters before them, and thus rely more heavily on the representations of the lawyers in particular cases. Lower court judges both see more cases and have fewer staff. In particular, their law clerks come out of a less competitive process and generally have no prior legal experience, while Supreme Court clerks attain their position after great competition and typically have a year or more of legal work before they come to their posts.

These conjectures about influences on judicial decisionmaking support several hypotheses. First, they imply that litigant choices will have a greater influence on the lower courts. Executive branch screening will be weakest at the lower levels of the judiciary, and judges will have more extensive contacts with the local bar. Accordingly, ceteris paribus, lower courts, compared to the Supreme Court, are more likely to produce outcomes that litigating lawyers favor. The Supreme Court, with greater control over its docket and, by tradition, always sitting en banc, might act more on the basis of the median policy preferences of the Justices. Under the normal structure of litigation, the lower courts get the first opportunity to address open legal questions, with the Supreme Court choosing the moment when to intervene and bless or correct the path taken. Accordingly, one might predict gradual expansion of regulatory jurisdiction, including extraterritorial extensions, through lower court decisions, with episodic resistance by the Supreme Court.

In different government structures, of course, different dynamics can result. The European Community, for example, lacks a popularly elected executive, the function of its Parliament is more complicated, and its mechanism for judicial selection and choice of judicial structure is completely different from that of the United States. Accordingly, much of this informal model is inapplicable. Thus my conjectures are limited to the United States, although specialists in comparative government might find ways of revising and extending them to other systems (cf. [17]).

\section{The Morrison Case}

The conjectures, if nothing else, resonate with the particular story of securities-law extraterritoriality. The statutory provision at issue, Section 10(b) of the Securities Exchange Act of 1934, authorizes the Securities and Exchange Commission (SEC) to issue regulations defining sanctionable misbehavior in connection with the purchase or sale of a security [18]. The U.S. Court of Appeals for the Second Circuit and its district courts play an outsized role in securities litigation, largely due to the presence of the country's leading financial center in their jurisdiction. The history of securities litigation hence is largely a story of the relationship between the Second Circuit and the Supreme Court.

In 1942 , the SEC promulgated Rule 10b-5, which broadly prohibits fraudulent or deceptive practices in connection with the purchase or sale of a security [19]. In 1946 a federal district court ruled that victims of 10b-5 violations may bring suit in their own right for compensation, and later lower court decisions coalesced around this result [20]. Class actions suits based on Rule 10b-5 took off in the mid-1960s, and in 1968 the Second Circuit in Schoenbaum v. Firstbrook [21] ruled that actions in Canada that affected the market price of securities sold in the United States fell within 10b-5's scope. Judge Lumbard, the author of that decision, had worked in securities regulation before joining the bench and, his opinions indicate, generally preferred expanding the scope of that regime. Three Second Circuit decisions in the early 1970s, all written by Judge Friendly, both more famous and more conservative than Lumbard, moderated Schoenbaum by limiting regulatory scope to instances where foreign actions had a direct effect on a U.S. victim (and not simply an effect on the market) or a perpetuation of fraud affecting a foreign transaction involved substantial conduct on U.S. territory [22-24].

So the law stood, with insignificant variations in other Circuits, until Morrison. That case involved Australian investors in an Australian company that sought compensation for injuries resulting from the company's misleading statements about certain transactions undertaken in the United States. The Second Circuit, applying its case law, ruled that the alleged misconduct fell outside the scope of U.S. jurisdiction. The Supreme Court, while affirming the result, effectively spanked the Second Circuit for its legal analysis. It held that Section 10(b) and Rule 10b-5 applied only to sales transactions that take place on U.S. territory or (less clearly) involving securities registered in the United States under the Securities and Securities Exchange Acts [25].

The Second Circuit approach generally benefitted lawyers by employing vague standards to determine the extraterritorial scope of U.S. regulation. The openended effects and conducts tests increase the need for legal services at both the planning and dispute resolution stages. Moreover, while the rule might have been suboptimal for some clients of the defense bar, its effects on them were mixed. While vague extraterritoriality produced a heightened regulatory burden on 
U.S. financial institutions involved in foreign transactions, it imposed at least as large costs on some of their foreign competitors. There is every reason to believe, in short, that lawyers in general liked the Second Circuit approach, because it benefitted them directly and substantially and had only mixed effects on their clients. The Supreme Court's intervention in turn can be interpreted as policy-driven and consistent with other efforts of that Court to constrain litigationfriendly behavior by lower courts [26].

\section{Alien Tort Litigation}

The alien tort litigation saga also resonates with my informal model. These cases first appeared in 1980, although the so called Alien Tort Statute (ATS), the measure on which they rest, is much older [27]. The earliest suits attacked foreign government officials and others who wielded state power to commit atrocities against a local population. Beginning in the late 1990s, however, plaintiffs began going after multinational corporations, not all based in the United States, that operate in areas where civil conflict has unfolded or brutal and oppressive regimes otherwise have terrorized the local population. The cases rest on the theory that a U.S. court would provide a remedy for any violation of international law that constituted a tort and injured an alien [28].

As with securities fraud litigation, the ATS suits gained support from sympathetic lower federal courts, punctuated by occasional Supreme Court resistance. In 2004 the Supreme Court in Sosa v. Alvarez-Machain admonished the lower courts to limit the range of international law obligations to which this statute could apply, but the scale, if not the scope, of suits in the lower courts continued to grow [29]. The Court returned to the fray in Kiobel. A majority maintained that the presumption against extraterritoriality as expounded in Morrison applied to alien tort suits. Because the case involved Nigerian victims of atrocities that took place in Nigeria and were said to have been procured by an Anglo-Dutch company, the ATS could not provide a remedy. In general, the Court declared, foreign events can give rise to an ATS suit in U.S. courts only when a claim touches and concerns the territory of the United States "with sufficient force to displace the presumption against extraterritorial application" [30].

The Kiobel dissenters did not believe that the presumption has anything to do with a statute that enforces international legal norms. Rather, they would authorize a tort suit wherever the case involved either a U.S. defendant or "an important American national interest" [31]. Foremost in the latter category would be instances where a person sought refuge in the United States after committing a grave violation of international human rights law. Even these justices, however, rejected that idea that victims of human rights violations anywhere in the world generally could seek justice through an ATS suit.

The alien tort regime that Kiobel circumscribed, like the securities regulation regime cut back in Morrison, was great for plaintiffs' attorneys, had mixed effects on defense counsel, and clearly was adverse to the interests of foreign corporations. From the late 1990s on, plaintiffs' attorneys saw alien tort suits against wealthy defendants as a new growth opportunity in the wake of other cutbacks on tort litigation in the United States. Counsel who represented U.S. corporate defendants welcomed the work but also respected their clients' preference not to be sued. Were suits to proceed, however, these clients did want maximum exposure for their foreign competitors. Only foreign defendants, both wealthy individuals and businesses, had an unmitigated desire to bar these suits. As with Morrison, then, the lower courts' relatively permissive approach to alien tort litigation coincided with the general preferences of the litigating bar, while the Supreme Court's Kiobel decision reflects the policy preferences of the Court's majority.

\section{The Political Economy of the Choice of Mechanisms to Determine Extraterritoriality}

In the prior section I focused on the incentives facing Congress, the Executive and the judiciary in deciding whether to extend regulation extraterritorially. One can use these factors to analyze potential mechanisms for choosing extraterritorially. By mechanism, I mean the rules constraining the process that determines whether a particular regulatory regime will have any extraterritorial effect. To simplify, I describe three types of mechanisms-a clear statement of extraterritoriality by Congress, a clear statement by the Executive based on a delegation of authority by Congress, and extension by private litigation. The choice of mechanism involves both different political economies and, I will argue, significantly different welfare effects.

Given the political economy of extraterritoriality discussed in the prior section, one would expect to observe significant extraterritorial regulation expressly adopted by Congress. Congress will exert maximum effort to benefit domestic producers, and the Executive will resist such protection only intermittently. Even under a clear statement regime, one would expect many instances of an extraterritorial regulatory regime.

Casual empiricism confirms this conjecture. U.S. legislation has more express extraterritoriality than one usually encounters in national laws. U.S. tax law, for example, contains more outbound taxation-taxes on overseas capital and transactions-than one sees in most rich countries. First, as to individuals, the United States is almost alone in taxing the worldwide income of all its citizens, not just its residents [32]. Second, as to corporations, Subpart F contains aggressive rules for imputing the income of foreign subsidiaries to U.S. parents [33]. As best I can tell, other countries do not have as strong a regime for re- 
sourcing income of a foreign corporation as domestic income. This example is significant because taxation arguably is the most pervasive and salient form of national regulation. Taxation of overseas transaction in effect punishes firms that employ offshore production, and thus conforms to the interest of domestic producers.

Taxation aside, Congress has had no difficulty adopting laws that expressly extend U.S. regulation overseas. One is tempted to infer that Congress still believes that the United States enjoys the same economic hegemony it wielded back in 1945 . Numerous examples exist. Although the effects doctrine in antitrust was developed judicially, Congress codified this development in 1982 [34]. The Foreign Corrupt Practices Act regulates the bribery of only foreign persons, albeit with other jurisdictional requirements [35]. EEOC v. Arabian American Oil Co. contains a lengthy list of other statutes with express extraterritorial effect [36]. Congress responded to the last case almost immediately with an express, if limited, extension of extraterritorial regulation [37].

The puzzle, if there is one, is why Congress does not do this more often. The answer, it appears, is resistance from the Executive, which channels foreign governmental pressure as well the concerns of U.S.based multinational firms. The Byrd Amendment of 2000 illustrates the dynamic: A locally interested Senator exploited the Senate's procedures to insert a provision in a bill that the President could not veto. The President obtained repeal several years later in the wake of international retaliation [38]. The consistent opposition of the Bush II and Obama Administrations to congressional efforts to impose sanctions on China for its currency policies offers another example. The Executive's resistance has delayed these measures for years.

What one sees less frequently is delegation by Congress to an agency of the Executive of discretion to extend regulation extraterritorially. In trade law, a possible example is Title III of the Trade Act of 1974, which gives the Executive authority to sanction states for overseas conduct that affects the interests of U.S. exporters [39]. Even this example is complicated, however, as Congress in 1988 sought to make this tool nondiscretionary in specified instances. Informal rather than formal sanctions attached to the Executive's refusal to exercise this authority, and in practice no confrontations between the branches occurred. In 1994 Congress modified Title III by nesting it within the Executive's authority to seek WTO dispute resolution. At least when the malefactor belongs to the WTO (as does almost every significant exporter, including now even Russia), the Executive thereby acquired significant control over the sanctioning process.

A different instance of a delegation involves Section 929P(b) of the Dodd-Frank Wall Street Reform and Consumer Protection Act. Congress apparently intended to modify the holding of Morrison by giving the
SEC and the Department of Justice, but not private plaintiffs, the authority to sanction extraterritorial violations of Rule 10b-5 [40]. In effect the statute leaves it to the exclusive discretion of the Executive to determine when the Securities Exchange Act might apply extraterritorially and limits sanctions to those that the Executive can seek [41].

At first glance the relative paucity of delegations seems surprising. Congress has at least one clear incentive to delegate regulatory authority to the Executive: After delegation, influential Members then can lobby the agencies on behalf of interested persons (see [42]). Perhaps the reason for the paucity is that extraterritoriality is different. Congress might believe that the Executive is especially susceptible to foreign pressure and therefore an untrustworthy delegate with respect to this issue. Even clear legislative statements of extraterritoriality run up against the Executive's prosecutorial discretion, as illustrated by the current version of Title III of the Trade Act of 1974. Congress might believe that expressly endorsing the Executive's power not to act serves no useful purpose.

The third mechanism for choosing to regulate extraterritorially is to leave the question to the courts. This approach requires legislation that does not advert clearly to the issue and judicial willingness to fill the statutory gap with a rule that permits at least some extraterritorial application. The now repudiated securities law decisions in the Second Circuit and the host of lower-court ATS cases illustrate this approach, as does the pre-1982 judicial interpretation of the Sherman Act. Other instances where the lower courts currently assume responsibility for determining extraterritoriality in the absence of clear approval from the Supreme Court include civil RICO (see [43-46].

The previous section sketches out some reasons why lawyers would prefer this approach but persons at risk of regulation might not. Delegations to the judiciary to determine extraterritoriality result in caseby-case lawmaking. Vague standards, the inevitable product of judicial management of competing policy claims, invite litigation, which lawyers like and clients do not. In some industries, the cost of the legal risk might be offset by the prospect that foreign competitors will face the same, and perhaps even greater, costs once regulation is exported. Within the judiciary, resistance to this mechanism comes mostly from the Supreme Court, where Justices have greater freedom to pursue their policy preferences and are less hostage to the agenda-setting of litigants than are lower court judges.

One suspects that, even if extraterritorial regulation has net benefits for some domestic producers, they would prefer the decision to come through the legislative process (see [47]). Extraterritorial extension achieved through case-by-case decisionmaking entails considerable uncertainty. The extension is never absolute, but subject to a fact-specific test such as the direct-effects standard. The standard increases risk along 
several dimensions. A domestic producer cannot be confident when it can escape regulation or when its competitors will be sanctioned. Moreover, as long as any one regulatory statute generates judicial extraterritorial extension, there remains a threat that other statutes might generate similar outcomes. The uncertainty about application thus extends across a range of statutory regimes.

Another factor in the mix is the Executive. On the one hand, at least some administrations internalize the interests of litigators, at least to some extent. The Obama Administration, through an amicus brief, defended the approach of the Second Circuit under the Securities Exchange Act [48]. It also persuaded the Solicitor General in its Kiobel amicus brief to back away from its earlier strong opposition to extraterritoriality [49]. On the other hand, the Executive sometimes prefers to have a monopoly over regulation rather than competing with private attorney generals. Private competition undermines the ability of the Executive to bargain for cooperation through plea bargains, because then the Executive cannot immunize defendants from civil liability sought directly by victims. This dynamic exists in all regulatory schemes, but the stakes go up when extraterritoriality is involved. Where foreign application exists, private liability disrupts the bargains not only of domestic regulators, but of foreign regulatory authorities as well. This disruption in turn impedes international regulatory cooperation in other areas, such as sharing of intelligence. The Bush II Administration relied on this argument in F. Hoffman-LaRoche Ltd. v. Empagran S.A., where is successfully persuaded the Court to limit standing under the Foreign Trade Antitrust Improvements Act so as to limit private competition with public extraterritorial enforcement [50].

The relative skepticism of the Executive toward judicial management of the extraterritorial scope of regulation also might explain why the Supreme Court pushes back against legislation that invites but does not command extraterritorial application. As noted above, the Executive invests more in the selection of Supreme Court justices, who in turn are less influenced by the preferences of the litigating bar than are lower court judges. It is plausible that skepticism about Congressional efforts to smuggle extraterritorial application into ambiguous legislation might be one of the characteristics for which the Executive looks in its Supreme Court nominees.

\section{Welfare Effects of Extraterritorial Regulation through Litigation}

Finally, although this essay is anchored in positive political economy analysis, a brief note about the welfare effects of extraterritorial regulation, in particular regulation through litigation, is warranted. Political economy has its greatest salience when identifying public decisionmaking that reduces overall welfare.
There exist substantial reasons to believe that extraterritorial regulation effected through the litigation process does exactly this.

Regulation through litigation comprises two elements-prescriptive jurisdiction and adjudicative jurisdiction. Prescriptive jurisdiction involves the sovereign's decision to apply its rules to an offshore transaction. Adjudicative jurisdiction involves the court's ability to hear a case against a particular party, including nonresidents. Expansive prescriptive rules mean applying a local, presumably more stringent, rule to offshore conduct. Expansive adjudicative rules mean submitting offshore actors to U.S. litigation, whatever the substantive rule might be.

Alan Sykes has analyzed the welfare costs of litigation-based regulation. He observed that the extension of regulation through litigation does not result in universal application of the regime. Rather, the rules apply only to firms that engage in activities in the United States or own assets located there. Subjecting a subset of producers to a regulatory regime not imposed on others results is the functional equivalent of a trade barrier, which has well documented costs in terms of distorting production and sales decisions [51].

Sykes's argument focuses on prescriptive jurisdiction, but it can be extended to adjudicative jurisdiction. To the extent that defending in a U.S. courtroom is more costly than in a foreign court (due to unique practices such as civil jury trials, class action procedures, contingency fees arrangements for plaintiffs' attorneys, broad pretrial discovery, and access to punitive damages), broad adjudicative jurisdiction imposes costs on firms that enter the U.S. market. In deciding whether to compete in the U.S. market, foreign firms must take account of a set of procedural rules that function as a tax on doing business. Moreover, the tax is unique, because other civil litigation systems do not use these devices, or do so to a lesser extent.

Particular welfare arguments apply to delegating the decision whether to regulate extraterritorially to courts. Instability of domain rules-the determination of the scope of conduct to which a set of rules applies -has unambiguously negative effects (see cases cited in [47]). One can defend vagueness in standards that regulate primary conduct by arguing that postponing definition of legal requirements until application allows the regulator to exploit information that was hidden at the time of the standard's promulgation. No such argument applies to domain rules. Uncertainty about the applicable legal regime, as opposed to the particular rule governing primary conduct, only encourages opportunism by persons who, after the fact, find application of a particular regime beneficial.

The litigation mechanism by its nature produces vagueness and uncertainty about one particular domain question, namely the applicability of a regulatory regime to foreign conduct. As a normative matter, it has clear costs and dubious benefits. It thus appears 
that the persistence of this mechanism represents a classic public choice story, in which a homogenous and concentrated interest group (litigators) obtain rents but produce a net loss in social welfare.

\section{Conclusion}

In a world where changes in information and transportation technologies encourage the growth of transborder transactions, the question of extraterritorial regulation takes on greater salience. The issue has two dimensions: the policy question of whether to apply a regulatory regime extraterritorially, and the structural question of how to assign the authority to resolve the policy question. Political economy analysis can shed light on both of these dimensions.

This paper extends traditional political economy accounts of U.S. lawmaking by focusing on the distinct incentives surrounding Supreme Court and lower court decisionmaking. This extension provides

\section{References and Notes}

1. United States v. Aluminum Co. of America, 148 F.2d 416 (2d Cir. 1945) (case appealed directly from Southern District of New York to the Supreme Court, which referred the case to the Second Circuit because of a lack of a quorum of the Justices). For an effort by an influential private organization to codify the general principle of regulatory extraterritoriality, see American Law Institute, Restatement (Third) of the Foreign Relations Law of the United States $\S \S 402-04$ (1987).

2. A. Ahlström OY v. Commission (Joined Cases C89. 104, 116, 117, 125 to 129/85), [1988] E.C.R. 5193. The ECJ sought to disguise its embrace of extraterritorial regulation by asserting that the "implementation" of the alleged price-fixing cartel involved conduct on EC territory. Most observers have found it impossible to detect any difference between the European concept of "implementation" and the US concept of "effects".

3. Stephan PB. Global Governance, Antitrust, and the Limits of International Cooperation. Cornell International Law Journal. 2005;38(1):173-218.

4. EEOC v. Arabian American Oil Company, 499 U.S. 244 (1991). Two years later it backtracked a bit. Hartford Fire Ins. Co. v. California, 509 U.S. 764 (1993). See: Kramer L. Extraterritorial Application of American Law After the Insurance Antitrust Case: A Reply to Lowenfeld and Trimble. The American Journal of International Law. 1995;89(4):750-758.

5. Morrison v. Australia National Bank Ltd., 561 U.S., 130 S. Ct. 2869 (2010).

6. Kiobel v. Royal Dutch Petroleum Co., 569 U.S., 133 S. Ct. 1659 (2013).

7. The leading early cases are Filartiga v. PeñaIrala, 630 F.2d 876 (2d Cir. 1980) and Kadić v. Karadžić, 70 F.3d 232 (2d Cir. 1995). Recent cases that had reached an opposite conclusion include Sarei v. Rio an explanation for the Court's most recent high profile decisions in this area. It also points toward a normative assessment. It indicates that the tendency of Congress to tolerate, and of lower courts to embrace, judicial management of the decision whether to apply regulation extraterritorially almost certainly has significant welfare costs. The recent efforts of the Supreme Court to resist this tendency may reflect not only the particular political economy of the selection of justices, but also constrain those costs.

\section{Acknowledgements}

I am grateful to participants in a workshop at Duke University and to a panel discussion at the 2011 Annual Meeting of the American Political Science Association for comments and criticisms. I also would like to thank three anonymous referees for their helpful suggestions.

Tinto, PLC, 671 F.3d 736 (9th Cir. 2011), vacated and remanded, 133 S. Ct. (2013); Flomo v. Firestone Nat. Rubber Co., LLC, 643 F.3d 1013 (7th Cir. 2011) (dicta); Doe v. Exxon Mobil Co., 654 F.3d 11 (D.C. Cir. 2011); Abdullahi v. Pfizer, Inc., 562 F.3d 163 (2d Cir. 2009).

8. Trachtman JP. The Economic Structure of International Law. Cambridge, MA, USA: Harvard University Press; 2008.

9. Guzman AT. Choice of Law: New Foundations. Georgetown Law Journal. 2002;90(4):883-940.

10. My work, which employs political economy analysis in addition to welfare assessments, includes: Stephan PB. Regulatory Competition and Anticorruption Law. Virginia Journal of International Law. 2012;53 (1):53-70; Stephan PB. The Problem with Cooperation. In: Guzman AT, editor. Cooperation, Comity and Competition Policy; 2010. pp. 217-227; [3], supra note 3; Stephan PB. Institutions and Élites: Property, Contract, the State, and Rights in Information in the Global Economy. Cardozo Journal of International and Comparative Law. 2002;10(1):305-317; Stephan PB. The Political Economy of Conflicts of Laws. Georgetown Law Journal. 2002:90(4):957-970; Stephan PB. Choice of Law and Its Consequences: Constitutions for International Transactions. Brooklyn Journal of International Law. 2000;26(1):211-220; Regulatory Cooperation and Competition-The Search for Virtue. In: Bermann GA, Herdegen M, Lindseth PL, editors. Transatlantic Regulatory Cooperation: Legal Problems and Political Prospects; 2000. pp. 167-202.

11. For a general discussion of the comparability (in political economy terms) of rule-making through legislation and through litigation, see: Goetz $\mathrm{CJ}$, Brady G. Environmental Policy Formation and the Tax Treatment of Citizen Interest Groups. Law and Contemporary Problems. 1975;39(4):211-231.

12. Brewster R. Rule-Based Dispute Resolution in 
International Trade Law. Virginia Law Review. 2006;92 (2):251-288.

13. Brewster R. The Domestic Origins of International Trade Agreements. Virginia Journal of International Law. 2004;44(2):501-544.

14. Stephan PB. Accountability and International Lawmaking: Rules, Rents and Legitimacy. 1997:17(1): 695-697.

15. For the Byrd Amendment, see: Agriculture, Rural Development, Food and Drug Administration, and Related Agencies Appropriations Act of 2001, Pub. L. No. 106-387, §§ 1001-03, 114 Stat. 1549, 1549A-72 to $1549 \mathrm{~A}-75$, repealed by Deficit Reduction Act of 2005, Pub. L. No. 109-171, § 7601, 120 Stat. 4, 154. For the extension of Exon-Florio, see: Foreign Investment and National Security Act of 2007, Pub. L. No. 110-49, 121 Stat. 246. Although the direct effect of both these measures is to restrict imports, the trigger for the restrictions is overseas conduct. In the case of Byrd Amendment, the trigger was either overseas pricing of comparable goods or the receipt of subsidies by a foreign producer. In the case of the Exon-Florio regimes, one of the concerns about foreign investment is access to domestic national security secrets that will lower overseas production costs.

16. There is significant and suggestive research on the correlation of judicial voting behavior and the party affiliation of the nominating President. E.g.: Yung CR. Beyond Ideology: An Empirical Study of Partisanship and Independence in the Federal Courts. George Washington Law Review. 2012;80(2);505567; Fischman JB. Estimating Preferences of Circuit Judges: A Model of Consensus Voting, Journal of Law and Economics. 2011;54(4):781-809; Fischman JB, DS Law. What Is Judicial Ideology, and How Should We Measure It? Washington University Journal of Law \& Policy. 2009;29(1):133-214; Cameron CM, Park J-K, Beim D. Shaping Supreme Court Policy Through Appointments: The Impact of a New Justice. Minnesota Law Review. 2009. 93(5):1820-1870; Daniel R. Pinello. Linking Party to Judicial Ideology in American Courts: A Meta-Analysis. The Justice System Journal. 1999;20(3):219-254; Cross FB, Tiller EH. Judicial Partisanship and Obedience to Legal Doctrine: Whistleblowing on the Federal Courts of Appeals. Yale Law Journal. 1998;107(7):2155-2176; Revesz RL. Environmental Regulation, Ideology, and the D.C. Circuit. Virginia Law Review. 1997;83(7):1717-1772. None of these studies, however, attempts to identify or measure any differences in this correlation as a function of the judge's place in the federal hierarchy.

17. Voigt S. Empirical Constitutional Economics: Onward and Upwards? Journal of Economic Behavior \& Organization. 2011;80(2):319-330.

18. Securities Exchange Act of 1934, § 10(b), 48 Stat. 881, 891.

19. 17 C.F.R. § $240.10 b-5$.

20. For a skeptical account of these events that nonetheless accepted the implied private right of action as a fait accompli, see: Blue Chip Stamps v. Manor Drug Stores, 421 U.S. 723, 729-30 (1975).

21. 405 F. 2d 200, modified on other grounds en banc, 405 F. 2d 215 (2d Cir 1968).

22. Leasco Data Processing Equip. Corp. v. Maxwell, 468 F. 2d 1326 (2d Cir. 1972).

23. Bersch v. Drexel Firestone, Inc., 519 F. 974 (2d Cir. 1975).

24. IIT v. Vencap, Ltd., 519 F. 2d 1001 (2d Cir. 1975).

25. Within days Congress appeared to have modified Morrison so as to allow the Department of Justice and the Securities and Exchange Commission, but not private litigants, to bring suits based on foreign conduct that satisfied either the effects or conduct tests. For discussion of this enactment, embodied in the Dodd-Frank Wall Street Reform and Consumer Protection Act, see [40].

26. A representative sample of other cases where the modern Supreme Court reined in litigation-friendly lower courts includes: Janus Capital Group, Inc. v. First Derivative Traders, 564 U.S., 131 S. Ct. 2296 (2011); Stoneridge Investment Partners, LLC v. Scientific-Atlanta, Inc., 552 U.S. 148 (2008); Sosa v. AlvarezMachain, 542 U.S. 692 (2004); F. Hoffmann-La Roche Ltd. v. Empagran S.A., 542 U.S. 155 (2004); Gonzaga University v. Doe, 536 U.S. 273 (2002); Correctional Services Corp. v. Malesko, 534 U.S. 61 (2001); Alexander v. Sandoval, 532 U.S. 275 (2001); Sale v. Haitian Centers Council, 509 U.S. 155 (1993); EEOC v. ArabianAmerican Oil Co., 499 U.S. 244 (1991); Middlesex County Sewerage Auth. v. Nat'l Sea Clammers Ass'n, 453 U.S. 1 (1981); California v. Sierra Club, 451 U.S. 287 (1981); Pennhurst State Sch. \& Hosp. v. Halderman, 451 U.S. 1 (1981); Universities Research Ass'n v. Coutu, 450 U.S. 754 (1981); Touche Ross \& Co. v. Redington, 442 U.S. 560 (1979); Blue Chip Stamps v. Manor Drug Stores, 421 U.S. 723 (1975).

27. The details of the historical background are unimportant for our purpose. For discussion, see: Sosa v. Alvarez-Machain, 542 U.S. 692, 712-14 (2004); Filartiga v. Pena-Irala, 630 F.2d 876 (1980); For the scholarly case against extraterritoriality, see: Bellia Jr. AJ, Clark BR. The Alien Tort Statute and the Law of Nations. The University of Chicago Law Review. 2011;78(2):445-552.

28. The statute in question, codified at 28 U.S.C. $\S 1350$, gives the federal district courts "original jurisdiction of any civil action by an alien for a tort only, committed in violation of the law of nations or a treaty of the United States".

29. Sosa, note 23 supra, at 731-33. To be technical, the Sosa Court ruled that the statute did not directly adopt any tort rules, but rather presupposed that they existed and that federal courts had the authority to develop them. The Court admonished the lower courts to create tort law with respect to only a narrow range of international obligations. The lower courts, however, found that this limited range extended to many situations, and dozens of suits survived initial motions to dismiss. See [7]. 
30. Kiobel v. Royal Dutch Shell Co., 133 S. Ct. at 1669.

31. Kiobel v. Royal Dutch Shell Co., 133 S. Ct. at 1671 (Breyer J, dissenting). As a technical matter, most cases involving an alien plaintiff and a U.S. defendant would fall within the diversity jurisdiction of the U.S. judiciary, regardless of the substantive law that might apply. The dissenters' formulation, however, would allow federal courts to create international human rights law, rather than looking to state or foreign law to apply to the tort claim.

32. 26 U.S.C. §§ 61; 26 C.F.R. § 1.1-1(b). Hong Kong on occasion has used this approach, but to my knowledge no other jurisdiction does.

33. 26 U.S.C §§ 951-964.

34. Foreign Trade Antitrust Improvements Act of 1982, 96 Stat. 1233, 1246, codified qt 15 U.S.C. § $6 a$. One might wonder why Congress clarified and to some modest extent limited the Sherman Act's extraterritoriality, given the assumptions made in the rudimentary model discussed above. One plausible refinement is that Congress balanced the interests of domestic firms that operated overseas with those of domestic firms that only face import competition. The latter might wish for stronger extraterritoriality, but the former most likely want some clarity about their legal exposure for their overseas activities. The legislation can be seen as a compromise between these interests.

35. Simplifying considerably, the FCPA applies to issuers (within the terms of U.S. securities laws) and their agents as well as U.S. subjects and their agents. Foreign issuers and their agents and the foreign agents of U.S. persons also have to satisfy an extremely loose instrumentality-of-interstate-commerce test, while U.S. issuers and U.S. persons do not. In addition, since 1998 foreign persons are regulated if they use an instrumentality while on U.S. territory to violate the substantive provisions of the Act. Foreign Corrupt Practices Act of 1977, Pub. L. No. 95-213, Title I, § 104, 91 Stat. 1496 (1977), amended by Omnibus Trade and Competitiveness Act of 1988, Pub. L. No. 100-418, Title V, $\S$ 5003(c), 102 Stat. 1419 (1988); Violent Crime Control and Law Enforcement Act of 1994, Pub. L. No. 103-322, Title XXXIII, § 330005, 108 Stat. 2142 (1994); International Anti-Bribery and Fair Competition Act of 1998, Pub. L. No. 105-366, § 3, 112 Stat. 3304 (1998).

36. 499 U.S. 244, 258-59 (1991).

37. Section 109 of the Civil Rights Act of 1991 extends Title VII to cases where a U.S. citizen suffers discrimination in overseas employment, but only if the employer is a U.S. person or controlled by a U.S. person, and if application of Title VII does not violate local law.

38. See [13]. One might object that this involved only an import tax, but, as noted above, the conduct that triggered the tax (which the statute converted into a bounty for domestic plaintiffs) was extraterritorial, namely selling goods outside the United States at a higher price than their import price or accepting production subsidies from foreign governments.
39. Trade Act of 1974, P.L. 93-618, Title III, as amended by Omnibus Trace and Competition Act of 1988, P.L. 100-418, Title I, Subtitle C, 102 Stat. 1164, and Uruguay Round Agreements Act of 1994, P.L. 103-465, Title III, 108 Stat. 4939, 4993, codified at 19 U.S.C. §§ 301-10. These sanctions apply only to imported goods, but they function as retaliation for extraterritorial acts of foreign states.

40. Dodd-Frank Wall Street Reform and Consumer Protection Act, Pub. L. 111-203, 929P(b), 124 Stat. 1864. I say "apparently" because, as afficionados know, the statutory language does not address the case's holding. Morrison read Section 10(b), and therefore Rule 10b-5, as nonextraterritorial in application. Section 929P(b), however, gives jurisdiction to the courts to hear claims under $10(\mathrm{~b})$ based on territorial conduct or effects, but does not modify 10(b) itself. In other words, the legislation creates federal court jurisdiction to hear a set of cases that, according to Morrison, has no elements. See: Painter RW. The DoddFrank Extraterritorial Jurisdiction Provision: Was It Effective, Needed or Sufficient? Harvard Business Law Review. 2011;1(1):195-230. I suspect that the courts will forgive this confusion between prescriptive and adjudicatory jurisdiction, but perhaps they will not.

41. As to public enforcement, the statute revives the vague direct-effects-or-substantial-conduct test, giving the courts some role in determining the precise extent of extraterritorial jurisdiction. Public sanctions, however, can be less consequential than the potential liability generated by class actions on behalf of large numbers of securities market participants.

42. Aronson PH, Gellhorn E, Robinson GO. A Theory of Legislative Delegation. Cornell Law Review. 1982;68(1):1-67.

43. Pasquantino v. United States, 544 U.S. 349, 354 n. 1 (2005) (reserving issue).

44. Norex Petroleum Ltd v. Access Industries, Inc., 631 F.3d 29 (2d Cir. 2010) (no extraterritoriality in light of Morrison).

45. Liquidation Comm'n of Banco Intercontinental, S.A. v. Renta, 530 F.3d 1339 (11th Cir. 2009) (applies extraterritorially).

46. Poulos v. Caesars World, Inc., 379 F.3d 654 ((9th Cir. 2004) (applying pre-Morrison securities law precedent by analogy).

47. Stephan PB. Privatizing International Law. Virginia Law Review. 2011;97(7):1573-1664.

48. Brief for the United States as Amicus Curiae Supporting Respondents, Morrison v. Australia Bank Ltd., No. 09-1191.

49. Kiobel v. Royal Dutch Shell Co., 133 S. Ct. at 1668 (noting change in position).

50. Brief for the United States as Amicus Curiae Supporting Petitioners, F. Hoffman-LaRoche Ltd. V. Empagran S.A., No. 03-724.

51. Sykes AO. Transnational Forum Shopping as a Trade and Investment Issue. Journal of Legal Studies. 2008;(2):339-378. 


\section{About Librello}

Librello is a publishing house established in Basel, Switzerland. All content published by Librello is open access, available upon publication for any reader. We strongly believe that open access improves the exchange of scientific knowledge, and consists in a more ethic way of publishing the results of research supported by public funds.

Librello is an innovative publishing enterprise. Our novel model works on a membership basis to decouple the payment from the publication. On one side, we can afford a stringent peer-review with no economic pressure, and the authors also profit from our business model by being able to submit multiple manuscripts by a single annual fee.

Librello Publishing House

4000 Basel

Switzerland

http://librelloph.com 